IZA DP No. 8220

Labour-Market Institutions and the Dispersion of Wage Earnings

Wiemer Salverda

Daniele Checchi

May 2014 


\title{
Labour-Market Institutions and the Dispersion of Wage Earnings
}

\author{
Wiemer Salverda \\ AIAS and AMCIS, University of Amsterdam \\ Daniele Checchi \\ University of Milan \\ and IZA
}

Discussion Paper No. 8220

May 2014

IZA

P.O. Box 7240

53072 Bonn

Germany

Phone: +49-228-3894-0

Fax: +49-228-3894-180

E-mail: iza@iza.org

Any opinions expressed here are those of the author(s) and not those of IZA. Research published in this series may include views on policy, but the institute itself takes no institutional policy positions. The IZA research network is committed to the IZA Guiding Principles of Research Integrity.

The Institute for the Study of Labor (IZA) in Bonn is a local and virtual international research center and a place of communication between science, politics and business. IZA is an independent nonprofit organization supported by Deutsche Post Foundation. The center is associated with the University of Bonn and offers a stimulating research environment through its international network, workshops and conferences, data service, project support, research visits and doctoral program. IZA engages in (i) original and internationally competitive research in all fields of labor economics, (ii) development of policy concepts, and (iii) dissemination of research results and concepts to the interested public.

IZA Discussion Papers often represent preliminary work and are circulated to encourage discussion. Citation of such a paper should account for its provisional character. A revised version may be available directly from the author. 


\section{ABSTRACT \\ Labour-Market Institutions and the Dispersion of Wage Earnings ${ }^{*}$}

Considering the contribution of the distribution of individual wages and earnings to that of household incomes we find two separate literatures that should be brought together, and bring 'new institutions' into play. Growing female employment, rising dual-earnership and part-time employment underline its relevance. We discuss the measurement of wage inequality, data sources, and stylized facts of wage dispersion for rich countries. The literature explaining the dispersion of wage rates and the role of institutions is evaluated, from the early 1980s to the recent literature on job polarization and tasks as well as on the minimum wage. Distinguishing between supply-and-demand approaches and institutional ones, we find the former challenged by the empirical measurement of technological change and a risk of ad hoc additions, without realizing their institutional preconditions. The institutional approach faces an abundance of institutions without a clear conceptual delineation of institutions and their interactions. Empirical cross-country analysis of the correlation between institutional measures and wage inequality incorporates unemployment and working hours dynamics, discussing the problems of matching individuals to their relevant institutional framework. Minimum wage legislation and active labour market policies come out negatively correlated to earnings inequality in US and EU countries.

JEL Classification: D02, D13, D31, J22, J31, J51, J52

Keywords: labour-market institutions, household labour supply, hourly wages, hours worked, annual earnings, dispersion, inequality measures, household incomes, minimum wage, unions, employment protection

Corresponding author:

Daniele Checchi

Department of Economics

University of Milan

via Conservatorio 7

20122 Milano

Italy

E-mail: daniele.checchi@unimi.it

\footnotetext{
* Forthcoming as Chapter 19 in: Atkinson, Tony and Bourguignon, François (Eds.), Handbook of Income Distribution, Volume 2, Elsevier/North Holland.
} 


\section{Labour-market institutions and the dispersion of wage earnings}

Wiemer Salverda (University of Amsterdam) and Daniele Checchi (University of Milan) ${ }^{1}$

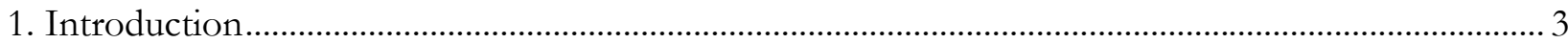

2. Earnings distribution and income distribution: A short tale of two long literatures ........................... 6

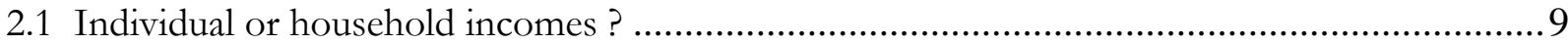

2.2 A cursory review of the literature related to household incomes distribution and labour

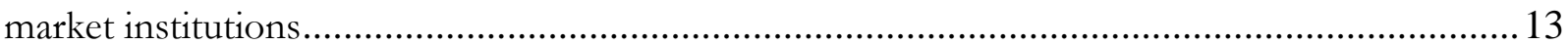

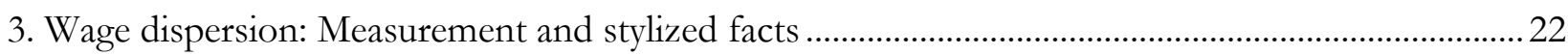

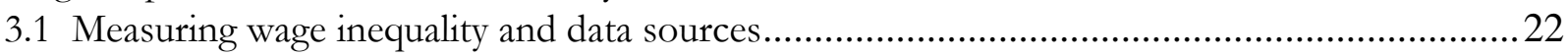

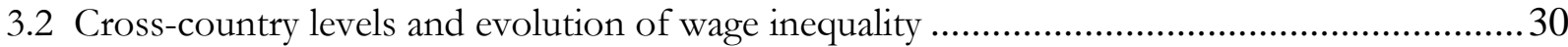

3.3 Additional evidence on earnings inequality in European countries and the United States......41

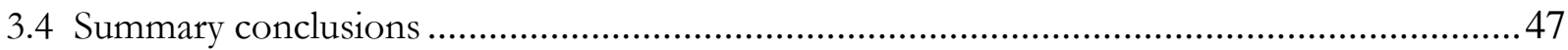

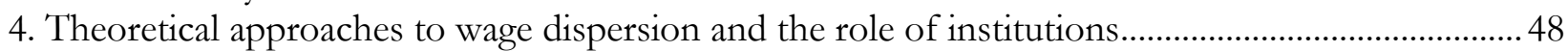

4.1 The wage inequality debate 1980-2000 and the role of labour-market institutions .................48

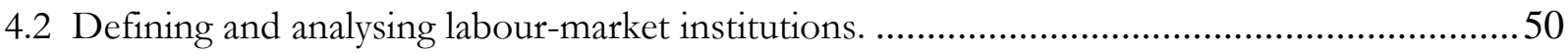

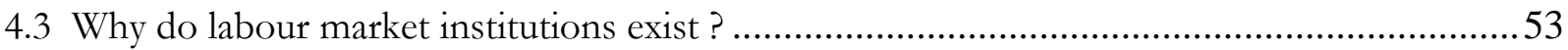

4.4 Do labour market institutions matter for the economy ?.....................................................56

4.5 Recent theories based on demand and supply of labour inputs ......................................57

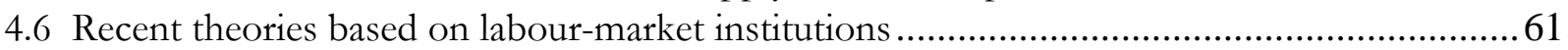

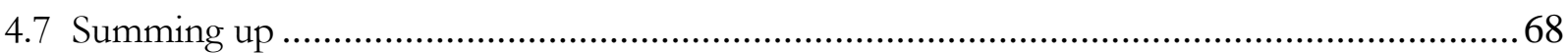

5. Labour market institutions and wage inequality: An empirical assessment .......................................69

5.1 A simple scheme to account for between-group inequality ............................................... 72

5.2 The within-group inequality and the role of labour market institutions ................................79

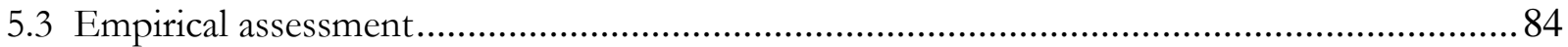

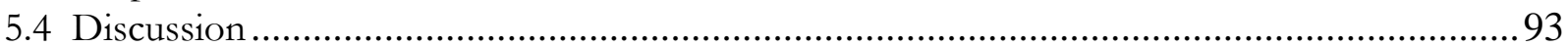

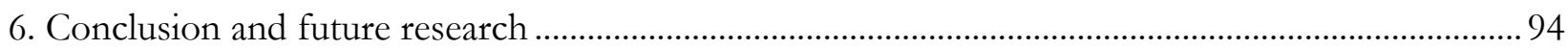

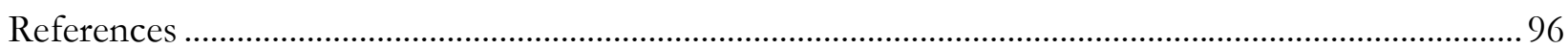

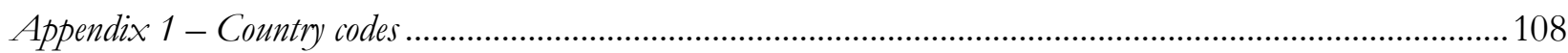

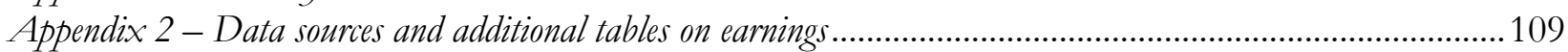

Appendix 3 - Data sources and descriptive statistics on labour market institutions ............................................114

Appendix 4 - Literature summary tables: Household incomes and earnings and Wage dispersion and institutions

\footnotetext{
1 We are grateful to Christina Haas, John Schmitt, Thomas Lemieux, Nicola Fuchs-Schündeln for their help with the data and Anna Salomons for some useful suggestions. We thank in particular our editors, Tony Atkinson and François Bourguignon, for their very helpful comments and suggestions.
} 


\section{Introduction}

This is not 'simply' a study of the literature regarding wage inequality in the labour market, even apart from the fact that that literature is immense. The income distribution is the focus of the present Handbook and provides the ultimate rationale for considering the dispersion of wage earnings here. It is natural therefore to consider the distribution of individual wages and earnings in the labour market eventually in the light of what it may contribute to the distribution of incomes of households, which are the common unit of analysis for the income distribution. One may surmise that the subject how wage inequality and income inequality relate has gained relevance - and also complexity - as the growing labour-market participation of women and the concomitant rise of dual-earner households make societies move away from the world of the single-earner breadwinner model in which labour-market earnings closely resemble household income. ${ }^{2}$ The recent literature on household joblessness provides further encouragement. Nevertheless, the two strands of study, of wage dispersion on the one hand and household income distribution on the other, are miles apart. There is a growing literature aiming to measure the distance between the two distributions and attempting to bring them together, but it is still small and also rather diverse. More importantly, there is very little in this literature that also accounts for the role of institutions with respect to the interrelationship between the two distributions, though that role will be significant as one can infer from the burgeoning literature on institutions and female labour supply. In addition, these are often new institutions (e.g., parental leave, child care arrangements, job entitlements in case of maternity leave and/or of changing from full-time to part-time employment) which seem deserving of attention together with the traditional labour-market institutions (minimum wage, employment protection, union density, etc.).

However, institutions in relation to wage dispersion are our overarching purpose and a very demanding purpose in its own right, and it would be a bridge too far to also try and overcome the gap and incorporate the income distribution in our approach. Instead we take a swift look at said literature and the stylized facts of the subject, and we will do so at the start of our argument to make the best of it as a heuristic device for our ensuing take on wage dispersion and institutions. Thus, we do hope to make a contribution on which future analysis can expand, by providing a building block that may be used subsequently for constructing a unified economic theory of income distribution which is still missing (Atkinson and Bourguignon, 2000, 26). By the way, that building block itself needs to account for the very fact that neither a unified theory of earnings dispersion is available. We intend to do that by reviewing the literature on institutions and earnings distribution in a framework that may be relevant also for further use in studying the household income distribution.

Concretely, we explicitly include in our focus the distribution of annual earnings from labour as the income distribution is commonly measured and analyzed on an annual basis. ${ }^{3}$ This entails, first, that we will study both wage rates and (annual) hours of work - which taken together make up annual earnings - as well as the dispersion of both, and their interrelationship. Thus we aim to go beyond, e.g., Francine Blau and Lawrence Kahn (1999), who do address the effects of wage setting institutions on wage inequality as well as on employment but for the latter restrict themselves to aggregate employment effects and ignore its dispersion over individuals and households as well as its relationship to wage dispersion. It implies that one needs to consider the role that institutions play not only in relation to the wage rate, the hours worked and the individual probability of employment, but ultimately also in relation to the household distribution of employment - what we can call a double-edged employment perspective. At the same time this brings into play the role of unemployment and joblessness (zero hours) the frequency of which may also be affected by institutions. More generally, individual

\footnotetext{
${ }^{2}$ In a world of joint within-household labour supply the two distributions will deviate from each other unless households supply the same amount of hours and wage rates are identical across household members.

3 We will be more precise about such concepts in Section
}

3. 
institutions that primarily concern one of these aspects, say the wage rate, will need to be considered also in relation to the other aspects. The separate effects may differ and in the end it is their joint effect that counts. ${ }^{4}$

Second, we will contemplate the relevance and the effects of labour-market institutions from this distribution point of view. Particularly, we will on the one hand leave aside the literature that focuses on wage dispersion in relation to the matching of workers to given jobs (e.g. Mortensen, 2005, on search, or Rosen, 1986, on compensating differentials). We also leave out the literature on other important facets of inequality such as earnings mobility or its role as a work and career incentive. On the other hand we will look - to the extent that we can - for institutions that may affect the distribution of employment over households (e.g. equal treatment, working-hours non-discrimination, child-care provisions or tax measures) or the supply of hours over the year (e.g. temp agency work, temporary contracts). Thus different institutions from the usual suspects may come into play, for example, new rules and regulations regarding part-time jobs and pay, or the 'reconciliation of work and family life', while at the same time those usual suspects will be checked for their effects in this domain. The 'new' institutions will need to be considered in their own right but, naturally, also in relation to the previous ones. We need to be careful though that the assortment of institutions under scrutiny be manageable, as in modern society labour-market behaviour has become so central to human existence that virtually any institution might be thought to have an effect.

In our take on the literature, we aim to be careful in considering the role of institutions not in isolation of the 'normal' economy - compare, e.g., the meticulous evaluation of the literature by Lawrence Katz and David Autor (1999) who first discuss the role of supply and demand and after that turn to institutions, or the warning given by Blau and Kahn $(1999,1416)$ with regard to international comparative studies of the effects of institutions "that many things besides the institutions in question may differ across countries, so we cannot be certain if the institutions are really responsible for the observed differences in outcomes." Similarly, we need to be aware of non-institutional effects influencing market labour supply such as, e.g., technical progress in household production (cf. Kahn, 2005). More generally, we sympathise with Alan Manning (2011) who prefers to phrase his recent overview not in terms of canonical models, where "precision relates to the models and not the world and can easily become spurious precision when the models are very abstract with assumptions designed more for analytical tractability than realism." (2011, 975). In our view, the distribution of earnings is very much a phenomenon of crucial importance in 'the world'. Though we aim to broaden the scope to include the dispersion of employment, we do not and cannot possibly pursue this in a general equilibrium format. Further to this, being aware of significant country differences we leave open the possibility that one size may not fit all.

In addition, we like to stress that the time period effectively covered in the chapter is determined by the literature that we aim to address. Though that period may seem long to some, harking back to the end of the 1960s for certain countries, it is important to realise that the trends found may be selective. The long-run historical perspectives adopted in the top-incomes literature (Alvaredo et al., 2013) or in Atkinson's (2008) internationally comparative study of the earnings distribution suggest that preceding trends may diverge, sometimes radically, and might throw a different light on the mechanisms at work. Ultimately, this may tell a different story but the study of this is in its infant stage.

Before continuing we like to mention a caveat regarding the two concepts of 'dispersion' and 'inequality', which we have used indiscriminately so far as indicating the squeeze or stretch of a distribution. A major reason for many to pay attention to the dispersion is that a large part of it coincides with social or economic inequality as it is commonly understood. However, more precisely the dispersion shall be thought to relate to a range of observations, wages or incomes in this case, which are not all the same and therefore are unequal in a mechanical, mathematical sense of the word. Inequality, by contrast, provides a qualifier to such observations that makes them unequal in the sense of analyses providing an explanatory interpretation of the observations, either individual or aggregated. So, strictly speaking, dispersion and inequality are different concepts. Not all mechanical differences

\footnotetext{
${ }^{4}$ Interestingly, Olivetti and Petrongolo (2008) consider the interaction of hours and wages from a different perspective, focusing on the effect on the gender pay gap of the selection of women into employment.
} 
will also be inequalities from an analytical point of view; for example differences in individual earnings that reflect differences in efforts. Conversely, not all analytical inequalities will also be mechanical differences; for example, individual earnings that are identical in spite of differences in efforts. Having said this we will continue using the two words interchangeably below as the chapter is aimed at evaluating a set of such qualifying analyses. Note, finally, that measures of dispersion or of inequality (Gini coefficient etc.) are the identical, and usually called measures of inequality - which we will also do below.

Some of the above references indicate the existence of various overviews of the literature that are relevant our study of earnings inequality, which are found in the first volume of the Handbook of Income Distribution, all volumes of the Handbook of Labor Economics, and the Oxford Handbook of Economic Inequality. We will not redo those but gratefully build on them when useful. Note that not only economists but also political/social scientists have studied the subject (Alderson and Nielsen 2002, Oliver 2008, Kenworthy and Pontusson 2005, Becher and Pontusson 2011, Wallerstein 1999, Golden and Wallerstein 2011, DiPrete 2005). We will allude also to some of their results.

Our contribution takes the general level of inequality as its starting point but cannot escape digging below that surface. Thus we may for example touch upon the tails of the distribution - top incomes, (in-work) poverty - where much of the action is. However, for a deeper understanding of those tails as well as the complementing middle we refer to the treatment of polarization (Chapter 6), top incomes (Chapter 8), in-work poverty (Chapter 25) elsewhere in this handbook. More generally, the labour market also figures as one of the multiple causes of inequality in Chapter 20. On another dimension, our contribution stops short of the within-household distribution (see Chapter 17) or any further analysis of gender inequality (see Chapter 13). Finally, this chapter will cover those countries that have well-developed, comprehensive formal labour markets. This restricts the selection of the literature to analyses that concern the USA, Canada, Japan, Korea, Australia, New Zealand, the member states of the European Union, and some other European countries such as Iceland, Norway, and Switzerland.

\section{Lay out}

The lay out of the chapter is as follows. First, in Section

2, we will briefly discuss the literature that regards the link between wage dispersion and the household income distribution, considering the distributions of earnings and employment from both the individual and the household perspective, and presenting some stylized facts. In Section

3 we discuss the measurement of wage inequality and some relevant data sources and present some stylized facts of wage dispersion for a selection of countries. Next, in Section 4 we discuss theories aimed at explaining the dispersion of wage rates and the role of institutions. Section

5 then addresses the role of labour-market institutions empirically, with the help of a model that that incorporates several features advocated in the preceding sections, such as a focus on earnings, i.e. the product of wage rate and annual efforts, and that inserts as explanatory variables a number of 'new institutions' related to household labour supply. In addition, it used recent internationally comparative data. Finally, Section

6 concludes by summarising the main findings and considering issues warranting further research. 


\section{Earnings distribution and income distribution: A short tale of two long literatures}

In spite of recent declines in the labour share in GDP or National income, ${ }^{5}$ the income that people generate in the labour market is obviously the most frequent and most important part of household incomes, and the inequality of labour earnings seems an important determinant of income inequality at face value. Figure 19.1 pictures in three panels the role of 'labour households', which are defined as households receiving more than half their total income from wage earnings, across 26 countries of the European Unions. Panel A ranks the countries by the income share of labour households (the markers) and the same ranking is adopted for the other panels. Panel A indicates that labour households receive the majority of all incomes, ranging from slightly over 50 percent in Greece and Italy up to a maximum of 84 percent in Estonia. They comprise significantly smaller shares of all households, however, ranging from less than half in Greece and Italy ${ }^{6}$ to 66 percent in Luxembourg. Clearly, these households' mean incomes are above average in all countries. This is borne out by Panel B which indicates similar shares with a focus on the Top- $10 \%$ of all incomes in a country. The income share always exceeds the household share and does so by far: on average the income share is 14 percentage points higher than the household share. This contrast with the Bottom- $90 \%$ (not shown): here the gaps between the two shares are modest and they can be positive as well as negative; the resulting cross-country average is almost nil. At the same time, in Panel C, the Gini coefficients for all households always exceeds that for labour households and they move in striking parallel in various countries characterized by high labourincomes inequality such as the UK, Portugal, Lithuania, Bulgaria, Latvia and Estonia (overall correlation is 0.75 ). The Gini levels do not follow the smooth ranking of increasing income shares but vary substantially (correlation 0.23 ). Therefore rather dissimilar Gini coefficients can go together with very similar income shares as the middle group, ranging from Germany to Belgium, illustrates (Panel C versus Panel A). However, for labour households income shares in the Top- $10 \%$ and the Gini coefficient show a more similar pattern (Panel C compared to Panel B) (correlation 0.56). So income from labour is highly important indeed but its effects on income inequality show significant variation and warrant further scrutiny.

\footnotetext{
5 We leave aside here the relationship between the labour share in GDP (declining in many countries) and the income distribution. Compare, e.g., Atkinson (2009), Glyn (2009), Checchi and Garcia-Peñalosa (2009), and OECD (2012).

${ }^{6}$ Note that the low household share largely explains the low income share.
} 
Figure 19.1 - Importance of labour households and their annual incomes, 26 European countries ranked by total income share, 2010

A. Share in total income and total number of households

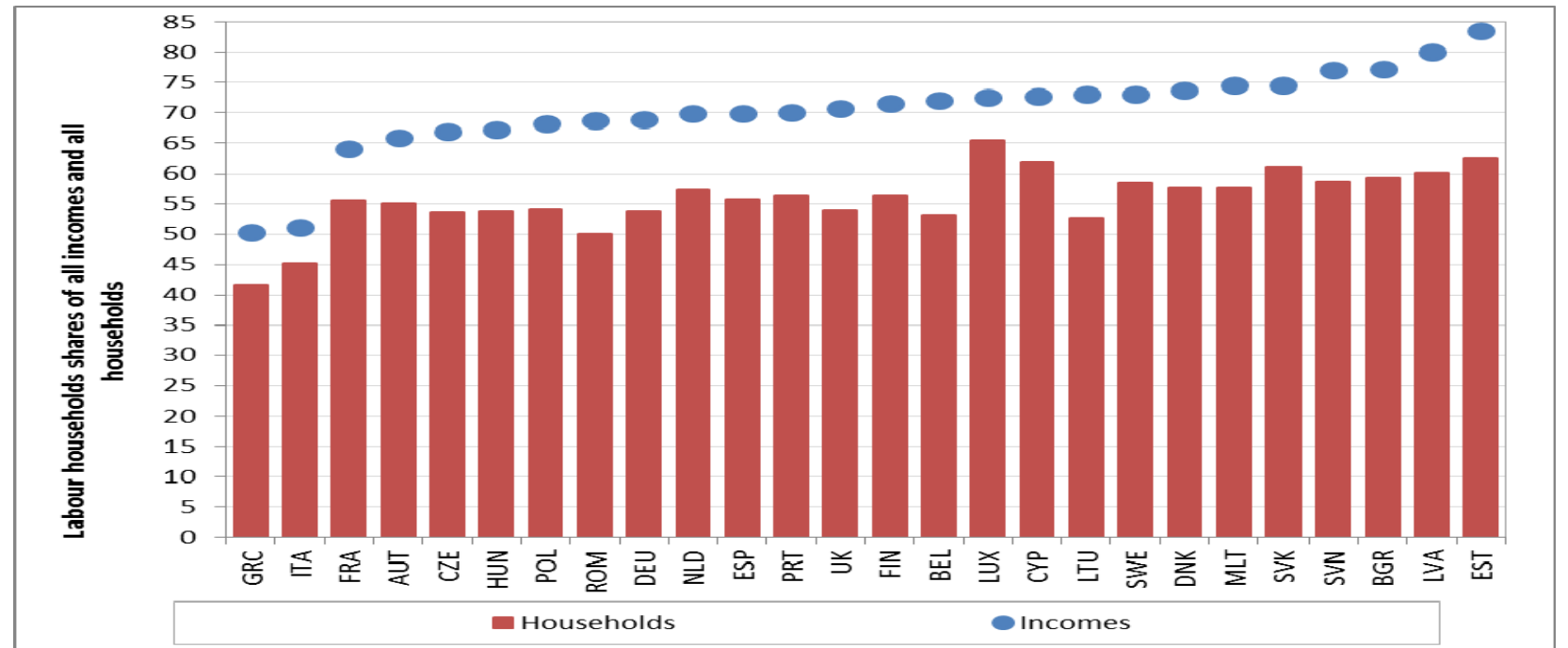

B. Share in income and number of households of Top- $10 \%$ of all incomes

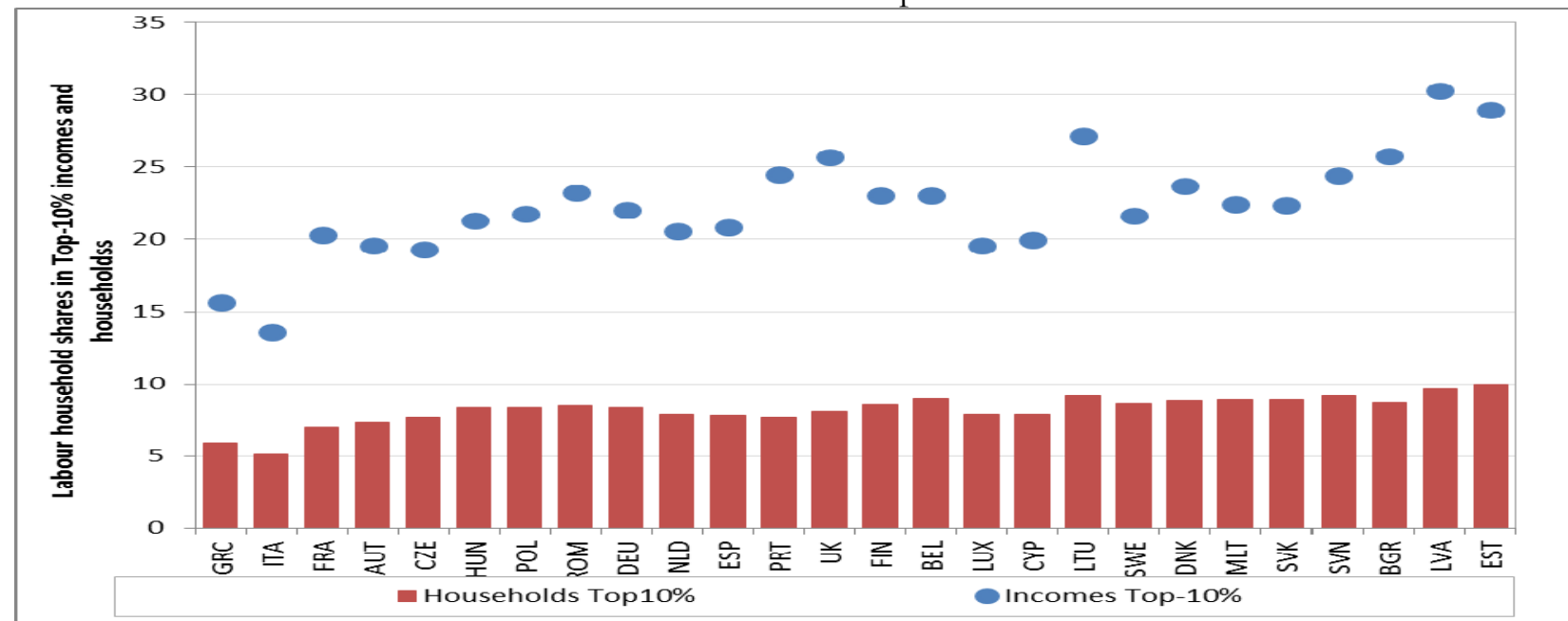

C.

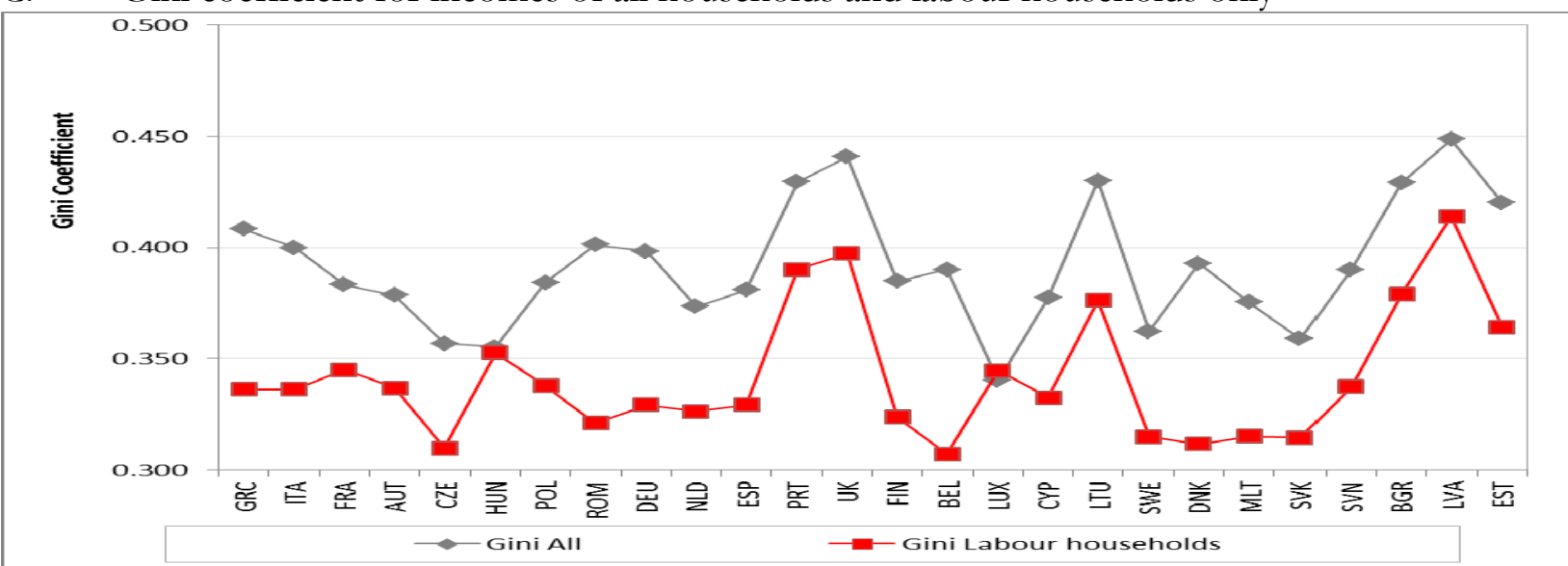

Reading note: In Greece labour households receive $50 \%$ of all incomes and make up $42 \%$ of all households; among them $6 \%$ have an income in the Top- $10 \%$ of the overall income distribution receiving $16 \%$ of all incomes; the Greek Gini coefficient for all incomes is 0.408 while for labour households it is 0.336 .

Explanatory note: Labour households derive more than $50 \%$ of their total income from wage earnings. We use the ISO 3alpha country codes in all relevant graphs (see list in

Appendix 1). Unfortunately, data for Ireland are not available.

Source: Calculated from EU-SILC 2011 (compare Salverda and Haas (2014) for a comparison for the working-age bracket only). 
Another measure of inequality, the income share of the top decile of the distribution, tells basically the same story for all incomes as the Gini and the top share are highly correlated (0.91) (compare Leigh, 2009). However, the gap between all incomes and labour incomes is more substantial here: the correlation of the two top shares is only 0.32 - and suggests that the role of high levels of household earnings differs significantly between countries. The linkage between the dispersion of wages and the income distribution is clearly important and also warrants further research.

Though the literature on the two distributions is not absent and perhaps even growing, is not the subject of a strong strand. Instead, one may surmise, there are two largely separate, extensive literatures, one addressing (individual) wage inequality in the labour market and the other (household) income inequality in society. As Peter Gottschalk and Sheldon Danziger (2005, 253) observe "Labor economists have tended to focus on changes in the distribution of wage rates, the most restrictive income concept, since they are interested in changes in market and institutional forces that have altered the prices paid to labor of different types. At the other extreme, policy analysts have focused on changes in the distribution of the broadest income concept, family income adjusted for family size. This reflects their interest in changes in resources available to different groups, including the poor." It confirms that the conclusion drawn eight years before by Peter Gottschalk and Timothy Smeeding $(1997,676)$, that "an overall framework would simultaneously model the generation of all sources of income ... as well as the formation of income sharing units" and be considered "the next big step that must be taken", was still a tall order when Gottschalk and Danziger's made their contribution. Yet another five years later, Jiŕi Večerník $(2010,2)$ observes that "there seems to be a gulf between the analysis of personal earnings and household income". It seems a foregone conclusion that for the combination of individual wage and earnings inequality and household earnings and income inequality the unified economic theory of income distribution, hoped for by Anthony Atkinson and François Bourguignon (2000, 26), is not yet forthcoming though interesting contributions may be found below. ${ }^{7}$

This divide has a technical aspect which deserves some attention. The dispersion of wages is commonly conceived as the distribution of hourly wages, i.e. wage rates. The income distribution, by contrast, focuses on annual incomes, and therewith annual earnings, which are the product of hourly wages and annual hours worked. Next to the wage distribution, this brings into play the distribution of hours worked during the year, which in turn are the product of jobs and hours on the job. These hours have become a significant dimension of employment in many countries because of the growing importance of part-time employment and temporary jobs. Their presence adds to the traditional effect on annual hours that is exerted by the turnover during the year of people who join or leave employment. ${ }^{8}$ As a result we deem it essential to distinguish between various distributions: wages (which are hourly), earnings (which are annual), employment (which concerns annual hours worked), and incomes (which include other sources than earnings).

A second difference is that the wage distribution is commonly conceived in gross terms, that is pre-tax, while on the income side there is a strong focus on disposable incomes - after transfers and taxes which are often also standardized (equivalized) for the size and composition of the receiving household ${ }^{9}$. The third difference is that the dispersion of wages rests on the individual as the unit of analysis while the income distribution is based on the household which can be a combination of individuals. Thus for linking the two distributions the individuals from the one side need to be linked to

\footnotetext{
${ }^{7}$ However, for a number of developing countries (which are not the subject of this chapter) a valuable attempt with interesting results has been made by Bourguignon et al. (2004) in decomposing household income inequality changes along the relevant dimension of labour-market behaviour and outcomes.

${ }^{8}$ Including temporary employment of less than one year this is reflected in the difference between the distributions of fullyear and the part-year employed. For example, Salverda et al. (2013), Figure 2.11, shows for the Netherlands that the P90:P10 percentile ratio is halved when attention shifts from all earners to full-year earners only.

${ }^{9}$ Equivalisation serves to account for the demands that household members put on income as well as the economies of scale of jointly managing a household (Förster, 1994; Atkinson, Rainwater and Smeeding, 1995; OECD, 2009). Note that applying equivalisation not only to disposable incomes but already to market incomes and gross incomes (e.g., OECD, 2011; and various contributions to the special issue of the Review of Economic Dynamics), may affect the perception of labour market outcomes on the one hand and changes between these three distributions on the other hand.
} 
their households on the other side. Importantly, this puts the limelight on the distribution of employment and corresponding earnings over households. There is a significant literature on the other side of this employment coin, the non-employment or joblessness of households, especially in comparison to individual joblessness, which was started by Paul Gregg and Jonathan Wadsworth in the mid-1990s (Gregg et al., 1996, 1998, 2008). However, this literature is not often linked to the distribution of incomes albeit it may be to poverty (De Graaf-Zijl and Nolan, 2011).

\subsection{Individual or household incomes?}

Before discussing the main points found in the literature we present a few stylized facts that may demonstrate the relevance of considering the linkages between the two distributions. First, we consider the employment side of the matter. A core message from the joblessness literature is that in many countries individual workless rates have fallen over the past 20 years, but household-based workless rates have not (Gregg et al., 2010, 161). Or to put it the other way around, the growth in (individual)employment-to-population ratios has not been mirrored in a corresponding increase in what can be termed the 'household employment rate'. The implication is that much of the additional jobs growth has gone to households already containing a worker. Figure 19.2 illustrates this for a number of European countries since the mid-1990s: most of the decline in individual non-employment has gone to households already engaged in employment and much less has contributed to a lowering of the number of people living in jobless households.

Figure 19.2 - Changes (percentage points) in individual and household employment, 11 European countries, 1995-2008

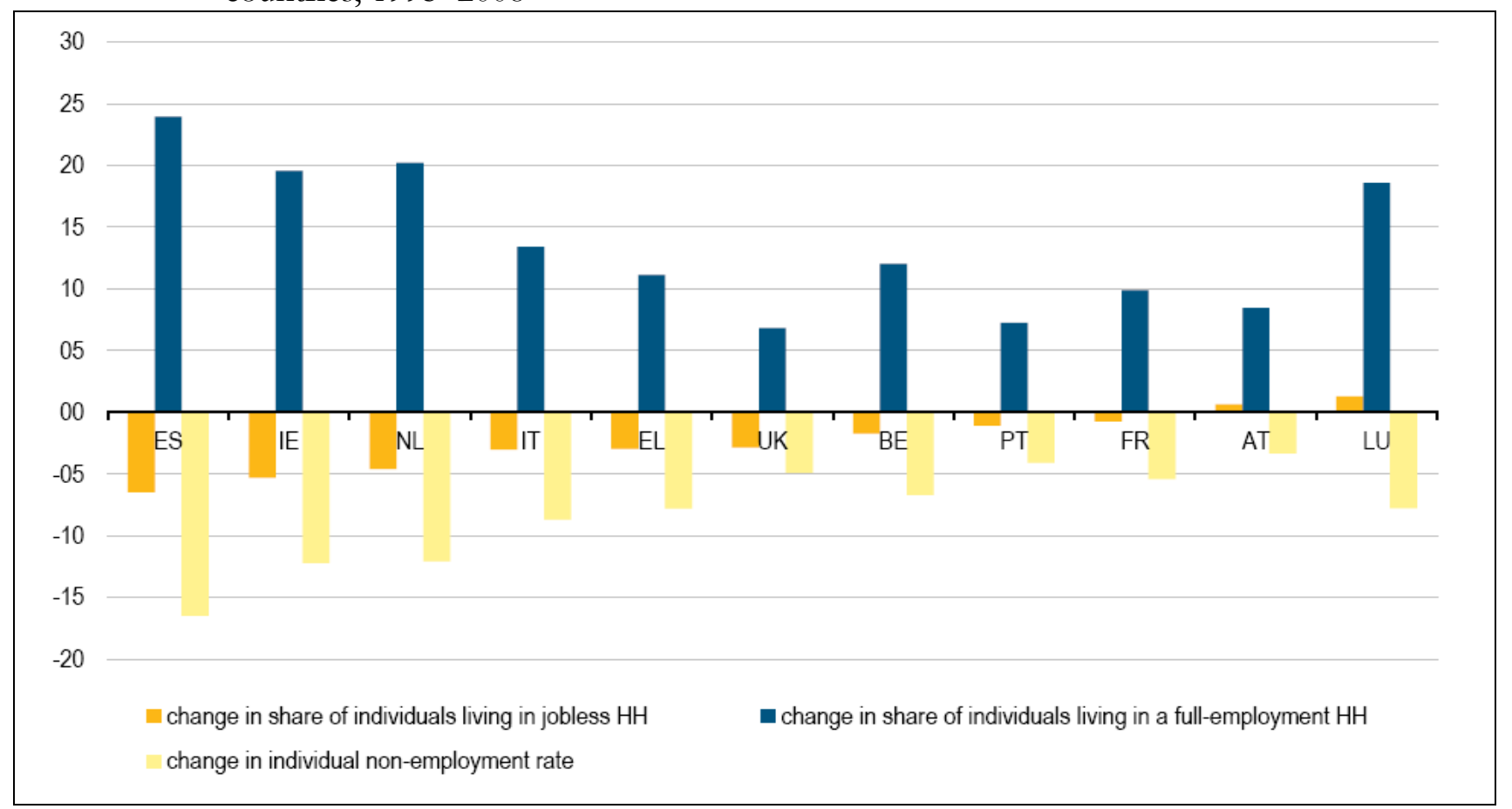

Reading note: In Spain the share among individuals of those in work who are also members of a household where everyone is in work increased by 24 percentage points between 1995 and 2008; the share for those living in households without work declined by 7 percentage points; the share of individuals without work declined by 16.5 percentage points.

Explanatory note: In full-employment households everyone is in work; this includes single-person households. Employment follows the ILO definition and includes the self-employed. Persons aged 18 to 24 whose status is 'inactive' are considered to be full-time students and excluded. For country codes see

Appendix 1.

Source: Eurostat - Corluy and Vandenbroucke, 2013, Figure 1 (based on the European Labour Force Survey). 
Figure 19.3 adds a particularly sharp example of the divergence between the two rates of employment for prime-age adults for the UK, one for persons (the traditional individual employment-to-population ratio), the other for households (the percentage of relevant households which have at least an employed person among their members). The former rate always exceeds the latter and the gap between the two has grown rapidly from two percentage points at the end of the 1970s to 13 percentage-points since the early 1990s. ${ }^{10}$ Often such developments have gone hand in hand with an expansion of part-time employment. The correlation of individuals' levels of pay to their numbers of hours worked can tell us whether this hours dimension enhances or mitigates inequality. A positive correlation implies a more unequal distribution of annual earnings than of hourly earnings among individuals. The correlation has tended upwards significantly and turned from negative to positive in some countries while it still is negative in other countries. the correlation seems particularly strong for British women (Figure 19.4).

Figure 19.3 - Employment rates (\%) for individuals aged 25 to 59 and their households, United Kingdom, 1978-2005

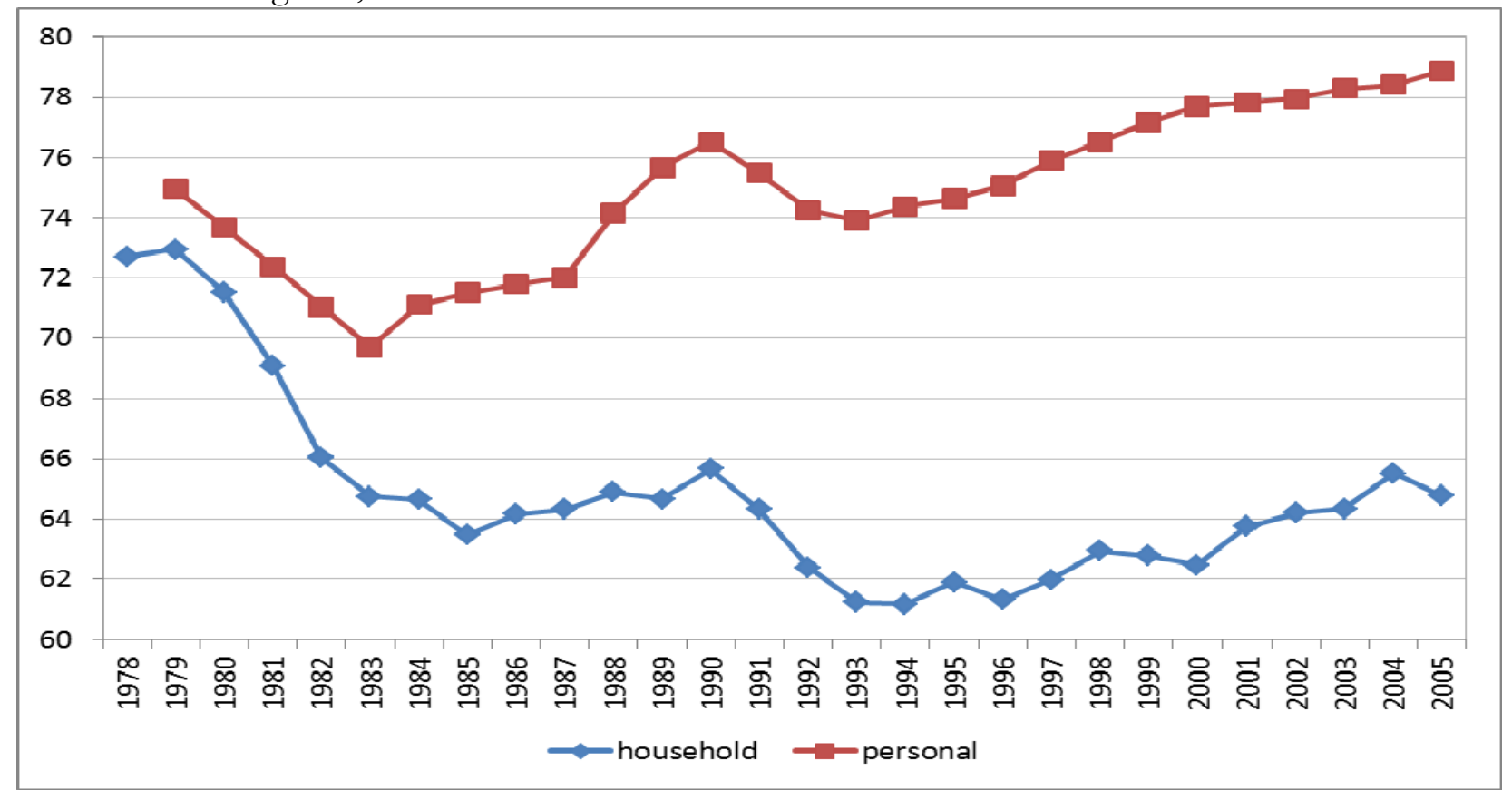

Reading note: The share among individuals aged 25 to 59 who are in work grew from $75 \%$ in 1979 to $79 \%$ in 2005 ; the share of households corresponding to these individuals where at least one person is employed, declined from $73 \%$ to $65 \%$.

Source: derived from Blundell and Etheridge (2010), Figures 2.1 and 2.3 (based on Labour Force Survey and Family Expenditure Survey).

Compared to single-breadwinner households this complicates the relationship between the wage distribution and the income distribution. At the same time it makes the scrutiny of that relationship all the more important. Thus the role of dual-earner and multiple-earner households has expanded, and is now substantial in many European countries as is indicated in Figure 19.5. With the exception of Italy and Greece dual-earners and multiple-earner households are the majority among household, and evidently employees in those households make up an even larger share of all employees. In particular the role of multiple-earner households varies substantially across countries, from $4 \%$ of all households in Greece to $27 \%$ in Bulgaria.

\footnotetext{
10 Atkinson (1993, $335 \mathrm{ff}$ ) discusses a 11.5 percentage points decline in the family (adult) employment rate for the UK between 1975 and 1985 and infers that half the increase in inequality can be attributed to this "shift in work".
} 
Figure 19.4 - Correlation of individual wage level and annual hours worked, by gender, ages 25 to 59 , United States, United Kingdom, Canada and Sweden, 1967-2005

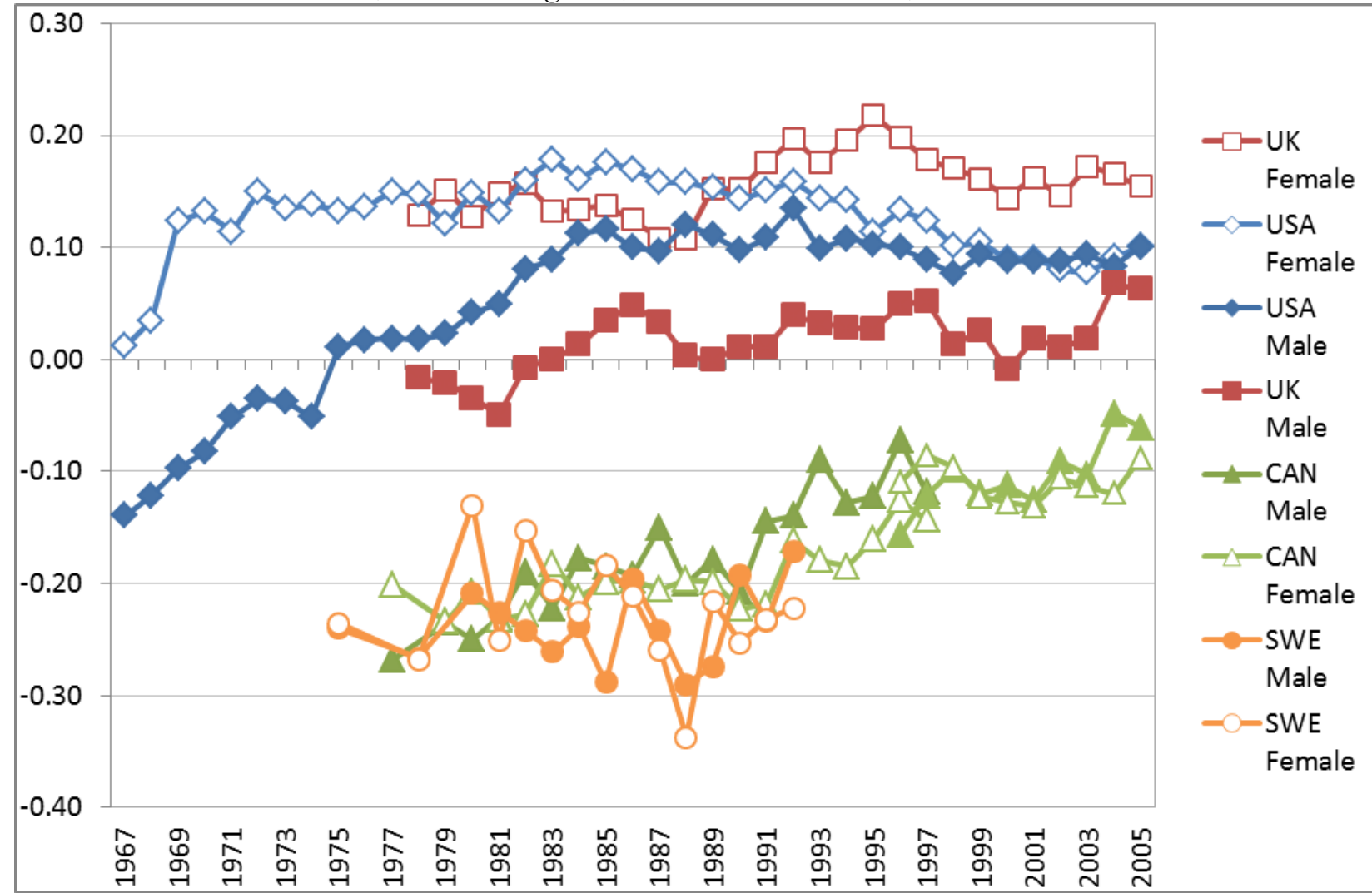

Reading note: The correlation between the annual hours worked and earnings per hour among US males changed from -.10 in 1967 to +0.10 in 2005.

Source: Blundell and Etheridge (2010), Brzozowski et al. (2010), Domeij and Floden (2010), Heathcote et al (2010).

In a (full-time working) single-earner world the correspondence between wage dispersion and income distribution seems pretty straightforward: a high individual wage directly implies a high household income. This traditional situation may provide another explanation, for lack of a problem, why the literature on the linkage between the two distributions seems underdeveloped. The formation of households and their labour supply may affect the distribution of incomes depending on the correlation of earnings levels between the earners in a household. A positive correlation will enhance household earnings inequality, in addition to the frequency of the occurrence of joint earnings. Changes in mating behaviour or in partners' employment participation or in both at the same time will be behind this. Figure 19.6 indicates the rise in the correlation between such earners for the USA. It has roughly doubled over 1975 to 1990, which is less than half the 40-year period, and remained largely stable since. However, the level and evolution of this may differ between countries and, apparently, over time. Conversely, household joint labour supply may also affect the dispersion of wages, if additional earners would operate their labour supply at a less extensive margin of pay or working hours given that a main income is already secured in the household, or if they would trade off pay and hours for a scenario combining paid labour with other activities, such as household care or participation in education. 
Figure 19.5 - Working-age households with employees by number of earners, 26 European countries, 2010

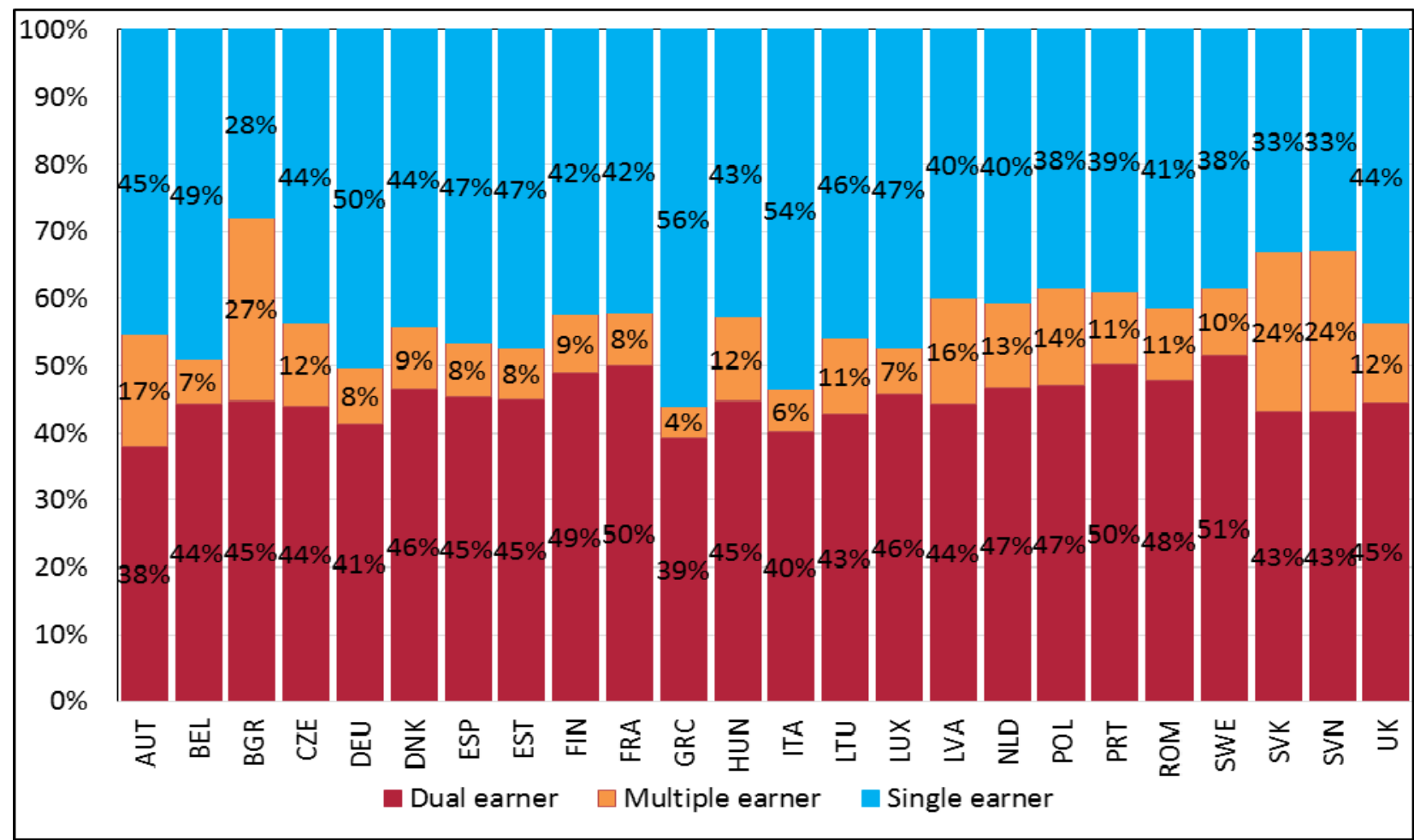

Reading note: In Austria 38\% of households with at least one member in employment have two persons employed, 17\% have 3 or more persons employed, and $45 \%$ have 1 person employed (including single-person households).

Explanatory note: Earners need to have positive hours and earnings as well. The household main earner is aged below 65, Students as identified in the dataset are excluded. Naturally, female employment participation, traditionally large in what are now former communist countries, is an important determinant.

Source: Salverda and Haas (2014), Figure 3.9.

Figure 19.6 - Correlation of earnings between married partners, United States, 1967-2005

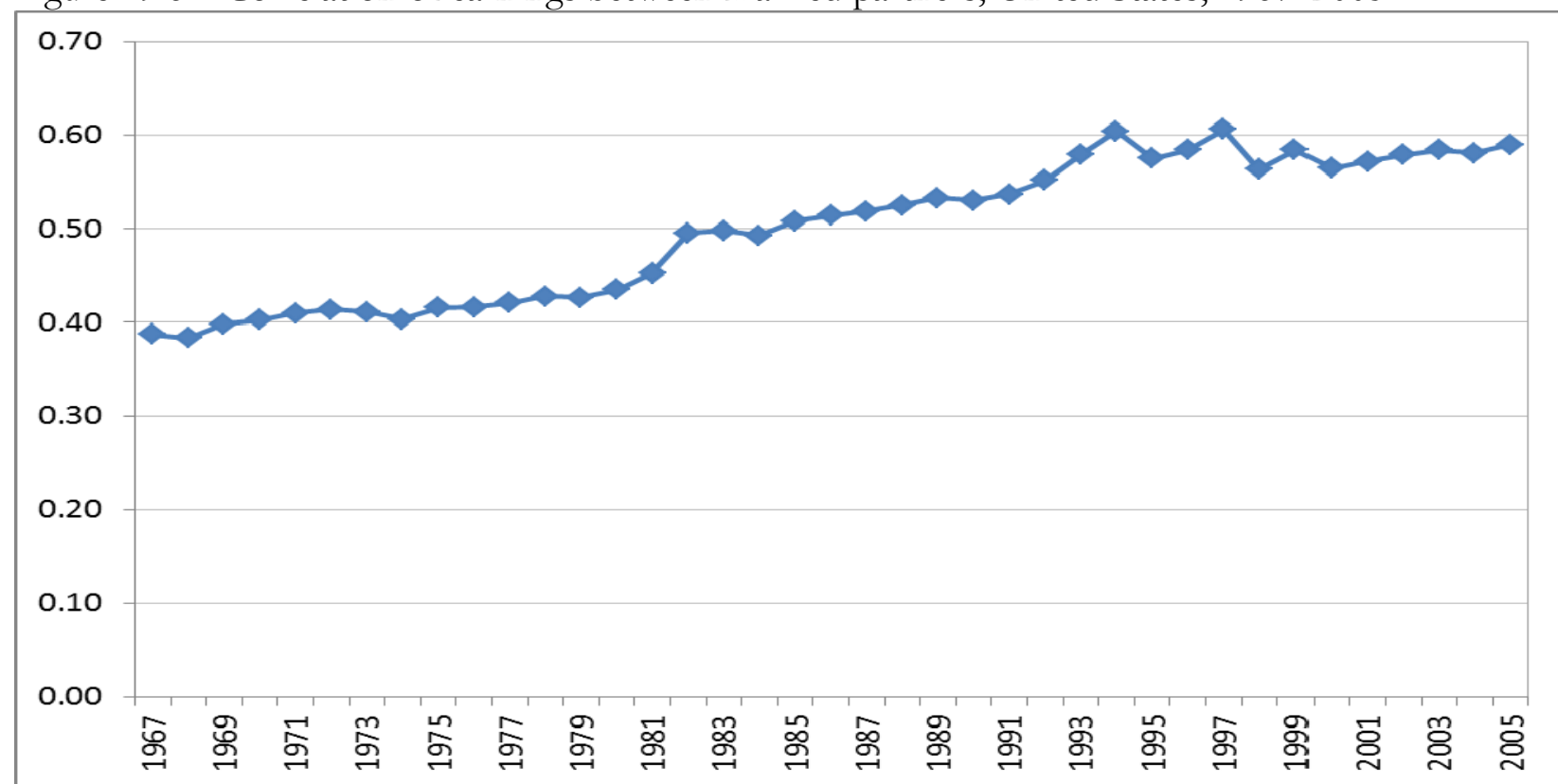

Reading note: Correlation of earnings levels between married partners in households from less than 0.40 to around 0.60 . Source: Heathcote et al. (2010).

In the end, household formation and the two distributions will all be endogenous to each other, and household formation should be added to the list of "stages for comprehending the distribution of income: aggregate factor incomes, differences in earnings and in capital incomes, the role of the corporate sector and of financial institutions, and the distributional impact of the state" (Atkinson, 2007a, 20). 


\subsection{A cursory review of the literature related to household incomes distribution and labour market institutions}

The literature on the linkage between the two distributions is diverse and cannot be viewed yet as a strong and coherent strand. More than occasionally contributions to the subject are found in papers dedicated to other issues than the income distribution, such as the design of transfer programs (e.g., Liebman, 1998). Our own reading of the literature on household incomes distribution leads us to conclude that it pays little attention to the role of labour market institutions, which is after all the focus of our chapter. This is the very reason that we only touch upon the household context of the dispersion of wages here. Daniele Checchi and Cecilia García-Peñalosa $(2008,2010)$ do address labour market institutions and income inequality. In a comparative cross-country and macroeconomic perspective they show the relevance of institutions especially in terms of their effects on the level of unemployment (i.e. zero hours and earnings) which in turn contributes significantly to the level of income inequality. ${ }^{11}$ We will elaborate on elements of their approach later in the chapter. Certainly, some contributions investigate the effects on the income distribution of one particular institution, the minimum wage itself the subject of a large literature for its effects on the dispersion of wages. Charles Brown (1999, Section 9.2) in his survey of that literature observes that many families have several earners, so that a minimum-wage worker can be part of a relatively affluent family and adds that the level of the minimum wage will be of little help in reducing income inequality, basing himself on simple statistics showing that the poor fraction among low-wage workers is low and that many poor families have no workers. David Neumark and William Wascher (2008) sum up many of their own and other contributions to the minimum wage literature. In their view the combined evidence of income and employment effects for the USA is best summarized as "indicating that an increase in the minimum wage largely results in a redistribution of income among low-income families" (p. 189) as some may see their income rise while others may see their employment and therewith their income diminish. However, Arindrajit Dube (2013) finds sizeable minimum-wage elasticities for the bottom quantiles of the equivalized family income distribution and argues from an evaluation of the existing literature, including works by Neumark and Wascher, that the finding is consistent with that.

There is however another emerging literature that studies the role of institutions in connection with the household incomes distribution, especially new institutions of relevance such as parental leave, tax credits including the American EITC or the British WTC, or entitlements to remain in the same job (e.g., Thévenon, 2013; Thévenon and Solaz, 2013; Dupuy and Fernández-Kranz, 2011; Eissa and Hoynes 2004, 2005; Mandel and Semyonov 2005; Brewer et al. 2006; Vlasblom et al., 2001; Dingeldey, 2001). However, mostly it preoccupies itself with the employment effects and ignores the income side, and it is strongly focused on particular aspects of inequality as, for example, female labour supply or the motherhood gap in employment participation, and does not consider the aggregate picture of inequality nor the effects on earnings inequality or the interrelationship between the two distributions. ${ }^{12}$ We leave that literature out here though we will try below to incorporate some of those new institutional measures in our broader framework. Note finally that we leave out the demographically motivated literature that focuses exclusively on the contribution to income inequality of household structure and composition (e.g., Brandolini and D'Alessio, 2001; Burtless, 2009; Peichl et al., 2010); we do include however contributions considering this in a broader framework that encompasses earnings inequality (e.g., Burtless, 1999).

In the collection of contributions there seem to be two main approaches (see Table A.7 in Appendix 4 for a summary of the relevant literature). The first approach is based on a direct comparison of the

\footnotetext{
11 OECD (2011) also advocates including the unemployed zeros in studying the contribution of the earnings distribution to the income distribution.

${ }^{12}$ Liebman (1998, table 2) finds a slight increase in the incomes shares of the lowest and the second quintiles in total income in the mid-1990s) as a result of EITC; nevertheless these shares remain well below those obtained twenty years earlier . Note also that Hysplop (2001) and Schwartz (2010) look specifically at the contribution of the association of partners' earnings to inequality on the earnings side.
} 
different distributions, the second one on a decomposition of income inequality that focuses on the sources of income, particularly earnings. The latter shows substantial variation in its choice of the measure of income that is decomposed (mainly established aggregate measures of inequality such as the Gini coefficient, but also newly devised ones such as the 'polarization index' designed by Corluy and Vandenbroucke, 2013). ${ }^{13}$ More importantly, this literature also varies in the precise technique of decomposition that is applied, which matters as the technique affects the outcome. In the literature there is no single generally accepted way of decomposing, which hampers the establishment of stylized facts. ${ }^{14}$ This situation partly motivates the first, comparative approach. In addition to this, it can be observed that the decomposition approach takes one of the two distributions as its starting point and does not consider the effects on the other distribution. Thus it remains unclear when, e.g., growing female employment participation increases household earnings inequality if it also raises individual earnings inequality. We briefly discuss each of the two main approaches.

\section{Comparing distributions}

One of the first contributions was made by Gottschalk and Smeeding (1997). They discuss various types of distributions and inequality measures on both the earnings and the income side, but largely in isolation of each other. Their conclusion is that "Better structural models of income distribution and redistribution that can be applied across nations are badly needed. Ideally, an overall framework would simultaneously model the generation of all sources of income (labor income, capital income, private transfers, public transfers, and all forms of taxation) as well as the formation of income sharing units" (p. 676). That is still a tall order today. In the absence of such a framework decomposition leaves us with "purely accounting exercises" (p. 668).

Gary Burtless (1999) compares the distributions of annual individual earnings distributions on the one hand and personal equivalized incomes on the other hand for the USA between 1979 and 1996. With the help of simple counterfactual exercises regarding the personal income distribution when holding the levels of earnings inequality constant, he finds that two-thirds of the observed increase in overall income inequality would have occurred leaving only one third for the changes in earnings. Within the latter share he attributes 13\% of the increase to the growing correlation between male and female earnings in families. Also the increasing share of single-adult families among the population has contributed because the greater inequality within that group.

Deborah Reed and Maria Cancian (2001) also simulate counterfactual distributions for the USA over the period 1969-1999, instead of pursuing a decomposition approach. They argue that this simulation allows using multiple measures of inequality, looking at different points in the distribution, and incorporating changes in the marriage rate. They find that changes in the distribution of female earnings account for most of the growth in family income throughout the distribution and disproportionately more at the bottom, leading to a decrease in inequality. By contrast, changes in male earnings account for over 60 per cent of the growth in the Gini coefficient of the family income distribution.

Gottschalk and Danziger (2005) analyze in an interconnected way the evolution of inequality in four different percentile distributions: hourly individual wage rates, annual individual earnings (and therewith annual hours), annual family earnings, and annual family adjusted total income. The first two distributions are at one side of the earnings-incomes gulf, the other two at the other side. Interestingly, they bridge the gulf by ranking individuals for their annual earnings according to the total earnings of their households (p. 247) using consistent samples of individuals. Earnings exclude the self-employed

\footnotetext{
${ }_{13}$ Note that this considers the distribution of employment over households and not the distribution of employment over pay, occupations or tasks as in Chapter 6.

${ }_{14}$ Gottschalk and Smeeding (1997, 669) express doubts regarding decompositions and point to the rather different outcomes in the literature. Equally, Gottschalk and Danziger $(2005,249)$ state that they "do not attempt to decompose the change in family income into its component parts because there are many ways to do so and there is no consensus on the most appropriate decomposition." See Shorrocks (1983) for dire warnings and Kimhi (2011) for a recent critique, but also Cowell and Fiorio (2011) for a possible way out.
} 
and the analysis splits throughout between men and women. The focus is the American evolution over the last quarter of the previous century using CPS data. ${ }^{15}$

Anthony Atkinson and Andrea Brandolini (2006), though for the most part considering trends in wage dispersion, compare the Gini of the individual annual earnings dispersion to the Gini of adjusted disposable household income for a set of eight countries: Canada, Finland, Germany, the Netherlands, Norway, Sweden, the UK, and the USA, using LIS data from around the year 2000. They draw the comparison on an annual basis and including part-time and part-year earnings, but they leave the distribution of employment out from their analysis, and, consequently, they also do not compare directly to the hourly wage rates, the traditional pay inequality in the labour market. In addition, they do not compare individuals and households on the basis of an identical ranking as is done by Gottschalk and Danziger. They find that the Nordic and Continental countries have similar Gini values for earnings and for incomes respectively while both are higher for Canada and the USA; the UK is found to be European on earnings and North American on incomes (p. 58).

Lane Kenworthy (2008), observes that "if every household had one employed person, the distribution of earnings among households would be determined solely by the distribution of earnings among employed individuals" (p. 9). He mentions the possibility that households have different numbers of earners, adding that this number is mainly determined by the number of adults in the household. However, he leaves this aside in the analysis and focuses on the dichotomy between "some earner(s) or none" (p. 9). Using LIS data for 12 countries (Australia, Canada, Denmark, Finland, France, Germany, Italy, the Netherlands, Norway, Sweden, the UK and the USA), he finds pre-tax pre-transfer household income inequality to be strongly related to the inequality in individual earnings of full-time employed individuals, all equivalized for household size and composition. The association to the incidence of households with zero earnings (for the head of household) is less, and to marital homogamy, defined as the correlation between spouses' annual earnings, it is still smaller. The total employment rate and the part-time employment rate appear to play no role.

Večerník (2010), also using LIS data, considers employees only and does so in conjunction with their households. His focus is the effects of transition in four CEE countries, in a comparison with Germany and Austria. He specifically draws other earners than the spouses in a household into the comparison, and effectively distinguishes between dual-earner and multiple-earner households. He shows that the latter category of employees can make an important contribution to household earnings, that earnings inequality among this group is very high in all countries, and that the contribution to overall inequality can also be very substantial. Slovakia combines the highest earnings share (19\%) with a lower Gini coefficient than elsewhere, and a major contribution to overall inequality (39\%). This contrasts strongly with Germany where both the income share and the contribution to overall inequality are the lowest $(4 \%$ and $8 \%)$ and the within-group inequality is the highest (0.93). It seems to suggest that the population of other earners may have a very different character in Western Europe than in the East. ${ }^{16}$

Finally, Wiemer Salverda and Christina Haas (2014), using EU-SILC data, build on some of the above approaches comparing decile distributions and the top-to-bottom inequality ratios (the shares or means of the tenth top decile relative to that of the first decile) in a cross-section of 25 EU countries in 2010. They show how the dual-earner households and especially the multiple-earner households concentrate towards the top of the household earnings distribution: on average across EU countries only one tenth of households in the top decile are single-earner households while almost $90 \%$ are in the bottom decile

\footnotetext{
${ }^{15}$ Gottschalk and Danziger's approach is very apt in an inter-temporal perspective but difficult to interpret in a cross-section as it ranks male and female earners according to their respective households, which must be largely overlapping sets that concentrate higher up the income distribution, to the extent that both male and female in a household do have earnings. A disadvantage is that they do not discuss the role of singles nor of possible third earners in the household. They find that "for females, changes in hours more than offset the rise in wage inequality. The acceleration in male wage and earnings inequality during the early 1980s disappears when earnings of other family members are included." (p. 253). Thus the household is found to mitigate inequality growth in the labour market.

${ }_{16}$ Večerník (2013), studying the evolution of the two distributions in the Czech Republic between 1988 and 2009, again with the help of regressions on both sides, finds an important role on both sides for education which runs via the employment and earnings of women as marital partners
} 
(compare Figure 19.5 for the average picture). Unsurprisingly, dual-earner and multiple-earner households reach the top by combining wage levels often from well below the top of the earnings distribution, in contrast to the few single-earners whose households make it to the top. On average over the countries, the main earner's earnings are only $60 \%$ of a single earner's in a dual-earner household and less than 50 per cent in a multiple-earner household. Salverda and Haas draw a comparison of the household earnings distribution with two different ways of distributing the individual earners: one ranked according to their households' earnings, the other by their own individual earnings. They find that households add to household earnings inequality primarily by the combination of activities of their members while that combination at the same time mitigates the individual labour-market inequalities in both hours worked and levels of pay: workers with higher earnings or longer hours combine with those working or earning less. At the same time in international comparison the variation in hours is modest -clearly, one can only work so many hours regardless of the country - while the main difference reflected in the comparative level of household earnings inequality is after all the traditional inequality of individual's own wages in the labour market.

Figure 19.7 - Top-to-bottom ratios (S10:S1) for employed individuals and their households, 26 European countries, 2010
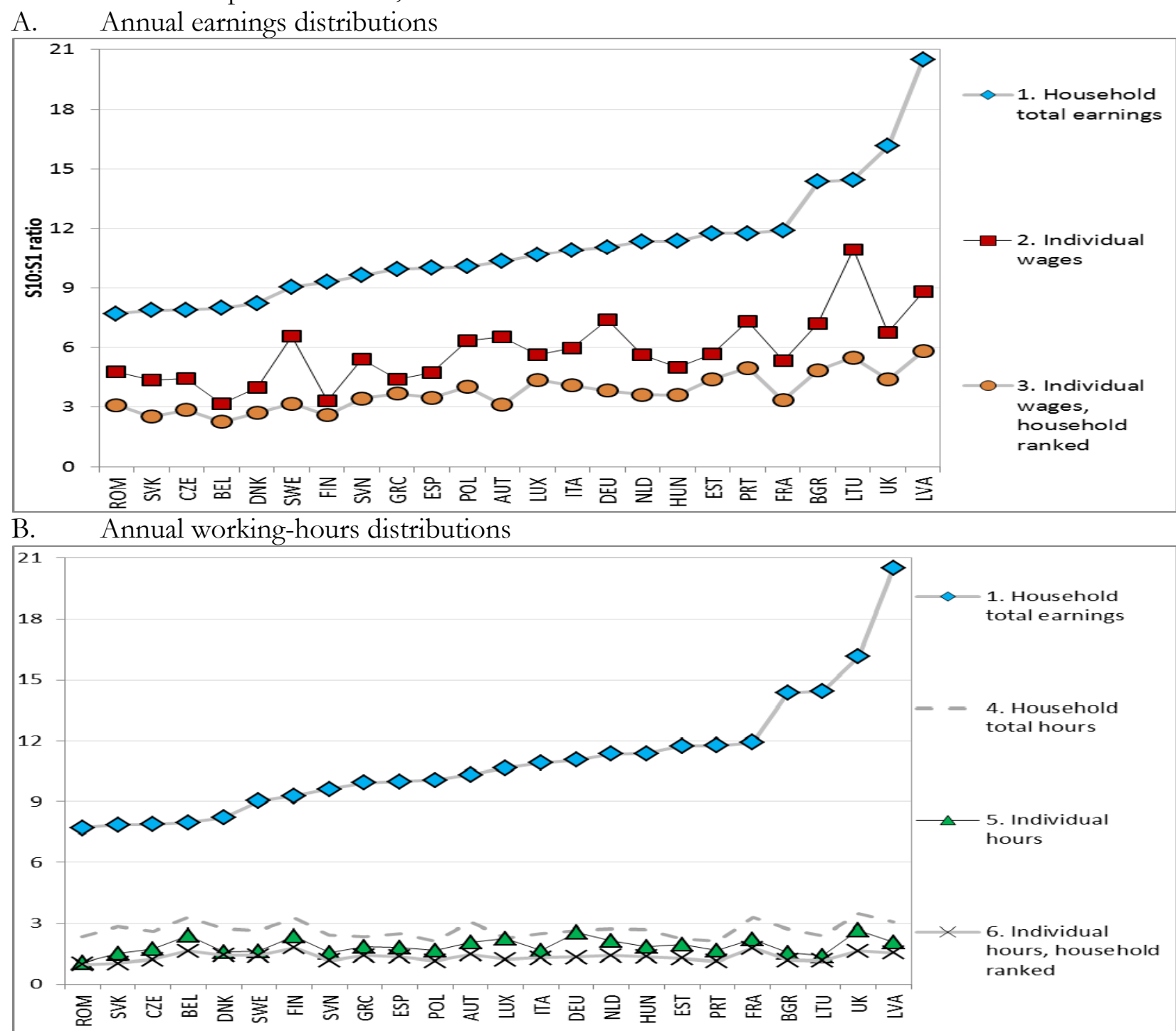

Reading note: In Romania average household total annual earnings in the $10^{\text {th }}$ decile of such earnings are 8 times higher than in the $1^{\text {st }}$ decile; annual earnings of individuals in the $10^{\text {th }}$ decile of such earnings are 5 times higher than in the 1 st decile if persons are individually ranked, and only 3 times if they are ranked according to their households total annual earnings.

Explanatory note: The sample concerns households receiving their main income from earnings. The Top-to-bottom ratio is between the average level of the tenth decile to the first decile.

Source: Salverda and Haas (2014), Table 3.2. 
Figure 19.7 compares household total earnings to individual wages in Panel A, and to hours worked in Panel B. The lower level of individual earnings inequality and annual-hours that is attained if persons are ranked by their households (Lines 3 and 6) instead of as individuals in the way they appear in the labour market (Lines 2 and 5), shows the mitigating effects of households compared to the labour market. Households earnings and hours (Lines 1 and 4) are more unequally distributed due to the adding up of individual earnings which however are attained at lower and higher levels. Panel B also shows compared to Panel A that the inequalities in hours are substantially smaller than in earnings within as well as across countries, which seems understandable as there are only so many hours in a year and the number of employees combined in a household is modest in practice.

\section{Decompositions of household income inequality}

The second relevant approach in the literature is based on decompositions of income inequality, especially by sources of income which enables scrutinising the contribution that earnings or employment make to inequality. There is significant variation among the decomposition studies: their nature and the variable decomposed, and also the technique of decomposition (see Fortin et al. 2011 for an overview). The results may depend on the choice.

In one of the first studies, Anthony Shorrocks (1983) using the American PSID over 1968-1977, concludes that "Dollar for dollar capital income and taxes have more distributional impact than earnings, which in turn exceeds the impact of transfer income" (which is defined to include retirement pensions and annuities).

Hans Van Weeren and Bernard Van Praag (1983) use a special dataset covering seven European countries (Belgium, Denmark, France, (West) Germany, Italy, the Netherlands, and the UK) in 1979 to decompose income inequality into subgroups. Interestingly, they look, inter alia, at the employment status of the head of household as well as the number of persons contributing to household income. At the time both characteristics make the largest contribution to inequality in Denmark while employment makes the smallest contribution in the Netherlands and the number of earners in the UK.

Blackburn and Bloom (1987) draw a careful comparison of the family annual earnings distribution and the individual annual earnings distribution for the US over the years 1967-1985. Using various aggregate inequality measures they find that annual earnings inequality has hardly changed while income inequality has. Descriptively splitting the distribution in five parts the change seems largely concentrated in what they term the 'upper class', family with earnings over and above 225 per cent of the median. From a time-series regression analysis they conclude that particularly the growth of nonprincipal earners in those households contributes to this growth. Blackburn and Bloom (1995) draw an international comparison at various points during the 1980s. For the United States, Canada, and Australia they find that income inequality increased among married couple families and that the increases are closely associated with increases in the inequality of husbands' earnings. Evidence of an increase in married-couple income inequality is found also for France and the United Kingdom, but not for Sweden or the Netherlands. In various countries that increased inequality of family income is closely associated with an increased correlation between husbands' and wives' earnings. A more detailed examination in Canada and the United States suggests that this increase cannot be explained by an increase in the similarity of husbands' and wives' observable labour market characteristics in either country. Rather, it is explained partly by changes in the interspousal correlation between unobservable factors that influence labour market outcomes.

Lynn Karoly and Gary Burtless (1995) follow Robert Lerman and Shlomo Yitzhaki (1985) in decomposing the evolution of the Gini coefficient of American distribution of personal equivalized incomes between 1959 and 1989, basing themselves on Census and CPS data. They find largely the same results as Burtless (1999) does for his more recent period. A large part of the reduction in income inequality before 1969 is attributed to the decline in earnings inequality among male heads of families. After 1969 the same group is responsible for more than one-third of the increase in inequality. Since 1979 the improved earnings of women have increased inequality as they were concentrated in families with high incomes. 
Maria Cancian and Robert Schoeni (1998) consider ten countries using LIS data for the 1980s. They find that the labour force participation of wives married to high earning husbands increased more than for those married to middle-earning men. ${ }^{17}$ At the same time, the mitigating effect of wives' earnings actually increased slightly in all countries. In their view an unprecedented increase in the correlation of earnings between the partners would be needed to make the effect disequalizing.

Evelyn Lehrer (2000) finds from the US National Survey of Families and Households that between 1973 and 1992-1994 the equalizing influence of the wife's contribution grew substantially stronger partly due to a decrease in the dispersion of female earnings relative to that of male earnings. This seems to contrast with Karoly and Burtless (1995); however, her finding relates to married couples and their earnings only, not to the full personal income distribution.

Daniela Del Boca and Silvia Pasqua (2003) consider husbands and wives in Italy between 1977 and 1998 using regional differences and the absence of wives' incomes as a counterfactual. The added worker effect is found in households especially in the North where there is more acceptance and more choice of working hours and more child care support available. Here the reduction in the dispersion of wives' earnings seems to have offset increases in the dispersion of husbands' earnings as well as the increased correlation in the earnings between the spouses between 1989 and 1998.

David Johnson and Roger Wilkins (2003) following John DiNardo, Nicole Fortin and Thomas Lemieux (1996), studying Australian inequality over the period 1975-1999, find changes in the distribution of work across families - for example, an increase in both two-earner families and noearner families - were the single most important source of the increase in private income inequality, with such changes on their own accounting for half the increase in inequality

Mary Daly and Robert Valetta (2006), using CPS data for the USA and adopting partly the method of Burtless (1999) in combination with the decomposition technique proposed by DiNardo et al. (1996), find a more substantial contribution (50-80\%) of men's earnings to increased American inequality between 1969 and 1989 than Burtless. This increase was counteracted by the growing employment participation of women. They explain the larger role of males as their methodology can account for growing inactivity and unemployment.

The Review of Economic Dynamics' Special Issue of $2010^{18}$ presents an interesting and important inventory of various dimensions of economic inequality, including the distributions on both sides of the individual earnings versus household incomes divide as well as the distributions of wages versus that of hours. The set of papers for seven countries contains useful descriptives of the distributions. In addition, some decomposition exercises are done on the log-variance of either earnings or hours. These decompositions concern a limited but important range of characteristics (gender, education, age, experience, region, family structure). They appear to explain little of the evolution and in virtually all cases leave most of the action to the residual. Of particular interest is Figure 19.8, where Panel A specifies the variance of $\log$ individual hourly wages and Panel $\mathrm{B}$ that of individual annual hours worked. The two are at different levels, the latter nowadays being much lower than the former, and their evolution seems to trend in opposite directions, clearly up for the former and declining for the latter. For annual earnings - seldom known from the contributions - the implication is a more substantial variance, which then feeds into household earnings.

\footnotetext{
17 They do not decompose strictly speaking but use a simple split of the coefficient of variation between married partners to look at the contribution of wives to inequality among this category; so they do not address the income distribution as a whole.

18 Relevant to the set of countries covered here are Canada: Brzozowski et al. (2010), Germany: Fuchs-Schündeln et al. (2010), Italy: Japelli and Pistaferri (2010), Spain: Pijoan-Mas and Sánchez-Marcos (2010), Sweden: Domeij and Floden (2010), UK: Blundell and Etherigde (2010), and finally USA: Heathcote et al. (2010). In spite of the fully comparative set up from the start, there are still some incomparableness left, especially with regard to annual individual earnings and to the household earnings distribution which is not always given on the same basis (pre-government, pre-tax, after-tax or equivalised disposable income).
} 
Figure 19.8 - Evolution of variance, by gender, ages 25 to 59, United States, United Kingdom, Canada and Sweden, 2010

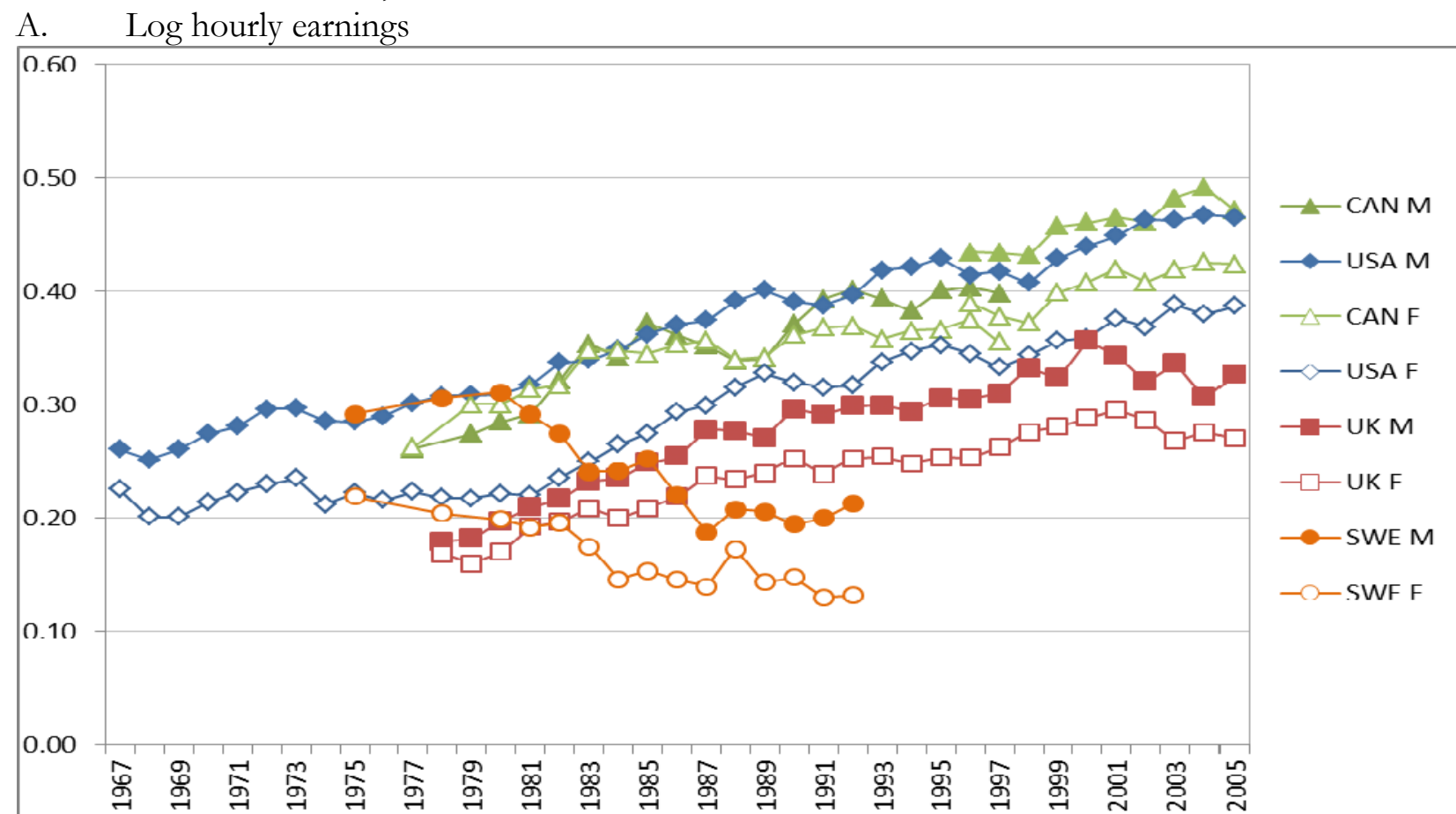

B. Annual hours worked

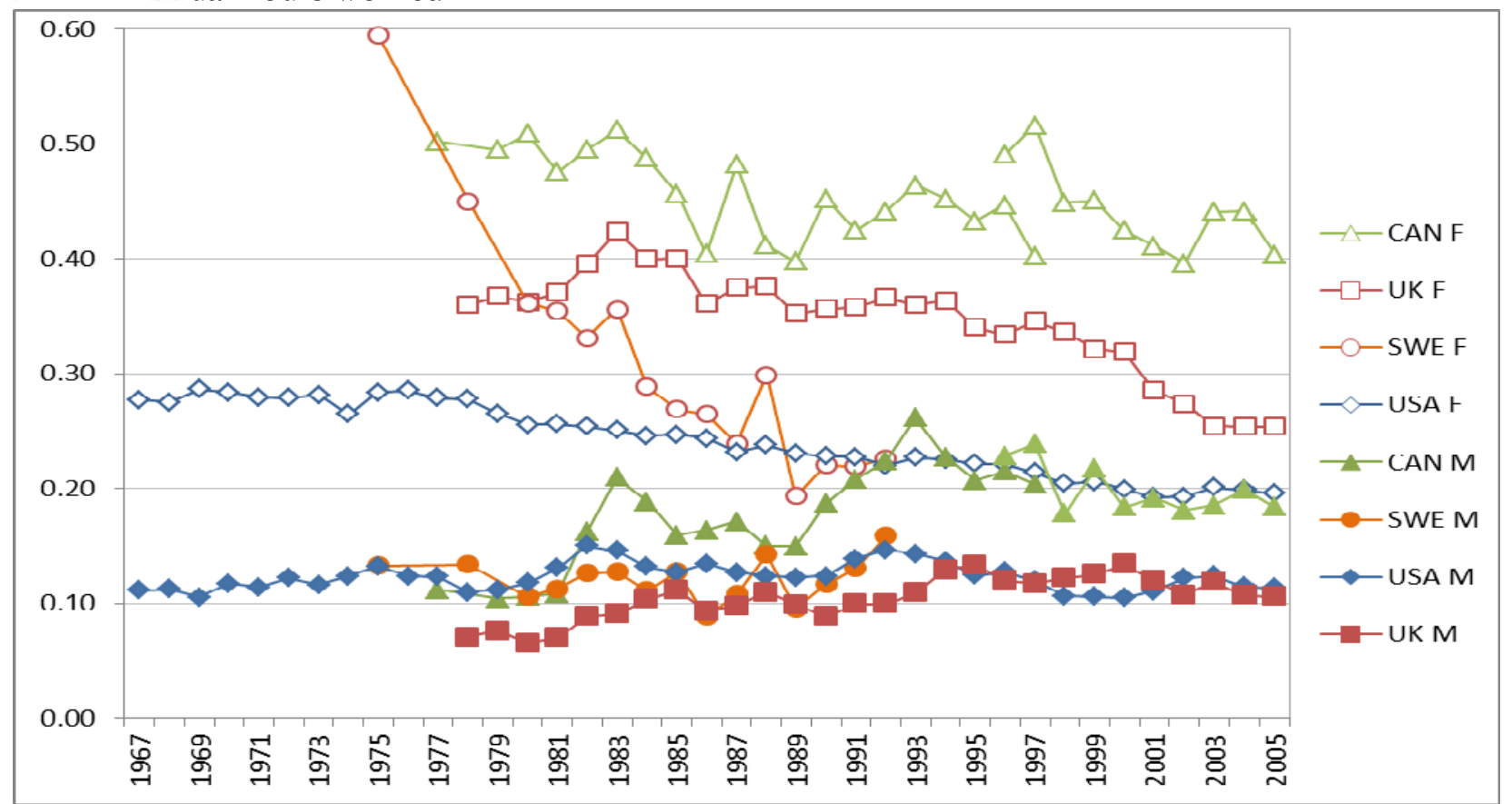

Reading note: The variance of log hourly earnings of US males increased from 0.26 in 1967 to 0.47 in 2005.

Explanatory note: $\mathrm{F}$ - females, $\mathrm{M}$ - males.

Source: Blundell and Etheridge (2010), Brzozowski et al. (2010), Domeij and Floden (2010), Heathcote et al. (2010).

Yuqian Lu, Réné Morisette and Tammy Schirle (2011) study Canadian developments in the family earnings distribution (equivalized) from 1980 to 2005 using Census data for those two years and 1995. They again adopt the decomposition approach developed by DiNardo et al. (1996). For 1980-1995 they find substantial increases in family earnings inequality, but for 1995-2005 some decrease. Changes in the earnings structure, such as those attributed to educational attainment, and changes in family composition (less married couples, more single and single individuals and lone parents) have been key factors contributing to growing family earnings inequality. Substantial changes in family characteristics (including a surprising decline in educational homogamy and the implied mating of women below their level) have had the most important counteracting effects as has continued growth in women's 
employment rates. Interestingly, the authors take a special look at the Top- $1 \%$ of the distribution, mention that it has increased substantially between 1995 and 2005 in contrast with declining family earnings inequality; however, they do not further highlight this in their analysis.

Jeff Larrimore (2013), again focusing on American CPS data, now for 1979-2007, and with the help of a shift-share decomposition finds important differences between the three subsequent decades: changes in the correlation of spouses' earnings accounted for income inequality growth in the 1980s but not in the 1990s (consistent with Figure 19.6), while during the 2000s changes in earnings of male household heads diminished income inequality and the continued growth in income inequality was due to growing female earnings inequality and declining employment of the two sexes.

Figure 19.9 - Contributions of household earnings to total net-equivalized household income inequality, United Kingdom, 1968-2008

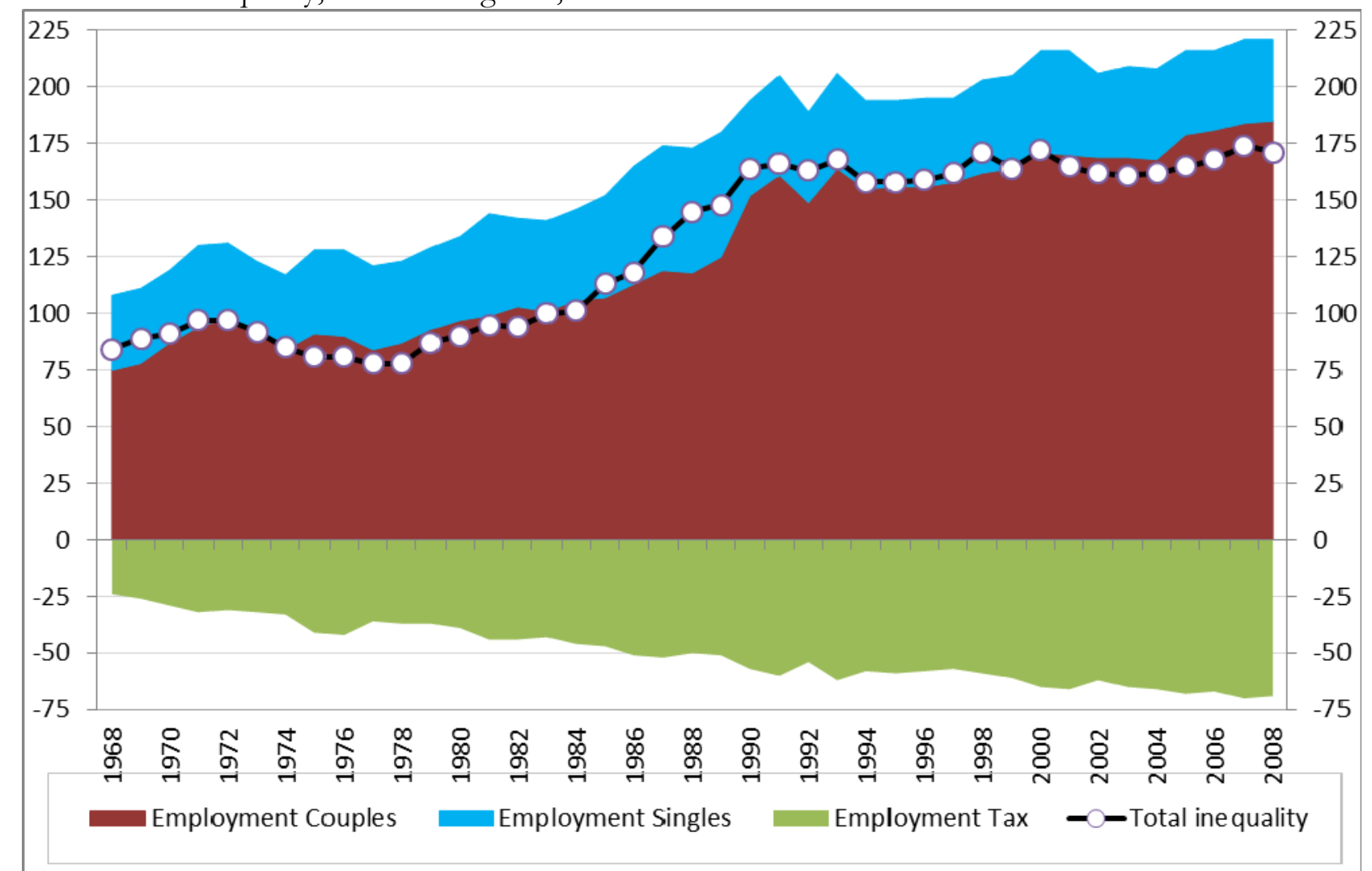

Reading note: The line of total inequality results from adding up the contributions to inequality from couples and singles in employment and subtracting the tax they pay.

Explanatory note: Inequalities are measured as the variance of $\operatorname{logs}(\mathrm{x} 1000)$. Contributions do not exactly add up as nonemployee categories receiving market income, pension have been left out. These contributions happen to partly cancel out but their aggregate has grown from 0 points in 1968 to 19 points out of the total of 171 that is shown for 2008.

Source: Brewer and Wren-Lewis 2012, Table 5.

Finally, the most extensive decomposition study seems to be the one reported by Mike Brewer, Alastair Muriel and Liam Wren-Lewis (2009) and Brewer and Wren-Lewis (2012). For the National Equality Panel (Hills et al. 2010) they have dissected the trends in British inequality over the long period 19682006 in many respects using a regression-based decomposition technique developed by Gary Fields (2003) and Myeong-Su Yun (2006). ${ }^{19}$ The results are presented in Figure 19.9. Total inequality of all households (line with white markers) moves to a higher level over the 1980s, from less than 100 to more than 160. The contribution that household gross earnings make to this is split between the singleearner and dual-earner households respectively and the total of taxes paid by both (stacked shaded

${ }^{19}$ Unfortunately they compare gross earnings to net net-equivalised household incomes, but they also decompose between (aggregate) taxes and benefits. 
areas). The role of singles has remained unchanged on balance, with a temporary increase during the 1980s. Dual earners run largely parallel to total inequality; their growth is also somewhat concentrated in 1980s but has continued after that at a slower pace. Taken together single and dual earners lag the inequality growth of the 1980s somewhat. That gap is filled by incomes from self-employment, investment and pensions whose role more than doubles during the 1980s (not shown). ${ }^{20}$ The net effect of earnings is less as taxation (the negative area which needs to be deducted) has also increased. After an initial rise up to the mid-1970s the rise is more gradual and extends over the period as a whole but hardly changes relative to earnings.

At the end of this overview a careful and detailed comparison of these results, including replication studies, seems advisable to find out where they diverge or even contradict and to seek an explanation whether differences are real - i.e., related to the period or the sample that is the focus - or artificial i.e., due to the dataset, the method of decomposition or also the approach to equivalization. Unfortunately, however useful such a meta study is entirely outside the scope of our contribution.

\section{A heuristic help for the role of institutions and earnings}

Though we cannot and will not pursue a comprehensive approach to wage dispersion and income distribution we may still ask what we can learn from the above and take with us for the contemplation of wage dispersion and institutions. We need to keep in mind, first and foremost, that labour market earnings make a major contribution to household incomes as well as their dispersion. By implication, the lack of such earnings resulting from unemployment or joblessness makes a large contribution too.

Important developments are found that tend to diminish the direct influence of wage dispersion on the income distribution as the growing female labour-market participation and at the same time enhance the role of household joint labour supply. This complicates the relationship between the two distributions, and it may also affect the labour-market behaviour of labour supply. Anyway, it brings into play a collection of new institutions that may affect both employment, hours worked, and pay, as well as their concentration across households. This may influence the level of wage inequality. It seems advisable to take the new institutions into account in addition to the traditional ones arising from labour-market analysis on its own.

Another important inference to draw is about the importance of considering hours and their dispersion in addition to wages. The inclusion of hours is important for several reasons. They are needed to arrive at the full picture of the earnings input that the labour market makes into household incomes. The hours dispersion differs significantly between the sexes, between countries and also changes over time. In addition, the growing role of part-time and temporary jobs in itself makes this a more important dimension, and one which may also play a role in determining the dispersion of pay given the correlation between hours and pay. There may also be different trade-offs between hours and pay in different countries. At the same time, the role of hours may be relatively less important, that is more modest because of natural constraints, than that of pay in an international comparison.

Second, it seems safe to conclude that one size does not fit all (countries). Significant differences are found, especially between different periods, and these seem to get more attention the further behind the period is, witness Larrimore's most detailed account of such periodization in his 2013 publication.

Interestingly, comparable decompositions of important characteristics such as gender, age, education, and family type, seem to play an amazingly small and also often flat role in virtually all countries, leaving a large role to residuals, which may point to national idiosyncrasies.

\footnotetext{
${ }^{20}$ The relative role of benefits (including tax credits) grows until the mid-1980s but is almost halved subsequently.
} 


\section{Wage dispersion: Measurement and stylized facts}

Before we turn to the analysis of wage inequality and institutions in Section 4 we discuss here first the ways to measure these and present then what seem to be the current stylized facts of the literature concerning wage inequality. Section

3.1 starts with a discussion of the issues involved in measuring wage inequality and a quick presentation of data sources. This is followed by a presentation of the 'stylized facts' which we define as the state-ofthe-art knowledge of wage inequality currently accepted by scholars as necessitating explanation in spite of their different views and approaching. These facts regard, first, the aggregate level of inequality, referring to the most comprehensive distribution at the national level. For this we discuss outcomes according to different measures of inequality as well as for different definitions of the wage variable. Second, Section

3.2 considers disaggregate inequality, which highlights specific parts of the distribution - such as the tails or the middle - on the one hand, and inequalities among various subsamples of the population according to demographic or labour-market criteria on the other hand. Then (Section

3.3) we provide some new empirical evidence from a cross-section comparison of 30 countries for the most recent year available, which we elaborate on in our empirical approach in Section

3.4 concludes.

\subsection{Measuring wage inequality and data sources}

Blackburn and Bloom (1987) have argued in detail the need of precision for measures and definitions of wage inequality. ${ }^{21}$ Following their suggestions, we need to pay attention to at least four dimensions:

1) the measure of inequality

2) the definition of the wage variable (including its time dimension)

3) the selection of the sample of the population that is being covered

4) the nature of the data sources.

Clearly, the study of wage inequality adds several significant issues of measurement to those of longterm concern to the study of inequality (e.g. Atkinson, 1970; Chapter 6 this volume; Jenkins and Van Kerm 2009). We consecutively address these four issues before we turn to data sources, and to the stylized facts in the following section.

Before starting this we mention a general observation. Wages are defined here as 'wage rates', 22 preferably controlled for hours worked ${ }^{23}$ and therewith for differences in workers' efforts, while we

\footnotetext{
21 "The often-contradictory conclusions reached by studies of recent trends in income and earnings inequality are largely explained by the reliance of researchers on a remarkably wide range of conventions of data analysis. For example, the list of important dimensions in which previous studies vary includes: the time period covered; the way family units are defined; the population to which the studies of individual earnings generalize (e.g., all earners, private non-agricultural workers, male earners, wage and salary workers, fulltime, year-round workers, etc.); the measures of earnings and income (e.g., total family income, equivalent family income, total family earnings, wage and salary income, etc.); the unit of time for the measurement of earnings (e.g., annual, weekly, or hourly); the nature of the earnings measure (e.g., usual earnings or average earnings); measures of inequality (e.g., the Gini coefficient, income-class shares, variance of logarithms, coefficient of variation, mean logarithmic deviation, etc.); the use of individual or grouped income/ earnings data; the treatment of sample weights; the treatment of observations with imputed incomes; the handling of top-coded values of income and earnings; and other criteria for including observations in the sample, such as the age of the respondent and whether the respondent was working at the time of the survey or in the year preceding the survey." Blackburn and Bloom $(1987,603)$

22 'Wage rates' as hourly wages can be part of wages scales agreed between unions and employers, albeit implicitly, when the agreement also covers hours of work. However, actual individual earnings will often deviate from these scales because of bonuses, performance pay, labour-market scarcities etc. (see, e.g., Salverda, 2009).
} 
consider 'earnings' or 'wage earnings' as the product of those wage rates with the hours worked and therefore reflecting also differences in individual efforts. For convenience we say in general that we are addressing 'wage inequality'. However, this does not mean that we restrict ourselves to the inequality of wages rates only; to the contrary, we aim to also consider the dispersions of hours and earnings. When doing so we will try to be clear and not just mention 'wages' but use the appropriate concepts : weekly, monthly, or annual hours or earnings. ${ }^{24}$ Wage rates serve the clear analytical purpose of enabling comparisons between individuals on the basis of the same efforts made in terms of time dedicated to paid work, measured in hours. As already argued, hours are an increasingly important dimension of labour-market functioning and inequality and shall be given their due.

\section{Measures of inequality}

While the Gini coefficient is a very popular measure in the analysis of income inequality, it hardly figures in the analysis of wage inequality. Variance, mean log deviation, the Theil index, and standard deviation are used though. ${ }^{25}$ Unfortunately, because of their aggregate nature these measures tell us little about where in the distribution the differences over time or across countries reside, though decomposition of these measures, as far as possible, can certainly be helpful for understanding the underlying processes. In wage-inequality analysis it is the percentile ratios that play a remarkably important role: the P90:P10, P90:P50, and P50:P10 ratios, which mutually relate the $10^{\text {th }}, 50^{\text {th }}$, and $90^{\text {th }}$ percentiles to each other. ${ }^{26}$ These ratios are directly helpful in focusing attention on particular parts of the wage distribution and they are intuitive at the same time. Their evolution over time reflects differential changes in wages at specific points of the distribution. As we will see below, up to this very day the debate on the effects of the minimum wage on wage inequality is framed almost exclusively in terms of these ratios. The ratios have also provided important leverage to the shift that has occurred in the debate about the role of technology as a determinant of growing wage inequality. Their popularity may relate also to an easier consistency with the analytical focus on the individual and his or her efforts in the labour market in contrast to income analysis. ${ }^{27}$ Note that the ratios are based on the upper boundary wage levels of the chosen percentiles (or deciles), and not on their means, sums, or shares in the total of wages. This implies certain limitations to the use of these ratios, and it seems advisable to add measures that broaden to averages, sums, or shares. For example, a top-to-bottom ratio between the means, sums, or shares of the top decile on the one hand and that of the bottom decile on the other hand (denoted as S10:S1) may find inequality growing much farther apart than the P90:P10 ratio would suggest, if important changes are actually occurring within the two tail deciles and affecting their withinspread. ${ }^{28}$ Precisely that is the upshot of the recent analysis of top-income shares, where the sum and the share of the top decile, and its within-distribution over smaller fractions, are the very subject of study. In a similar vein, much of the current minimum-wage debate appears to be effectively analyzing changes found within (and perhaps even restricted to) the bottom decile of the wage distribution. Note that the OECD has recently introduced the top-to-bottom ratio in its income inequality and poverty

\footnotetext{
${ }^{23}$ Note that this may add to measurement error.

${ }^{24}$ Here we differ from OECD $(2011,26)$ which follows a more complex scheme that risks creating confusion: Their 'dispersion of hourly wages' equates to our dispersion of wages whilst their 'wage dispersion' equates to our 'distribution of annual earnings'. 'Labour income' is a concept encountered in the US inequality literature and effectively considered as a wage rate; however, it actually amounts to a wage rate multiplied by the efforts (usually for full-time workers on a weekly basis).

25 There is an extensive literature discussing the properties and validity of these measures, such as the violation by the standard deviation of the transfer principle - see, e.g., Chapter 7 of this Handbook or Jenkins and Van Kerm (2009). Compare, e.g., Karoly (1992) who considers empirical outcomes for a broad range of such measures for American wage inequality.

26 Also denoted as decile ratios: D9:D1, D9:D5, and D5:D1, between the 1 st, $5^{\text {th }}$, and $9^{\text {th }}$ deciles, the aforementioned percentiles being their upper boundaries. Comparisons for all percentiles encountered in the literature below, may be considered a visual generalization of this type of measures.

${ }^{27}$ Relative to the individual employee the type of the household as a unit of analysis shows much more variation, which is difficult to square with the use of exact percentile income levels as it is accidental what type may be found at a particular income level.

${ }^{28}$ Compare the 'poverty gap' which acts as an indicator of the within-spread of poverty.
} 
database. ${ }^{29}$ In addition to these quantile ratios, the ratio between the average wage and the median wage is sometimes also found as in indicator of wage inequality, similarly the Kaitz index relates the level of the minimum wage to the average wage in the analysis of minimum wage effects. One disadvantage of all such ratios, however, is that they cannot be decomposed (Lemieux, 2008, 23) ${ }^{30}$, though they may be further split into ever smaller fractions.

Figure 19.10 - Shares (\%) of workers earning a poverty wage or a low wage, United States, 1973-2011

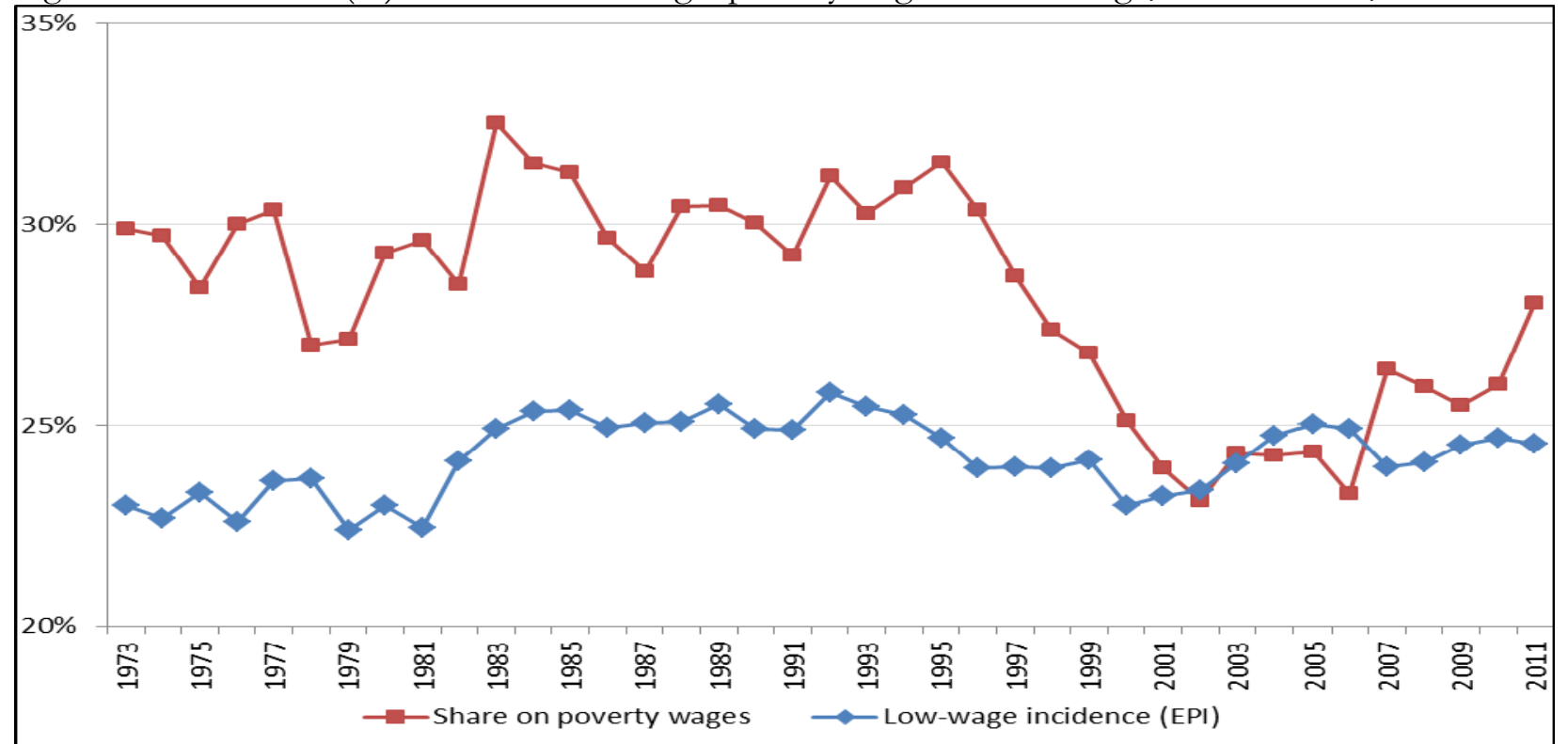

Reading note: The percentage of all employees earning a poverty wage fluctuates around 30 until 1996 and then falls substantially; the percentage earning a low wage fluctuates around 25 from 1983 onward.

Explanatory note: Poverty wages are earned by individuals whose household incomes are below the official poverty threshold; low wages are defined as being at or below two-thirds of the median wage: on authors' estimation for hourly earnings of all workers using linear interpolation in the decile distribution.

Source: Authors' calculation on EPI, State of Working America 2012, data underlying Figures 4.E and 4.C

Some other indicators are available in the same family of disaggregate measures that can also relay information about wage inequality. These relate to parts of the distribution that are defined with the help of an external wage-level criterion. The most important one in practice, regularly published by the OECD, is the incidence of low-wage employment (see Lucifora and Salverda, 2009; Gautie and Schmitt, 2010). This is defined as the share of all employees in the wage distribution who are found having wages below the level of two-thirds of the median wage. ${ }^{31}$ It is important to realise that this is a concept that relates to the analysis of the labour market, in contrast with in-work poverty that depends on the household-income position of the wage earners concerned; nonetheless the former is definitely relevant to the analysis of the latter. The concept of low pay is only infrequently used in US analyses of wage inequality where the in-work poverty concept is more frequent, perhaps because the poverty threshold is of such central concern in that country's public discourse. ${ }^{32}$ The divergence between the two concepts signifies that workers may be poor - on the basis of their household situation - at wage

${ }^{29}$ See http://www.oecd.org/els/soc/income-distribution-database.htm.

${ }^{30}$ However, Firpo, Fortin and Lemieux (2009) develop a decomposition method based on recentered influence function (RIF) regressions, which they actually apply to these ratios.

31 While there is a clear and internationally endorsed measure of low pay this is not readily available for high pay. Salverda et al. (2001) define high pay as over and above 1.5 the median wage but other definitions can also be found in the literature. The OECD Earnings Database also specifies high pay - using the same definition - but so far only for a few countries. By implication as long as the tails are not well defined there is also no clear measure available of the polarization of the wage distribution, which might easily be defined as what remains in the middle of the distribution after excluding low-wage and high-wage employment. Instead polarization seems to be gauged more as a qualitative phenomenon from ad hoc visual inspections of real wage growth, as we will see later.

32 We disregard the debate about the 'experimental poverty measures': in principle the same difference of focus attaches to the European concept of poverty (see Chapters 4, 9, 10 and 25 of this volume). 
levels that are well above the low-pay threshold, and vice-versa that workers receiving low pay may be found in households well above the poverty level. ${ }^{33}$ Unsurprisingly, the evolution over time may differ between low pay and poverty wages. Figure 19.10 clearly points this out for the USA. Over 1995-2002 the share of employees earning poverty wages shows a particularly sharp decline, while the incidence of low pay remains unchanged. Household composition, household joint labour supply and the evolution of prices determining the poverty lines can influence the former but not the latter, which depends on wage developments.

As an analogue to low-wage employment one can conceive of the incidence of pay at or below the minimum wage as another simple measure of wage inequality. Strikingly, in spite of decades of intense debate on the employment effects of the minimum wage such statistical data are sporadic. Internationally, a possible explanation may be the non-universality of statutory minimum wages or their complex nature when, for example, it is less evident to whom they apply or not - a problem that is absent in measuring the low pay incidence.

Finally, as implictly suggested above, the share of top wages in the wage distribution - a direct corrollary to top-income shares - provides another possible statistic that can throw light on wage inequality. We will see later that pay at the top plays an increasingly important role in the wageinequality debate.

\section{Definitions of the wage variable ${ }^{34}$}

Most of the literature restricts the definition of the wage variable to the payments received by employees from their employers and we will follow that convention here. This excludes for reasons of principle both the unemployed and the self-employed (however, this does not mean that they should be excluded from the analysis of labour markets and wage inequality - compare our approach in Section

5). We will focus on gross wages, including taxes and contributions which are paid by the employee (also when the employer actually withholds them on behalf of the tax authorities). However, gross wages are not available for all countries all of the time though, fortunately, they now increasingly are (e.g., very recently France, Greece, Switzerland started to provide gross wages; net wages will likely show a lower levels of inequality because of tax progression). In addition, even gross wages are a more restricted concept than 'employee compensation' in the sense that they exclude employer contributions such as for occupational pensions and other provisions. This is for the practical reason of lacking observations in most countries. ${ }^{35}$ The full-gross wage defined as employee compensation including employee taxes and contributions seems the most appropriate concept in principle as it includes what can be called the 'social wage'. This encompasses entitlements financed out of employee and employer contributions and income tax, and varies varies significantly between countries (Gautié and Schmitt, 2010). Finally, the wage concept mostly comprises payments which are actually made by the employer and may leave out informal cash payments such as tips, in spite of their (suggested but often statistically unknown) importance for low-wage earners in some countries.

Given this definition of wages there is one crucial dimension about which we aim to be as clear as possible. This regards their time dimension, which appears to greatly influence the apparent level of inequality. We have already touched upon this above when mentioning the distinction between hourly wage rates and their multiplication by hours worked. Most of the US inequality debate has been framed

\footnotetext{
${ }^{33}$ For 2011, the US low-pay threshold can be put at \$11.89 per hour (EPI State of Working America 2012, Table 4C), which at 2000 hours of work in a year would generate annual earnings of $\$ 21,340$, well above the official poverty threshold for a single-person household $(\$ 11,702,<65$ years) and only slightly below that for two-adults-two-children households $(\$ 22,811)$. The poverty thresholds range up to $\$ 50,059$, depending on household size and composition, which is 2.3 times low-wage annual earnings. We disregard for a moment taxes and contributions and also that the poverty levels are rather low as underlined by the introduction of the Experimental and Supplemental Poverty Measures.

${ }^{34}$ For a deeper discussion of these definitory issues and the issues of composition and statistical observation considered next see Atkinson (2008), Chapter 3: Taking Data Seriously: Where the Data Come From and How We Should Use Them.

35 Commonly such contributions are not well known to the employee and they are left out in household surveys as a consequence. They may differ considerably over the wage distribution and between countries. Among the stylised facts below we will however mention an excellent example of information on the distribution of employee compensation.
} 
in terms of full-time weekly wages if not full-time full-year wages (Acemoglu and Autor, 2011, 1049) 'earnings' in our definition. Though this seems largely a matter of data convenience it may have important implications for comparisons. First, it ignores the incidence of part-time employment which varies significantly over time and across countries. Second, it overlooks the dispersion of full-time working hours itself, which can be considerable and may differ between countries. ${ }^{36}$

Third, different time periods for wages/earnings bring into play different, additional elements of pay such as bonuses and other special payments that are made with a lower frequency, e.g., on an annual basis. Such payments usually have an increasing effect on inequality, which risks to be missed by a shorter time horizon - the use of an annual average of shorter-term wages can potentially mend this problem, but this is not standard practice.

Fourth, the use of time for the weighting of the observations bears on the level of inequality too. This issue regards the working hours of the employee. Pay observations - including for hourly pay - can be taken simply over the head count of employees or alternatively over the count of hours worked, that is over employees weighted by their working hours. The latter boils down to full-time equivalent wage levels and lends part-time employees a lesser weight in determining the average and the quantiles. Evidently, such weighting reflects more closely the economics of the labour market and less the receiving side of labour's personal incomes, which affect their significance for household welfare and spending; both sides deserve consideration and attention should not focus exclusively on one or the other.

Finally, there is yet another timing issue on the employee side: wages can concern all who are in work during a year or they may be restricted to those who work the full year, or alternatively all workers may be considered in terms of full-year equivalents. Covering all includes the people who enter or leave employment (or both) in the course of the year; in the full-year option they are left out, in the annualized full-year equivalent approach they will be weighted also by the part of the year that they are in work. The share of part-year workers naturally differs between social groups, but it can differ also over countries and over time, because of the business cycle or because of a different or changing role of temporary jobs. New entrants in particular may have low wages and significantly affect inequality at the left-hand tail of the distribution. Finally, the part of the year they actually cover - say three months instead of four - will affect their earnings considerably and may have a significant effect at the margin on annual earnings inequality. ${ }^{37}$

To conclude, we do not think there is one best definition of the wage or earnings variable - it depends on the purpose of the analysis. We do think though that definition and purpose should be explicit and mutually consistent and that short-cuts adopted for reasons of data covenience should be scrutinized for their hidden properties and potential effects on the outcomes.

\footnotetext{
36 The OECD database on "Usual hours worked by weekly hours band", covering 28 countries, indicates for 2012 that on average $76 \%$ of men and $65 \%$ of women work 40 hours or more in 2012 , with a highly comparable cross-country pattern for the two genders. However, these shares vary from around 10\% only in Denmark to almost 100\% in Estonia, Greece, Hungary, Poland and Slovenia. The evolution over time also differs. On average for the 13 countries with data for both 2012 and 1983, the share among male full-timers decreases from $81 \%$ to $66 \%$, among women from $69 \%$ to $53 \%$. In various European countries the shares working longer hours plummets: for example in Denmark from 95\% (men) and $85 \%$ (women) to $12 \%$ and $8 \%$ respectively, in Germany from $100 \%$ and $99 \%$ to $73 \%$ and $64 \%$ respectively. However, in the USA it remains unchanged at slightly above $90 \%$ and the growing number of women adapts upwards to males. This female adaptation is also found in the UK but not in various other countries, where the gap can even grow.

${ }^{37}$ The time basis of the wage variable should be a matter of concern as it may cause major differences in the level of wage inequality. On an annual basis inequality may be five to six times larger than on an hourly basis (Karoly, 1993, Appendix B2B); the annual dispersion of hours worked explains the difference. Even on the much used weekly basis there is a clear dispersion in the hours of work (Karoly, ibidem). Second, the dispersion of hours within categories in combination with their weight in the total will affect outcomes, cross-section and over time. For example, men's hours dispersion seems much more compressed than women's and their compositional weights have developed strongly; in other words, full-time full-year working men are becoming steadily less representative of the wage distribution as a whole.
} 


\section{Composition and samples of the population}

Another issue worth mentioning is the part of the population that is covered by the analysis. A pars pro toto approach, that views a part of the population as representative of the whole, is particularly dangerous in inequality analysis. Subsets of the population may occupy very different positions in the overall distribution and inequality may differ significantly between them and their inclusion or exclusion can exert large marginal effects on the level of inequality even when they are relative small compared to the whole population. Selection along dimensions such as gender, age, education or experience on the side of the person, or industry, occupation, the nature of the employment contract and its protection, and the (part-time) working hours on the side of the job, can greatly affect the aggregate outcome. The issue may seem obvious but it frequently is a source of error, confusion or even distortion. For example, contributions may focus on men, on people working full-time, on the working-age population, or on positive incomes only, as if assuming that all the rest of the population makes no difference to the general outcome nor to that of the selected group. Imagine that women increasingly occupy low-paid jobs while men are ousted and leave employment; both groups could potentially see their wage inequality fall though overall it might actually increase. Another, realistic example, is that Dirk Krueger and Fabrizio Perri (2006) draw conclusions about household consumption inequality for the U.S. as a whole on a (laudably specified) sample that leaves out non-working-age households, those without an income from labour, and rural households - which are groups that may substantially affect inequality at the margin. Finally, even if all the population is covered all the time, compositional shifts across categories may be highly relevant to the evolution of inequality and will need proper scrutiny. Vice-versa, aggregate stability of inequality can go together with changing in inequality within many distinct categories; in the extreme case even all categories could face inequality change in the same direction (together with shifts in their positions relative to each other). Finally, it is important to add the observation - found in the overview of the literature below - that the distinction of between-inequality and within-inequality (the residuals, after all) depends on the variables chosen as the basis for the decomposition. That choice will likely be inspired by what are considered to be the stylized facts; as a consequence, insufficient attention may be paid to the implications of large residuals and these may actually obtain an importance of their own as is underlined by some of the literature that we will be discussing.

\section{Data sources /statistical observation}

Individual wages seem more cumbersome to observe statistically than household incomes. For incomes the collection of taxes provides a strong and universal incentive for gathering administrative data. Such data usually combine considerable precision regarding the core variables with clear limitations for other variables such as personal characteristics - for example, educational attainment is of no direct importance to the tax authorities. This motivation may be less compelling for a comprehensive collection of wage data. Administrative data may be gathered for registering individual social security entitlements but their nature and coverage will depend on the idiosyncracies of the entitlement rules, for example the sampling may be restricted to those who can qualify for the entitlements in question (e.g., after a probation period, working a minimum of hours, excluding overtime earnings), or focus on their work histories and not their actual earnings, or cover their earnings up to a relevant threshold only. This may hamper their use particularly in international comparisons.

Dedicated surveys, by contrast, require a special effort and consequently are subject from the start to cost-benefit trade-offs which will affect the range of variables, the population samples, and the time periods covered. This explains why surveys may concentrate on information that is easier to collect, and also that significant international differences occur in the availiability of data and in their coverage. As a result, one can understand the long-time focus in OECD data and American data and analyses on fulltime workers ${ }^{38}$ : collecting hours information on top of earnings information to enable determining hourly wages, or information on workers who have left during the year on top of those permanently

\footnotetext{
${ }^{38}$ Stretching al the way from the 1980s to Acemoglu and Autor (2011) included. Heathcote et al. (2010, 24) point out the
} inadequacy of this focus. 
employed or present at the time of the survey, is simply more demanding and costly. This may be the case particularly if the information is gathered from employers. Note though that ICT developments are greatly facilitating the transfer of firm data to statistical offices. Employers will by their own interest dispose of the most accurate information about pay. By contrast, if the information is gathered from households, the information on wages will be less precise as respondents may not know the details of wage components or taxation and contributions, or respondents may actually be less well-informed other members of the household. Equally, the information about hours of work may differ between employer sources and household sources as the former will focus on legally formalized working time while the interest of the latter will be in the actual hours that a job involves possibly including the necessary travel times. Interestingly, a concentration on full-time full-year workers may make little sense in a household survey as it will add to the costs. At the same time, employers will be less well informed about workers' personal characteristics such as educational attainment or the worker's household situation, while the availability and quality of that information from a household survey may be superior compared to employer surveys. Another advantage of administrative tax data can be their more comprehensive time coverage - tax is paid over the full year -, while households surveys may have important limitations when at the time of the survey questions are asked relating to the year, be it the preceding year or the current one. Adding the dimension of hours to that of earnings can only complicate this. ${ }^{39}$ Finally, administrative data will normally cover very large shares of the population and ascertain that all essential questions are answered, while other surveys can cover only much smaller samples and suffer from considerable non-response to questions, ${ }^{40}$ generating less accurate results also as a consequence of that. Non-response will be more important for the current focus on wages at the very top; unsurprisingly, tax data play a large role here though the top-coding of responses may still affect the availability of data, but that is no different for wages than for incomes. As administrative data will be available anyway, increasingly the statistical offices are trying to use these instead of asking fresh questions to households or firms, and use those data for imputations in other surveys, blurring the distinction between the two types of information as a result. Naturally, both administrative and survey data are subject to changes over time. The tax system or social-security rules may change and ask for new variables or drop existing ones. A survey may be adapted also because of costs, or simply because a new survey is started without paying due attention to the continuity with its precedessors. ${ }^{41}$

Having said this the main data source in the literature is first and foremost the American Current Population Survey CPS. It is a household survey, started in the 1940s and providing tabulated data from then, that has made microdata available for research since the early 1960s (the more adequate CPS ORG - outgoing rotation groups - data being available since 1979 only). CPS comes in different 'tastes': the March CPS or the May and/or ORG CPS, and one needs to be careful which one to use, partly depending on the purpose of its use. The March CPS is not good for hourly wages, while the CPS ORG does a better job here and also has a much larger sample size than the May CPS, that in addition may be seasonally affected while the ORG CPS data cover the full (preceding) year. ${ }^{42}$ However, the practice of topcoding of labour incomes may reduce the usefullness of this source of data for studying earnings inequality. ${ }^{43}$ Several other American data sources are sometimes used, such as the Panel Study of Income Dynamics PSID (which we will use below for better mimicking European SILC data) and the Census, and also employer surveys such as the Employment Cost Index microdata (Pierce, 2001 and 2010).

\footnotetext{
39 Below we are forced to combine from EU-SILC survey-time working hours with preceding year information; the American PSID is subject to similar problems.

${ }^{40}$ Up to one-third of CPS wage observations may be imputed by the surveyors (John Schmitt at CEPR Washington DC personal conversation).

${ }^{41}$ The break between ECHP and EU-SILC is a case in point, but over its long duration the American CPS also shows several important changes.

42 See also Lemieux (2008) for a detailed discussion.

43 "For example, in the March CPS, reported wages and salaries were until recently top-coded at \$150,000 a year, which is barely above the 95th percentile of the distribution of earnings in the tax data of Piketty and Saez (\$125,471 in 2004). One well-known data set for which topcoding is not an issue is the Panel Study of Income Dynamics (PSID), which is unfortunately not ideal either for studying top-end inequality because of smaller sample sizes." (Lemieux 2008, p.32).
} 
Second, on the EU side increasingly two consecutive EU-wide (panel) surveys provide microdata for research: the European Community Household Survey ECHP and the Statistics on Income and Living Conditions EU-SILC. The ECHP covers the EU15 only, with the exception in the first years of Austria, Finland and Sweden, who joined the EU in 1995. The survey performed eight annual waves in the years 1994 to 2001, generating annual data for the years 1993 to 2000. Sample sizes and degrees of panel attrition diverge substantially across countries depending on the value attached to the survey in the country. ${ }^{44}$ The ECHP was discontinued and has been replaced with EU-SILC, which is still in force today. SILC has annual waves starting in 2003/2004 and extending to 2012 at the time of writing again relaying full-year data for the preceding years (in most countries). SILC's country coverage follows the extension of EU membership and attains full coverage of EU-27 together with Iceland, Norway, Switzerland and Turkey in $2007 .^{45}$ There is a host of small differences between countries in sampling, definitions, etc., and these also change over the years. Importantly, the gross wage variable has been available for all countries since the wave of 2011 only while up to then some countries provided net wages only (France, Italy, Switzerland). ${ }^{46}$

Another easily accessible and often-used international dataset is the OECD's earnings database, which provides tabulated data. It has been built since the mid-1990s and now covers 34 countries $^{47}$ albeit with rather uneven time coverage. Only seven countries go back in time before 1990, and complete coverage is very recent (2010). In most cases the data are provided by the national statistical offices, in a few cases they are derived by the OECD from other surveys or provided by national experts. However, definitions and samples vary widely between countries, covering the entire set of possible differences that we have just discussed, ranging from all all individual employees to full-time, full-time full-year employees and full-time equivalent employees, from hourly wages to weekly, monthly, and full-time equivalent annual earnings, and from gross to net after taxes and contributions. The latest version of the full database contains 90 different series endorsing 33 different definitions. It commonly details the outcomes also for the two genders. For the website version of the database the OECD has chosen to present only one series per country, 33 in total. This reduces diversity to 9 different definitions; the mode (20 series) concerns full-time employees' weekly or monthly gross earnings (which may be deemed reasonably comparable ${ }^{48}$ ) but only 11 of those go back in time before the year 2000 . All definitory properties are admirably documented in the database and offer the user the opportunity to consider the differences and their potential effects. Nevertheless, the database is clearly not immune to the problems of secondary datasets that Atkinson and Brandolini (2001) have stressed for incomes but which are equally important for wages and earnings. ${ }^{49}$

\footnotetext{
44 Particularly, the educational variable suffers from different national interpretations of the common data gathering conventions in the course of the waves. In France and the Netherlands almost all responderts are misclassified at the lowest level of education from 1997 onwards. At the same time the UK drastically alters its classification of educational attainment with a strong upward effect among the population as a result.

${ }^{45}$ See epp.eurostat.ec.europa.eu/portal/page/portal/microdata/documents/SILC_IMPLEMENTATION_headezr.pdf

46 The most advanced experiment in income and wealth data harmonisation is known under the old name of Luxemburg Income Study-LIS (http://www.lisdatacenter.org/). LIS is home to two databases, the Luxembourg Income Study Database, and the Luxembourg Wealth Study Database. The income dataset contains information for 46 countries, in some cases going back to the 1970's. A parallel project was started at Cornell University, known as Cross-National Equivalent File-CNEF, 1970-2009, in collaboration with other research partners (see http://www.human.cornell.edu/pam/research/centersprograms/german-panel/cnef.cfm). The Cross-National Equivalent File 1970-2009 contains equivalently defined variables for the British Household Panel Study (BHPS), the Household Income and Labour Dynamics in Australia (HILDA), the Korea Labour and Income Panel Study (KLIPS) (new this year), the American Panel Study of Income Dynamics (PSID), the Russian Longitudinal Monitoring Survey (RLMS-HSE) (new this year), the Swiss Household Panel (SHP), the Canadian Survey of Labour and Income Dynamics (SLID), and the German Socio-Economic Panel (SOEP).

${ }^{47}$ The usual suspects from America, Asia and Europe together with Chile, Iceland, Israel, and Turkey.

48 Often a week is takes as $4 / 13^{\text {th }}$ of a month, or vice-versa.

49 They discuss other attempts of international data gathering apart from the OECD's, consider some of their use in the literature, and list the factors that influence what they call 'a bewildering variety' of inequality outcomes. It is highly important to consider the variation and its implications when using the data for international comparisons of levels as well as evolution. Atkinson and Brandolini "caution strongly against mechanical use of such data-sets." They also mention that country fixed effects may not provide a remedy and that even when data are uniformly defined the precise definition may have an effect on the conclusions that can be drawn. Atkinson (2008) extensively discusses similar issues with a focus on earnings, and adds important detail by wage definitions and time periods for 20 countries out of the OECD's 28.
} 
Finally, Atkinson (2008) provides the results of an in-depth study of the earnings distribution in 20 countries, inspired by the work of Harold Lydall (1968). He advocates a long-run picture on a year-byyear basis, showing that "drawing on isolated years ... can be misleading". For each country an extensive appendix documents the available data sources and the properties of the data and the presents the evolution at various percentiles of the distribution, ranged separetely for the lower and the upper half of the distribution. The series end in 2004 and stretch back in time to well before those of the OECD database. For 15 countries they start before 1960 and cover most of the postwar period and some of those (Canada, France, Germany, USA) go back to before the war. ${ }^{50}$ This long time span helps to realise the particular nature of the more recent developments that are the subject of the debates considered in this chapter. Roughly speaking, strong declines in inequality over previous decades preceded the increase on with the literature started to focus in the 1980s. Preferably, the analysis should be able to also explain the declines.

To conclude is seems natural that contributors to the literature are requested to specify their definitions, samples - including censoring or top coding - as well as sources. Given the long history of using the CPS this is increasingly becoming standard practice in American contributions but it certainly needs endorsement in international comparisons. Equally important, but not frequently practised, it seems highly advisable to consider the possible implications that data limitations and data choices made may have for the conclusions that are drawn.

\subsection{Cross-country levels and evolution of wage inequality}

We now turn to the stylized facts of earnings inequality as we derive them from the literature. This is done in two steps. We start with the US, which is the country having the best information and where the debate and the analysis of earnings inequality have developed most strongly, enabling us to spell out most of the issues at stake. We contemplate the variation in outcomes between different measures of inequality where feasible, between different definitions of the wage variable where necessary, and between different data sources where reasonably available. In addition to discussing aggregate outcomes, we take a look at some breakdowns both of the earnings distribution itself and by segments of the (employee) population. Next to the US, we continue with a consideration of various other countries aimed at comparing the inequality trends but also at identifying gaps in the available data that hamper comparability. In Section

3.3 we provide some new empirical evidence from a cross-section comparison of the EU countries and the USA for the most recent year available, based on EU-SILC and PSID which we will use for our empirical approach in Section 5. We end with summary conclusions regarding the stylized facts in international comparison.

\section{U.S. earnings inequality}

Much of the American literature focuses on men or at least distinguishes between the sexes, treating them separately and seldom putting them together in the overarching distribution. This contrasts with other countries and seems a paradox as US female employment started growing earlier than elsewhere and also grew more fiercely in the sense of being predominantly full-time and extending high up the overall earnings distribution (Salverda et al., 2001). It may be explained from the early start of the inequality debate in the US at a time that data did not really allow putting them together. This split risks ignoring the genders' mutual interaction in labour supply and demand and overlooking also the contribution of the within-country doubling of the labour force between the late 1960 and mid-2000s,

\footnotetext{
50 Atkinson and Morelli (2012) update the P90:P50 ratio to more recent years for most of these countries and add a few other countries.
} 
Figure 19.11 - Inequality of individual earnings, United States, 1973-2012

A. P90:P10 ratios of hourly (EPI) and full-time weekly (OECD) earnings

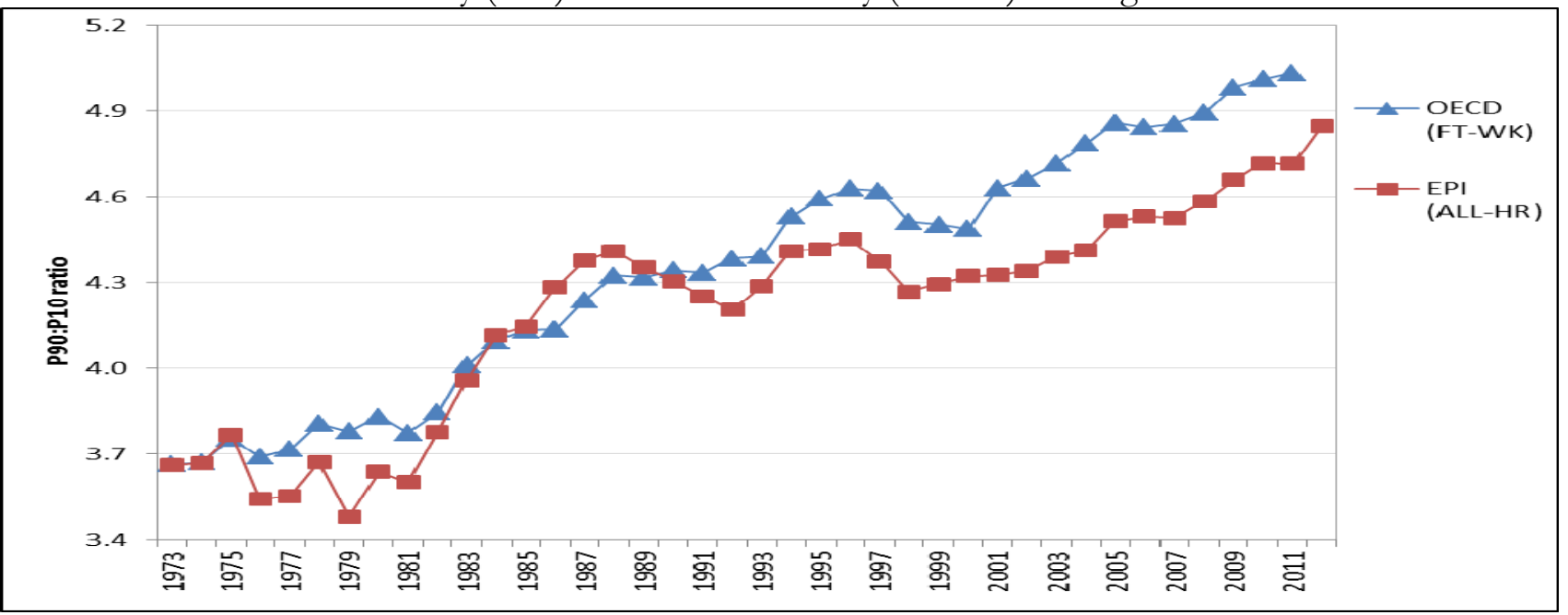

B. P90:P50 and P50:P10 ratios of hourly (EPI) and full-time weekly (OECD) earnings

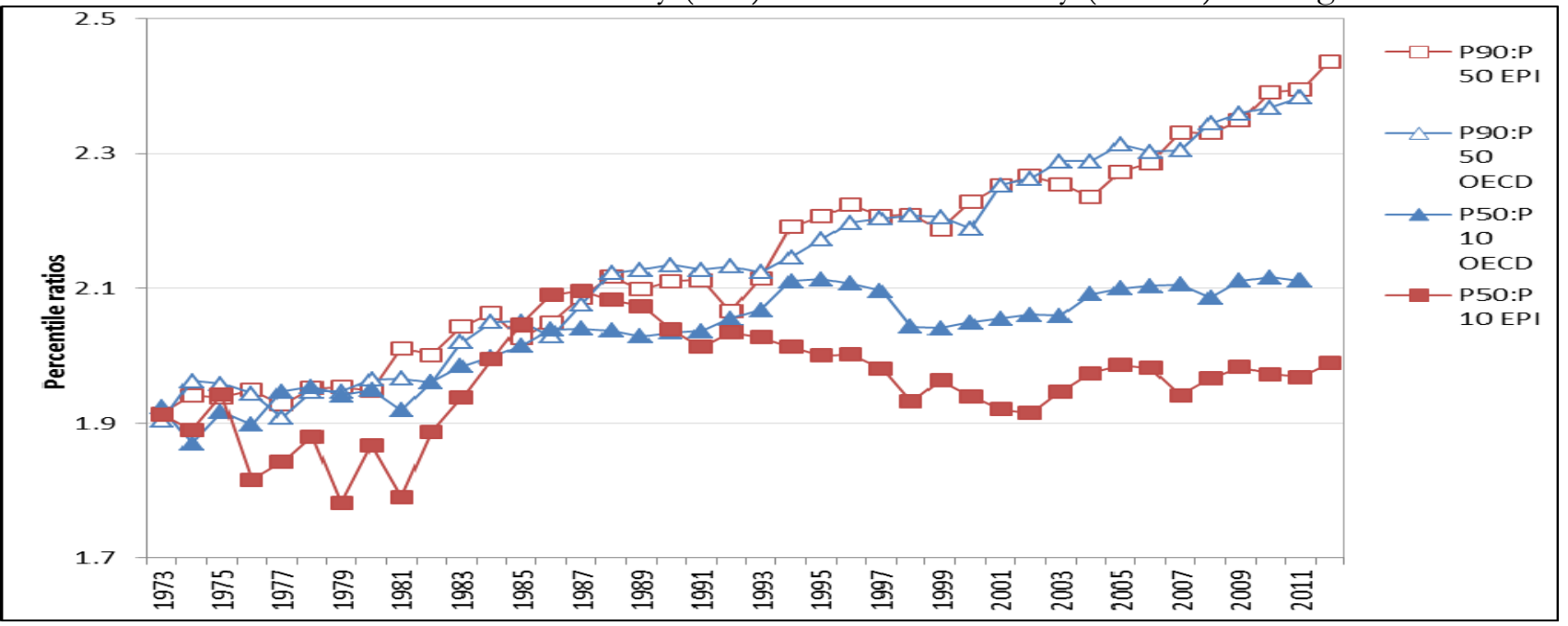

C. Wage and compensation growth by percentile, 1987-2007

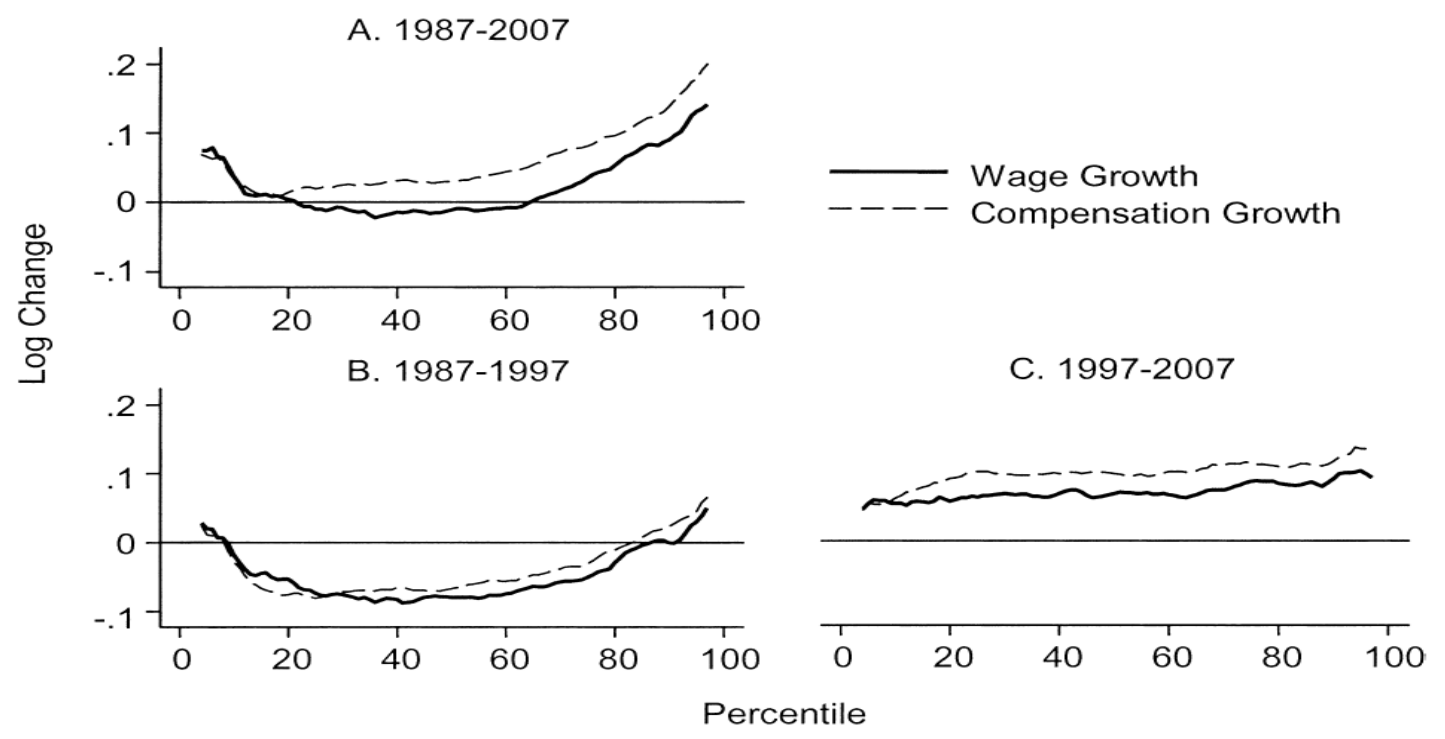

Sources: OECD Gross earnings: Decile ratios (26 October 2013), Economic Policy Institute EPI, State of Working America 2012, Washington: Real wage deciles, all workers, 2012 dollars (based on data from the CPS), and Pierce (2010), Figure 2.5 (based on Employment Cost Index data). 
which has remained in the shadow of the worldwide Great Doubling, famously coined by Freeman (2006). For this reason and for the sake of international comparability and also because it allows covering the recent years since the mid-2000s, we start with a quick look at the aggregate level of all employees irrespective of gender. That comprehensive picture is provided by Figure 19.11. Panel A. indicates the overall percentile ratio, P90:P10, from two different sources, the EPI's State of Working America and the OECD's Gross Earnings Database. EPI covers hourly wages of all employees, presumably based on head count individuals and not full-time equivalents; the OECD data, by contrast, concern weekly earnings of full-time employees and therefore miss out on part-time employment.

Starting at exactly the same level in 1973, EPI shows a much stronger increase in the ratio between 1979 and 1988 than OECD, directly followed by a decline while the OECD series remains unchanged. At the end the inequality level according to EPI is well below the OECD's. ${ }^{51}$ The conceptual difference between the two is important as it is found throughout the literature. Lemieux (2010) as well as Heathcote et al. (2010) provide state-of-the-art overviews of developments for many aspects of American earnings inequality from around 1970 to the mid-2000s, entirely based on hourly wages (but always split by gender). ${ }^{52}$ Other important contributions (e.g., Acemoglu and Autor, 2011), by contrast, draw to an important extent on full-time weekly or full-time full-year workers (equally split by gender). Autor et al. (2008, Figures 2 and 3) draw a useful comparison between hourly and full-time full-year earnings inequality trends.

Panel B pictures the percentile ratios of the common split between the upper and the lower half of the distribution from the same two sources. It suggests that the difference between the sources and the definitions concentrates in the bottom half; in the upper half the two series are almost identical, which is understandable as here virtually all employees will be working full-time. The divergence between the two halves is an important observation to retain. The panel also suggests, in accordance with much of the literature using the gender breakdown, that developments since the early 1990s have been different from before as on the one hand lower-half inequality hardly changes in contrast to the preceding period while, on the other hand upper-half inequality keeps on growing relentlessly, and ends far exceeds bottom-half inequality. With the EPI data the divergence starts in 1992, with the OECD in 1995.

Finally, Panel $\mathrm{C}$ adds a rather different way of presenting the evolution of inequality: the cumulative changes in real wage levels for each of the 100 percentiles over different time periods, using the work by Pierce (2010). This has become a convenient way of presenting the data in the polarization debate that we will report on later. The discontinuous periodization highlights apparent differences but may suffer from a certain arbitrariness at the same time. With its detail this type of presentation seems to implicitly criticise the use of more aggregated measures such as the Gini coefficient or the overall percentile ratio. The panel shows a much flatter pattern of changes over the 1990s than over the 1980s when strong declines in real wages occur for most percentiles between the tails of the distribution. Nevertheless real wage growth mostly increases with the wage level. Interestingly, the panel elaborates also on total compensation (dashed lines), which includes employer contributions on top of wages. This is unique feature which will be mentioned only here. We may conclude from it that the comprehensive concept of earnings does not change the general patterns for the 1980s and 1990s though it reinforces inequality levels somewhat during both periods. ${ }^{53}$

Figure 19.12 draws a comparison (for men only) of the intuitive overall percentile ratio with the oftenused aggregate measures of $\log$ wage variation and the Gini coefficient and also with the ratio of average wages in the top and bottom decile (S10:S1). All measures show much higher levels nowadays than in the 1970s. However, the variance grows substantially more strongly than the Gini coefficient,

\footnotetext{
51 Our aim is not to seek an explanation; a possible one may reside in the variation in full-time hours across individuals. See Autor et al. (2009, Figure 3) for outcomes similar to Panels A and B.

52 The two seem rather different at first sight; e.g., Lemieux finds much lower levels of the variance for both males and females, however, from 1979 to 2005 the trends are largely identical.

53 Congressional Budget Office (2012, Table 7) suggests (for annual earnings) that the relative top-up of cash wages and salaries with contributions to deferred compensation and employer contributions to health insurance and payroll taxes has grown over the quintiles of employee incomes.
} 
while the percentile ratio fluctuates between them, the S10:S1 ratio runs away from the rest after $1993 .^{54}$ The divergence between the S10:S1 ratio and the common P90:P10 ratio implies that the rapid rise has to do with the within distribution of the two tails which none of the other three measures seem to be able to capture adequately. The top-incomes literature has already shown its importance at the top end, but the dispersion within the bottom decile merits equal attention. ${ }^{55}$ Apparently, the strength of the increase in the dispersion depends on the measure chosen and also their periodic ups and downs do not fully coincide.

Figure 19.12 - Four measures of hourly wage inequality: United States, Men only, 1967-2005, $1979=100$

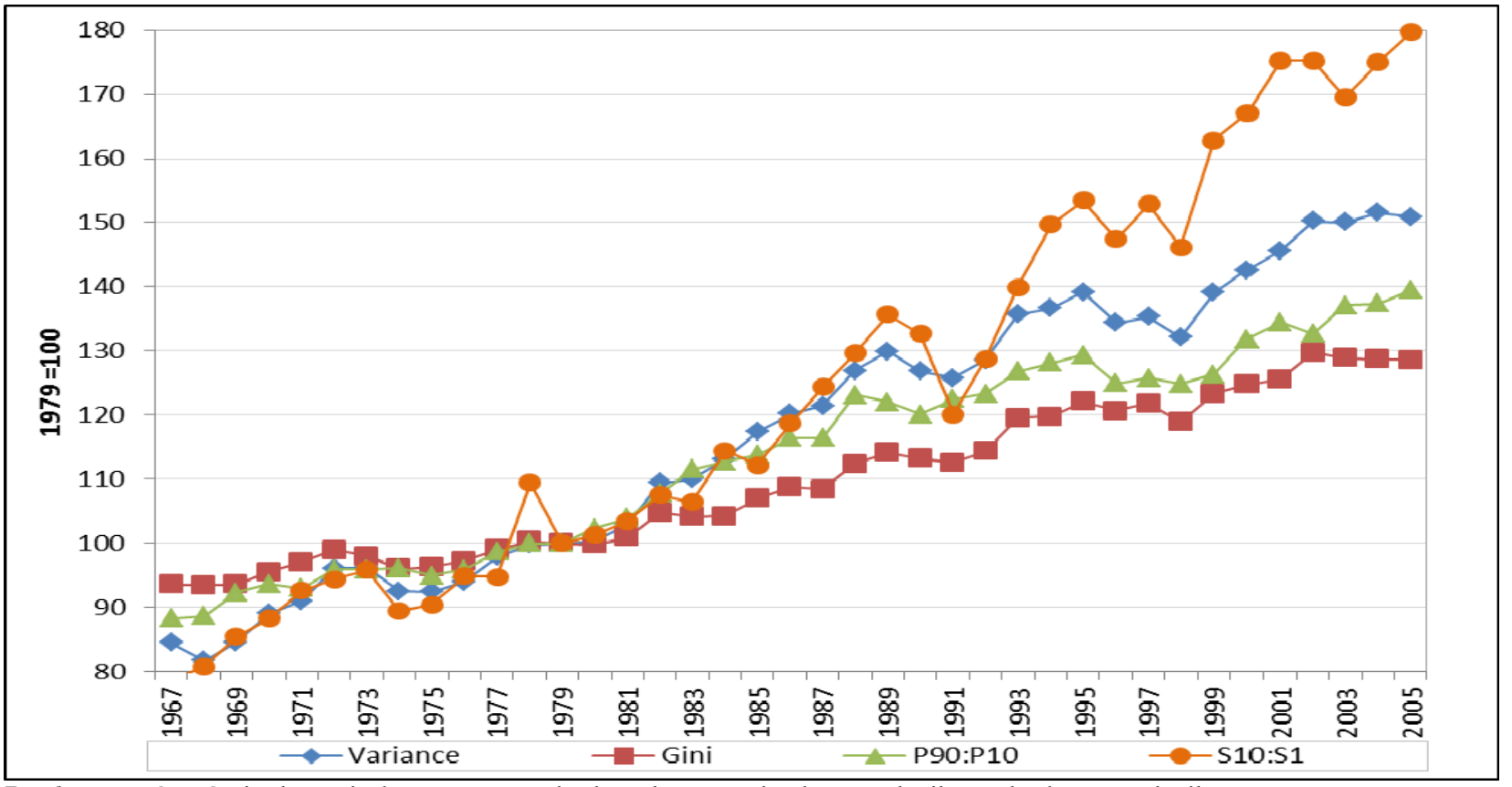

Reading note: S10:S1 is the ratio between averahe hourly wages in the top decile to the bottom decile.

Explanatory note: Figures cover individuals aged 25-60 who work at least 260 hours per year, with wages at least half of the legal federal minimum wage.

Source: Heathcote et al. (2010), Figures 4 and S10:S1 derived from Figure 7 (based on March CPS).

The top and bottom half split of Figure 19.11 has provided a first breakdown of the aggregate by focusing on parts of the distribution. The incidence of low pay or high pay, and the size of the remaining middle are indicators of the same sort. The former was already shown in Figure 19.10. It moves up from $23 \%$ in 1975 to $25 \%$ in the mid-10980s and has been rather stable at about that level since. Over the same period the share of high-paid, defined as earnings exceeding 1.5 times the median hourly wage, increases from $21 \%$ to $25 \%$ in the mid-1980s and further to $28 \%$ (not shown). As a result the remainder in the middle shows a considerable fall before the mid-1980s (55\% to 50\%) and another slighter fall over the current crisis (49\% to 47\%). A narrower definition of high pay following the topincomes literature is pursued by Lemieux (2010), who endorses a simple repair for the top-coding of earnings in the $\mathrm{CPS}^{56}$ and presents percentiles distributions similar to those of Pierce above, which we reproduce in Figure 19.13. Starting in 1974 the period is covered is significantly longer but still split into two parts, now on both sides of the year 1980. Separate distributions are given for men and women. Again developments are more positive and spread more evenly over most of the distribution during the second period after 1989 than before. The longer period covered up to 1989 shows a more skewed picture than Pierce's. Particularly, real wage change in the bottom 20\% seems more negative now for men, while an increase in the lowest percentiles for women may help explaining the surprisingly upward

\footnotetext{
54 The evolution of the S10:S1 ratio seems to imply that the variance is plausible measure to use here in spite of its sensitivity to outliers in the distribution.

${ }^{55}$ Since the mid-1980s the incidence of the minimum wage ranges entirely within this decile.

${ }^{56}$ Checking against the Pareto parameter based approach of Piketty and Saez (2003) he concludes that results are the same.
} 
move found by Pierce. At the same time, it is clear that among men the high part of the distribution has run away from the rest with a steep gradient within the top decile. The top percentile ratios seem to support this (not shown). They are almost identical and trend upwards together until the end of the 1990s when female inequality starts to lag behind. The bottom-half ratios run largely parallel to each other with the one for females indicating a substantially lower level of inequality. The more positive development of wages for women seem suggestive of a declining gender gap. This is borne out clearly by Heathcote et al. (2010, Figure 5) who after a slight increase of the gap from 1967 to 1978 find a continuous decline after that year, sharp up to the mid-1990s and more modest since then. The current gap $(30 \%)$ is much smaller than before but certainly not negligible.

Figure 19.13 - Percentage change in real hourly wages, by gender and percentiles, United States, 1974 2004.

A. Men

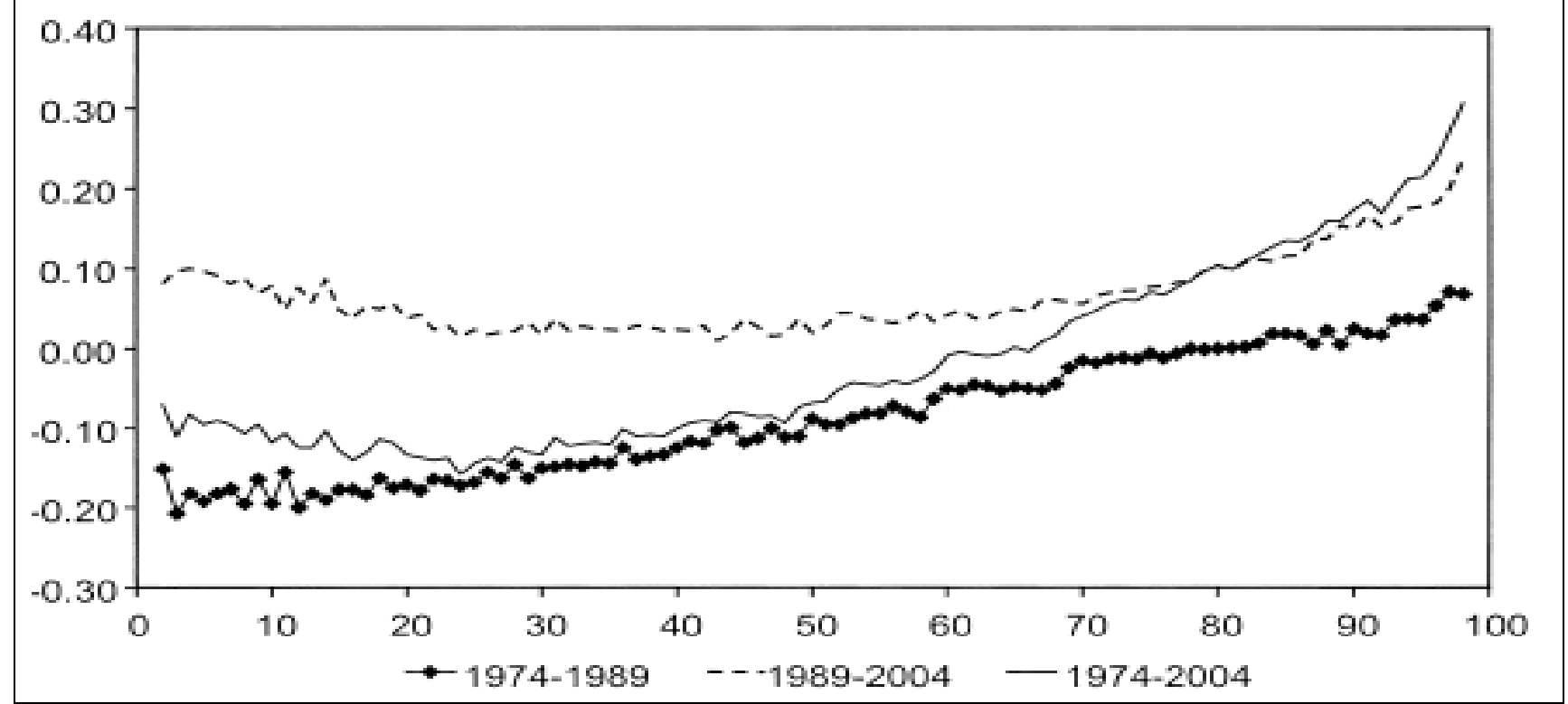

B. Women

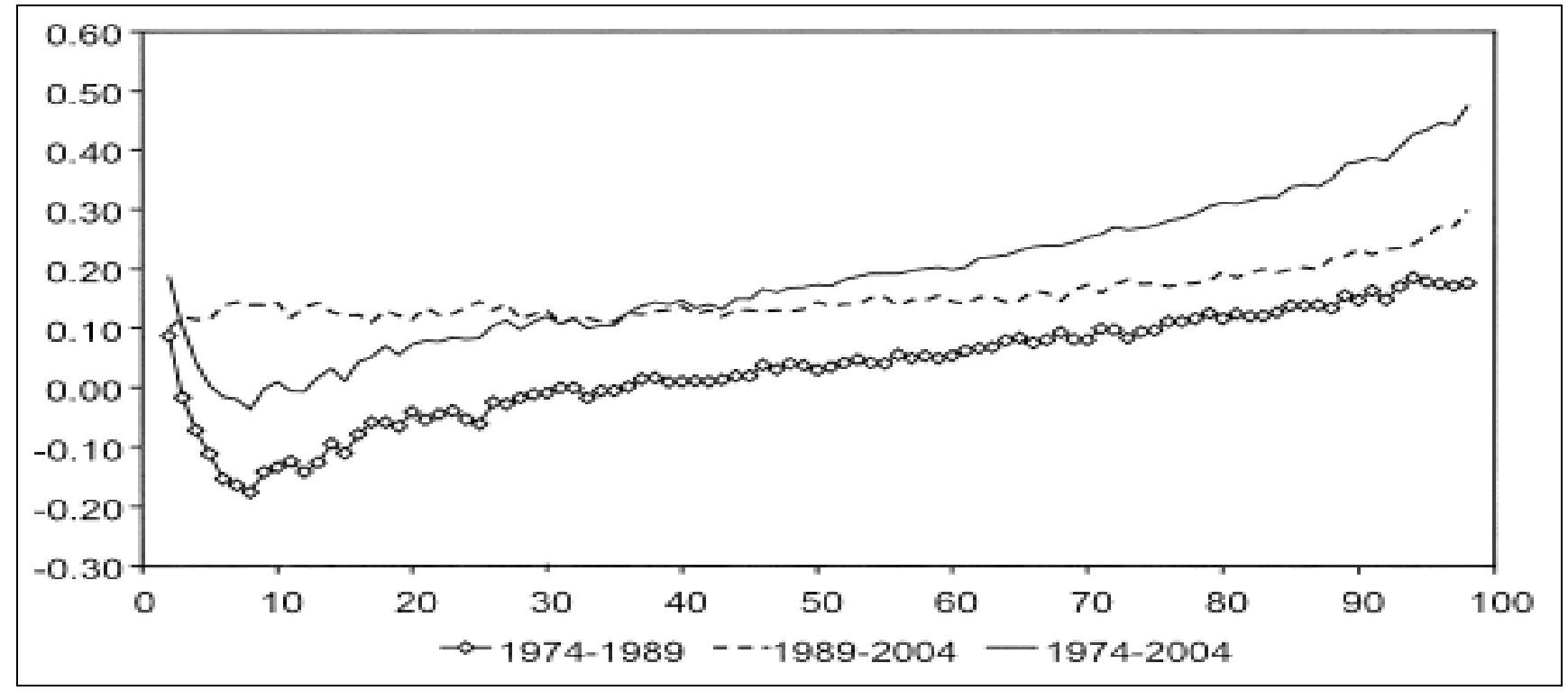

Source: Lemieux (2010), Figure 1.7.

Next to gender, educational attainment is the most important dimension for breaking down inequality. Its role has been a bone of contention in the literature from the start, as we will see later. Here Lemieux (2010) presents differentials for various levels of attainment relative to high school graduates (Figure 19.14). They appear to be mostly flat with slight declines at the lower levels but with the clear exception 
of the highest two levels, particularly the highest. These start growing away upwards particularly over the 1980s and more modestly since. For men the top-bottom gap almost doubles. At the end of the period the differentials seem almost identical between the two sexes. Heathcote et al. (2010, Figure 5) present a college wage premium defined as premium as the ratio between the average hourly wage of workers with at least 16 years of schooling, and the average wage of workers with less than 16 years of schooling. The premium increases significantly though more for $(52 \%$ to $92 \%)$ than for women $(58 \%$ to $69 \%$ ).

We stop here and refer for further detail of other dimensions of the earnings dispersion, such as experience or nationality/country of birth, to the literature itself. Before we continue we like to stress again the important role of residuals. These outcomes for gender and education rest on simple decompositions, and most of the action appears to reside in the residuals, which develop largely in parallel to the growth in overall 'raw' inequality (Heathcote, 2010, Figure 5). The implication is that other factors of influence need to be incorporated in the analysis and/or that idiosyncracies, which may be immune to further analysis, play a non-negligible role. Lemieux (2010, Figure 1.8) finds interestingly that the importance of residuals grows with the level of earnings, especially over the period 1974 to 1989.

Figure 19.14 - Educational differentials relative to the high-school level, by gender, United States, 1973-2006

A. Men

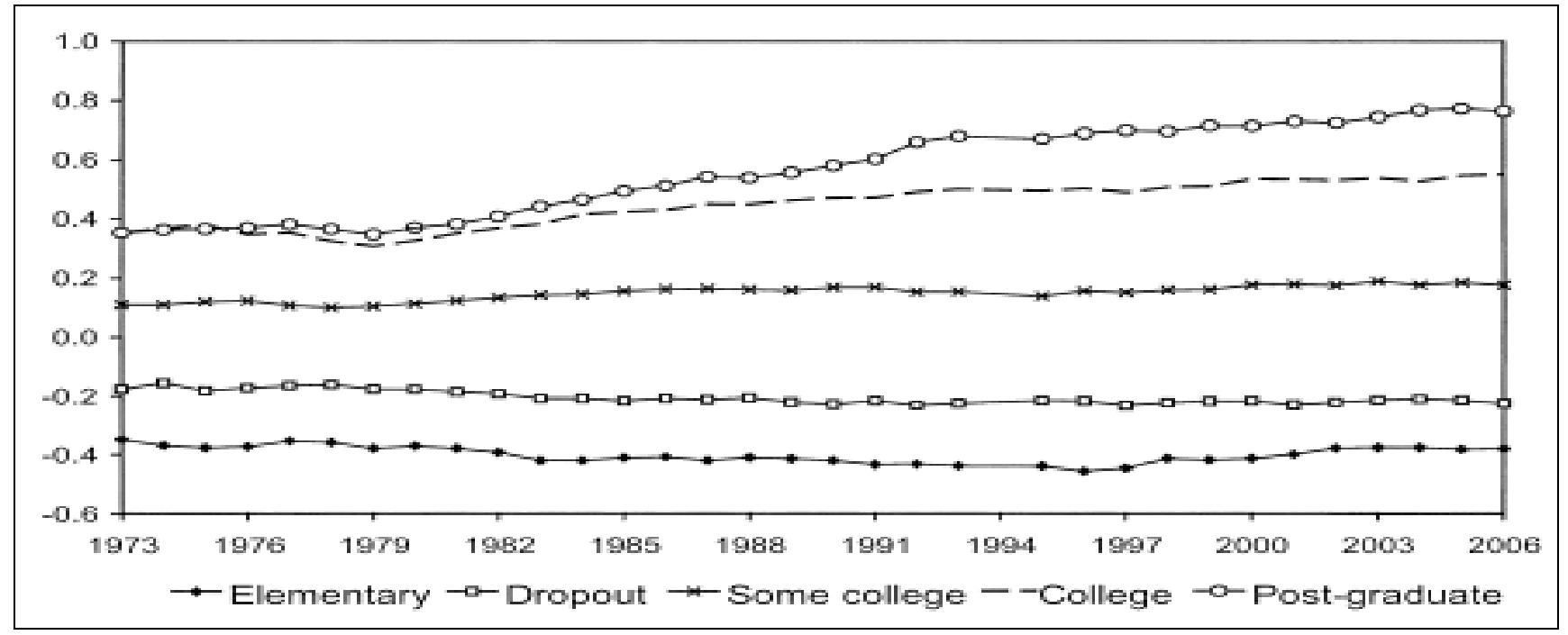

B. Women

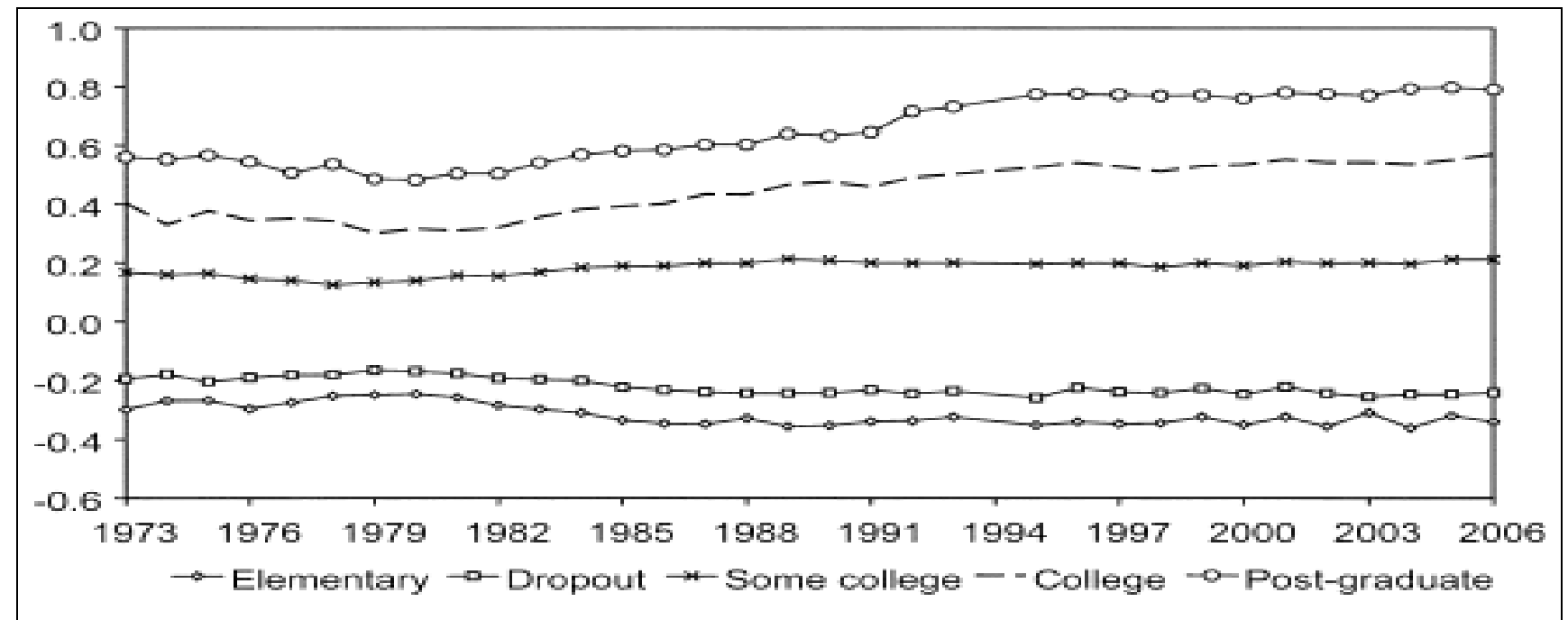

Explanatory note: Using a decomposition based solely on education and experience.

Source: Lemieux (2010), Figure 1.3. 


\section{Earnings inequality in other countries}

We now turn to inequality trends in other countries. The Review of Economic Dynamics (RED) (2010) special issue dedicated to cross-sectional facts regarding elements of economic inequality provides the most precise cross-country comparison of the earnings dispersion and several of its important facets, using as uniform a template of data treatment and presentation as possible. ${ }^{57}$ Unfortunately, it has several drawbacks. The limited number of countries of relevance here is only seven, and for our comparison it is even further reduced as Italy and Spain focus on earnings net after taxes, which are unsuited for a comparison to gross earnings, and relevant data for Sweden end in 1992 when the country's financial crisis had just started. That leaves us with the UK, Canada and Germany. We turn to these results first and after that we turn to the OECD's earnings database to see what we can learn for other countries.

Figure 19.15 presents three measures of individual hourly earnings dispersion, for men and women together, as found in the RED contributions: the variance of log wages, Gini coefficient, and overall percentile ratio. All indicators for the three countries tend to rise over time. The British variance increases very rapidly up to a level 60 per cent above the start of 1978, which well exceeds the other two measures (and also the variance in the US), and subsequently falls over the 2000s. The other two measures for the UK also show an decline over that last period. This contrasts with the OECD's percentile ratio (not shown), which (covering full-time weekly earnings) is at a somewhat lower level but continues rising until 2006 and remains unchanged until 2011. For Canada the rise is also considerable, +20 to $40 \%$ depending on the measure, and continues until the end of the period. Mutual differences between the measures are smaller. The OECD's percentile ratio (not shown), again for fulltime weekly earnings and available after the mid-1990s only, shows continued growth over the entire 2000s. Finally, in Germany data are available from 1983, the rise of the three indicators concentrates in the period after unification. The variance shows a clear rise and it is virtually identical for the percentile ratio - in contrast with the other two countries. Taken over the same 1983-2004 period their growth is stronger than in the UK or Canada. The rise of the percentile ratio must rest on the use of hourly earnings as the trend of the OECD's ratio (not shown), which concerns full-time monthly earnings, is largely flat over the 1990s and early 2000s. However, the increase in the Gini coefficient is modest relative to the other indicators as well as the other countries.

In Figure 19.16 we split the overall percentile ratio in its two contributing halves, P90:P50 and P50:P10. We a find strong divergence between the countries. The high levels and strong rise of the bottom-half ratios in Canada and Germany ${ }^{58}$ are strikingly different from the UK; the German ratio moves up as much as the British but over a considerably shorter period. Canada and the UK share a decline in recent years though. Upper-half inequality rises very little in Germany and clearly less than in Canada and the UK. Generally, the pattern of the two British trends is very similar to the US in Figure 19.11, while Canadian trends look surprisingly different. This clearly call for further scrutiny. ${ }^{59}$

\footnotetext{
${ }^{57}$ Brzezowski et al. for Canada: 1978-2005, Fuch-Schundeln et al. for Germany: 1984-2005, Japelli and Pistaferri for Italy: 1980-2006, Pijoan-Mas et al. for Spain: 1994-2001, Domeij and Flodén for Sweden: 1978-2004 (effectively 1975-1992 only), Blundell and Etheridge for UK: 1977-2005, and Heathcote et al. for USA: 1967-2005 (but always split by gender). Unfortunately, Spanish data are net after taxes and will be left out here. Krueger et al. provide a summary overview in the Introduction. Individual earnings dispersion is addressed as part of the study of the household distribution of earnings (mentioned above, see e.g., Figure 19.4).

${ }^{58}$ For Germany this rise is absent in the OECD's (full-time) data, and therefore also in the overall ratio that was mentioned.

${ }^{59}$ Fortin and Lemieux (2014) conclude to a role of provincial minimum wages and natural-resources growth.
} 
Figure 19.15 - Dispersion of hourly wages, United Kingdom, Canada and Germany, late-1970s to mid2000s

A. United Kingdom, $1979=100$

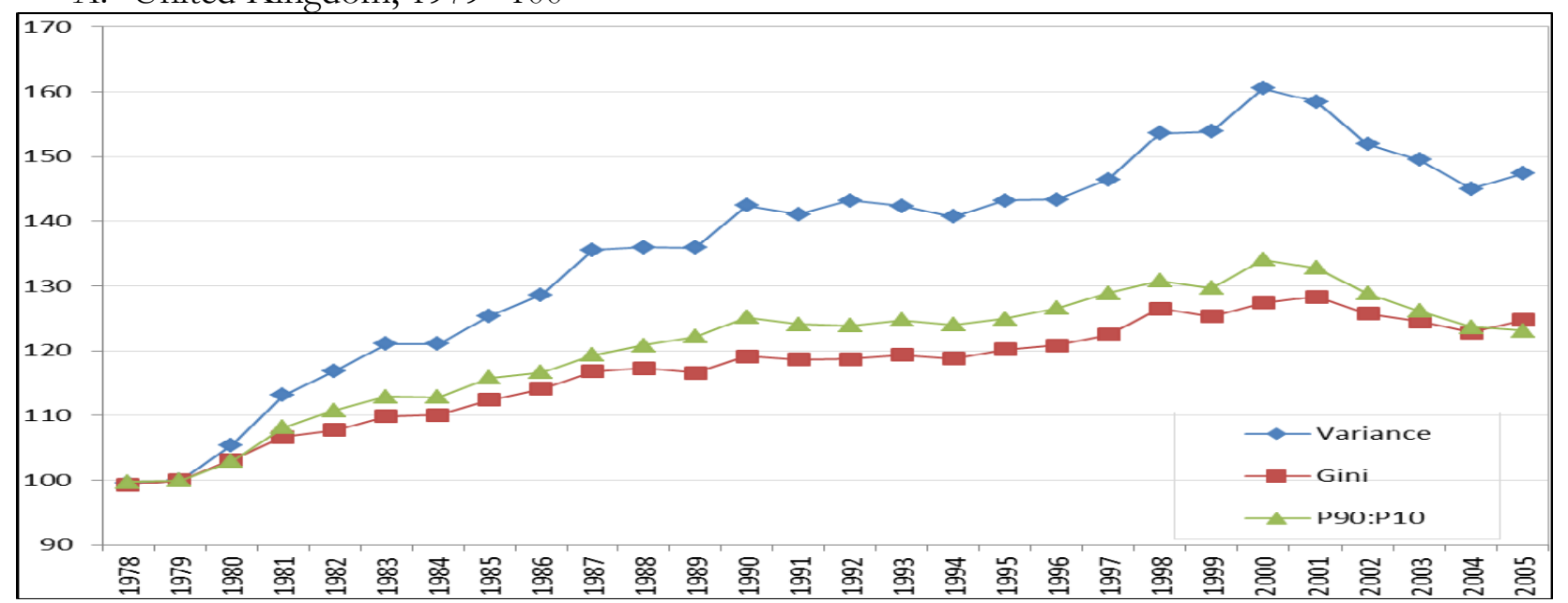

B. Canada, $1979=100$

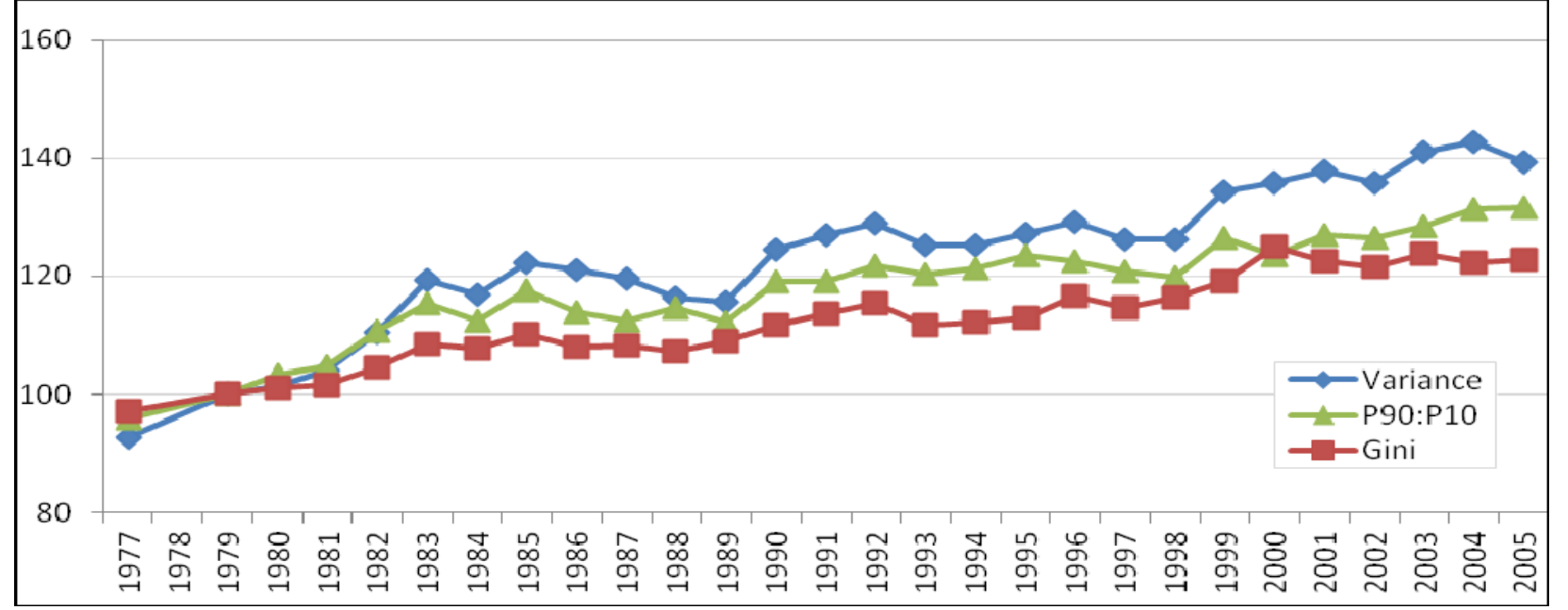

C. Germany, $1983=100$

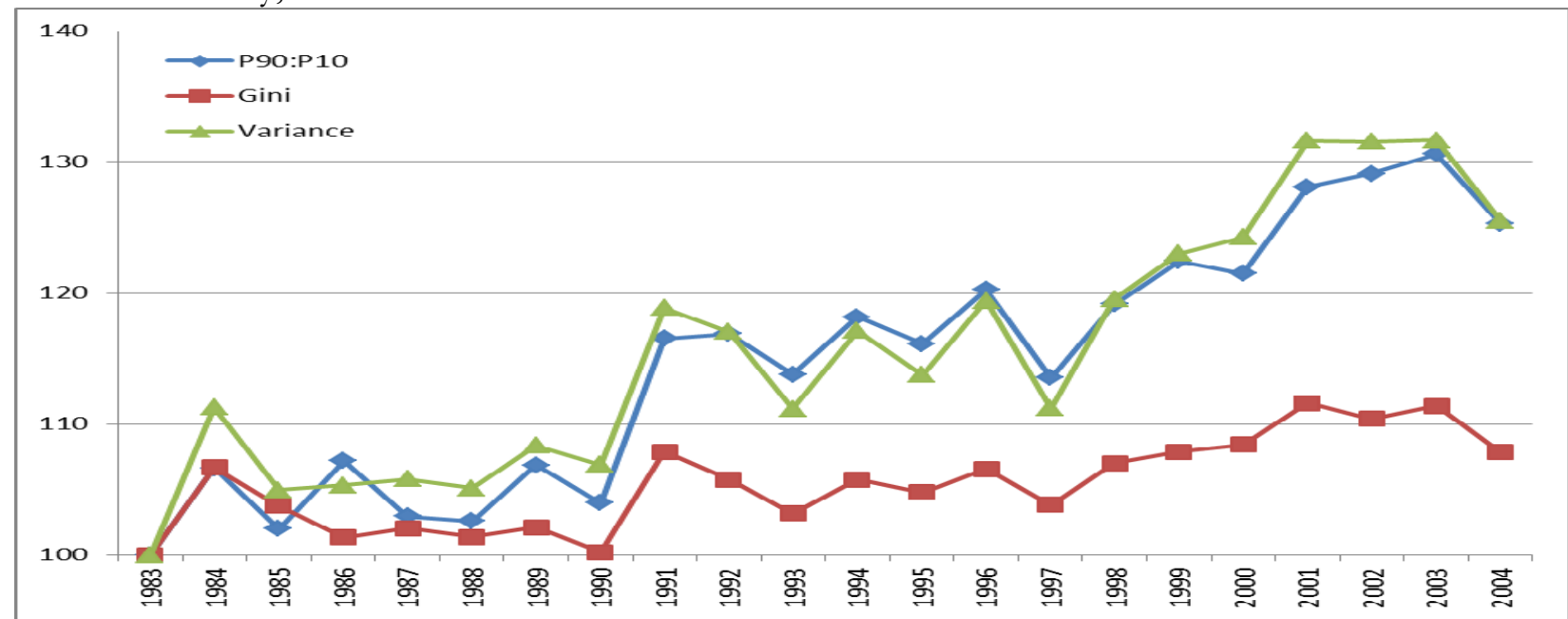

Explanatory note: Figures cover individuals aged 25-60. Derived from the data underlying Figures 3.1 (UK), 4 (Canada) and 6 (Germany) as posted on the RED website. Datasets concern for Canada the Survey of Consumer Finances SCF 1977-1997 and Survey of Labour and Income Dynamics SLID 1996-2005, for Germany the German Socioeconomic Panel GOEP, and for the UK the Family Expenditure Survey FES and Labour Force Survey LFS.

Sources: Brzezowksi et al. (2010), Fuch-Schündeln et al. (2010), and Blundell and Etheridge (2010). 
Figure 19.16 - Lower and upper half inequalities in Canada, Germany and United Kingdom, 19772005

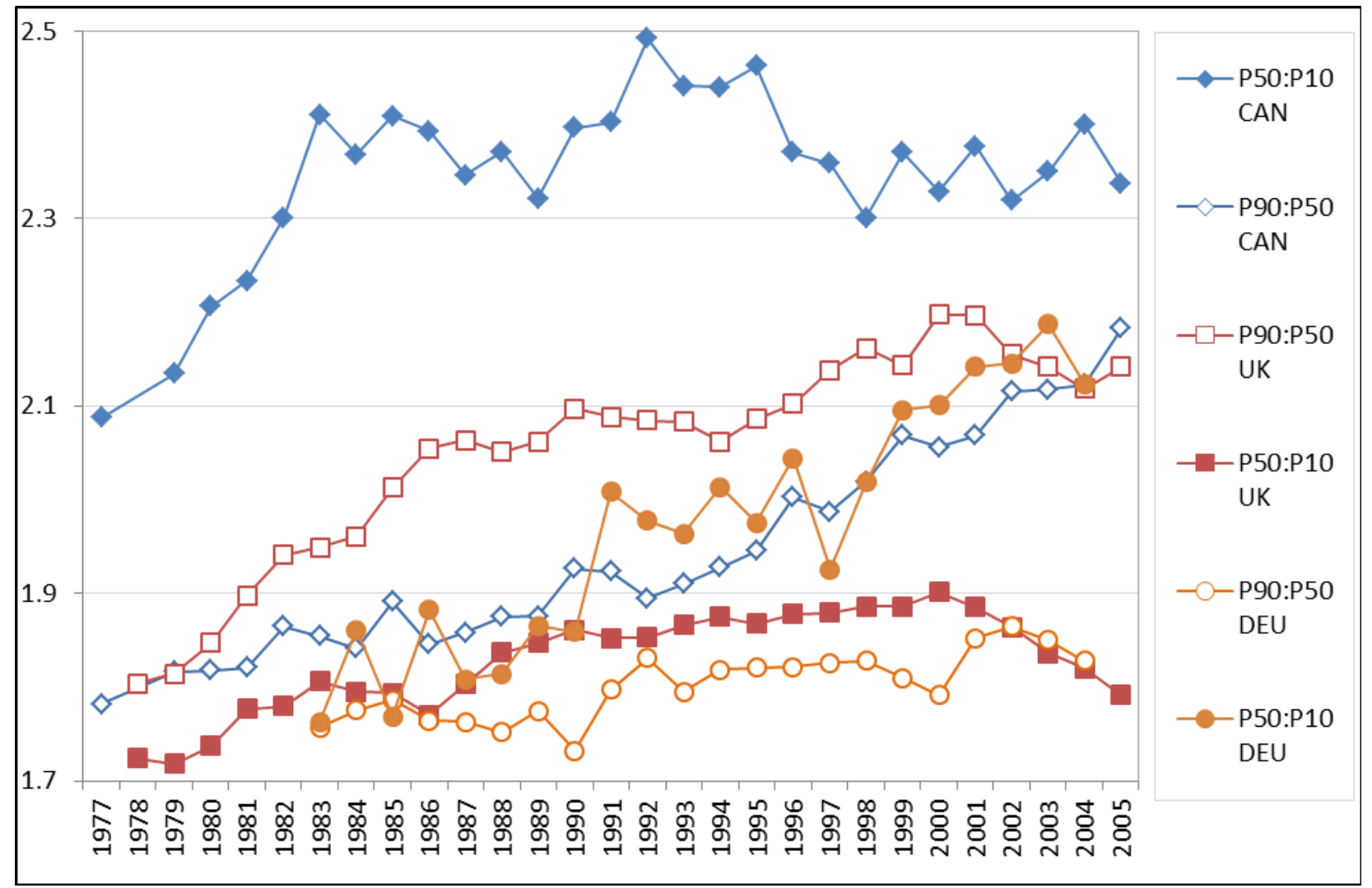

Sources: Blundell and Etheridge (2010), Brzezwoski (2010), and Fuchs-Schündeln et al. (2010).

Unfortunately, wage changes by percentile, which have come to play an important role in the American debate, are not available for other countries. The RED papers have also looked at the roles of gender and educational attainment. The gender pay gap for Canada is small from the start, comparable to the US gap at the end of the period (30\%), and it trends downward only very slowly. The German gap declines slightly more steeply and ends below (20\%) the American level in the mid-2000s. The British gap, finally, declines somewhat more strongly; it is below the American level in the late 1970s but ends at about the same level. Note again that the decompositions made in the RED papers are based on gender, educational attainment and experiences only and that in these three counties, as in the US, residuals are quantitatively important and behind most of the increase in inequality. 
Figure 19.17 - Earnings inequality trends in 8 OECD countries, 1975-2011

A. P90:P10

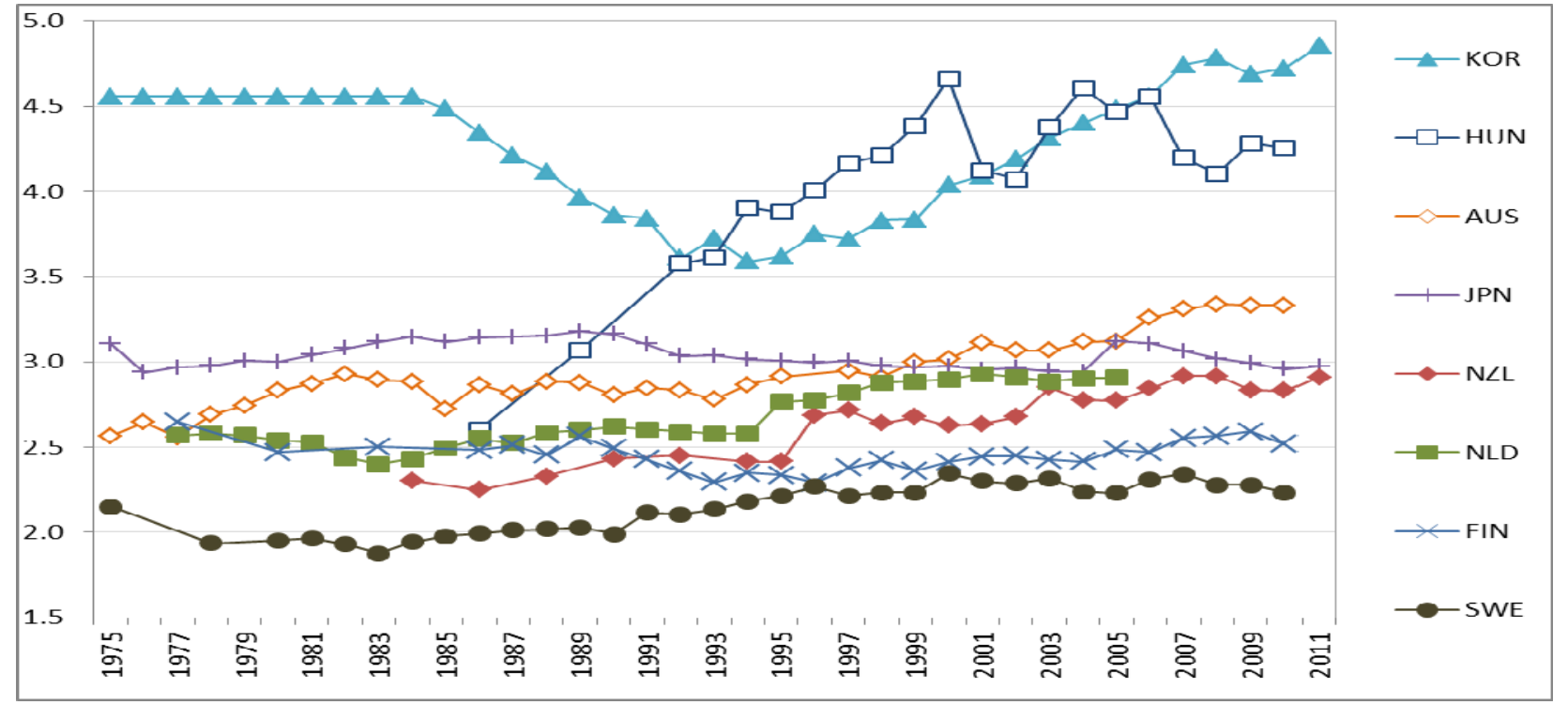

B. P90:P50

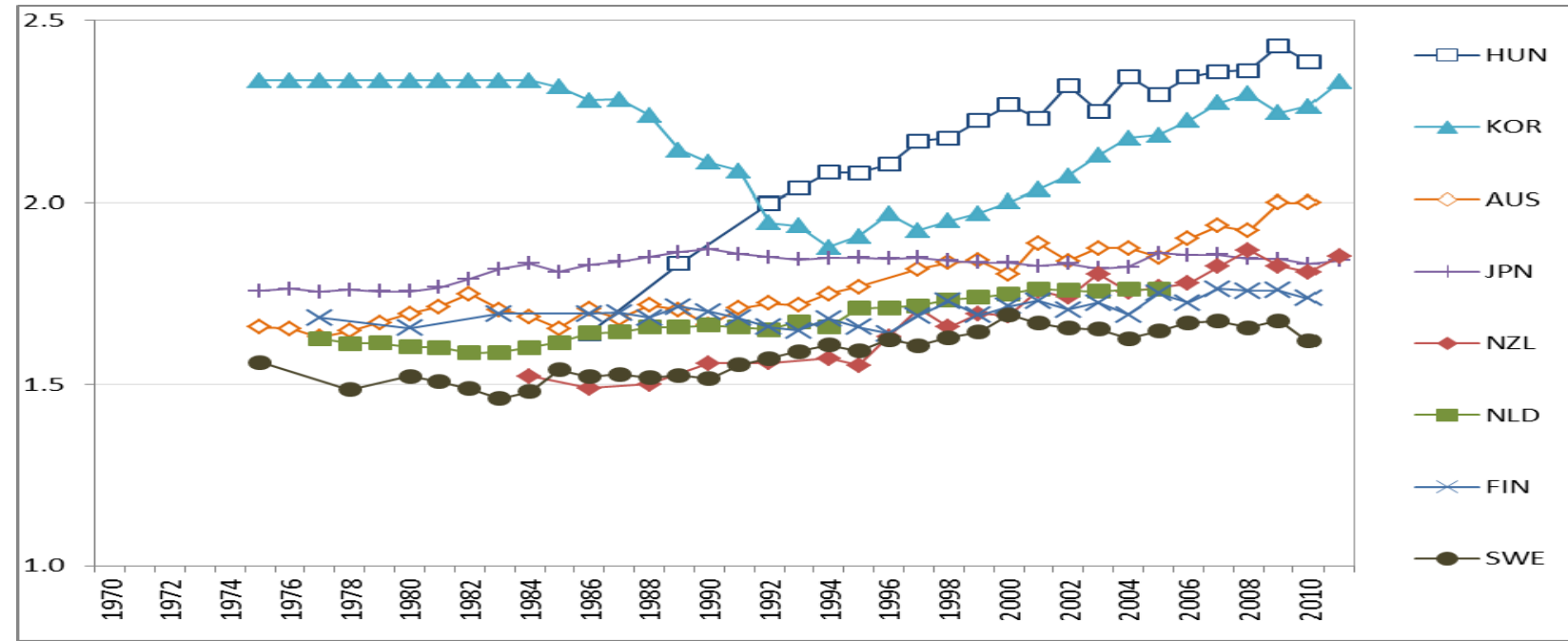

C. P50:P10

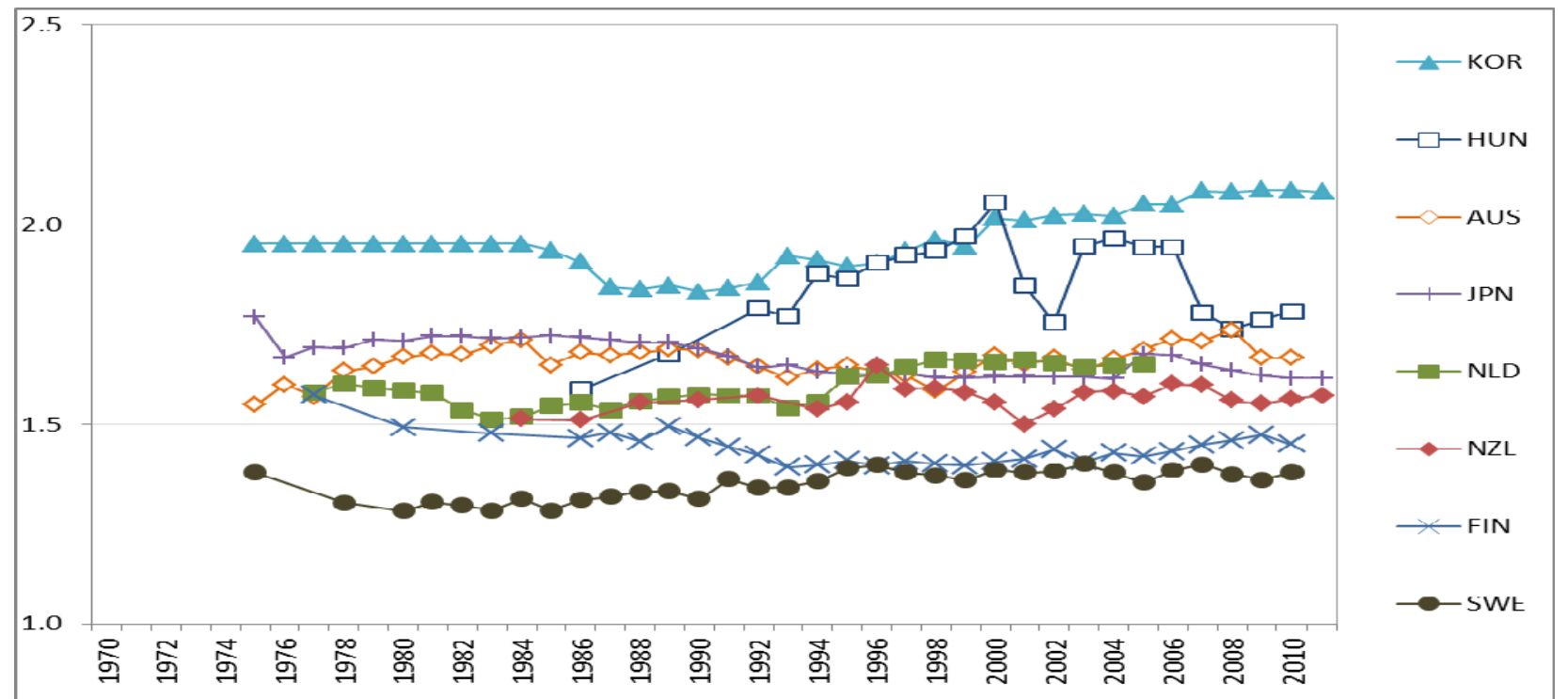

Explanatory note: full-time workers only; hourly earnings for NZL, weekly for AUS, monthly for HUN, JPN, ad KOR, fullyear for FIN, NLD and SWE

Source: OECD Earnings decile ratios database. 
With the help of the OECD's earnings database of percentile ratios, the evolution of individual earnings inequality can be described for a number of other countries (see Figure 19.17). ${ }^{60}$ As already stated it is a secondary database and it has to be used with great care. It comprises a wide array of wage definitions and concomitant samples of the employee population. We first select eight countries that focus on gross earnings of full-time workers (be it hourly, weekly, monthly or annual ${ }^{61}$ ) and also have a long-run series. Given the diverging incidence of part-time employment the full-time focus will be more or less representative of the country, but there is nothing we can do about that apart from being aware that in (various European) countries where part-time jobs have become more important and tend to be overrepresented in the low-wage segment of employment the actual picture of inequality will plausibly be more pessimistic both in cross-section and over time than found here for full-time workers only. With the exception of Japan and Finland over the period as a whole and Korea over its first half, overall inequalities in Panel A seem to be trending upwards, albeit to varying degrees and with different timings. Compared to the rest, Hungary and Korea show strong episodic changes, which apparently hang together with deep political change - the end of communism and of dictatorship respectively. The two halves of the distribution are pictured in Panels B and C. With the exception of Hungary and Korea, differences in trends seem to be relatively small. Lower-half inequality is usually less than upperhalf inequality and most of the overall rise can be attributed to the upper half. In the stable cases of Japan and Finland lower-half inequality declines somewhat but in all other countries it grows at some point in time. Comparable information about gender and educational differentials is not available.

Finally, Figure 19.18 assembles remaining short-run information on gross earnings. This concerns fulltime workers with the exception of Denmark (all workers, head-count) and Norway (all workers, fulltime equivalents). Countries seem to move into a closer band: higher-inequality countries move down (Portugal, Poland, Greece, Spain) while most of the rest moves upwards. Breaking down into halves (not shown) the strong declines in Portugal and Poland are due primarily to the upper half though lower-half inequality also falls. Portugal combines extremely high levels in the upper half with low levels in the bottom half. For the rest increases and decreases seem split roughly equally between the two halves.

Figure 19.18 - Short-run earnings inequality trends in 11 OECD countries, 1994-2011

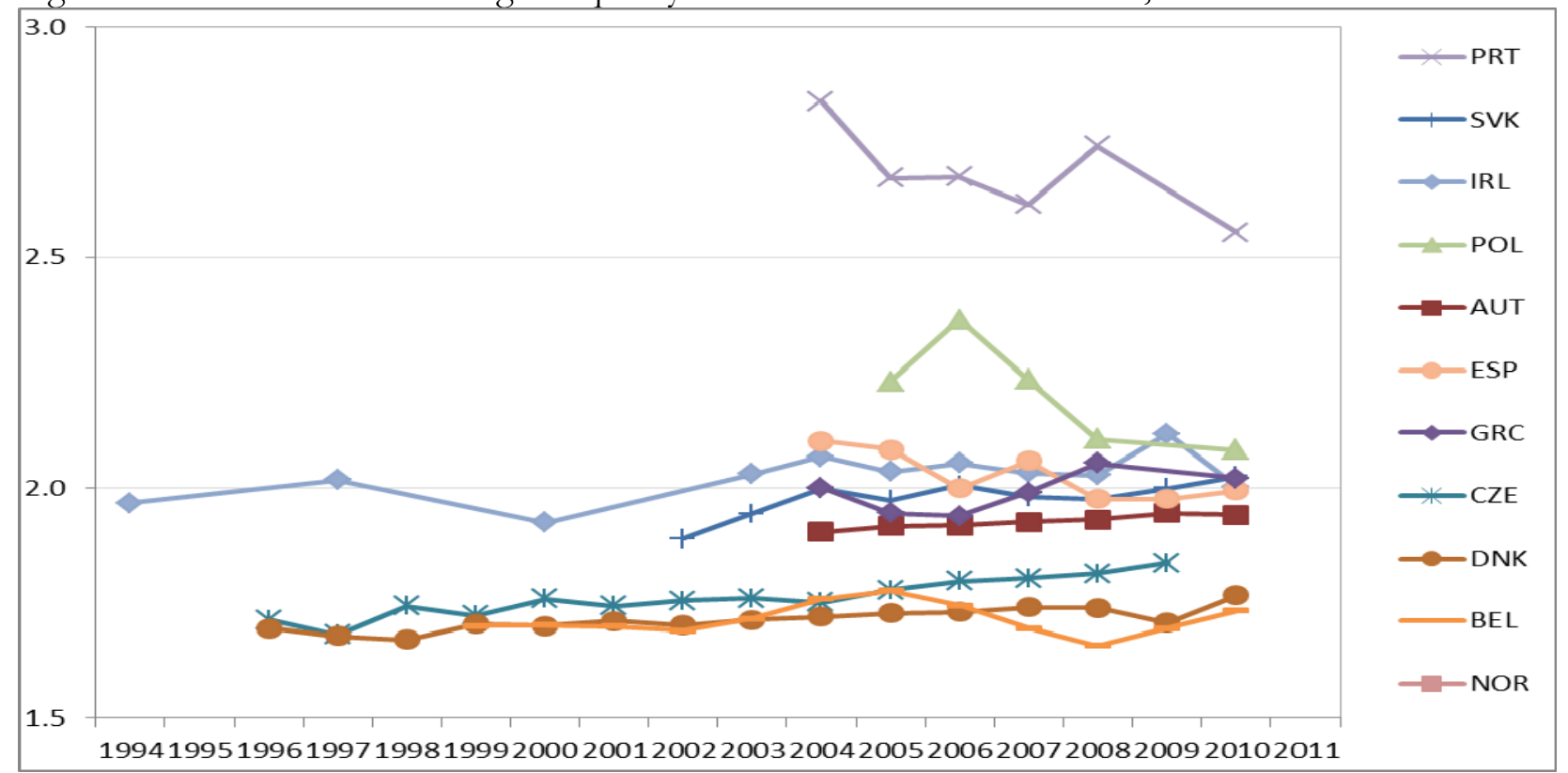

Explanatory note: Gross earnings only; full-time workers except DNL (all, head count) and NOR (all, full-time equivalents). Source: OECD Earnings decile ratios database.

\footnotetext{
${ }^{60}$ See Blau and Kahn (2009) for a more detailed international analysis based on this dataset.

${ }^{61}$ As a result levels cannot be precisely compared cross-country. Finland, the Netherlands and Sweden sample full-year workers, which may partly explain their relatively low levels of inequality.
} 


\subsection{Additional evidence on earnings inequality in European countries and the United States}

From the data that we will be using in Section

5 we have derived a cross-section comparison for the most recent year, which provides a useful complement to the above stylized facts. It covers 27 European Union countries, Iceland and Norway as well as the USA. First, we consider a selection of inequality indicators, keeping in mind the household context that was discussed in Section

2. In the analysis of income inequality it is common practice to make use of the Gini concentration index or, at a lesser extent, of the mean log deviation (thanks to its property of decomposability). In earnings inequality analysis, by contrast, the most common indicator is the standard deviation of log earnings and/or the decile or percentile ratio. In Figure 19.19 we show that different measures provide largely similar country rankings in a cross-country perspective, while Table 19.1 provides the correlation indices for the same variables. As known from the literature the first two indices look at the bulk of the distribution, while the other two emphasise better what is happening at the tails (Cowell 2000 - see also Heshmati 2004). ${ }^{62}$

Table 19.1 - Cross-country correlation indices of various inequality measures, annual earnings of fulltime employees, EU countries, Iceland, Norway and United States, 2010

\begin{tabular}{|l|c|c|c|c|}
\hline & Gini index & $\begin{array}{c}\text { Mean log } \\
\text { deviation }\end{array}$ & $\begin{array}{c}\text { Standard } \\
\text { deviation of } \\
\text { logs }\end{array}$ & $\begin{array}{c}\text { Percentile ratio } \\
\mathbf{9 0 / 1 0}\end{array}$ \\
\hline Gini concentration index & 1.000 & & & \\
\hline mean log deviation & 0.871 & 1.000 & & \\
\hline standard deviation of logs & 0.409 & 0.770 & 1.000 & \\
\hline decile ratio 90/10 & 0.790 & 0.855 & 0.689 & 1.000 \\
\hline
\end{tabular}

Explanatory note: Full-time is defined as working 1000 hours per year or more.

Source: Authors' calculations on EU-SILC 2010 and PSID 2011.

Since the tails of the distribution may be affected by the increasingly diversified regimes in working hours, we prefer to work with the Gini concentration index, and we provide evidence of various inequality dimensions with the help of this measure. We start with a country overview, as reported in table 19.2. The first column shows the level of inequality associated with labour earnings, which here include gross earnings from employees and the self-employed together with benefits received by the unemployed. The level found here always exceeds the one pictured in the second column for the earnings of full-time employees who comprise a subset of the population considered in the first column. Manifest country-rank reversals occur, plausibly due to a large share of self-employment (as in the case of Greece, Poland or Romania - see table A.1 in

Appendix 2) and/or the combination of the unemployment rate and the generosity of the welfare state (as in the case of the Nordic countries - see also Figure 19.20).

${ }^{62}$ We speculate that the rather lower level of correlation found for the standard deviation may be attributable to top incomes. 


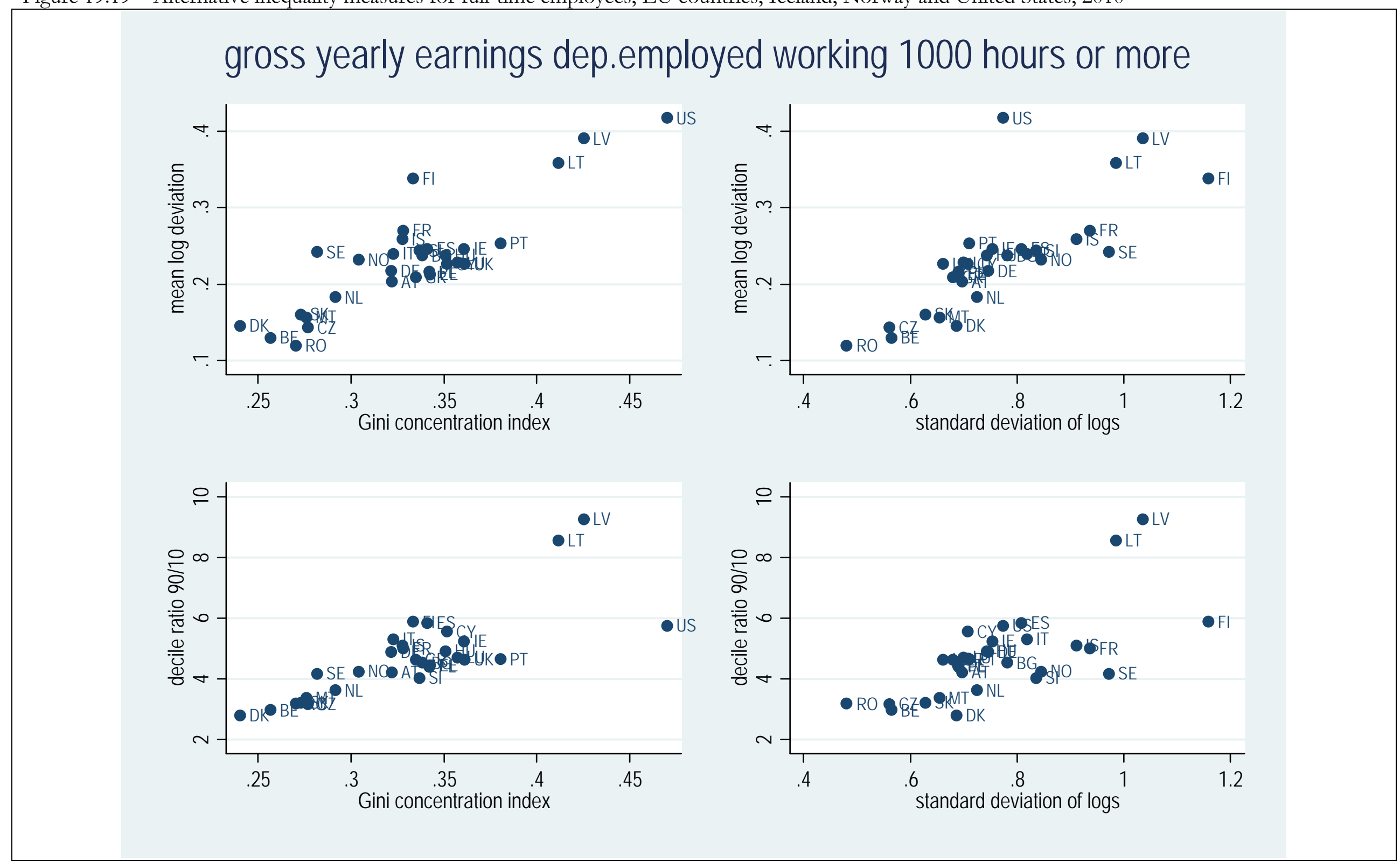


Table 19.2 - Inequality measures for individual annual and hourly earnings and hours, EU countries, Iceland, Norway and United States, 2010

\begin{tabular}{|c|c|c|c|c|c|}
\hline & $\begin{array}{l}\text { Gini of annual } \\
\text { labour } \\
\text { earnings } \\
\text { (including } \\
\text { self-employed } \\
\text { and } \\
\text { unemployment } \\
\text { benefits) }\end{array}$ & $\begin{array}{c}\text { Gini of annual } \\
\text { gross earnings } \\
\text { (hours }>1000) \\
\text { dependent } \\
\text { employment }\end{array}$ & $\begin{array}{l}\text { Gini of annual } \\
\text { hours worked } \\
\text { (positive } \\
\text { values) }\end{array}$ & $\begin{array}{l}\text { Gini of hourly } \\
\text { gross wages } \\
\text { dependent } \\
\text { employment }\end{array}$ & $\begin{array}{c}\text { Correlation of } \\
\text { hours and } \\
\text { hourly wages }\end{array}$ \\
\hline Austria & 0.376 & 0.322 & 0.167 & 0.325 & -0.162 \\
\hline Belgium & 0.332 & 0.257 & 0.173 & 0.266 & -0.284 \\
\hline Bulgaria & 0.422 & 0.338 & 0.084 & 0.318 & -0.150 \\
\hline Cyprus & 0.392 & 0.352 & 0.130 & 0.350 & -0.077 \\
\hline Czech Republic & 0.341 & 0.277 & 0.095 & 0.252 & -0.124 \\
\hline Denmark & 0.278 & 0.240 & 0.108 & 0.228 & -0.190 \\
\hline Estonia & 0.412 & 0.342 & 0.117 & 0.351 & -0.208 \\
\hline Finland & 0.361 & 0.333 & 0.156 & 0.340 & -0.271 \\
\hline France & 0.376 & 0.328 & 0.176 & 0.321 & -0.201 \\
\hline Germany & 0.420 & 0.322 & 0.181 & 0.307 & 0.038 \\
\hline Greece & 0.485 & 0.335 & 0.146 & 0.338 & -0.245 \\
\hline Hungary & 0.392 & 0.351 & 0.084 & 0.317 & -0.004 \\
\hline Iceland & 0.338 & 0.328 & 0.172 & 0.337 & -0.196 \\
\hline Ireland & 0.448 & 0.361 & 0.210 & 0.374 & -0.216 \\
\hline Italy & 0.407 & 0.323 & 0.135 & 0.308 & -0.230 \\
\hline Latvia & 0.494 & 0.425 & 0.114 & 0.401 & -0.124 \\
\hline Lithuania & 0.494 & 0.412 & 0.099 & 0.403 & -0.144 \\
\hline Luxembourg & 0.428 & 0.357 & 0.166 & 0.355 & -0.145 \\
\hline Malta & 0.347 & 0.276 & 0.109 & 0.285 & -0.156 \\
\hline Netherlands & 0.359 & 0.292 & 0.174 & 0.290 & -0.123 \\
\hline Norway & 0.329 & 0.304 & 0.134 & 0.287 & -0.115 \\
\hline Poland & 0.464 & 0.342 & 0.122 & 0.354 & -0.178 \\
\hline Portugal & 0.453 & 0.380 & 0.104 & 0.374 & -0.144 \\
\hline Romania & 0.419 & 0.270 & 0.046 & 0.271 & 0.045 \\
\hline Slovak Republic & 0.347 & 0.273 & 0.082 & 0.253 & -0.084 \\
\hline Slovenia & 0.397 & 0.337 & 0.073 & 0.314 & -0.102 \\
\hline Spain & 0.444 & 0.341 & 0.142 & 0.313 & -0.209 \\
\hline Sweden & 0.321 & 0.282 & 0.139 & 0.336 & -0.295 \\
\hline United Kingdom & 0.466 & 0.361 & 0.193 & 0.371 & -0.094 \\
\hline United States & 0.570 & 0.470 & 0.164 & 0.603 & 0.036 \\
\hline Average & 0.408 & 0.332 & 0.133 & 0.331 & -0.145 \\
\hline
\end{tabular}

Source: See Table 19.1.

Where countries differ more is in the distribution of working hours: since the distribution of hours worked is much less unequal than the distribution of wages (compare second and third column of Table 19.2), the inequality in hourly wages (computed dividing yearly earnings by worked hours) tends to mimic the inequality in yearly earnings (correlation coefficient is 0.90$)^{63}$,. This is another important dimension of inequality in the labour market, because given the existing demand for labour inputs, this work can be accomplished by a variable number of individuals, according to existing labour standards and cultural attitudes (regarding female participation, labour sharing within the couples, retirement rules, and so on).

\footnotetext{
63 The US exception is accounted by the fact that hourly wages for European countries are deduced by dividing annual earnings by worked hours, while in the PSID the interviewees are directly asked about their hourly wage. Using the same accounting procedure would reduce the Gini index on hourly wage for US to a more reasonable 0.47.
} 
Figure 19.20 - Inequality in annual labour earnings, EU countries, Iceland, Norway and United States, 2010

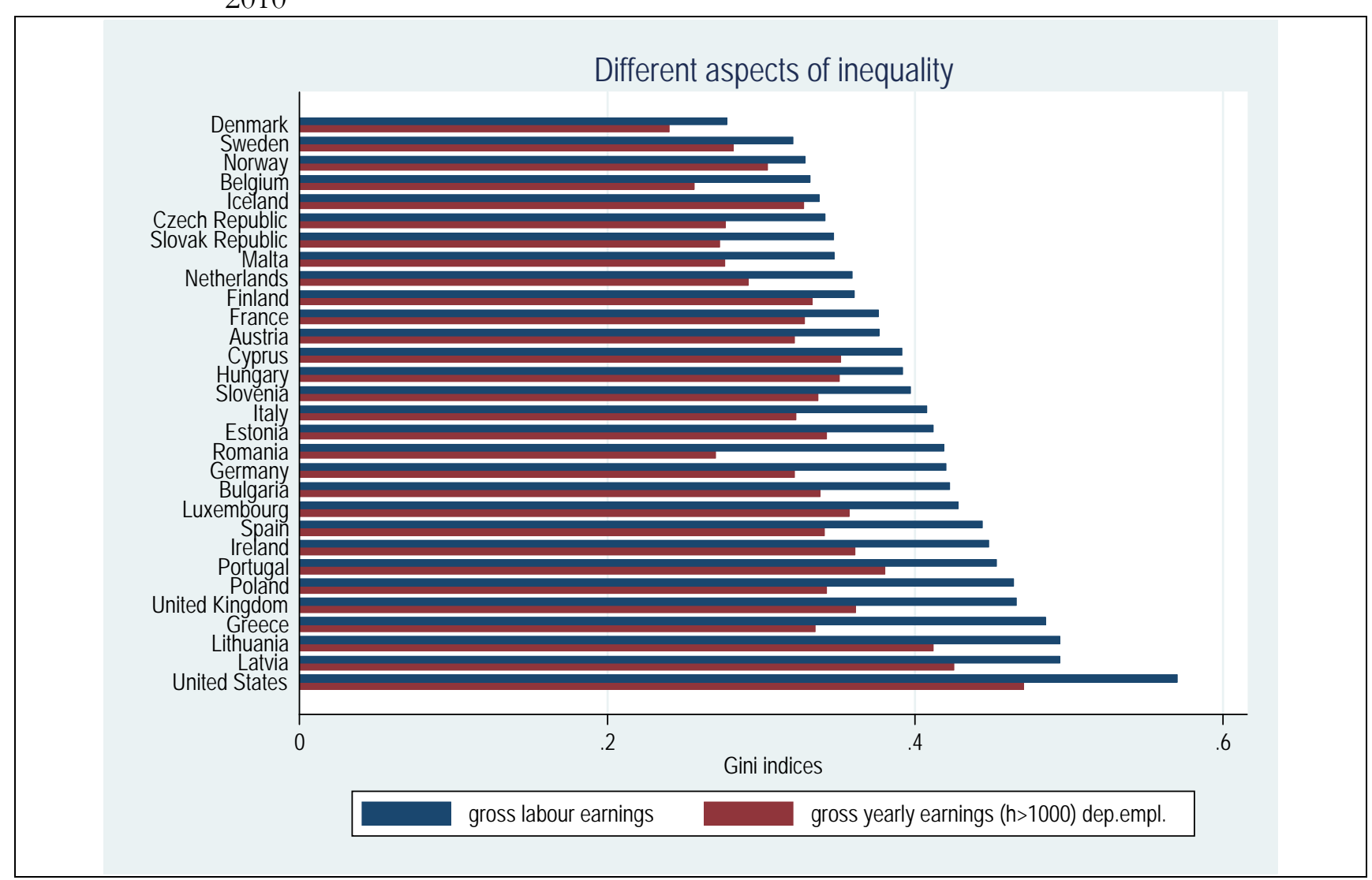

Source: See Table 19.1.

Figure 19.21 - Inequality in earnings and hours, EU countries, Iceland, Norway and United States, 2010

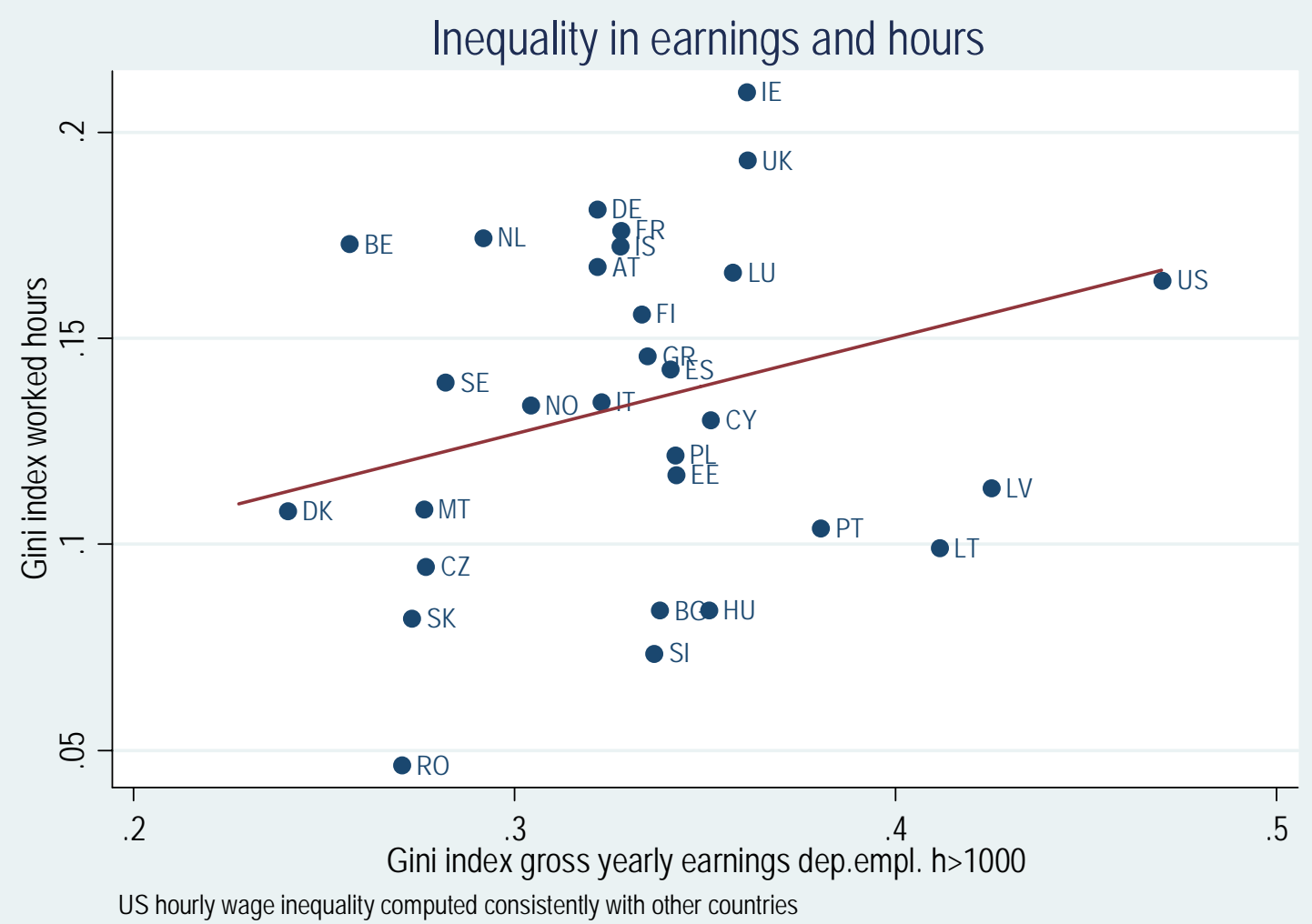

Source: See Table 19.1. 
As can be seen from Figure 19.21, the distribution of work may contribute to global earnings inequality, despite being the lowest in formerly planned economies (especially Romania, Czech and Slovak Republics, Hungary and Slovenia). When a job is characterized by full-time working hours the contribution of working hours to inequality is minimal; by contrast, when flexibilization of the labour market allows for various regimes of working hours (as in Ireland or Great Britain, but consider also the Netherlands, where part-time jobs are widespread), it contributes to the observed inequality in individual annual earnings (which can be partially mitigated by household dynamics, as previously discussed in Section 2). ${ }^{64}$ However the picture obtained here by means of aggregate indices is purely impressionistic, since hours and hourly wages tend to be negatively correlated in many countries. As a consequence of the latter, a high inequality in hours accompanied by a high inequality in hourly wages may produce a low level of earnings inequality; note, however, that this is a possible outcome not a necessary one and that measurement error in hours enhances the risk of spurious correlation.

It is interesting to note that individual workers may react to lower wages by working longer hours South Korea provides a clear example (Cheon et al., 2013, Figure 2.9). This is consistent with a standard model of labour supply where the income effect dominates the substitution effect. Competing explanations refer to a sort of Veblen's effect: partitioning workers by income layers, if consumption depends on consumption of richer people, an increase in the socio-economic distance increases the hours worked (Bowles and Park, 2005). The empirical evidence does not contradict this viewpoint (see the final column of Table 19.2, where we have computed the correlation between hours and wages at the individual level). While the correlation is negative almost everywhere, its intensity varies across countries: in some countries it exceeds 0.20 (notably Belgium, Finland and Sweden), in other countries it does not differ from zero, suggesting an independent distribution of wages and hours (e.g., UK and US as well as Germany - see also Bell and Freeman, 2001). Institutions may be responsible also for this outcome, since employers and workers may have different degrees of freedom in arranging working hours regime and/or resorting to non-standard labour contracts. Thus the two dimensions of inequality (hours and wages) correlate with the same set of institutions, and for this reason in the econometric analysis of Section

5 we will allow for this decomposition. But even the correlation between hours and wages itself may be influenced by existing regulations, since it can be considered as evidence of a higher or lower flexibility: the evidence depicted in Figure 19.22 shows that the possibility of adjusting hours when wages are relatively low contributes to reducing earnings inequality. ${ }^{65}$ For this reason, in the sequel we will study the correlation between this flexibility measures and labour market institutions.

The overall picture in terms of earnings inequality is well shown in Figure 19.20: inequality is higher in the so-called "liberal" market economies (UK, US and Ireland) to which one should add some "transition to market" economies (such as Poland, Lithuania and Latvia) and the Mediterranean countries (Greece, Spain and Portugal). At the other extreme we find the Nordic countries (except Finland). As Figure 19.23 shows in a clear way, the main determinants of this country ranking derive from the availability of employment opportunities, since countries characterized by high employment rates (including self-employment) are also the less unequal from the point of view of labour earnings. This is partly by construction: since we retain in our sample the entire labour force of the country, whenever the employment rate rises (and the unemployment rate consequently declines) the measured inequality in earnings declines (see the model proposed in Section

5).

\footnotetext{
64 These data on correlation between hours and hourly wages should be taken with caution, since the latter measure is obtained by dividing annual earnings by the former. As a consequence, hours and wages inequality are positively correlated Thus any measurement error in the latter generates a measurement error in the opposite direction for the former. However, unless different countries are hit by measurement errors in different (and systematic) ways, cross-country comparisons are still informative of the flexibility in adjustment.

${ }^{65}$ The US does represent an outlier, but even after removing this observation, the correlation between the two variables in Figure 19.22 remains positive.
} 
Figure 19.22 - Inequality and flexibility for adjustment, EU countries, Iceland, Norway and United States, 2010

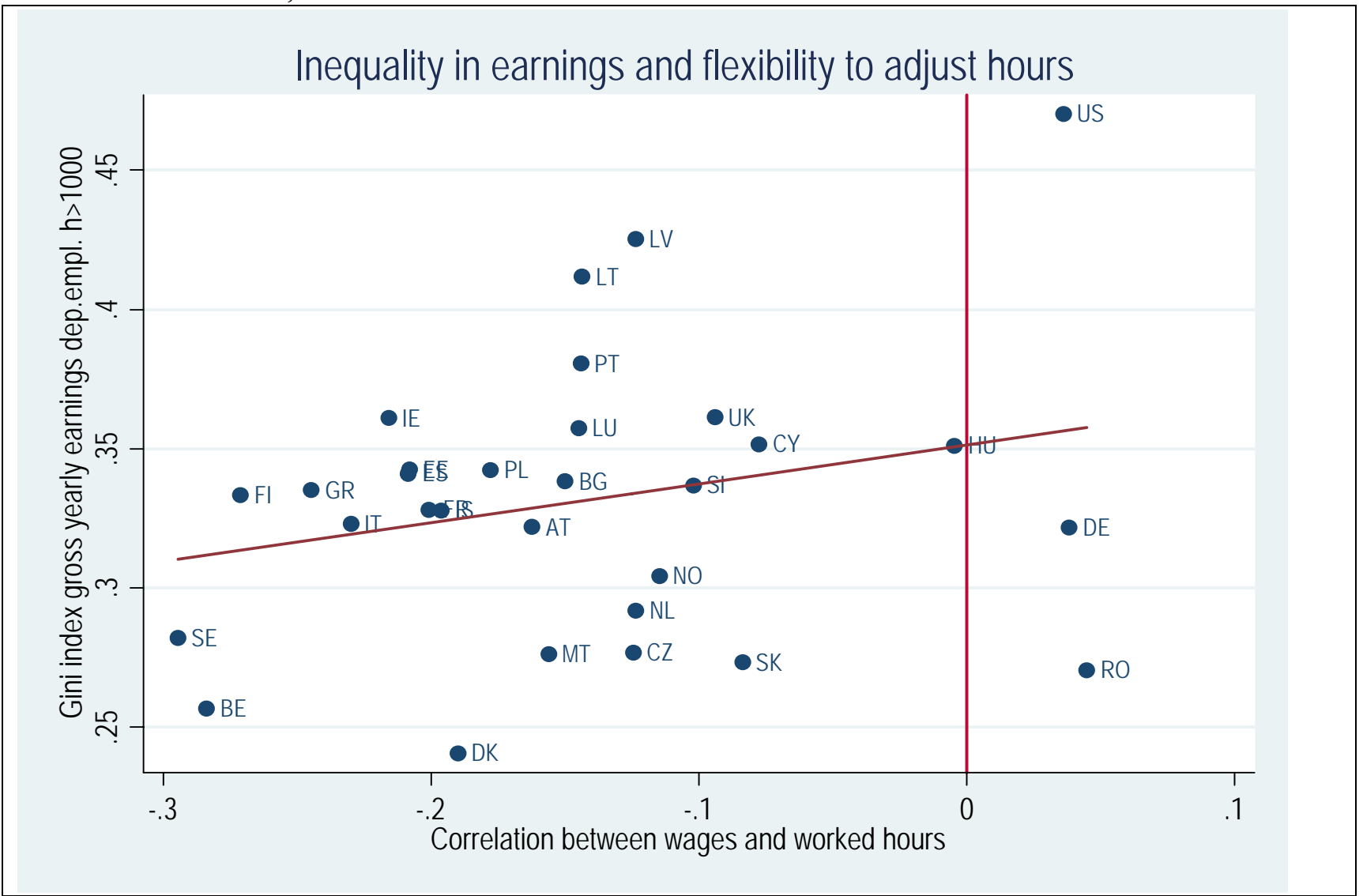

Source: See Table 19.1

Figure 19.23 - Inequality and employment, EU countries, Iceland, Norway and United States, 2010

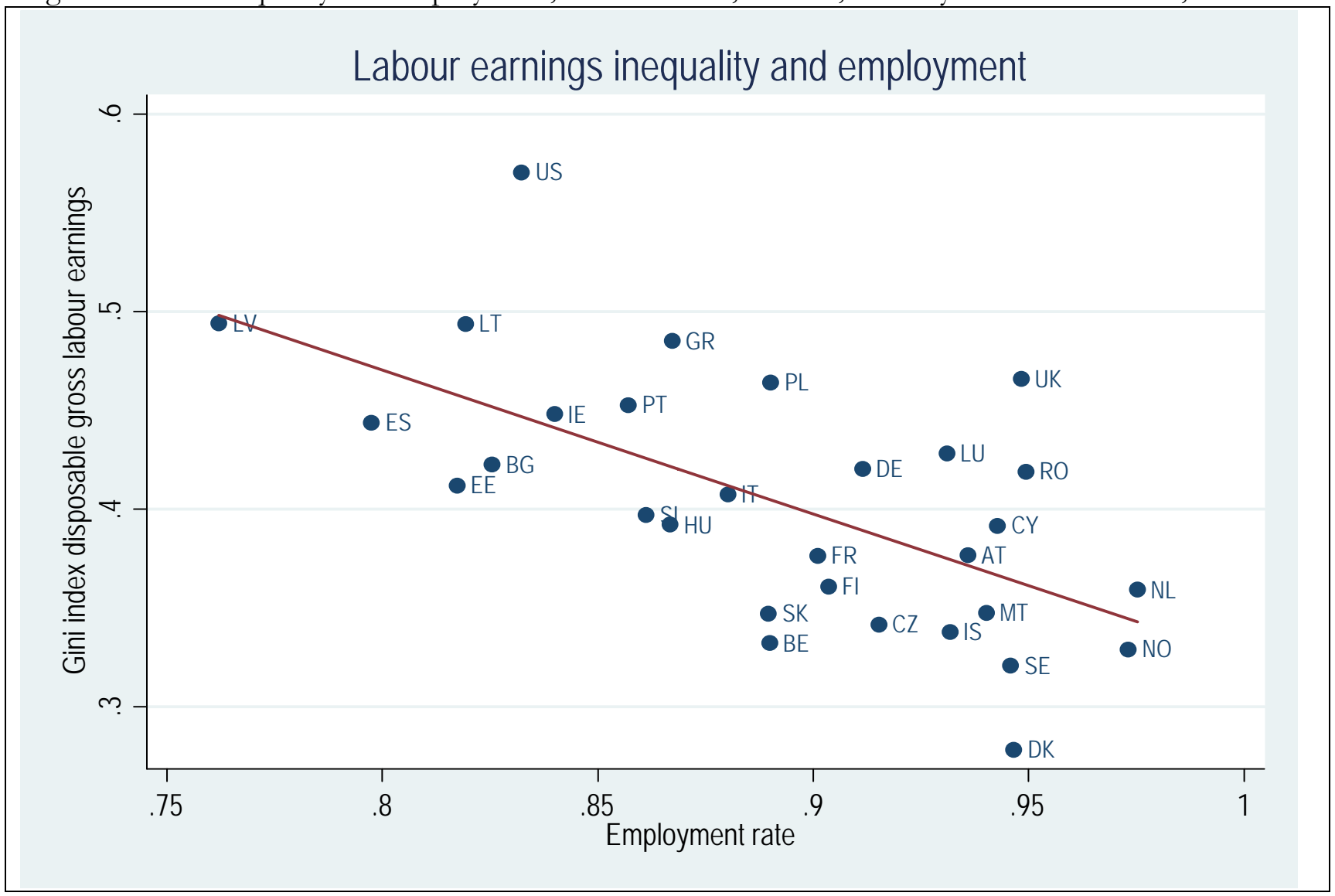




\subsection{Summary conclusions}

A key stylized fact for the US is that hourly-earnings inequality has increased secularly over the last 40 to 45 years, not more or less but more or even more, depending on the inequality measure that is chosen. The rise rests on a virtually continuous increase in inequality in the top half of the distribution; bottom-half inequality grew sharply until the end of the 1980s and after that has remained largely stable. The sharp upward evolution of earnings at the very top, that is reflected in the by now infamous Top-1\% incomes share, makes an important contribution to the continuous rise of that upper half. This is borne out by more detailed changes based on all 100 percentiles that at the same time shows some emptying out between the upper and lower tails of the earnings distribution.

A similar divergence between upper-half and lower-half inequality in recent years is found also for the other English-speaking countries (Australia, Canada, Ireland, New Zealand and the UK) though the stability of the bottom half may have started somewhat later than at the beginning of the 1990s, or was already there for most of the time. Note, however, that the absolute levels of inequality may differ substantially between these countries, both overall and in the two halves. In some cases bottom-half inequality far exceeds top-half inequality while in other countries it is the other way around - naturally the diverging evolution tends to inflate upper-half inequality relative to the bottom half.

The picture is less clear-cut for other countries, ranging from strong increases (Korea and Hungary since the 1990s) to compelling declines (Poland and Portugal in the 2000s; and a small decline for Spain). The comparison is complicated though by international differences in the concept of earnings and therewith in the sampling of the wage-earning population (by the way, also for Australia, Ireland and New Zealand here above). The sampling often targets full-time employees only, ignoring the parttime ones, who may actually be making important contributions to the level of inequality. Therefore inequality levels and trends in those countries may be underestimated in comparison. Some countries (Belgium, Finland and Japan show flat trends in of overall inequality and tend to register declining inequality in the lower half. Most of the rest (Austria, Czech Republic, Denmark, Netherlands, New Zealand, Norway, Slovakia and Sweden) do show a more modest rise but a rise nevertheless. In contrast to the English-speaking countries the rise seems to be spread over both halves of the distribution even if the level and the increase are less than in the upper half.

For a few countries the gender pay gap could be consistently compared. This decreased strongly in the US, more than in the UK, Canada or Germany, and from a high level so that currently the gaps are of largely the same magnitude. In the US educational differentials between the better-to-best educated and the lower-to-least educated have grown significantly. No internationally comparable stylized facts are available for those differentials though one may assume that the will have grown in many cases albeit it to different degrees.

A cross-section comparison of 27 European Union countries, Iceland, Norway and the USA underlines the importance of including the employment chances or in other words the distribution of individual hours worked and not focussing exclusively on the distribution of earnings. The two distribution hang together and do so in different ways, partly depending on labour-market institutions which may make the distribution of hours over individual employees more unequal, e.g. by allowing flexibilization or encouraging part-time hours. Naturally, the effect on household earnings depends on the combination of both hours and wage levels across the members of the household. 


\section{Theoretical approaches to wage dispersion and the role of institutions}

\subsection{The wage inequality debate $1980-2000$ and the role of labour-market institutions}

We start this paragraph with a brief introduction to the evolution of the literature on wage dispersion up to 2000 . We go back to the start of the literature on inequality in the 1980s to better understand the current situation and fill a lacuna in existing overviews. This is followed by a more detailed discussion of the study of labour-market institutions in the rest of this introduction. After that we discuss recent contributions in two main directions: supply and demand (4.2) and institutions (4.5); we sum up our findings at the end (4.7).

The literature in which the contemporary discussion on the dispersion of wages is rooted took off seriously in the course of the 1980s, kicked off with a detailed picture of changing male and female inequalities in the USA by Peter Henle and Paul Ryscavage (1980). ${ }^{66}$ This literature focused initially on the factual question about whether inequality had increased or not and it took some time before the factual doubts about that growth dissipated ${ }^{67}$, though factual questions have remained on the agenda throughout. It did not take long before the 'why?' question started being asked and answers were sought in many directions - more often than not in different directions at the same time incurring a risk of ad hocery. From the start some of these routes led to what in due course have become known as labour-market institutions. For example, Robert Plotnick (1982) attributed the (slow) increase in the variance of $\log$ (male) annual earnings - 'earned income' as it was usually called - between 1958 and 1977 entirely to the differential effects of the level of unionization, the dispersion in weeks worked, the age distribution of workers, and the inequality of education. Martin Dooley and Peter Gottschalk (1984) looked for a demographic explanation (viz. cohort size and the baby boom), while Dooley and Gottschalk (1985) added - on the factual side - the insight that real earnings of men earnings below a low-pay threshold were lagging behind. ${ }^{68}$ Barry Bluestone and Bennett Harrison (1982) launched the thesis of deindustrialization and expansion of low-wage employment, which in a later book (Bluestone and Harrison, 1988) turned into the famous 'Great U-turn' of growing inequality. This lent political significance to the issue which was particularly viewed as a polarization negatively affecting the middle class, which may sound familiar to current debates. ${ }^{69}$

Thus education, institutions, demographics, and the composition of the economy made an appearance in the literature almost from the start. From the early 1990s international trade and especially the competition with low-wage countries was added as another explanation (e.g., Wood, 1995). However, this is outside the focus on labour-market institutions of the current chapter. ${ }^{70}$ Though the interest in demographics may have waned (apart from the fact that gender has become a staple ingredient), the attentiveness to educational differentials, institutions, and the composition of the economy - industries and sectors at the time, occupations and tasks nowadays - has grown into a vast literature over the 1990s. The interest in education focused on the demand for skills in the economy on the one hand and their supply by the labour force on the other hand (e.g., Juhn et al., 1993). This has ushered in the thesis of 'skill-biased technological change' (SBTC for short) (Levy and Murnane, 1992; Bound and Johnson, 1989 and 1992) as the driving force behind the demand for skills. For some time this became the

\footnotetext{
${ }^{66}$ Henle (1972) already showed an increase in earned income inequality over 1958-1970.

${ }^{67}$ Blackburn and Bloom (1987) compared studies with conflicting outcomes, spelling out important differences in sample choice and definitions, and were about the first to consider both men and women; they concluded that "the time profile of earnings inequality, measured across individual workers, bas been quite flat since the late 1960s" (p. 604) combining a decrease in inequality among women with an increase among men.

${ }^{68}$ The threshold was defined as $\$ 3$, a good $40 \%$ above the Federal minimum wage in 1975 .

${ }^{69}$ Harrison, Tilly and Bluestone (1986) brought the issue to the Congress; Presidential candidates George Bush and Michael Dukakis discussed the status of the middle class and the nature of job growth in their campaigns of 1988 (Karoly, 1988, 13).

${ }^{70}$ Compare Machin (2008) for an evaluation, finding little support for this explanation.
} 
canonical model for explaining growing wage inequality. Evidently, the composition of the economy is not unrelated to this, if only because the skill structure differs between industries.

Technological change and economic composition together have become the supporting vector for the attention paid in the literature to supply and demand - or 'market forces' - as explanatory factors for differences and changes in wage inequality. In their first overview of the literature Frank Levy and Richard Murnane (1992) recommend future research to "get inside the black box of the firm" (pg.1374) and pursue the hedonic theory of labour demand that views a worker as possessing a fixed package of separate productive abilities and the wage as the sum of payments to them. The worker cannot separate these abilities and sell each to the highest bidder (Mandelbrot, 1962). As a result the unit price of a productive ability may vary across sectors (Heckman and Sedlacek 1985). Basically, Levy and Murnane seem to point in the direction of the route taken more recently by Daron Acemoglu and David Autor (2011) with their tasks based approach. At the same time it illustrates that technology is difficult to pin down empirically in economic studies and is usually subsumed in the unexplained part of modelling, also in the study of inequality. While Levy and Murnane focus almost exclusively on the USA, Gottschalk and Smeeding (1997) broaden the horizon to include various European and other countries. They pay considerably more attention to institutions and signal important problems of conceptualization and measurement and stress that both market forces and institutional constraints cannot be missed in the analysis. Peter Gottschalk and Mary Joyce (1998) focus on the evolution of inequality in international comparison and conclude that market forces can be used to explain much of the cross-national differences that have been attributed in the literature to differences in labour market institutions. They hasten to add that this does not mean that institutional explanations do not matter but that the presumption should not be that they always provide binding constraints. Basing themselves on both direct and indirect evidence Lawrence Katz and David Autor (1999, Section 5.5) in their comprehensive overview of the literature on wage structure and earnings inequality view SBTC as perhaps the most important driver of the long-run growth in demand for more educated workers. They are less assertive about an acceleration in the trend. One important issue for further research they see is that the advantage of the better skilled may be transitory and for the long run depend on a continuing chain of technological changes or, alternatively, that $20^{\text {th }}$ century technological changes may happen to be systematically skill biased. Another question is whether the change is exogenous or may endogenously be affected by the supply of different skills.

Parallel to the market view, the institution-focused approach thrives. Fortin and Lemieux (1997) convincingly demonstrate its relevance basing themselves on both current American experience and effects of the Great Depression. There are some empirically obvious candidates for explaining wage inequality - the extent of union membership and the minimum wage given the clear declines in both in the USA and the significant international differences, including the (de)centralized nature of wage bargaining. Richard Freeman (1991) finds an important but not overwhelming role for unionization in relation to increasing inequality; by contrast, DiNardo and Lemieux (1997) explain two thirds of the American-Canadian difference in male wage inequality growth from the faster decline of American unions; Blackburn, Bloom and Freeman (1990) attribute only a small role to the declining minimum wage. DiNardo, Fortin and Lemieux (1996) find a substantial contribution to increasing wage inequality for the declining level of the minimum wage between 1879 and 1988. Though Levy and Murnane (1992) mention these institutions in their overview, they barely touch upon institutions - and then for the USA only - and apparently see no clear research agenda there. During the rest of the 1990s, however, the interest in institutions widens far beyond the above-mentioned. This receives great stimulus from international comparisons where differences in institutions can more easily get into the limelight. Working under Different Rules (Freeman, 1994), Differences and Changes in Wage Structures (Freeman and Katz, 1995) and Francine Blau and Lawrence Kahn (1996) bring together important empirical studies of a variety of countries. On a somewhat different tack from wage inequality, Freeman (1988) and Richard Layard and Stephen Nickell (1991) contribute on labour market institutions and macroeconomic performance in OECD countries. At the same time David Card and Alan Krueger (1995a) dispel the consensus regarding the negative employment effects of the American minimum wage. As we will see later these effects have remained a bone of contention up to this very day for their effects on employment, but much less for those on the wage distribution which are generally agreed to 
be compressing (Blau and Kahn, 1999). The Handbook of Labour Economics Volume 3 concludes the 1990s by offering a rich palette of contributions on wage formation and inequality and institutions. Katz and Autor (1999) explicitly focus on earnings inequality and explanations from supply and demand on the one hand and from institutions on the other hand; Blau and Kahn (1999) treat labour market institutions in detail, while Charles Brown (1999) specifically considers the minimum wage literature. Nickell and Layard (1999) also discuss the effects of labour-market institutions but in relation to economic performance in general (the 'natural rate of unemployment' and the later NAIRU), a different strand in the literature going back to Friedman (1968).

\subsection{Defining and analysing labour-market institutions.}

Given the importance of the subject for the chapter we will pay attention to the issue raised by the treatment of institutions before turning to the discussion of recent developments in the inequality literature in the next two sections. We distinguish between conceptualizing (method) and analyzing institutions and consider this at a general level in the present subsection, which boils down to the question how economic analysis accounts for the existence of institutions. More specifically, their role in wage-inequality analysis is discussed in Subsection 4.5.

\section{Method}

First, the definition of institutions, and of labour-market institutions in particular, seems in need of more precision, generically as well as in specific cases. ${ }^{71}$ Too often in the literature they seem to be considered too obvious - and therewith perhaps too difficult - to warrant explicit definition. As Nickell and Layard (1999) say "It is difficult to define precisely what we mean by labour market institutions, so we simply provide a list of those features of the labour market which we shall consider." In the words of Freeman (2007), "While economists do not have a single tight definition of an institution, per Justice Potter's famous statement about pornography, they know institutions when they see them, and they see them everywhere." Those who actually venture a definition, come up with very broad ones, such as "A labour market institution is a system of laws, norms or conventions resulting from a collective choice and providing constraints or incentives that alter individual choices over labour and pay" (Boeri and Van Ours, 2008, 3), that may be begging important questions - in this case: Is the alteration of choice a practical matter or a theoretical issue? If the latter, this poses the risk that by definition any institution will imply a deviation from the theoretical ideal and also that institutions will be conceptually difficult to endogenize, meaning that an institution might endorse changes in behaviour that have already taken place instead of causing such changes. It may also make the identification of institutions differ between different theories. Further to the restriction to laws, norms or conventions: what about organizations? A trade union is an organization aimed at furthering the interests of its members. ${ }^{72}$ Can a policy be an institution or not - as, e.g., active labour market policies are regarded an institution by Nickell and Layard (1999) and by Werner Eichhorst et al. (2008)?

Institutions started their career in the inequality discussion as union density and the (de)centralized nature of wage bargaining. These are factors that can obviously influence individual wages but they are neither law, nor regulation or rule, and seem closer to physical organization. The minimum wage, another institution also present from the start, is (often) in the law though. Not only in the inequality debate but more broadly, institutions have come to encompass a wide array of factors and there seems to be no clear defining limit as to what can qualify as one or not. This makes institutions not only difficult to delineate but also tends to lend them a fundamentally ad hoc character. The selection of labour market institutions does not necessarily result from a systematic scrutiny but seems to reflect trial and error based on constrained and sometimes even biased knowledge. How otherwise to explain

\footnotetext{
${ }^{71}$ In the words of Freeman $(2000,11)$ "The absence of a general metric for measuring institutions at the national or firm level creates a problem for institutional economics. Measurement is, after all, the sine qua non of any scientific endeavour." See Autor (2013) for a similar worry regarding definitions and measurement for the tasks approach.

${ }^{72}$ Checchi and García-Peñalosa $(2008,607)$ do distinguish “employee organizations outside the direct control of policy-makers" as one form of 'collective intervention' encompassed in labour-market institutions.
} 
the immensely strong focus on unions while employer associations hardly figure, in spite of the fact that they are equally involved in collective bargaining and that 'employer density' - the percentage of workers in a sector who are employed by the negotiating firms - and not union density may actually provide the basis for declaring a collective agreement generally binding. ${ }^{73}$ The attention paid first to union density and only much later, when this appears to fail as an explanation, to the coverage of collective bargaining, is another case in point. ${ }^{74}$ Last but not least, it is difficult to understand, given the highly central role of educational differentials in the wage-inequality literature, that the educational system figures so little as an institution in this literature. ${ }^{75}$

In addition, in the literature, labour market institutions can be viewed as specific factors with an actual origin and presence in the labour market and only there (e.g. wage bargaining) but equally they may be factors that affect the labour market from outside that market (e.g., income taxation or the tax wedge). The latter definition, as a factor affecting the labour market irrespective of its origin, opens the door to a myriad of institutions and, unsurprisingly, many other factors have been added in the 30-year course of the debate. For example, Nickell and Layard $(1999,3047)$ include home ownership in their list of labour market "institutions" (their quotation marks), inspired by the finding of Andrew Oswald (1996) that it is one of the most important barriers to the geographical mobility of labour. ${ }^{76}$ Freeman (2007) lists, without presumption of being exhaustive: mandated works councils, employment protection laws, minimum wages, extension of collective bargaining coverage, lifetime employment, peak level collective bargaining, wage flexibility, teams, job rotation, temporary employment contracts, social dialogue, apprenticeship programs, occupational health and safety rules, defined benefit and defined contribution pension plans. To name a few other examples: Rebecca Oliver (2008) draws attention to industry-wide wage scales, Tito Boeri $(2011,1183)$ adds regulations on working hours, Blau and Kahn $(2002,4)$ include the public-sector share of employment. Anti-discrimination measures easily come to mind as a further example ${ }^{77}$, and we will meet more below when we discuss recent contributions to the literature. Obviously, the discussion of earnings in relation to household income in the preceding section suggests new candidate institutions such as parental leave, child care provisions, or individual entitlements to the choice of working hours.

Second, the analysis of the effects of institutions still demands attention even if they were clearly defined, for several reasons: the actual significance of individual institutions and the type of effects they may have, their embedding in a larger set of institutions and also in the wider economy, and the potential pitfalls of international comparisons which have taken centre stage in the literature.

In many studies institutions seem to be taken at face value and equated with what they look like de jure while, naturally, it is their de facto implementary force or 'bite' that counts (Eichhorst et al., 2008, 18). That bite may depend on its particular enforcement - laws and rules can be strictly enforced or they may be a dead letter that no one pays attention to. Enforcement may be automatic when it is the responsibility of a supervising inspectorate or it may be costly and cumbersome if it is the responsibility of the individual who feels duped - minimum wages and other provisions diverge importantly in this respect (Benassi, 2011). Institutions may also be general provisions whose precise nature is filled in by actual policy. The minimum wage is again a case in point when the law establishes its mere existence

\footnotetext{
73 Alan Manning (2011, 978-979) draws attention to employer collusion and points to research showing that "some institutions and laws in the labour market serve to aid collusion of employers to hold down wages". Though in his view it is clear that employers do not en masse collude, it would still seem logical to test centralised wage bargaining that results in protracted wage moderation for its potential as a form of nationwide monopsony.

${ }^{74}$ Availability of internationally comparative data was also a problem (e.g. Koeniger et al, 2007, 344).

${ }^{75}$ Leuven et al. $(1997,2004)$ criticise deriving skill levels from, inter alia, years of schooling in international comparisons. Nickell and Layard (1999, 3046) point to the same. Freeman and Schettkat (2001) and Mühlau and Horgan (2001) elaborate on the issue for the low skilled. Based on data from the International Adult Literacy Survey of the 1990s these contributions point out that the American low skilled attain much lower levels of literary and numeracy than their counterparts in various European countries. At first glance the recent Survey of Adult Skills seems to underline the same twenty years later (OECD, 2013, 118-125).

76 See also Blanchflower and Oswald (2013).

${ }^{77}$ Charles and Guryan $(2007,2008)$ explain one quarter of the racial wage gap for blacks in the USA from employer prejudice.
} 
while its actual (up-rated) level is determined by policy making - the USA being the leading example. ${ }^{78}$ For policies the bite is the heart of the matter. ${ }^{79}$ Note that this further blurs the distinction between institution and policy. Institutions may also differ in the nature of their implementation: legally prohibiting or prescribing certain behaviour, or economically encouraging or discouraging it, and consequently in the type of effects they may have. An example may be a prescriptive rule of employment protection versus a hiring subsidy for disadvantaged groups of active labour-market policies. Note that the implementation of an institution may not be either black or white but can have different shades, cross-section within as well as between countries, and can also differ over time. ${ }^{80}$ Evidently, the de facto significance of an institution may come close to actually measuring its effects and this can pose a methodological problem.

Often the effects are scrutinized for individual institutions as there is no clear theory on their coherence or interactions as a (national) set (Eichhorst et al., 2008, 17, 24, 29). However, institutions may partly balance or reinforce each other, say a country with strong employment protection could be mitigating the possible upward pressure on wages by collective bargaining or employment 'at will' may be neutralized by individual contracts. It is easier to expand union membership if workers are protected from the threat of being fired. Diffusion of part-timers may reduce the quest of work leave permits. Generosity of unemployment benefit schemes may increase voluntary mobility and raise the demand for publicly provided training. Similar functions may be provided by different institutions. For example, Andrea Garnero, Stephan Kampelmann and François Rycx (2013) conclude to the functional equivalence with regard to earnings inequality of statutory minimum wages in some European countries and minimum pay provisions of sector collective labour agreements combined with high bargaining coverage in other countries. ${ }^{81}$ Gottschalk and Smeeding $(1997,647)$ warn for the risk of double counting the effects of institutions when considered in isolation (union density and the minimum wage in their example).

There may be deeper dangers in international comparisons. Institutions may catch the eye more readily than other international differences and be considered in relative isolation, enhancing the risk of their effects being overestimated. Blau and Kahn (1999) focus their overview on some 20 OECD countries stating that this selection permits utilizing "the similarity in educational levels, technology, living standards and cultures among these countries as de facto controls in examining the effects of institutions". Freeman (2007, 18) cautions against the methodological implications of the fact that the number of countries is small compared to that of institutions. Conversely, appearances may be deceptive and the potential dissimilarities of institutions that may look the same at first sight, need to be taken into account. We have already seen the possible divergence between educational attainment and skill levels in spite of the extensive efforts spent on a standardized measurement of educational systems (ISCED). Freeman's (2000) plea for a metric may be more demanding than thought but above all it may be necessary but not sufficient. The above observations about the enforcement and bite of institutions apply particularly in a comparative context, to prevent comparing apples with pears. More importantly, there may be deep-seated differences in the general economy as have been illustrated forcefully in recent years by for

\footnotetext{
${ }^{78}$ See Boeri (2012) for a comparison of the effects of minimum-wage setting mechanisms, depending on the roles of unions and employers and the government in the process, across 66 countries.

${ }^{79}$ For the bite of the minimum wage see Kampelmann et al. (2013, 12-16) who discuss its relative money level in the wage distribution (Kaitz index) together with the share of minimum-wage employment in total employment. Eurostat's database on minimum wages ([earn_mw_cur] at http://epp.eurostat.ec.europa.eu/portal/page/portal/eurostat/home) is restricted to the former.

${ }^{80}$ For example, for involuntary dismissals Dutch employers have the choice between following an administrative procedure, with no costs apart from the time it may take to settle, or going to court, which normally will be costly as it implies a severance payment. In recent decades the choice between the two routes has drastically shifted towards the latter option even though the administrative procedure has become more efficient (Salverda, 2008, 105).

81 The resulting levels may differ though.
} 
example the havoc wreaked by the larger propensity to consume of private households in the USA compared to many other countries. ${ }^{82}$

In sum, the study of the role of institutions needs to account for the force of those institutions, their mutual interactions at the national level, supply and demand in the labour market, and also the broad structure of the economy. The latter potentially puts on the research agenda also institutions that affect the economy more broadly such as those governing the flexibility of exchange rates ${ }^{83}$ or international capital movements, which have undergone important liberalization in many European countries since the end of the 1970s and may have weakened employees and unions vis-à-vis employers. An important lesson of the minimum wage debate and the contribution made by Card and Krueger (1995a), who no longer started from the a priori of a negative effect on employment, is to prevent a stacking of the cards against institutions. As Freeman (2007, 2) observes, "many adherents to the claim (that labour institutions impair aggregate performance, authors) bold strong priors that labour markets operate nearly perfectly in the absence of institutions and let their priors dictate their modelling choices and interpretation of empirical results."

\subsection{Why do labour market institutions exist?}

The economic rationale and potentially beneficial effects of creating and/or preserving labour-market institutions need to be accounted for from the start. ${ }^{84}$ According to Freeman (2007) there are three ways in which institutions affect economic performance: by altering incentives, by facilitating efficient bargaining, and by increasing information, communication, and possibly trust. In his cursory review, the evidence shows that labour institutions reduce the dispersion of earnings and income inequality, which alters incentives, but finds controversial effects on other aggregate outcomes, such as employment and unemployment. ${ }^{85}$ In his opinion, the modest effect would be attributable to the fact that "...the political economy of institutional interventions rules out collective bargaining settlements and regulations that are truly expensive to an economy. No country would impose a minimum wage that disemployed a large fraction of the work force; and no union or employer would sign a collective bargaining agreement that forced the firm to close." In this perspective, a positive contribution of institutions would be observed whenever and wherever they solve transaction cost of individual bargaining, according to the prediction of the Coase theorem.

Regulations in the labour market as defined by Juan Botero and co-authors (2004) emerge by government desires to protect the weaker side in a labour relationship. ${ }^{86}$ They show that the orientation of governments to the political left is often associated to more stringent labour market regulations (political power theory), but find the legal origin to be even more relevant to accounting for cross-country

\footnotetext{
82 Glyn et al. (2003) find that the European-American services-employment gap resides largely in the distribution (retail) activities and personal services sector and show "that the much lower European level of goods consumption per head of the population was the dominating influence in explaining the much lower levels of employment than in the US distribution."(173)

${ }^{83}$ Blau and Kahn $(1999,1454)$ in their conclusions argue that exchange rates can adjust to compensate for institutional rigidities (and warn that introducing the Euro may take away that opportunity, which has been borne out in the meantime). ${ }^{84}$ Some recent examples are Acemoglu (2003), who argues that labour-market institutions stimulating wage compression in Europe may also incentivize investments in improving the productivity of the low skilled; Sutch (2010), who points to capital deepening and increased educational attainment as a consequence of the minimum wage (compare also Freeman, 1988); Nickell and Layard (1999), who consider that employee representation rights may induce management/worker cooperation and enhance productivity; or Atkinson (1999), who demonstrates that unemployment benefits, if accounting for their real-world rules, may actually be employment enhancing. A more fundamental, long-run perspective relates the origins of the welfare state, be it Beveridgean or Bismarckian, to the development of dependent employment.

85 Similarly Betcherman (2012) indicates four rationales for the existence of labour market institutions: “...imperfect information, uneven market power (between employers and workers), discrimination, and inadequacies of the market to provide insurance for employment-related risks." (pg.2). According to him, the literature can be classified according to a positive view (that he calls institutionalist), when institutions solve coordination problems, and a negative view, that he calls distortionary, when institutions prevent economic efficiency.

86 "Regulation of labour markets aiming to protect workers from employers takes four forms. First, governments forbid discrimination in the labour market and endow the workers with some "basic rights" in the on-going employment relationships, such as maternity leaves or the minimum wage. Second, governments regulate employment relationships by, for example, restricting the range of feasible contracts and raising the costs of both laying off workers and increasing hours of work. Third, in response to the power of employers against workers, governments empower labour unions to represent workers collectively, and protect particular union strategies in negotiations with employers. Finally, governments themselves provide social insurance against unemployment, old age, disability, sickness and health, or death." (Botero et al.2004, pg.1342).
} 
variation (especially when considering the transplantation of legal systems in the colonial era, much in line with sociological theories of path dependence - legal origin theory). According to the latter, commonlaw countries tend to rely more on markets and contracts, whereas civil-law (and socialist) countries on regulation (and state ownership): as a consequence, civil-law countries do regulate labour market more extensively than common law ones. The legal origin, possibly adopted for efficiency reasons in mother countries, becomes exogenous for former colonies, thus allowing a study of its causal impact on the origin of institutions. ${ }^{87}$ Following this line of argument, several papers account for the endogenous emergence of some labour market institution as an (optimal) solution for at least of a subset of agents. A controversial contribution to this approach is given by Gilles Saint-Paul (2000), who aims to identify gainers and losers of a given institution. In his view, each institution creates a rent (i.e. a difference between the paid wage and the outside option), which is unevenly distributed in the workforce. Since the employed workers enjoy most of the benefits of these rents, they obviously represent the largest constituency advocating the preservation of institutions (political insider mechanism). This has to be tradedoff against the rise of unemployment, which is associated to higher wages, and this represents the most serious threat to the continuation over time of an institutional set-up. If we accept Saint-Paul's view that the most relevant conflict within the workforce is between the skilled and the unskilled, then "...labour market rigidities mostly redistribute between skilled and unskilled labour." (Saint-Paul 2000, pg.6). Ignoring within-group inequality, this means that institutions affect earnings inequality by affecting the skill premium and the (unskilled) unemployment rate. In this perspective, institutions emerge when the constituency represented by the employed unskilled dominates those of the skilled and of the unemployed (which is a different coalition than the one supporting fiscal redistribution, for example). The relationship between inequality and institutions becomes ambiguous: institutions create or enhance wage differences, but wage inequality may support the introduction of labour market institutions as an alternative device for redistribution. ${ }^{88}$ Similarly, different institutions may reinforce each other, revealing the potential existence of a politico-economic complementarity, which contributes to explaining why empirically we observe clusters of institutions, often indicated as social models (Hall and Soskice 2001, Amable 2003). For reasons of viability, labour-market reforms are more likely to emerge after a period of crisis, when the bias towards the status quo is weakened and the rise of unemployment allows the formation of alternative constituencies. A rather different view on rents in the labour contract, however, is offered by Manning (2011). According to him, rents are pervasive in the labour market, because of frictions in hiring and recruiting, separation costs due to investment in specific human capital, and collusive behaviour on both sides (employers and employees). If imperfect competition is therefore taken as the relevant paradigm, ${ }^{89}$ the regulation of this market (via wage bargaining or wage setting by public authorities, as in the case of minimum wage) acts as a second best device, which may achieve Pareto improvements (as in the case of the minimum wage under monopsony).

In a recent contribution, Philippe Aghion et al. (2011) frame the existence of labour market regulations as an incomplete and less efficient substitute for the quality of labour relations. They rationalise their argument with a model of learning of the quality of labour relations: the unionization decision is seen as a costly experimentation device aimed at finding out more about cooperation at the workplace. Thus the existence of legal provisions (such as a minimum wage) reduces the learning incentive. Since beliefs are gradually updated based on past experiences, the authors obtain the prediction of a coevolution of beliefs (as measured by the quality of labour relations perceived by top executives) and institutions (as

\footnotetext{
${ }^{87}$ When they analyse the causal impact of legal indices on a measure of the skilled/unskilled differential, they find than only the "social security laws index" as an inequality enhancing causal impact (using the legal origin as instrument).

88 "Inequality, i.e. the gap between the skilled and unskilled productivities, determines the intensity of internal conflict. As we have argued, it is because of that internal conflict that it pays the middle class coalition to opt for rigid labour market institutions. Therefore we expect that the support for rents will be greater, the greater the inequality. This is actually true over some range, if inequality is low enough. But past a certain threshold inequality reduces the support for rents, because at high inequality levels the cost of rigidity in terms of job loss is too big." (Saint-Paul 2000, p.8). See also Brügemann 2012, who builds a model where stringent protection in the past actually reduces support for employment protection today.

89 "Many empirical observations (e.g. equilibrium wage dispersion, the gender pay gap, the effect of minimum wages on employment, employers paying for general training, costs of job loss for workers with no specific skills to list only a few) that are puzzles if one thinks the labour market is perfectly competitive are simply what one might expect if one thinks the labour market is characterized by pervasive imperfect competition." (Manning 2011, p.62)
} 
measured by the stringency of minimum wage)..$^{90}$ As a consequence, distrustful labour relations lead to low unionization and high demand for a direct state regulation of wages. In turn, state regulation crowds out the possibility for workers to experiment with negotiating and to learn about the potential cooperative nature of labour relations. This crowding-out effect can give rise to multiple equilibria: a "good" equilibrium characterized by cooperative labour relations and high union density, leading to low state regulation (the Nordic countries), and a "bad" equilibrium, characterized by distrustful labour relations, low union density, and strong state regulation of the minimum wage (some of the Mediterranean countries, and especially France). Their empirical application covers 23 countries over the period 1980-2003, and shows that the quality of labour relations is negative correlated with either union density or state regulation of the minimum wage (while controlling for other institutional measures like unemployment benefit and the tax wedge).

Also recently, Alberto Alesina et al. (2010) have proposed a model where the emergence of employment protection and minimum wage provision is accounted for by cultural traits, namely the strength of family ties. In their theoretical model individuals are born with different preferences with respect to family ties: those characterized by weak ties are geographically or sectorally mobile and achieve an efficient allocation by being matched to jobs providing the highest productivity; however, those characterized by strong ties rationally select labour market rules (such as firing restrictions and minimum wages) that restrain the monopsonistic power of local employers while accepting a less productive allocation. Another rationale of living close to family members is that it provides additional insurance against unforeseeable shocks (including unemployment). The authors prove the existence of two stable Nash equilibria: one where everybody chooses weak family ties, votes for labour market flexibility, and changes her of his initial location (high mobility); another where everyone chooses strong family ties, votes for stringent labour market regulation and stays in the original (birth) location. In the latter case the labour market is monopsonistic because workers are immobile, and workers limit employers' power by means of labour regulations. Empirically, they show the existence of positive cross-country correlations between the strength of family ties and labour market rigidities. More convincingly, they also find that individuals who inherit stronger family ties (i.e. second generation immigrants from countries which record high preferences for family values) are less mobile, have lower wages, are less often employed and support more stringent labour market regulations.

In their historical review of the introduction of severance payment schemes in 183 countries, Robert Holzmann et al. (2011) suggest three rationales for the introduction of such schemes: a) as a primitive form of social benefits (anticipating the introduction of benefits for unemployment and retirement), thus providing an answer to a demand for insurance; b) as an efficiency enhancing human resource instrument (a sort of bonding between workers and firms, in order to minimise the loss of firm-specific knowledge) solving the bold-up problem; and c) as a proper job-protection instrument, intended to enhance permanence in employment of main earners in the household.

If we restrict ourselves to the minimum wage, the historical account provided by Neumark and Wascher (2008) suggests that this institution has emerged as a counterbalance of power in the labour contract, preventing the exploitation of child labour (minimum-wage settlement power assigned to law courts in New Zealand in 1894 and in Australia two years later) or women (Fair Labor Standards Act, introduced at the federal level in the USA in 1938). Viewed in this perspective, the minimum wage would represent a device aimed at preventing a "race to the bottom" competition among firms, more than a measure aimed at sustaining the incomes of poor families. ${ }^{91}$ Seen from the side of union leaders, minimum-wage legislation represents an improvement in the outside options of workers, inducing an increase in their bargaining power. The sum of these two effects may create an unusual coalition of

\footnotetext{
90 While this prevents any causality analysis, it resembles the path dependence often advocated by sociologists in the analysis of institutions.

${ }^{91}$ In a similar vein, Agell and Lommerud 1993 proposed a model where setting higher wages promoted higher growth by eliminating low productivity enterprises.
} 
large companies and worker unions supporting the introduction and/or the periodical updating of wage minima. ${ }^{92}$

\subsection{Do labour market institutions matter for the economy?}

In their overview of labour-market institutions Blau and Kahn (1999) with a careful discussion of the rationale and draw some implications for studying the causalities. They look back at "an explosion of research" on the economic impact of institutions and conclude that institutions do appear to matter. In their view the evidence across the literature that institutions affect the distribution of wages is more robust than for employment levels. Freeman (2001) supports this, saying that institutions identifiably affect the distribution, but that other effects on the macroeconomy and on efficiency are hard to discover and modest at best. Later he states even more forcefully that "institutions have a major impact on one important outcome: the distribution of income ... By contrast, despite considerable effort, researchers have not pinned down the effects, if any, of institutions on other aggregate economic outcomes, such as unemployment and employment."(Freeman, 2009, pg.19-20; see also Freeman, 2005). Nickell and Layard (1999, pg.3078) seem more reticent about the role of institutions when they conclude that "Most of the gross features of unemployment and wage distributions across the OECD in recent years seem explicable by supply and demand shifts and the role required of special institutional features such as unions and minimum wages is correspondingly minimal." These are not the last words about the role of institutions with regard to the dispersion of wages - let alone that of earnings incorporating the hours dimension which we deem of special interest here - as we will see when we turn to more recent contributions to the literature in the next two sections and to our empirical approach in Section

5.

So over the 1980s and 1990s a vast literature has grown which seems to tend into two main directions: supply and demand on the one hand, institutions on the other. Each side acknowledges the relevance of the other, there is talk even of an SDI (supply-demand-institutions) model (Freeman and Katz, 1995; Katz and Autor, 1999; see also Lemieux, 2010) but little has grown out of that since, and in reality understandably given the above-mentioned concerns - the prime focus of the market view and the institutional view seems to have grown more independent of each other. The flurry of institutions make them look overdetermined, and, by comparison, technological change - the driver of supply and demand - underdetermined. Over the 2000s many new arguments have been developed: polarization of the distribution, offshoring of productive activities, sharp growth in the upper tail of the distribution, top taxation, focus on tasks and skills, two-tier nature of reforms of institutions, growing importance of performance pay, rise of 'new institutions', and last but not least new contributions have been made with regard to the minimum wage. These contributions seem firmly placed in either one or the other of the two main directions. In this respect the recent Volume 4 of the Handbook of Labor Economics repeats the preceding Volume 3. Acemoglu and Autor (2011) hardly even touch upon institutions in their conclusions, while Boeri (2011) focuses exclusively on aspects of institutions.

We think that Manning's (2011) approach of imperfect competition in the labour market which aims to leave behind the thinking in terms of canonical models and departures from these, may indicate a third route that can provide a different and ultimately more unified perspective. From the starting point that rents are inevitable and pervasive - though it is unclear how large they are and who gets them -, Manning (pg. 996) suggests that their very existence creates the 'breathing-space' in the determination of wages and allows the observed multiplicity of institutions on efficiency grounds. He concludes (p. 1031) that "One's views of the likely effects of labour market regulation should be substantially altered once one recognizes the existence of imperfect competition". "An important corollary seems that institutions do not "cause the labour market to function differently from a spot market" (Blau and Kahn, 1999, pg.1400) but that this

\footnotetext{
92 See their review of empirical evidence based on minimum wage voting across US states (Neumark and Wascher 2008, chpt.8).

${ }^{93}$ Note, however, his observation that the actual effects of (or, for that matter, the limits to) institutions are an empirical matter.
} 
market shall not be considered a spot market but instead needs institutions for its proper functioning from the very start. Thus, a better principle for analysing supply and demand as well as institutions may be that institutions are equally pervasive: every act of supply and demand goes together with an institution of some kind, and their existence and effects shall be accounted for from the start.

\subsection{Recent theories based on demand and supply of labour inputs}

The review of theories of earnings inequality provided by Derek Neal and Sherwin Rosen (1999) a decade ago focussed on the allocation of workers to jobs (the Roy model), on individual human capital accumulation (the Ben Porath model), on the search models (yielding variations in tenure - for a recent review see Rogerson et al. 2005 or Rogerson and Shimer 2011) and on imperfect observability of either ability or effort (efficiency wage and contract theories). They adopted an individual perspective of wage determination, which did not allow great scope for the institutional framework to affect the resulting earnings distribution. In such a perspective, wage inequality can be considered as the outcome of changes in the relative demand and supply of labour inputs. Starting from the original paper by Lawrence Katz and Kevin Murphy (1992) and the literature originated since then (reviewed in Katz and Autor 1999), the so-called canonical model predicts that the wage differential between skilled and unskilled workers accommodates an expanding demand for skilled labour (skill biased technological change-SBTC, induced by introduction of computers in production) and a contraction of the demand for unskilled labour (due to increasing competition by developing countries). Demographic changes (variations in cohort size, immigration) and/or educational choices may partly attenuate (or even offset) these changes. The resulting dynamics of inequality can be predicted by tracking down these movements (Acemoglu 2003).

In this framework, wage setting institutions affect the flexibility of relative wages, creating a trade-off between wage differential and relative unemployment; when considering inter-industry wage differentials, it translates into lower employee quit rates and longer queues of job applicants. ${ }^{94}$ Consider for example an increase in the relative demand for skilled labour (upskilling), at given supply of labour inputs. If the wage differential cannot adjust the relative excess demand for skilled labour (because minimum-wage legislation prevents a downfall of the unskilled wage and/or union bargaining prevents an excessive rise of the skill premium), then the unskilled workers will experience an increase in their relative unemployment rate. This effect will be more pronounced the higher is the substitutability between labour types.

It did not take long into the new century before David Card and John DiNardo (2002) mounted a fierce critique of the thesis of skill-biased technological change. Their arguments are both theoretical and empirical. From a theoretical point of view, a constant SBTC rate does not yield a permanent skilled/unskilled wage differential, as long as the relative supply is sufficiently elastic (see Atkinson, 2007b). On the empirical side, they revisit the evolution of American wage inequality since 1967, almost back to the starting point of the literature but now extending to include more recent occurrences over the 1990s. This refers to the problem already mentioned that technological change lacks a positive identification in economic models but is commonly subsumed in the unexplained left-overs. To avoid the tautology that this implies, they look for independent empirical measures of technological change that can be incorporated in the model: the introduction of PC's and the internet, the size of the IT sector in the economy, and the use of computers by individuals at work - particularly disaggregated by personal characteristics. ${ }^{95}$ From this material, the general trend in technological change seems unabated over the 1990s, if not increasing because of the internet. The disaggregated use of computers points, among other things, to a larger role among women than men, particularly among the less educated women while the best-educated men have closed the gap to their female counterparts. From this Card and DiNardo conclude that computer technology should have widened gender differentials for the

\footnotetext{
94 Katz and Autor 1999 also consider product market regulation, in that it creates differences in sectoral rents, which are partly appropriated by wage bargaining, thus contributing to the overall wage inequality.

${ }_{95}$ Note that DiNardo and Pischke (1997) show robust wage differentials for the use of pencils (in Germany) and draw attention to the possible selection effect that office tools tend to be used more by higher-paid workers.
} 
most highly educated and narrowed them for the least educated. On the inequality side, they argue from a fresh inspection of the data (using different samples, sources and inequality measures), "viewved from 2002" as they say, that there has been a pattern of a strong episodic rise in inequality in the 1980s, preceded by near stability before and after, during the 1970 s and 1990 s respectively. ${ }^{96}$ From a comparison of the two, demand and supply, they conclude to "a fundamental problem ... that rises in overall wage inequality have not persisted in the 1990s" and also to various puzzles, including the fact that the gender differential has diminished irrespective of education. In summary, they find the evidence for SBTC to be surprisingly weak. They do think there has been substantial technological change but deplore that this has diverted attention away from inequality trends that cannot be easily explained by this. The critique of SBTC is the main point of their contribution, not the design of an alternative explanation of inequality. However, Atkinson $(2007 \mathrm{~b}, 2008)$ points out that their critique of SBTC ignores the dynamics of the process and implicitly assumes a curve of skilled labour supply whose speed of adjustment is inversely related to the distance from an infinitely elastic one. International differences in the wage differential may reflect differences in the speed of that adjustment. Card and DiNardo end their contribution by teasing the reader with a quick exercise about the minimum wage that shows a strong correlation between the evolution of its real level and aggregate hourly wage inequality (P90:P10) over the entire period 1970-1999.

David Autor, Lawrence Katz and Melissa Kearney (2006) and (2008) have shown that the period of rising earnings inequality in the US labour market during the $70 \mathrm{~s}$ and the $80 \mathrm{~s}$ has been replaced by job polarization (simultaneous growth of the share of employment in high-skill/high-wage occupations and low-skill/low-wage occupations) in the following two decades. Despite the fact that the emergence of polarization crucially hinges on the procedure according to which occupations are ranked (educational attainment, wage rank, task content), also many European countries feature similar patterns: the decline in blue-collar jobs (mostly held by uneducated men) and the expansion of service jobs (mostly held by women and youngsters). One suggested interpretation (Autor, Levy and Murnane 2003) points to the increase in productivity of ICT, which would have replaced middle-skilled administrative, clerical and productive tasks with computer-operated machines.

Autor, Katz and Kearney (2008) have taken up the challenge of what they call a 'revisionist' literature of both the description and the explanation of US wage inequality since the 1970s. They object to the episodic interpretation of the rise in wage inequality, that is they contrast this with on-going inequality growth in the top half of the distribution combined with initially (1980s) increasing and subsequently (1990s) declining inequality in the bottom half. ${ }^{97}$ They view that initial lower-half increase as episodic indeed and incorporate the minimum wage as a potential explanatory factor in their approach; however, they find only a modest role when modelled together with relative supply and demand. For the 1990s they agree that the slowing down of inequality growth poses a problem for the SBTC thesis, but only for the 'naive' SBTC story as they call it which is based on a dichotomy of high skills and low skills. They aim to improve on this by arguing a more detailed approach, based on the dispersion of occupations by their skill levels, measured as the mean years of schooling of an occupation's occupants (weighted by their hours worked), and distinguishing between different types of tasks that can be performed in an occupation, showing that this works out differently between the 1980s and the 1990s

The occupations and tasks approach can be viewed as a step along the route for further research pointed out by Levy and Murnane (1992), opening up an important black box albeit it at the level of industry and not of the firm. ${ }^{98}$ In principle, though not always in practice, it also advances on the traditional SBTC approach by distinguishing between properties of the occupation and of the worker. Routine tasks were first stressed by Autor, Levy and Murnane (2003), polarization by Maarten Goos and Alan Manning $(2003,2007)$. The approach aims to provide an answer to the problem posed to the

\footnotetext{
${ }^{96}$ Lemieux (2006a, b) finds a concentration of the increase in the 1980s together with a concentration of within-group inequality change among male and female college graduates and females with some college, implying an increasing concentration of wage inequality at the very top of the wage distribution. In addition, Lemieux (2006c) finds a role for changes in the composition of the labour force after the 1980 s.

${ }^{97}$ They agree to compositional effects (Lemieux, 2006a) but for the lower half of the distribution only.

${ }^{98}$ Dunne et al. (2004) find most of the action between and not within establishments in US manufacturing.
} 
SBTC thesis by the strong slowdown in wage inequality growth after the 1980s. It implies a significant shift in the SBTC thesis and the underlying empirics. Modern technology is complementary no longer to higher levels of skills and education but to non-routine types of work. While before workplace computerization was indiscriminately interpreted as skill biased and furthering the demand for higher skills it is now taken to substitute for routine tasks which are defined as cognitive and manual activities that can be accomplished by following explicit rules. Therewith it reduces the demand for workers predominantly performing such activities, implying a more polarized effect on educational levels. Autor, Levy and Murnane (2003) focus on American employees and the period 1960-1998 and combine CPS data with Dictionary of Occupational Titles (DOT) classifications. They analyze the shift in tasks that has resulted from both compositional changes across occupations and changes in task composition within occupations, and find strongly diverging trends: negative for routine cognitive tasks from the 1970s and routine manual tasks from the 1980s and strongly positive for non-routine cognitive tasks while non-routine manual tasks decline steadily and strongly over the entire period. ${ }^{99}$ Note that they focus on employment effects and do not link the results to wage inequality, ${ }^{100}$ though the implication is clear and to some extent spelled out in Autor, Katz and Kearney (2006): low-wage and high-wage employment both expand while jobs with intermediate pay contract. Notably, employment trends do not seem to differ between the 1980s and 1990s, though, naturally, the gaps between increasing and decreasing types of tasks become much wider.

Goos and Manning scrutinize the UK data for similar developments between the mid-1970s and the late the 1990s, using a variety of datasets, samples and methodological approaches. They find a clear polarization across the distribution of occupations and, linking to wages, also across the wage distribution. They check various tenets of the SBTC thesis. They discuss first whether labour supply may have contributed to the polarization, because of the rapid growth in female workers and bettereducated workers but they find these changes unable to explain the polarization pattern. As to educational attainment, they find an increase in almost all occupations. This may be due to either rising requirements of the jobs or overeducation of the occupants. The data are insufficient to decide between the two hypotheses though the authors seem inclined to opt for the second one. On the demand side they touch upon other factors than technology that may have contributed: trade and especially the structure of product demand - though these are not necessarily fully independent from technology -, but find no explanation for polarization either. From a counterfactual exercise of the wage distribution over the 1975-1999 period restricted to changes in the occupational distribution only they conclude that polarization can explain large fractions of the rise in wage inequality (51\% lower half, $79 \%$ upper half). They underline the important implication that the contribution of within-job inequality is minor. This contrasts sharply with established explanations in terms of education and age where most of the action is within groups, and they point out that the between/within conclusion is sensitive to the choice of controls included in the earnings function. They leave open the explanation of inequality change in the lower half of the distribution which may be due to imperfect competition, including institutional changes such as declines in unionization or the minimum wage. Maarten Goos, Alan Manning and Anna Salomons (2009) show a polarization of employment by occupations for 16 European countries between 1993 and 2006; Goos, Manning and Salomons (2010, 2011, forthcoming) extend the analysis to include relative wages and capture effects also of product demand, induced by a lowering of relative prices in industries with routine tasks, and institutions. They find that relative occupational wage movements in Europe are not strongly correlated with technology and offshoring, which may be due to wage-setting institutions, and therefore consider relative wages as being exogenous. They conclude that the thesis of routine jobs is the most important explanatory factor for increasing polarization, whilst product demand shifts across industries mitigate it.

Christian Dustmann, Johannes Ludsteck and Uta Schönberg (2009) find increasing wage inequality for Germany in the upper half of the distribution over the 1980 s and 1990 s. ${ }^{101}$ This is attributed partly to

\footnotetext{
99 The authors consider the latter tasks as orthogonal to computerization and therefore not impinging on their results.

100 Interestingly, Goos and Manning (2007) fill that gap, showing - for 1983 only, the first possible year - that routine jobs are concentrated in the middle of the US wage distribution.

101 Spitz-Oener 2006 looks at the employment side of occupational polarization in Germany over the 1980s and 1990s.
} 
composition changes and largely to technological change, as occupations at the top grow faster. For the lower half they find increasing inequality only in the 1990s, not before. For this they suggest possible episodic explanations such as a decline in unionization and an inflow into the country of low-skilled labour after the demise of communist regime; the latter lends a role to the relative supply of skills. Following Autor, Katz and Kearney (2008) they conclude that the naive or canonical SBTC hypothesis cannot explain these trends but they find support for the 'nuanced' tasks-focused hypothesis as they note that occupations in the middle of the distribution decline compared to those at the bottom. In summary, they believe that the German results add unifying evidence to the pattern of polarizing effects of technological change already found for the USA and the UK.

We conclude our discussion of this stream of the literature with its current culminating point, the overview and further development of the task-based approach to SBTC by Acemoglu and Autor (2011) for the latest Handbook of Labor Economics (Ashenfelter and Card, 2011b). ${ }^{102}$ Note, however, that Mishel et al. (2013) provide various arguments why the evidence for the job polarization these is weak. While the canonical model builds on the unity of skills, tasks and job (better educated/talented workers obtain skilled jobs where they perform more complex tasks), the task-based approach considers a job as a collection of tasks, which can be executed by workers of different abilities, though at different level of productivity, and even by machinery. The empirical classification of tasks is still in its infancy; they are classified according to three attributes: routine, abstract, manual. 'Offshorability', meaning that the performance of certain tasks is internationally footloose, is added as another important job dimension, which can overlap with each of the three types of tasks. ${ }^{103}$ This theoretical approach improves upon the canonical model by accounting for job polarization, real wage decline for some groups of workers (but not in a monotonic relationship with skill ranks) and offshoring as an alternative explanation of reductions in jobs to technical change.

Acemoglu and Autor's model considers a continuum of tasks (unit of work activity that produces output, similarly to occupations) and different levels of skills (capability to perform various tasks); given existing supply of skills in the labour market, profit maximising firms allocate skills to tasks, given existing prices. Capital and/or offshoring may replace workers in performing tasks. The key assumption is the existence of comparative advantage of skills in executing tasks: more skilled workers are more productive in executing more complex tasks when compared to less skilled workers. This structure creates a sort of hierarchical sorting associated to comparative advantage.

Wage flexibility ensures full employment of all workers. Given perfect substitutability among workers in task assignment, wages dynamics depend on the relative supply of skills (as in the canonical model) and on task assignment rules, which then allow for a potential competition in task execution posed by technological progress and/or offshorability. With their model they make a sharp prediction: "if the relative market price of the tasks in which a skill group holds comparative advantage declines (bolding the schedule of comparative advantage constant), the relative wage of that skill group should also decline - even if the group reallocates its labour to a different set of tasks (i.e., due to the change in its comparative advantage)." (pg. 1152). The impact on the overall wage inequality is hard to predict, since the relative wages (high to medium skill and medium to low skill, when only three skill levels are considered) can move in opposite directions.

Acemoglu and Autor do not incorporate labour market institutions in their framework, which as they observe "depends crucially on competitive labour markets" (pg. 1159) and can be thwarted by labour-market

\footnotetext{
102 Autor (2013) adds a further overview of the literature stressing the need to develop a precise terminology and consistent measurement. He honorably concludes that "The economics profession is very far from a full understanding of the interactions among rising worker skills, advancing technology, improvements in offshoring and trade opportunities, and shifting consumer demands in determining the division of labour, the growth of aggregate productivity, and the level and inequality of earnings within and between skill groups. The 'task. approach' to labour markets does not come close to offering a solution to this vast intellectual puzzle."(pg. 27). Surprisingly, he also sounds an optimistic note about the future of middle-skill jobs. Autor and Dorn (2013) make a further addition venturing consumer preferences as a second force next to technological change that can help explain polarization through the growth of low-skill services in the USA. However, one cannot be sure about the general validity of this approach as consumer preferences may differ significantly across countries.

103 The concept of offshorability of jobs and its analysis in relation to wage inequality was developed during the 2000s by Levy and Murnane (2005), harking back to Blinder (2007), Lemieux (2008) and Blinder and Krueger (2009). Evidently, offshorability itself is conditional on both technological change and institutional preconditions.
} 
imperfections of search and information and institutions such as collective bargaining by unions. The impact of certain labour-market institutions may be enhanced by the way these affect the assignment of tasks to labour or capital as, for example, they may restrict the substitution of machines for labour for certain tasks, or conversely they may change the return to unionization, thus feeding back onto union density. The authors see this as an area for further research.

\subsection{Recent theories based on labour-market institutions}

The other main current in the literature does take the existence and effects of labour-market institutions into account. Also here interesting contributions have been made over the 2000s. At the start of the new century Olivier Blanchard and Justin Wolfers (2000) launched their hypothesis that the internationally differential effects of institutions may be found particularly in countries' responses to shocks. This view can offer a solution to the problem that on the one hand shocks alone cannot explain country differences while on the other hand institutions on their own cannot explain long-run country performances. Their focus is the macroeconomy and unemployment, not wage inequality. Blau and Kahn (2002) connect to the latter in much of their book, and later extend this further by accounting for demographic shocks (with Giuseppe Bertola, 2007). However, their strong focus on the international comparison of institutions may be the reason that they seem to overlook the shifting trend in the evolution of American wage inequality after the 1980s. The issue of this shift has been taken up by Lemieux (2008), for the US. He objects to the consensus view on inequality growth that has taken root in the early 1990s which views this growth as secular and all-pervading. As we have seen his (2010) contribution extensively revisits the American data on the evolution of wage inequality and pays particular attention to the very top of the wage distribution, improving on the traditional adjustment for top-coding. From this he concludes that in the 1970s inequality change was not all-pervading, while it was in the 1980s (though it also already showed more convexity at the top than at the bottom), and that since the 1990s inequality growth has been concentrated at the top of the distribution. Growth in residual ('within') wage inequality is general in the 1980s while later it is largely confined to the collegeeducated category. In particular, relative wages continue to grow for post graduates and their annual returns to education compared to high-school returns double between the mid-1970s and the mid2000s.

Lemieux (2008) also questions the consensus explanation of SBTC on the basis of this, but also because it leaves no room for a role of institutions in spite of the research that has shown the effects of unionization and wage setting. He advocates an explanation that can account for both the above findings and the international differences and explores the possible contributions of institutions as well as of supply and demand. ${ }^{104} \mathrm{He}$ finds that de-unionization can explain one third of the expanding inequality in each of the two halves of the distribution, and is also consistent with the divergence of English-speaking countries, where top incomes grew much more, from other countries. In addition to this the decline in the minimum wage has augmented lower-half inequality in the $1980 \mathrm{~s} .{ }^{105}$ On the side of supply and demand he thinks that more empirical research is needed before the tasks-based development of the SBTC thesis may be accepted as an explanation. That research should account for the fact that, contrary to what one would expect, the relative wages of occupations at the core of the IT revolution are suffering, and it should also answer the question why the process should not have occurred already during the 1980s. In addition, it should account for the growth of within-inequality at the top. For the latter he suggests modelling heterogeneous returns to education, which have as a key implication that both the level and the within-dispersion of pay of the better educated can rise relative to the less educated at the same time. ${ }^{106}$

\footnotetext{
${ }^{104}$ His main objection to SBTC is that technology is widely available across countries, while inequality growth is recorded only in the Anglo-Saxon world. However similar impacts are now also recorded in developing countries (Behar 2013).

105 Lemieux, Macleod and Parent (2009) add, as an additional institution, performance pay at the top - bonuses, stock options, etc. - and show that this can account for a large share of inequality growth above the $80^{\text {th }}$ percentile of the wage distribution.

106 Slonimczyk (2013) links overeducation to the differential growth of inequality in the two halves of the distribution.
} 


\section{Top incomes}

Interestingly, Lemieux's conclusion about upper-tail growth is consistent with the findings in the topincomes literature (Atkinson et al. 2011, Alvaredo et al. 2013, Atkinson and Piketty 2007 and 2010, especially the summary Chapter 13; Piketty and Saez 2003 and 2006). Often a strong rise in labour incomes at the top is found, particularly in the USA but not only there. ${ }^{107}$ This literature is suggestive of the role of yet another institution: income taxation, not as the traditional tax wedge but as marginal taxation at the top. ${ }^{108}$ "Higher top marginal tax rates can reduce top reported earnings through three main channels. First, top earners may work less and hence earn less - the classical supply side channel. Second, top earners may substitute taxable cash compensation with other forms of compensation such as non-taxable fringe benefits, deferred stock-option or pension compensation - the tax-shifting channel. Third, because the marginal productivity of top earners, such as top executives, is not perfectly observed, top earners might be able to increase their pay by exerting effort to influence corporate boards. High top tax rates might discourage such efforts aimed at extracting higher compensation." (Atkinson et al., 2011). Thus the rise in top incomes and pay may have been encouraged by the lowering of top marginal tax rates. However causation may also run in the opposite way, since the rise of capital incomes in recent decades may have produced pressure for tax reductions. In a recent series of papers, Piketty and co-authors have proposed formal models where the relationship between taxation and earnings has been carefully scrutinized. Most of the argument is a supply-side story, in the presence of imperfections: a reduction in the degree of progressivity would stimulate more effort and bargaining of CEOs and high rank cadres with stakeholders, thus raising earnings inequality. Thomas Piketty, Emmanuel Saez and Stefanie Stantcheva (2011) show a strong negative correlation between the Top$1 \%$ share and the top tax rate for a set of 18 OECD countries since 1960; the correlation also holds for CEO pay after controlling for firm characteristics and performance. The element of luck in CEO pay seems to be more important when tax rates are lower. It may point to more aggressive pay bargaining in a situation of lower tax rates. The high top tax rates of the 1960s were then part of the institutional set up putting a brake on top compensation through bargaining or rent extraction effects. In their view the SBTC explanation seems to be at odds with international differences in top pay shares as well as their correlation to tax rates.

\section{Minimum wage $e^{109}$}

New contributions to the literature of inequality and institutions are also found for various other individual labour-market institutions. First and foremost, we consider the literature on the effects of the minimum wage - an old debate by now (as old as the Department of Labor (viz. 1913) according to some $)^{110}$ that nevertheless continues to attract passionate contributions. The combination of wage and employment effects taken together determines the effects on annual earnings and, ultimately, incomes. Especially the impacts of a minimum wage on employment remain a bone of contention - "the canonical issue in wider debates about the pros and cons of regulating labour markets" in the words of Manning (2011, pg.1026). A complication is that the employment effects likely relate to the level of the minimum wage and also differ between worker categories (e.g., Abowd et al. 1999 and also Philippon 2001).

Neumark and Wascher (2008) hold a very critical attitude with respect to minimum wages. Exploiting cross-state and temporal variations in US, they conclude that minimum wages are ineffective in raising

\footnotetext{
${ }^{107}$ For example for the Netherlands (in spite of stability of the top income share as a whole): see Salverda and Atkinson (2007) and Salverda (2013).

108 DiPrete (2007) highlights the increase in external recruitment of CEO's and the concomitant growth of related institutions (governance and CEO pay benchmarking).

109 There is also an emerging literature on developing-country case studies, which confirm the inequality-reducing impact of minimum wage, both in the formal and informal sectors of the economy (e.g., Lemos 2009, Gindling and Terrel 2009).

110 Note that the UK minimum wage, introduced very recently in comparison with the USA (1999 vs 1938) has been a great source of new evidence thanks to the careful role of the Low Pay Commission - see Butcher (2012).
} 
low wages and reduce employment opportunities for their earners. ${ }^{111}$ However, Peter Dolton and Chiara Rosazza-Bondibene (2011) analyse employment effects for 33 OECD countries over 1976-2008 and find that existing evidence of negative effects is not robust. Arindrajit Dube, William Lester and Michael Reich (2010) generalise Card and Krueger's comparison of minimum-wage policy differences across US state borders and find no employment effects over 1990-2006, while David Neumark, Ian Salas and William Wascher (2013) dispute their method and results. Sylvia Allegretto, Arindrajit Dube and Michael Reich (2011) find no employment effects (including the hours dimension) distinguishable from zero over 1990-2009. Fabián Slonimczyk and Peter Skott (2012) use US state variation to confirm their model predictions of a negative effect of minimum wages on the skill premium, due to increasing overeducation of college-educated workers following an increase in mismatch. The overall effect is that a minimum wage would lead to a rise in both total and low-skill employment, accompanied by a fall in earnings inequality. Laura Giuliano (2013) studies personnel data of a large US retail firm and finds no aggregate employment effect but composition effects that run contrary to standard theory. Interestingly, Dube, Lester and Reich (2012) focus attention on effects on employment flows. In the view of Richard Sutch (2010) the disemployment effects of pricing low-skill jobs out of the market may create incentives to invest more in human capital.

Most of the recent discussion revolves around whether there are spillover effects on wages higher than the minimum. A higher statutory minimum wage in itself compresses the wage distribution as it prohibits paying lower wages. However, the higher minimum rise may send ripples up the wage distribution - in the most extreme case all wages could be increased to the same extent and the dispersion of wages would remain unchanged. The minimum wage debate of the 2000 s has generated new contributions particularly on this spill-over or knock-on issue. Wages higher up may be raised for several reasons (Stewart, 2012, 618): the higher price for low-skilled labour incites substitution demand for higher-skilled workers, realignment of the marginal product of minimum wage workers affects the marginal product of other workers, firms maintain within-firm pay differentials for motivation, and reservation wages increase more broadly in certain sectors.

During the 1990s spill-over effects were detected in various contributions. Card and Krueger (1995a, 295) conclude to no effect at or above the $25^{\text {th }}$ percentile of the wage distribution, which is well above the relative position of the minimum wage. David Lee (1999) endorses an approach that compares to an estimated 'latent' wage distribution (in absence of the minimum wage). He finds effects beyond the P50:P10 ratio on other percentile differentials across the entire distribution. At the end of the 1990s the consensus view agreed to spill-over effects though not extending high up the distribution (Brown, 1999, pg.2149). ${ }^{112}$ Over the 2000s views on this have changed. Neumark and Wascher (2008, Section 4.3.2) discuss the previous literature and observe that the percentile approach as used by Lee may conflate spill-over effects with disemployment effects of the minimum wage: as some of the least-paid lose their jobs wage levels may increase at all percentiles of the distribution. David Neumark, Mark Schweitzer and William Wascher (2004) do not link to the wage distribution but look instead at actual impacts on workers with wages up to 8 times above the minimum wage, using US states with no rise in their minimum wages as controls. They find a wage elasticity with respect to the minimum wage of 0.25 at 1.5 times the minimum wage and much smaller effects above that level. David Autor, Alan Manning and Christopher Smith (2010) are puzzled by Lee's effects on the upper half of the distribution and attribute these to an omission of variables and the insertion of the median wage on both sides of the

\footnotetext{
111 "Based on the extensive research we have done, and our reading of the research done by others, we arrive at the following four main conclusions regarding the outcomes that are central to policy debate about minimum wages. First, minimum wages reduce employment opportunities for lessskilled workers, especially those who are most directly affected by the minimum wage. Second, although minimum wages compress the wage distribution, because of employment and hours declines among those whose wages are most affected by minimum wage increases, a higher minimum wage tends to reduce rather than to increase the earnings of the lowest-skilled individuals. Third, minimum wages do not, on net, reduce poverty or otherwise belp low-income families, but primarily redistribute income among low-income families and may increase poverty. Fourth, minimum wages appear to have adverse longer-run effects on wages and earnings, in part because they binder the acquisition of buman capital. The latter two sets of conclusions, relating to the effects of minimum wages on the income distribution and on skills, come largely from U.S. evidence; correspondingly, our conclusions apply most strongly to the evaluation of minimum wage policies in the United States." (Neumark and Wascher 2008, pg.6).

${ }^{112}$ Lee (1999) is not covered in Brown's (1999) overview.
} 
equation (division bias). They stick to Lee's basic approach but propose econometric corrections and demonstrate the effects using a longer panel of US states with more variation in state minimum wages. They find substantial widening effects on the lower tail (P50:P10) of the decline in the real minimum wage over 1979-1988, but these effects remain well below those found earlier in the literature; they find only small effects for 1988-2009. Then they are puzzled by the large and increasing effects even at the $10^{\text {th }}$ percentile in spite of the fact that nowadays the minimum wage is received by less than $10 \%$ of workers. They confront those effects with the possibility of mismeasurement and misreporting of lower wages in the data and conclude from a detailed analysis that it cannot be ruled out that all of the spillover found is actually the result of such data problems.

Mark Stewart (2012) adopts the direct estimations of Neumark et al. (2004) over a range of fractions of the minimum wage extending up to 6 times the minimum wage using differences-in-differences for comparisons between these factions. In addition, he exploits comparisons between minimum wage upratings that have differed in size (including no change period before the introduction of the minimum wage in 1999) while accounting for differences in general wage growth. Using British data he concludes to no spill-over effects. As the level of the minimum wage is steadily below the $10^{\text {th }}$ percentile he draws the logical inference that the changes in the minimum wage have not affected lower-half wage inequality as measured by P50:P10. That seems fair enough but it also puts on the table the strength of this inequality measure as evidently the minimum wage may significantly affect the within-distribution of the bottom decile. The top-to-bottom ration S10:S1 may be better suited to capture such effects. Tim Butcher, Richard Dickens and Alan Manning (2012) revisit the effects on wage inequality and spill-overs for the UK and do find spill-over effects up to the first quartile of the distribution. In their view, decades of discussing the employment effects of the minimum wage - with very little to none as the consensus outcome - have been focusing on second-order effect and instead they advocate developing a theoretical framework for thinking about its first-order effects on wage inequality, which, naturally, should be able to allow the possible absence of employment effects. They develop a non-competitive model with wage-posting instead of bargaining ${ }^{113}$ with imperfectly elastic labour supply to the individual firm. The authors elaborate on their model to consider the spill-over effects to wage levels above the minimum wage. They derive those from a comparison between the actual wage distribution at and above the minimum wage and a counterfactual latent wage distribution derived with the help of the distribution preceding the introduction of the minimum wage in 1999. They find higher levels for the former compared to the latter up to $40 \%$ above the minimum wage, which corresponds with the $25^{\text {th }}$ percentile of the aggregate wage distribution.

Finally, Garnero et al. (2013) show that statutory minimum wages (or equivalent systems represented by sectoral minimum rates combined with high coverage of collective bargaining - see also Boeri (2012) are very effective in reducing earnings inequality. They combine harmonized micro-data from household surveys (EUSILC), data on national statutory minimum wages and coverage rates, and handcollected information on minimum rates from more than 1,100 sectoral-level agreements across 18 European countries over several years (2007-2009 - see also Kampelmann et al. 2013). Alternative specifications confirm that institutional variants of setting a wage floor reduce both between and within-sectors wage inequalities.

\section{Union presence}

Card et al. (2004) study the relationship between wage inequality and unionization in US, Canada and UK over the period 1980-2005, showing that within narrowly defined skill groups, wage inequality is always lower for union workers than non-union workers. For male workers, union coverage tends to be concentrated at the middle of the skill distribution, and union wages tend to be "flattened" relative to non-union wages. As a result, unions have an equalizing effect on the dispersion of male wages across skill groups. For female workers union coverage is concentrated near the top of the skill distribution,

\footnotetext{
113 Wage bargaining cannot explain the frequent uniform payment of the same low wage to workers with rather different characteristics. Hall and Krueger (2010, pg.25) conclude that their findings from a special survey of wage posting and bargaining practices in the US labour market "...is consistent with the view that a wage constrained by the minimum wage is inherently posted."
} 
and there is no tendency for unions to flatten skill differentials across groups. The effect of deunionization on US wage inequality is stronger at the top end of the distribution than at the bottom, as shown by Lemieux (2008) when updating the DiNardo et al. (1996) decomposition. In addition, the increase of performance pay schemes may have enhanced the within-group wage inequality at the top end of US distribution. ${ }^{114}$

The decline in workers' bargaining power in the Anglo-Saxon world is recorded by several authors (see for example Levy and Temin 2007), but we have not found any convincing decomposition of the relative contribution of each specific institutions. However, when taking the dynamics of the wage share in the domestic product as an overall indicator of workers' bargaining power, one would recognise a clear declining trend in most countries over the past decade, though some reversal can be recognized during the crisis period (ILO 2008 and 2010). ${ }^{115}$

A parallel decline in workers' bargaining power can underlie the decentralization of wage bargaining. Following recent changes in industrial relations in Denmark, Christian Dahl et al. (2011) show the existence of a wage premium associated with firm-level bargaining relative to sector-level bargaining, and a higher return to skills under more decentralized wage-setting systems. ${ }^{116}$

\section{Unemployment benefit}

Even if unemployment benefits and employment protection are negatively correlated in the data (Bertola and Boeri, 2005), in principle they do respond to the same problem of reducing the intertemporal variability of workers' earnings (Blanchard and Tirole, 2008). ${ }^{117}$ This may explain why research has paid less attention to the contribution of unemployment schemes to inequality reduction. Lorenzo Corsini (2008) studies the dynamics of the college premium in ten European countries over the last decade of previous century. He finds a positive impact of the generosity of unemployment benefit (but a negative correlation with duration), which is interpreted as the outcome of wage bargaining that takes into account the outside option. ${ }^{118}$ If we shift to individual data analysis, the results of Paul Bingley et al. (2013) on Danish data show that access to unemployment insurance is associated with lower wage-growth heterogeneity over the life cycle and greater wage instability, changing the nature of wage inequality from permanent to transitory. Given data limitations, the authors are unable to control for moral hazard behaviour of unemployed, who may be induced to lengthening their permanence in unemployment, thus increasing cross-sectional inequality. ${ }^{119}$

\section{Employment protection legislation}

\footnotetext{
${ }^{114}$ However existing comparative evidence on differences in executive compensation between US and Europe suggests that this labour market is fully globalised, and pattern of remuneration are quite similar (except in the banking sector). See Conyon et al. 2011

115 "The slow growth in wages was accompanied by a decline in the share of GDP distributed to wages compared with profits. We estimate that every additional 1 per cent of annual growth of GDP has been associated on average with a 0.05 per cent decrease in the wage share. We also found that the wage share has declined faster in countries with a higher openness to international trade, possibly because openness places a lid on wage demands based on a fear of losing jobs to imports. Inequality among workers has also increased. Overall, more than two-thirds of the countries included in our sample experienced increases in wage inequality. This was both because top wages took off in some countries and because bottom wages fell relative to median wages in many other countries." (ILO 2009, pg.60). See also Karabarbounis and Neiman 2013, who attribute the decline in wage share to the decline in the relative price of capital inputs.

116 Kenworthy (2001) discusses existing measures of wage-setting institutions.

117 Chetty (2008) derives the optimal replacement rate for unemployment benefit schemes which depends on the reducedform liquidity and moral hazard elasticities.

118 Vroman (2007) discusses the correct measure of (average) unemployment compensation from aggregate public expenditure on subsidies, to be contrasted with standard OECD replacement rate and duration series, which are commonly used, despite their being completely hypothetical (since they are derived from microsimulation models) and do not correspond to actual payments to entitled unemployed workers.

119 Using cyclical and across-US states variation, Farber and Valletta (2013) show that extending the duration of unemployment benefits (from a Federal requirement of a minimum of 26 weeks to 99 weeks at the cyclical peak of late 2009) lengthens unemployment spells, via a reduction in exits from the labour force (and not in job finding due to reduced search effort).
} 
Recent cross-country evidence has been summarized in the following way by World Bank (2012, 262): "Based on this wave of new research, the overall impact of EPL and minimum wages is smaller than the intensity of the debate would suggest.". However John Martin and Stefano Scarpetta (2011) express a different view, arguing that EPL reduces workers' reallocation and prevents efficiency gains for highly productive workers, while avoiding job losses and/or real wage reductions for unskilled workers. ${ }^{120}$ In their review they list a series of papers based on changes in dismissal regulation, which find mixed evidence of EPL impact on labour productivity (see among others Boeri and Jimeno 2005, Kugler and Pica 2008, Schivardi and Torrini 2008, Bassanini et al. 2009). Productivity dynamics may translate one to one into wage dynamics in a competitive environment; in non-competitive models firing restrictions raise the bargaining power, creating artificial divisions among workers when groups of firms are exempted (see Leonardi and Pica 2013). Similarly EPL exemptions for firms may create artificial wage differences among workers, due to their differential cost, thus enhancing wage inequalities: for example Karin Van der Wiel (2010) provides evidence referring to a policy reform of terms of notice in the Netherlands. There is a further connection between EPL and wage inequality that can be found in comparative analysis: Alex Bryson et al. (2012) show that higher labour (and product) market regulation is associated with lower use of incentive pay (ranging from $10 \%$ of covered workers in Portugal to $50 \%$ of the workforce in US). Since incentive-pay schemes increase within-group earnings inequality (Lemieux et al. 2009), this induces a negative correlation at the aggregate level between earnings inequality and EPL indexes.

\section{Labour market policies}

Kluve (2010) provides an extensive meta-analysis based on a dataset that comprises 137 active labour market program evaluations from 19 countries. Four main categories of ALMP are considered across European countries: (i) training programs, (ii) private sector incentive schemes (such as wage subsidies to private firms and start-up grants) (iii) direct public employment programs, and (iv) "services and sanctions", a category comprising all measures aimed at increasing job search efficiency, such as counselling and monitoring, job search assistance, and corresponding sanctions in case of noncompliance. His main findings is that traditional training programs have a modest significant positive impact on post-program employment rates, while both private-sector incentive programs and services and sanctions show a significantly better performance. Evaluations of direct employment programs on the other hand are around 25 percentage points less likely to estimate a significant positive impact on post-program employment outcomes. While effectiveness is here defined in terms of employment impact, they can be easily mapped one-to-one to wage inequality whenever the unemployed are taken into the picture.

\section{Stepwise institutional change}

A new and different line of argument regarding institutions is nicely summarized by Tito Boeri (2011). After reviewing existing institutional differences among European countries and stressing their persistence over time, he proposes a taxonomy of institutional changes (reforms), in terms of orientation and phasing-in. The orientation concerns the question whether they reduce (e.g., by making employment protection less strict and/or unemployment benefits less generous or by expanding the scope of activation programs) or increase the wedge (e.g., by increasing labour-supply-reducing taxes on relatively low-paid jobs) introduced by labour market institutions between supply and demand. Boeri accordingly classifies a reform as either decreasing or increasing the (institutional) wedge. The second characteristic relates to the phasing-in of reforms: this can be either complete or partial. In the former case, the change in the regulation eventually involves everybody. In the latter case, even at the steady state, the reform is confined to a subset of the population. The timing is also important. Even a

\footnotetext{
120 Similar results are found in Messina and Vallanti (2007). However result significantly differ when using aggregate or microdata. For example using a German employer-employee matched data-set Bauer et al. (2007) do not find any evidence of variable enforcement of dismissal protection legislation on the employment dynamics in small establishments. Considering that labour churning is typically associated to increased earnings variability, their result would imply lack of correlation between employment protection and wage inequality. Analogous lack of significant impact of firing restrictions is found by in Martins (2009).
} 
complete phasing-in may involve a very long transitional period, so that the steady state institutional configuration is attained beyond the planning horizon of management's potentially involved by the reform. (Boeri 2011, 1184) A two-tier reform is then defined as the case involving either a partial phasing-in or when its complete phasing-in requires more than 30 years, the average length of the working life in many countries. According to data collected over the period 1980-2007 for the European Union, the two-tier pattern is prevailing in most of the institutional dimensions. This has obvious implications in terms of earnings inequality, especially between insiders and new entrants (typically women and youngsters). With the help of a search model à la Pissarides-Mortensen, Boeri shows that institutions affect the threshold below which it is no longer convenient for either the employer or the employee to continue the work relationship. Even if the underlying inequality pattern depends on idiosyncratic shocks hitting individual productivity, the boundaries of the distribution of realized wages are institutionally determined, due to variation in the equilibrium unemployment. According to the model an increase in unemployment benefits raises the reservation productivity at which matches are dissolved as the outside option of workers has improved: in equilibrium there is a higher probability of job loss, a lower job finding rate, higher unemployment and average wage. ${ }^{121}$ Conversely an increase in firing taxes has the opposite effect of maintaining alive jobs with a lower match productivity. This reduces the gross job destruction rate and positively affects wages. An increase in employment conditional incentives (modelled as an employment subsidy) makes the labour market tighter, increases the duration of jobs at the expenses of a decline in entry wages. Finally, an increase in the activation scheme reducing recruitment costs features higher job finding and job loss rates, whilst the effects on unemployment and the average wage are ambiguous. When liberalising (wedge reducing) reforms are applied to only a fraction of workers (temporarily creating a dual labour market), then earnings inequality expands: insiders enjoy a surplus over outsiders at the same productivity levels, which is increasing in the difference in replacement rate offered to unemployed (coming from long-tenured jobs with respect to those coming from short-tenured jobs), in the employment conditional incentive and in firing taxes, which matter more when workers have more bargaining power.

Returning to the more general, internationally comparative literature developed by Blau and Kahn (2002) and others, we find the contribution of Winfried Koeniger, Marco Leonardi and Luca Nunziata (2007) who look beyond cross-sectional differences at the comparative evolution of wage inequality over time, and extend to more OECD countries over a longer period, focused on overall wage inequality of males taken from the OECD database. They treat the various institutions (union density, union coordination/centralization, the minimum wage, employment protection, unemployment benefit generosity and duration, and the tax wedge) simultaneously and also model some interactions. On the demand side they control for the aggregate economy (unemployment rate), the relative supply of skills, international trade (import intensity), and technology ( $R \& D$ intensity). They add some counterfactual simulations, including one that attributes US institutions to the other countries. They find compressing effects on the wage distribution of most institutions which explain at least as much as trade and technology do on the demand side. Applying American regulations would increase wage inequality in Continental Europe by $50 \%$ to $80 \%$. The authors observe, however, that endogenizing the institutions, that means accounting for their dependence on supply and demand, will likely reduce the effects somewhat.

Finally, as we have observed above the context of household (joint) labour supply potentially augments the number of institutions that need to be addressed, adding parental leave, maternity leave, part-time work regulations, and any other institution affecting the flexible use of working hours. Analyses of this (e.g. Dupuy and Fernández-Kranz, 2011; Thévenon and Solaz, 2013) are few and they are focused on employment chances and/or pay penalties of gender/motherhood/family, not on the wage dispersion.

\footnotetext{
121 For simplicity Boeri assumes that any unemployed person is entitled to the benefit, while actually this depends on the length of the contribution period and/or on belonging to specific categories (married/unmarried, with/without children, sector of employment, age).
} 


\subsection{Summing up}

Over time the literature seems to have gone in two different directions that tend to grow further apart - not in the sense of interactions (one retorting to the other) but in the sense of integrating the approaches into one framework. Freeman (2007, pg.24) signalled the risk of creating the social science equivalence of 'epicycles' - aimed at preserving Ptolemaic views on the earth as the centre of the universe - for the institutional approach. However, the same danger may be looming for the supplyand-demand approach which has been adding tasks, offshoring, and consumer preferences, in an attempt to dispel doubts about the relative demand of skills as a tautology. The institutional approach faces an abundance of institutions for which it lacks a clear criterion of choice, the supply-and-demand approach by contrast is challenged by the need for finding better empirical measures of technological change. However, a fortunate effect of the interactions just mentioned has been the great interest that is now taken in the very data on wage inequality. The take on the data's properties, advantages, and disadvantages has greatly improved over time. Consideration of the data at later points in time alter the stylized facts and also show that consensus explanations may be temporary and can break down when data for later periods become available and shine a different light on preceding periods. In spite of this, the prime aim of future work on both sides should be to integrate the other side into the framework. Pursuing that may be more a problem of empirical method for the institutional side while on the demand-and-supply side the problem may be more on the theoretical side as long as institutions continue to be viewed as alien bodies. For both sides there is a perspective of work to do at the firm level. Matched employer-employee data (Lane, 2009; Cardoso, 2010) can help enlighten the role of both institutions and labour supply and demand (see, e.g., Matano and Nattichioni, 2011, and Andersson et al., 2006, for some interesting attempts). In addition, though much attention has been paid to data quality, a better grasp of the customary use of inequality measures seems desirable. 


\section{Labour market institutions and wage inequality: An empirical assessment}

In this section we present an accounting framework and an empirical model aiming to assess the contribution of labour market institutions to shaping earnings inequality. Here we face the problem of identifying who are benefiting from (or disadvantaged by) the action of a specific labour-market institution. Before we have mentioned the stepwise changes introduced by many institutional reforms, which seem to create two-tier systems (Boeri 2011), implying that the effect of institutions on earnings inequality may significantly differ across age cohorts. To deal with this, the ideal dataset would be longitudinal, in order to be able to compute inequality measures over the lifetime of earnings, conditional of attrition in the sample creation. In addition, measuring institutions is not an easy task. Even if we restrict ourselves to the notion of institutions as rules inducing deviations from competitive market equilibria in economic transactions, these rules are still difficult to measure, because they often treat individuals differently or affect their behaviour differently (think for example of taxes and benefits, which are almost always conditional to family composition - Boeri and Van Ours 2008). Rules and norms change rather smoothly overtime, in the definition of used by Boeri (2011) reforms are rarely radical, and therefore it can take a significant amount of time before a minimum detectable effect may be observable. Despite these limitations, a significant literature has studied the correlation between institutional measures and earnings inequality measures (Alderson and Nielsen 2002, Rueda and Pontusson 2000, Wallerstein 1999 - more recently Scheve and Stasavage 2009, and Kierzenkowski and Koske 2012). It exploits in turn cross-country and/or over-time variations of the institutions to arrive at estimates of the correlation with earnings inequality. In many instances, the dependent variable (the inequality measures) are derived from secondary sources, and do not always allow for measures that are fully comparable across countries (Atkinson and Brandolini 2001). Some studies have computed their own inequality measures, relying on existing projects of data harmonization across countries (Atkinson 2007, Checchi and Garcia Peñalosa 2008). We have followed here the same line of research, by computing appropriate indices of earnings inequality from SILC and PSID datasets, described in Section

3. Given the absence of natural experiments to obtain estimates of the causal impact of specific norms onto the relevant inequality measures, we will obtain at best correlations between institutional measures and inequalities. In Section sample of the workforce population is concentrated in households where two members are employed (either as dependent or self-employed). As long as their earnings are not perfectly correlated, cohabitation (and expected income sharing) works as a shock absorber. However, one fourth of the population does not possess this insurance, since they are single-person households who by definition lack such shielding from the unemployment risk.

5.1 we consider a simple accounting scheme in order to discuss the correlation of market equilibria, institutions and between-group inequality, while in Section

5.2 we provide a decomposition of the within-group earnings inequality and correlate these measures with proxies for institutions. In Section

5.3 we correlate inequality measured across age cohorts with past institutional measures, finding evidence of inequality reducing impact of unions and minimum wages. Section 


\section{4 discusses the results.}

A simple accounting scheme is plotted in Figure 19.24, which adopts the core of a scheme presented in OECD (2011) and elaborates on that. It describes the process of generating earnings inequality in an institutional framework. Starting components, individual wages and hours worked, are clearly affected by either the bargaining activity of unions (where/when present and active) and/or by existing regulations (minimum wage, regulation on worked hours). This determines individual labour earnings among the employees, but the total level of employment (and its split between dependent and selfemployment) are conditioned by existing taxation as well as by employment protection (since so-called self-employment may disguise dependent employment conditions, especially in the case of a single purchaser ). In addition the generosity of public benefits to those laid-off or unemployed also contributes to reducing earnings inequality in the bottom part of the distribution. While we will not proceed further with our analysis in that direction, one should keep in mind that the list of potential institutions affecting earnings inequality at large should consider the household dimension. Half of 
Figure 19.24 - Accounting for the basic components of income inequality and the role of institutional measures

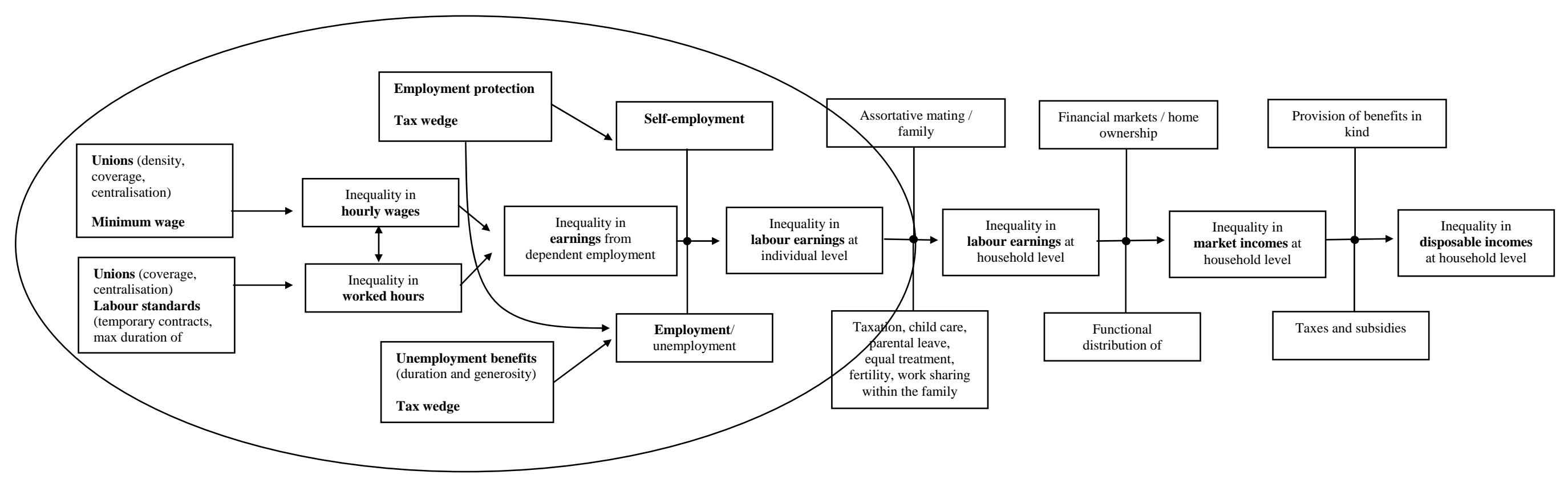

Source: Adapted from OECD 2011, box 1 
sample of the workforce population is concentrated in households where two members are employed (either as dependent or self-employed). As long as their earnings are not perfectly correlated, cohabitation (and expected income sharing) works as a shock absorber. However, one fourth of the population does not possess this insurance, since they are single-person households who by definition lack such shielding from the unemployment risk.

\subsection{A simple scheme to account for between-group inequality}

In order to frame our theoretical expectations before moving to the econometrics, let us consider a simple model which considers a partition of the population into groups. As such, it may be considered appropriate to sketch the between-group component of inequality, while the between-component incorporates idiosyncratic components (including different marriage attitudes in each group), which are not necessarily connected to the institutional framework. This model builds on Atkinson and Bourguignon (2000) and Checchi and Garcia-Peñalosa (2009). If the workforce is composed by skilled and unskilled workers, a fraction of which may be unemployed, an inequality measure (Gini index) can be expressed (see box 1 below)

$$
\text { Gini }_{\text {earnings }}=f\left(\begin{array}{c}
\alpha, \sigma, u, \gamma \\
\pm+ \pm_{-}
\end{array}\right)
$$

where $\alpha$ indicates the share of skilled workers, $\sigma$ wage differential between skilled and unskilled wage, $u$ the unemployment rate and $\gamma$ the generosity of the unemployment benefit. This ideal population can be represented on the unitary simplex (see Figure 19.25), which has its empirical counterpart in our dataset (see Figure 19.26). While it is intuitive that earnings inequality is increasing in skill premium and decreasing in the generosity of the unemployment support scheme (conditional on the replacement rate being less than 100\%), the effects of the other two parameters are ambiguous. Inequality is increasing in the skill composition as long as the initial fraction of skilled worker is small enough and/or not extremely well paid vis-à-vis the other unskilled workers (i.e. the skill premium is small). ${ }^{122}$ Eventually earnings inequality is increasing in unemployment rate in an intermediate range, while it exhibits negative correlation for high or low values.

We are now in the position to discuss the relationship between earnings (between-groups) earnings inequality, market determinants, and labour market institutions (LMI). Among the four parameters identified by the model, one is partly independent from LMI. The skill composition of the employed (parameter $\alpha$ ) depends on the interplay between demand and supply of skills. Demand for skill may be related to the technological development of an economy, which in turns relates to the international distribution of production and the possibility of off-shoring (Acemoglu and Autor 2011 and 2012). The supply of skills is the output of the educational system of a country, combined with expectations regarding wage premia. If we extend the notion of institutions to include educational systems, then this is the first determinant of wage inequality, which is non-linearly related to earnings inequality (Leuven et al. 2004). Given intergenerational persistence in educational choice, the skill composition of the labour force changes rather smoothly across generations, and can be taken as given, at least in the short run.

By contrast, the return to skill (parameter $\sigma$ ) is jointly affected by competitive market forces and by institutions. In a competitive environment, this relative wage should be negatively correlated with the relative supply, as is slightly the case in Figure 19.28 (Katz and Autor 1999). However there are significant deviations from such relationship, which among other factors depend on the bargaining activity of unions (typically pursuing an egalitarian stance, aiming to tie wages to jobs and not to people

122 The ambiguous effect of $\alpha$ on Gini is not surprising because a change in $\alpha$ leads to Lorenz curves which cross each other, meaning that the change in the Gini will depend on how they cross each other; as a consequence other inequality measures may yield results in contradiction with the Gini index. 
- Visser and Checchi 2009; see also the role of wage scales described by Oliver 2008) as well as the presence and coverage of minimum wage legislation .

The unemployment benefit (parameter $\gamma$ ) has an uncontroversial effect of reducing earnings inequality when unemployed people are counted in. However there is a general consensus that it has also a detrimental effect on the incentive to work, thus raising the unemployment rate. Since the unemployment benefit can be thought of as a proxy for the outside option in wage bargaining or efficiency wage models, it also creates an upward wage push, which contributes to a positive correlation between benefit and unemployment. The overall effect is therefore $\frac{\partial G i n i}{\partial \gamma}=\left.\frac{\partial G i n i}{\partial \gamma}\right|_{u=\text { constant }}+\frac{\partial G i n i}{\partial u} \cdot \frac{\partial u}{\partial \gamma}$ which can be either positive (for a high level of unemployment and/or a weak elasticity of unemployment to benefit) or negative (for a low level of unemployment and/or a high elasticity of unemployment to benefit). In our sample, the correlation tends to be positive (see Figure 19.29 however, this concerns short-run unemployment rates, while such a correlation should be studied using multi-period unemployment rate in order to dispense with cyclical fluctuations). Once again, this is not the unique determinant of the unemployment rate (parameter $u$ ), since in a more general equilibrium model it depends on the state of the aggregate demand as well as on the average labour cost, which should incorporate the tax wedge. In addition, it may also be correlated with many other LMI variables, sometimes referred as determinants of the NAIRU (Nickell 1997).

Still on the side of between-group inequality, we have purposely ignored the functional distribution of income between profit and wages, even though some of these parameters may be correlated to the labour share in the value added. Checchi and Peñalosa (2009) have shown that the same LMI affecting the functional distribution of value added, also affect the distribution of income sources at the individual level, thus modifying income inequality at the aggregate level.

\section{Box - A model for between-group inequality in earnings}

Let us suppose that the workforce has unitary measure and is composed of three groups of individuals:

i) a fraction $\alpha \in(0,1)$ of the employed is made of skilled workers, earning a wage $w^{s}=(1+\sigma) w^{u}$, where $\sigma>0$ is the skill premium; ${ }^{123}$

ii) a complementary fraction $(1-\alpha)$ is given by unskilled workers, who obtain a wage $w^{u}$.

iii) a fraction $u$ is unemployed and get a benefit $b=\gamma \bar{w}$ where $\gamma \in[0,1]$ is the replacement rate and $\bar{w}$ is the average wage within the employed labour force; skilled and unskilled workers experience the same unemployment rate. ${ }^{124}$

Each economy can be described by two coordinates, the unemployment rate $u$ and the workforce composition $\alpha$, and can be represented as a point in the unitary simplex. In Figure 19.25 the economy corresponding to point $A$ is characterized by $10 \%$ of unemployment, $2 / 3$ of unskilled employees and one third of skilled ones. The same scheme could be applied to other dual partitioning of the labour force (young/old, male/female, native/foreign, etc.). The actual distribution of the population across different countries in our sample of analysis is reported in Figure 19.26.125

Our reference measure of inequality, the Gini concentration index, can provide a measure of the between-group inequality when computed in this simplified population by considering the subgroup differences, obtaining the following expression

${ }^{123}$ We do not consider the presence of a fourth fraction of rich capitalists, as in Alvaredo 2011, who shows that when their population share is negligible (as in the case of top incomes), the Gini inequality index $G_{i n c o m e s}$ can be approximated by Gini $_{\text {incomes }}^{*} \cdot(1-S)+S$, where Gini ${ }_{\text {incomes }}^{*}$ is the Gini coefficient for the rest of the population and $S$ is the share of total income accruing to the rich fraction of the population. Similarly, the model could be complicated by introducing a third group of workers with intermediate level of skills, in order to account for the possibility of polarisation.

124 This simplifies the analysis, avoiding to model relative labour demand, which would allow for modelling a differential impact of institutions on worker subgroups: "Any observer of European labour markets in the last thirty years of the twentieth century would agree that it is a good stylized description of these markets to think of the labour market for high-skill workers as in equilibrium, with wages that adjust to offset demand and supply imbalances, while the low-skill labour market is in disequilibrium, with involuntary unemployment and unresponsive real wages." (Saint-Paul 2000, 5).

${ }^{125}$ A worker is arbitrarily classified as skilled when possessing a post-secondary school degree. This explains why formerly planned economies exhibit such wide variations in skill endowments. 


$$
\text { Gini }_{\text {earnings }}=\frac{(1-u)^{2} \alpha(1-\alpha)\left[w^{s}-w^{u}\right]+(1-u) \alpha u\left[w^{s}-b\right]+(1-u)(1-\alpha) u\left[w^{u}-b\right]}{2[(1-u) \bar{w}+u b]}
$$

Using previous definitions, the equation (1) can be re-expressed as

$$
\text { Gini }_{\text {earnings }}=\frac{(1-u)^{2} \alpha(1-\alpha) \sigma+(1-u) u(1-\gamma)(1+\alpha \sigma)}{2[1-u(1-\gamma)](1+\alpha \sigma)}=\frac{(1-u)^{2} \frac{\alpha(1-\alpha) \sigma}{(1+\alpha \sigma)}+(1-u) u(1-\gamma)}{2[1-u(1-\gamma)]}
$$

Thus the (between groups) inequality in the earnings distribution is parameterized over four characteristics: the employment rate $(1-u)$, the labour force composition $\alpha$, the skill premium $\sigma$ and the generosity of the unemployment benefit $\gamma$. It is easy to show that $\frac{\partial G i n i}{\partial \gamma}<0$ and $\frac{\partial G i n i}{\partial \sigma}>0$, namely that other things constant earnings inequality is increasing in skill premium and decreasing in the generosity of the unemployment support scheme. Less clear cut results obtain with respect to the other two parameters. It can be proved that $\operatorname{sign}\left[\frac{\partial G i n i}{\partial \alpha}\right]=\operatorname{sign}[1-\alpha(\alpha \sigma+2)]$ which is positive for $0 \leq \alpha<\frac{\sqrt{1+\sigma}-1}{\sigma}$. Thus inequality is increasing in the skill composition as long as the initial fraction of skilled worker is small enough and/or not extremely well paid vis-à-vis the other unskilled workers (i.e. the skill premium $\sigma$ is small). In the case of unemployment tedious calculations ${ }^{126}$ prove that

$$
\frac{\partial \text { Gini }}{\partial u}>0 \quad \text { iff } \quad \frac{1}{1-\gamma}\left(1-\sqrt{\gamma \frac{A \gamma-(1-\gamma)}{A-(1-\gamma)}}\right)<u<\frac{1}{1-\gamma}\left(1+\sqrt{\gamma \frac{A \gamma-(1-\gamma)}{A-(1-\gamma)}}\right), A=\frac{\alpha(1-\alpha) \sigma}{(1+\alpha \sigma)}<1
$$

Thus earnings inequality is increasing in unemployment rate in an intermediate range, while it has a negative correlation for high or low values. The Gini surface over the unitary simplex is represented in Figure 19.27: notice that the hump-shape is consistent with the just mentioned derivative.

So far we have only considered the between-group inequality, ignoring the within-group component, because the former is easier to correlate with labour market institutions. If we want to take into account both components in an explicit way, we need to resort to a decomposable inequality index, like the generalized entropy index (with $\alpha=0$ ), known as mean logarithmic deviation $M L D=\frac{1}{n} \sum_{i=1}^{n} \lg \left(\frac{\bar{y}}{y_{i}}\right)$ (Jenkins 1995). In the framework of the present model it can be decomposed as

$$
\begin{aligned}
M L D_{\text {earnings }}= & \underbrace{\alpha(1-u) \cdot M L D_{\text {skilled }}+(1-\alpha)(1-u) \cdot M L D_{\text {unskilled }}+u \cdot M L D_{\text {unemployed }}}_{\text {within-group inequality }}+ \\
& \underbrace{\alpha(1-u) \cdot \lg \left(\frac{\mu}{w^{s}}\right)+(1-\alpha)(1-u) \cdot \lg \left(\frac{\mu}{w^{u}}\right)+u \cdot \lg \left(\frac{\mu}{\gamma \bar{w}}\right)}_{\text {between-group inequality }}
\end{aligned}
$$

where $\mu$ is the mean income in the population. So far we have neglected the funding of the unemployment benefit scheme (which could derive from profit and rent taxation). In such a case

$$
\mu=(1-u) \bar{w}+u \gamma \bar{w}=(1-u(1-\gamma)) \bar{w}=(1-u(1-\gamma))\left(\alpha w^{s}+(1-\alpha) w^{u}\right)=(1-u(1-\gamma))(1+\alpha \sigma) w^{u}
$$

On the contrary, if we impose a balanced budget, such that unemployment benefits are to be financed by earnings taxation, we require that $(1-u) t \bar{w}=u \gamma \bar{w}$ where $t$ is the average tax rate. As a consequence

126 If we rewrite the Gini index as Gini $=\frac{(1-u)^{2} A+(1-u) u B}{2(1-u B)}$ where $A=\frac{\alpha(1-\alpha) \sigma}{1+\alpha \sigma}<1$ and $B=(1-\gamma)<1$, then $\operatorname{sign}\left[\frac{\partial G i n i}{\partial u}\right]=\operatorname{sign}\left[-B(A-B) u^{2}+2(A-B) u+B-A(2-B)\right]$ which has two real roots under the sufficiency condition that $A>\frac{B}{1-B}$. These roots are given by $u_{1,2}=\frac{(A-B) \pm \sqrt{(A-B)(1-B)(A-B-A B)}}{B(A-B)}=\frac{1}{B}\left(1 \pm \sqrt{\frac{(1-B)(A(1-B)-B)}{(A-B)}}\right)$, which corresponds to what is reported in the text. 


$$
\mu=(1-u) \bar{w}+(1-u) t \bar{w}=(1-u)(1+t)(1+\alpha \sigma) w^{u}
$$

If we replace definition (4) into equation (3) we obtain

$$
\begin{gathered}
M L D_{\text {earnings }}=\underbrace{\alpha(1-u) \cdot M L D_{\text {skilled }}+(1-\alpha)(1-u) \cdot M L D_{\text {unskilled }}+u \cdot M L D_{\text {unemployed }}}_{\text {within-group inequality }}+ \\
\underbrace{\alpha(1-u) \cdot \lg \left(\frac{(1-u)(1+t)(1+\alpha \sigma)}{1+\sigma}\right)+(1-\alpha)(1-u) \cdot \lg ((1-u)(1+t)(1+\alpha \sigma))+u \cdot \lg \left(\frac{(1+t) u}{t}\right)}_{\text {between-group inequality }}
\end{gathered}
$$

It is easy to prove that the between-group component of MLD is increasing in $\sigma$ and decreasing in $\gamma$ (under the balanced budget constraint). In addition the between-group component is increasing in $\alpha$ for low values, but it changes sign above the threshold defined by $\alpha^{*}=\frac{1}{\lg (1+\sigma)}-\frac{1}{\sigma}$. The main difference with the Gini measure of inequality is that the gradient of the between-component with respect to the unemployment rate $u$ takes the sign of $\left[1-\frac{(1+\alpha \sigma) \gamma}{\left(1+\sigma^{\alpha}\right)}\right]$ suggesting that inequality is increasing whenever the replacement rate and/or the wage premium are low.

Figure 19.25 - The distribution of the population

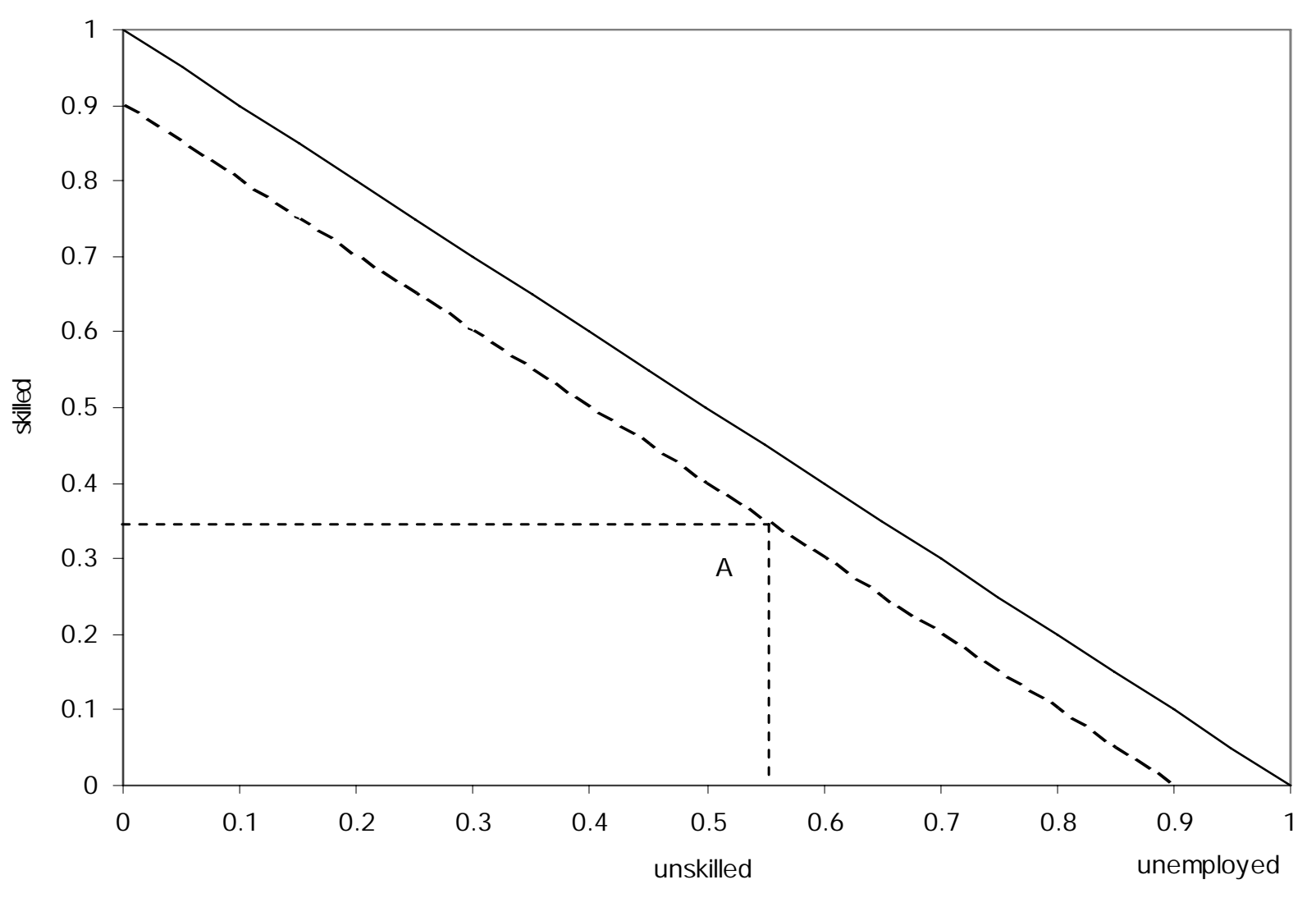


Figure 19.26 - The distribution of the employee workforce (aged 20-55) - SILC 2010 and PSID 2011

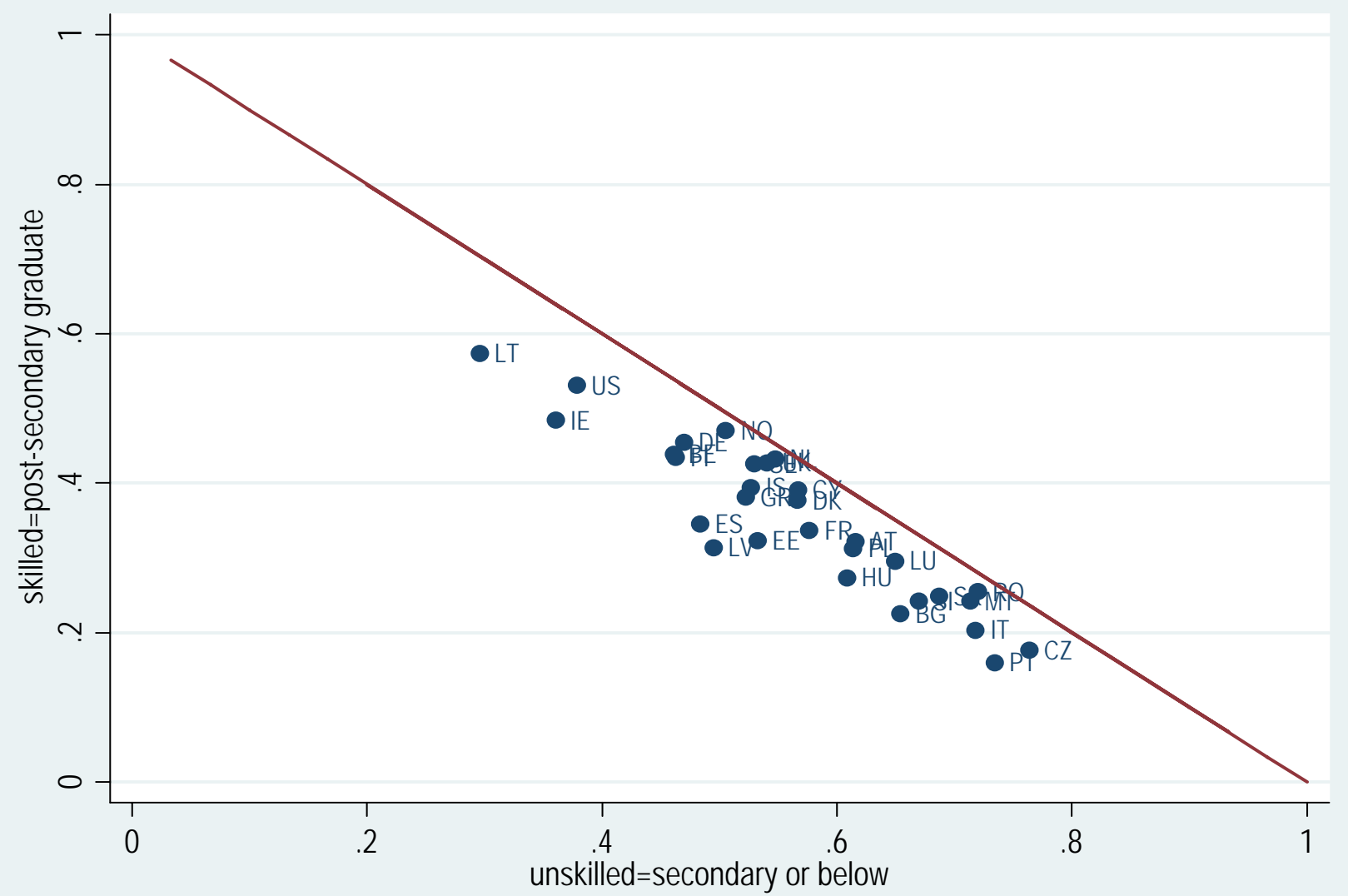

Figure 19.27 - Plot of the Gini surface $(\gamma=0.5, \sigma=2)$

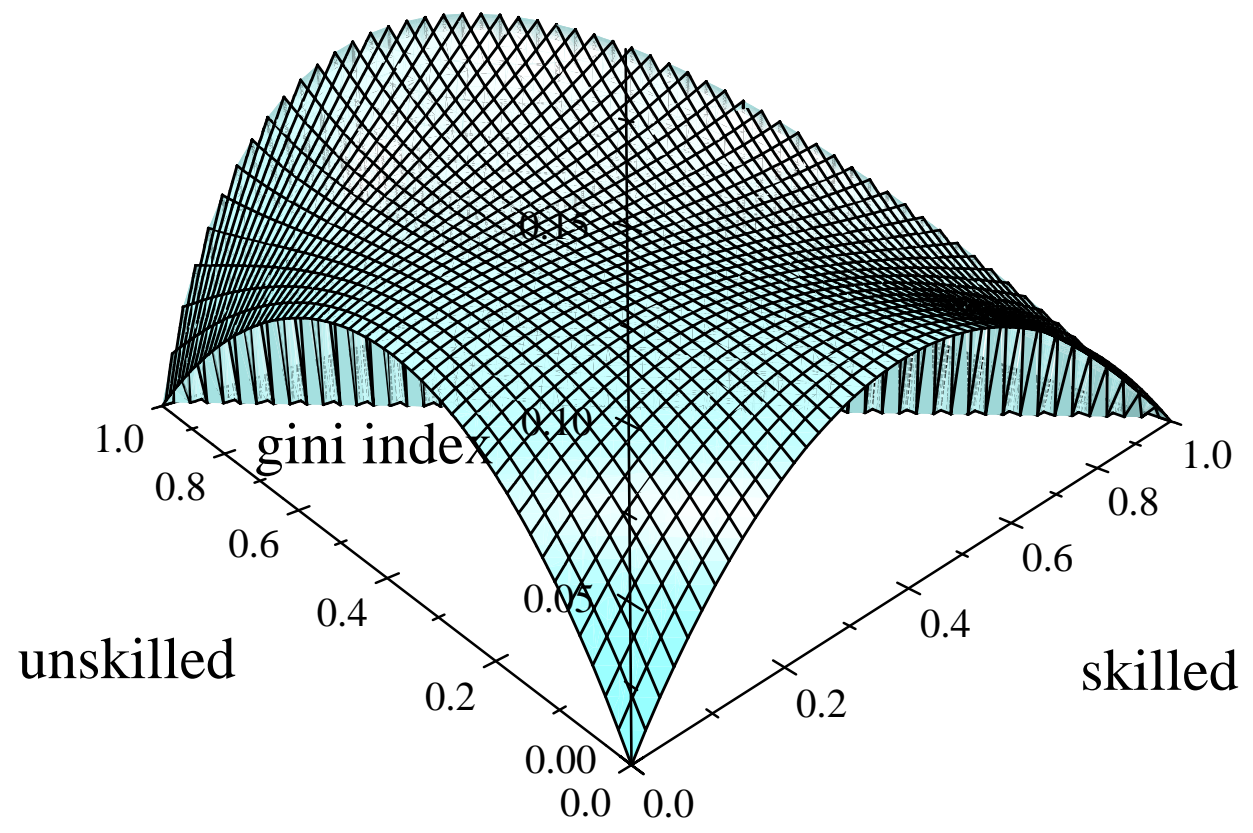


Figure 19.28 - Return to skills and skill availability for dependent employees (aged 20-55) - SILC 2010 and PSID 2011

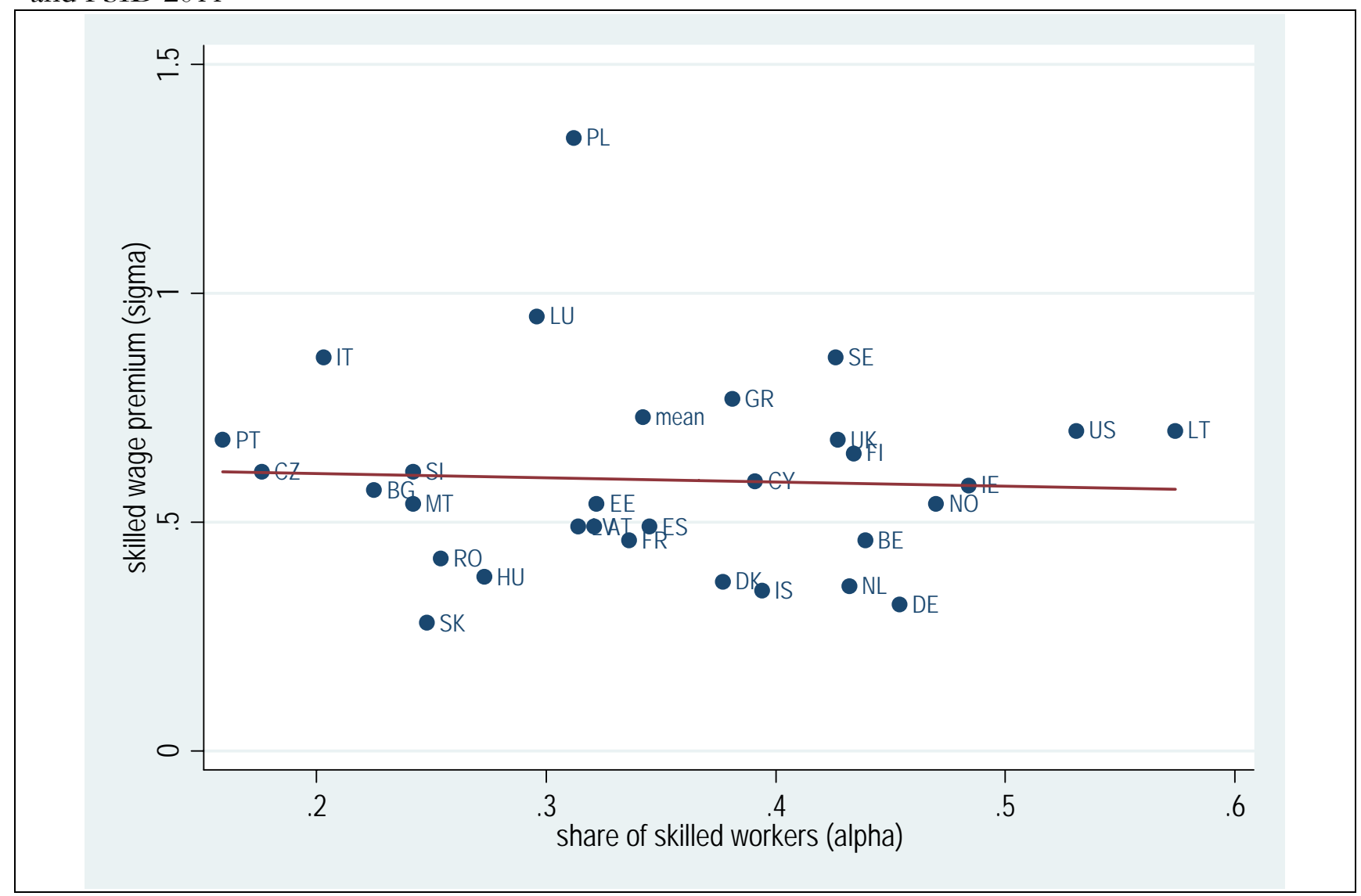

Figure 19.29 - Unemployment benefit and unemployment rate - SILC 2010 and PSID 2011

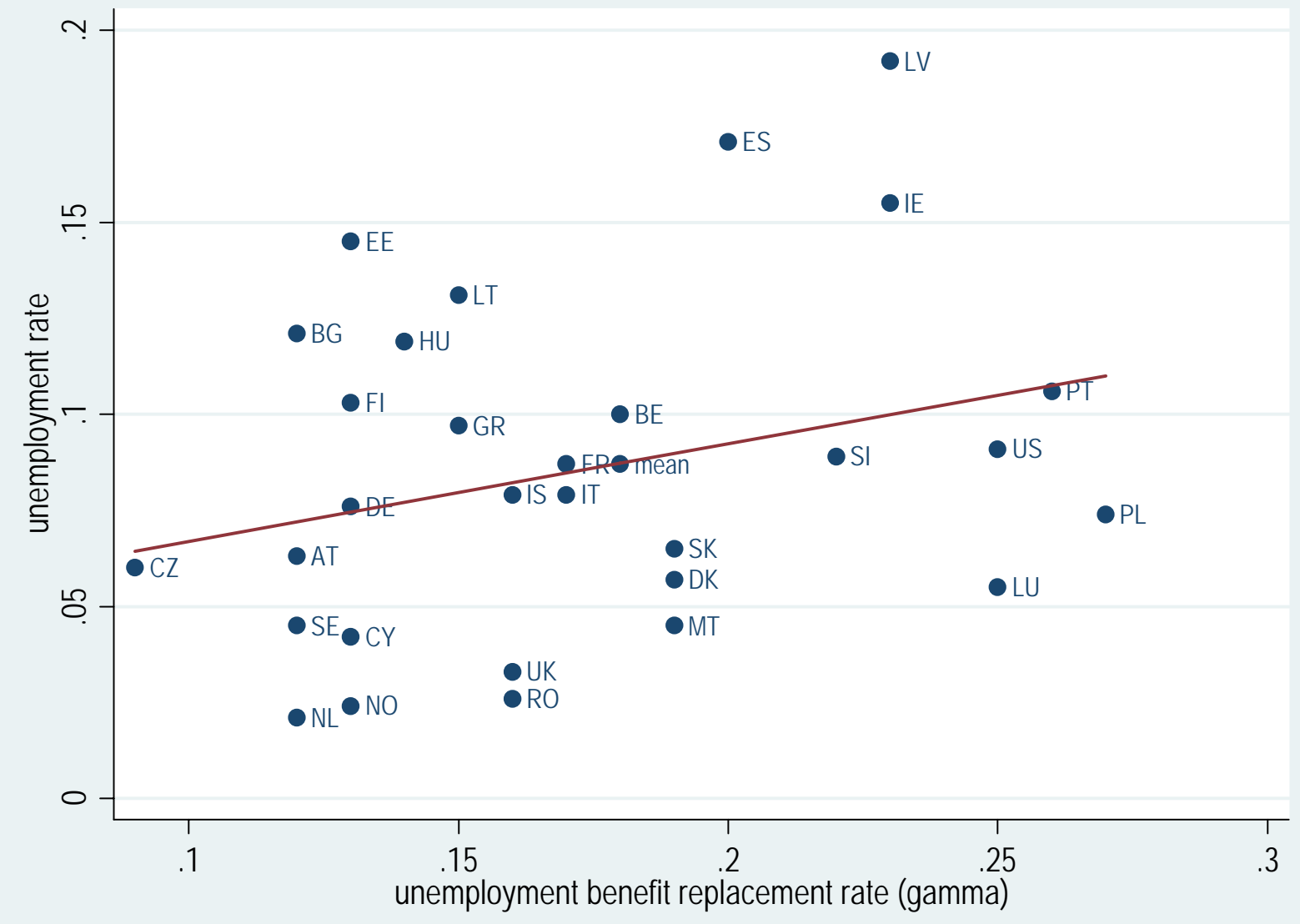


If we are to check the predictive ability of this simple model, we can use observed sample parameters $(\alpha, \sigma, u, \gamma)$ to predict earnings inequality in each country, well aware that this captures only the between-group component. We define as skilled workers all employees holding a post-secondary degree, and compute the skilled wage as their mean wage. Correspondingly, we define as unskilled all the remaining employees (and obtain their wage); finally, we compute the unemployment share and their mean benefit. The relevant parameters which are needed for the between-group inequality measures are reported in Table A.4. In column 10 we report the estimated Gini, which has to be compared with the actual one computed on the same dataset in Column 11. The two coefficients are highly correlated (rank correlation coefficient is 0.57 ). ${ }^{127}$

Using the Gini index computed over four parameters, we can claim that the between-group component accounts for almost one third of overall earnings inequality, the remainder being attributable to individual heterogeneity (age, gender, finer partition of educational attainments - including variations of hours). It is rather surprising that such a simple model, based on four parameters only, is able to account for a significant portion of the observed cross-country differences in earnings inequality. Looking at Figure 19.30 we notice that some countries (lying to the right of the regression line) are characterized by higher-than-the-mean between-group inequality (or lower-than-the-mean overall earnings inequality): not surprisingly the Nordic and the Mediterranean countries (except Portugal) are on this side, indicating that in these countries institutions may help to reduce the corresponding withingroup inequality. On the left side of the regression line, however, we find the liberal market economies (US, UK and Ireland) and some transition economies (Latvia, Lithuania and Hungary) as well as some continental European country (like Germany and the Netherlands). These countries are characterized by individual rather than collective wage setting, thus raising the between-group component of earnings inequality.

Figure 19.30 - The between-group component of earnings inequality - SILC 2010 and PSID 2011

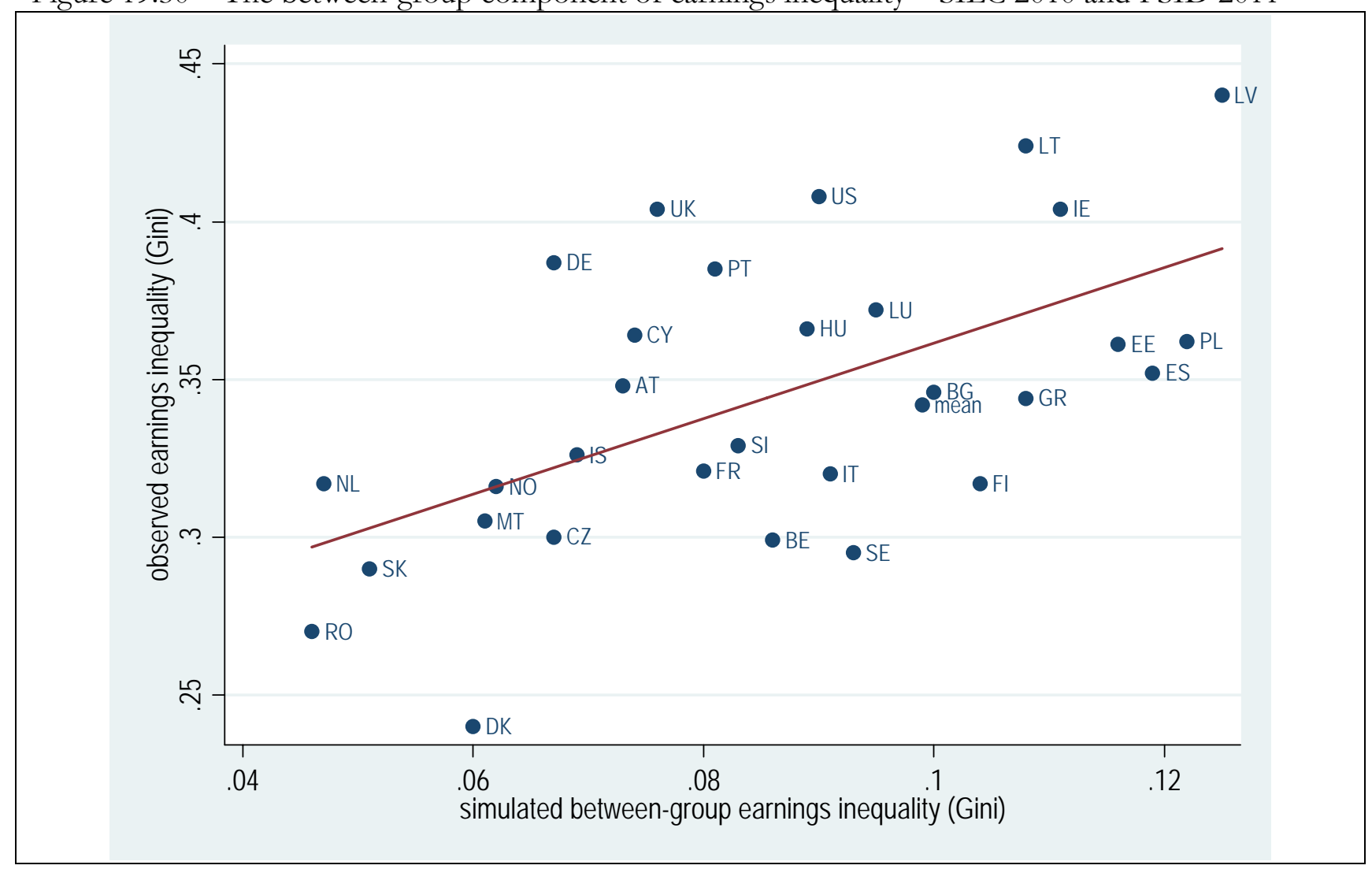

\footnotetext{
${ }^{127}$ Regressing the observed Gini in labour earnings onto the simulated one computed according to equation (2) yields the following estimation: Gini $_{\text {observed }}=0.24+1.20 \cdot$ Gini $_{\text {simulated }}$ with an $\mathrm{R}^{2}=0.33$.
} 


\subsection{The within-group inequality and the role of labour market institutions}

We now consider the within-group component of inequality. In order to obtain an exact decomposition of earnings inequality for employees, we abstract from self-employment (we think it is potentially affected by existing labour market regulations but it often also records negative incomes which are not easily dealt by inequality measures) and we restrict ourselves to individuals aged below 55 (in order to minimise country differences attributable to a different extent of early retirement ${ }^{128}$ ) who receive either a positive income from dependent employment or from unemployment benefit. Using the mean $\log$ deviation to decompose earnings inequality, we find that on average the between-component accounts for one fifth of the observed inequality, being highest in Portugal (30\%), Hungary (28\%) and Slovenia $(28 \%)$ and lowest in Sweden (7\%), Norway (8\%) and the Netherlands (11\%) (see Table 19.3).

The within-group component follows common patterns: inequality is highest among the unemployed, ${ }^{129}$ but its contribution to the within-group component is limited, the country average being 16\%. Skilled workers are characterized by higher earnings inequality than the unskilled ones, and this is not surprising once we consider that their wage will more frequently be determined by individual bargaining. The unskilled workers (who on average comprise $57 \%$ of the workforce) do contribute half of total within-group inequality, and it is here that we may expect to find the strongest impact of labour market institutions (especially the minimum wage and bargaining activity of unions) ${ }^{130}$.

If we now consider the potential role of LMI in shaping the wage distribution within workers' types, we do expect a differential impact according to the way in which different workers are affected. ${ }^{131}$ We spent some effort to collecting consistent information on institutional variables for the same countries, mostly from various OECD datasets. We tried to build long series in order to match individuals of different age cohorts to the institutional setup prevailing either at the beginning of their work careers or during their entire career. Data sources and descriptive statistics are in the Appendix 3.

128 The SILC codebook allows for the classification as unemployed of early retired workers if they perceive themselves as such ("Early retirement for economic reasons can be included here according to the respondent's feeling, i.e. a person in early retirement for economic reasons will be included here if he/she classifies him/herself as unemployed." (Eurostat, Description of Target Variables: Cross-sectional and Longitudinal 2010 operation (Version February 2010, 139).

${ }^{129}$ Inequality among (unemployment) benefit recipients is significantly affected by the duration of unemployment spells, by differences in the entitlement rights and in the take-up rates. While we do not have adequate data do cope with all these factors, if we just replace the current figures for the benefit with its monthly average (simply dividing the yearly received subsidy by months in unemployment) we obtain that the inequality in monthly unemployment benefit significantly declines for some countries (Austria, Czech Republic, Netherlands, Norway) but it increases in others (Estonia, Ireland, Italy), the country average of MLD remaining almost unchanged (from 0.388 to 0.381 ).

${ }^{130}$ Freeman and Schettkat (2001) follow a similar approach when comparing US and Germany earnings inequality, showing that inequality within each educational group is higher in the former country, and they attribute it to the role of bargaining structures.

${ }^{131}$ Eichhorst et al. (2008) provide a recent review of how labour-market institutions are measured and their impacts on unemployment. 
Table 19.3 - Earnings inequality decomposition - dependent employees or unemployed (Mean log deviation) - SILC 2010 and PSID 2011

\begin{tabular}{|c|c|c|c|c|c|c|c|c|c|}
\hline & \multicolumn{3}{|c|}{$\begin{array}{l}\text { Decomposition of total } \\
\text { inequality }\end{array}$} & \multicolumn{6}{|c|}{ Decomposition of the within-group component: } \\
\hline & \begin{tabular}{|c|} 
Overall \\
yearly \\
gross \\
earnings \\
inequality
\end{tabular} & \begin{tabular}{|c|} 
Between \\
group \\
inequality
\end{tabular} & $\begin{array}{c}\text { Within } \\
\text { group } \\
\text { inequality }\end{array}$ & $\begin{array}{c}\text { Population } \\
\text { share of } \\
\text { skilled } \\
\text { workers }\end{array}$ & $\begin{array}{l}\text { Inequality } \\
\text { in yearly } \\
\text { gross } \\
\text { earnings of } \\
\text { skilled } \\
\text { workers }\end{array}$ & \begin{tabular}{|c|} 
Population \\
share of \\
unskilled \\
workers
\end{tabular} & \begin{tabular}{|c|} 
Inequality \\
in yearly \\
gross \\
earnings \\
of \\
unskilled \\
workers
\end{tabular} & \begin{tabular}{|c|} 
Population \\
share of \\
unemployed \\
workers \\
(receiving a \\
positive \\
benefit)
\end{tabular} & \begin{tabular}{|c|} 
Inequality in \\
unemploy- \\
ment \\
benefits \\
(conditional \\
on being \\
unemployed)
\end{tabular} \\
\hline Austria & 0.234 & 0.031 & 0.203 & 0.321 & 0.223 & 0.616 & 0.181 & 0.063 & 0.327 \\
\hline Belgium & 0.179 & 0.048 & 0.131 & 0.439 & 0.124 & 0.461 & 0.119 & 0.100 & 0.214 \\
\hline Bulgaria & 0.241 & 0.046 & 0.195 & 0.225 & 0.176 & 0.654 & 0.161 & 0.121 & 0.410 \\
\hline Cyprus & 0.263 & 0.031 & 0.232 & 0.391 & 0.255 & 0.567 & 0.214 & 0.042 & 0.270 \\
\hline \begin{tabular}{|l|} 
Czech \\
Republic
\end{tabular} & 0.184 & 0.033 & 0.151 & 0.176 & 0.171 & 0.764 & 0.119 & 0.060 & 0.494 \\
\hline Denmark & 0.129 & 0.016 & 0.113 & 0.376 & 0.111 & 0.566 & 0.101 & 0.057 & 0.243 \\
\hline Estonia & 0.270 & 0.033 & 0.237 & 0.322 & 0.200 & 0.532 & 0.194 & 0.145 & 0.475 \\
\hline \begin{tabular}{|l|} 
Finland \\
\end{tabular} & 0.204 & 0.049 & 0.155 & 0.434 & 0.145 & 0.462 & 0.132 & 0.103 & 0.294 \\
\hline France & 0.229 & 0.031 & 0.198 & 0.336 & 0.197 & 0.576 & 0.173 & 0.087 & 0.367 \\
\hline Germany & 0.334 & 0.069 & 0.265 & 0.454 & 0.234 & 0.470 & 0.276 & 0.076 & 0.381 \\
\hline Greece & 0.224 & 0.031 & 0.193 & 0.381 & 0.197 & 0.522 & 0.164 & 0.097 & 0.328 \\
\hline Hungary & 0.250 & 0.071 & 0.179 & 0.273 & 0.206 & 0.608 & 0.150 & 0.119 & 0.262 \\
\hline Iceland & 0.218 & 0.027 & 0.191 & 0.394 & 0.169 & 0.527 & 0.178 & 0.079 & 0.384 \\
\hline Ireland & 0.316 & 0.048 & 0.268 & 0.484 & 0.250 & 0.361 & 0.233 & 0.155 & 0.406 \\
\hline Italy & 0.224 & 0.027 & 0.197 & 0.203 & 0.205 & 0.718 & 0.169 & 0.079 & 0.436 \\
\hline Latvia & 0.418 & 0.076 & 0.342 & 0.314 & 0.279 & 0.495 & 0.261 & 0.192 & 0.653 \\
\hline \begin{tabular}{|l} 
Lithuania \\
\end{tabular} & 0.377 & 0.061 & 0.316 & 0.574 & 0.295 & 0.296 & 0.248 & 0.131 & 0.566 \\
\hline Luxembourg & 0.260 & 0.060 & 0.200 & 0.296 & 0.205 & 0.649 & 0.196 & 0.055 & 0.213 \\
\hline Malta & 0.199 & 0.029 & 0.170 & 0.242 & 0.179 & 0.713 & 0.150 & 0.045 & 0.453 \\
\hline Netherlands & 0.200 & 0.023 & 0.177 & 0.432 & 0.172 & 0.547 & 0.167 & 0.021 & 0.563 \\
\hline Norway & 0.230 & 0.018 & 0.212 & 0.470 & 0.204 & 0.505 & 0.200 & 0.024 & 0.605 \\
\hline Poland & 0.253 & 0.038 & 0.215 & 0.312 & 0.226 & 0.614 & 0.188 & 0.074 & 0.387 \\
\hline Portugal & 0.259 & 0.078 & 0.181 & 0.159 & 0.246 & 0.734 & 0.163 & 0.106 & 0.204 \\
\hline Romania & 0.121 & 0.032 & 0.089 & 0.254 & 0.111 & 0.720 & 0.078 & 0.026 & 0.176 \\
\hline \begin{tabular}{|l|} 
Slovak \\
Republic
\end{tabular} & 0.180 & 0.029 & 0.151 & 0.248 & 0.172 & 0.687 & 0.113 & 0.065 & 0.476 \\
\hline \begin{tabular}{|l} 
Slovenia \\
\end{tabular} & 0.229 & 0.064 & 0.165 & 0.242 & 0.189 & 0.669 & 0.116 & 0.089 & 0.471 \\
\hline Spain & 0.249 & 0.057 & 0.192 & 0.345 & 0.177 & 0.483 & 0.171 & 0.171 & 0.284 \\
\hline Sweden & 0.230 & 0.016 & 0.214 & 0.426 & 0.245 & 0.530 & 0.166 & 0.045 & 0.484 \\
\hline \begin{tabular}{|l|} 
United \\
Kingdom
\end{tabular} & 0.306 & 0.058 & 0.248 & 0.427 & 0.261 & 0.541 & 0.231 & 0.033 & 0.359 \\
\hline United States & 0.339 & 0.045 & 0.294 & 0.483 & 0.310 & 0.468 & 0.271 & 0.049 & 0.347 \\
\hline Average & 0.245 & 0.044 & 0.201 & 0.340 & 0.203 & 0.575 & 0.174 & 0.085 & 0.388 \\
\hline
\end{tabular}

Table 19.4 summarises our theoretical expectations, mostly deduced from the existing literature. Betcherman (2012) reviews the empirical literature on the correlation between different institutional dimensions and earnings inequality. He concludes that the minimum wage is the less contentious among the institutional impact, being associated to an improvement in the bottom tail of the wage distribution, at least for the formal sector. Neumark and Wascher (2008) do not contest the inequality reducing impact of minimum wage (by creating a spike at the relevant threshold and/or inducing upward spillover effect across the entire wage distribution), though they stress the contemporaneous disemployment effect on low-wage earners, raising doubts about the overall effect on inequality at household level. ${ }^{132}$

132 Among the long-run impacts they also list the inhibiting impact on skill acquisition for youngsters, which will split over into greater earnings inequality in the future. Thus they conclude "Minimum wages do not deliver on their goal of improving the lives of low-wage workers, low-skill individuals, and low-income families" (p. 293). 
The effect of unions is mixed, combining a reduction of within-group inequality (among formal dependent employment, especially in terms of skill premium - Koeniger et al. 2007) and a potential increase in the wage gap between union-covered sectors and non union-covered sectors (including informal employment). Using cross-country data, Visser and Checchi (2009) find that union presence is associated with lower within-group inequality, since both the gender gap and the return to education are negatively correlated with union density. ${ }^{133,134}$ As a consequence, the skill premium declines, both as a result of wage compression and as a consequence of the incentives to over-invest in education. In addition, union presence is also associated to unemployment, though correlation may go in different directions: union density seems associated with higher unemployment (Bertola et al. 2007, Nickell et al. 2005, Flaig and Rottmann 2011), while centralized bargaining seems to attenuate this negative effect (Nickell 1997, Bassanini and Duval 2006 - see also Glyn et al. (2003) for a critical review of these results. Thus, the overall effect of unions on earnings inequality remains uncertain

The results of employment protection legislation are less clear-cut. OECD (2011) and (2012) show that EPL and wage coordination have a negative effect on earning inequality, while tax wage and wage coverage have a positive effect. The proposed rationalization is that unskilled workers are favoured by firing restriction, raising their relative bargaining power relative to skilled ones. ${ }^{135}$

Unemployment benefits, active labour market policies and the tax wedge may play an indirect role, via the impact on aggregate employment (or unemployment). The tax wedge in particular has been found to be significantly and positively correlated to the unemployment rate (Nickell et al. 2005; Flaig and Rottmann 2011). ${ }^{136}$ But these two institutions also affect different groups of workers in different ways, especially along the gender divide (Bertola et al. 2007): as a consequence, they may impact on the household distribution of earnings via changes in the redistribution of work opportunities within the family. In addition, when aiming to decompose the contribution to inequality associated with hourly wages and hours worked, the legal framework (limitation to part-time, family or individual taxation) may lead to opposite impacts on labour supply, the corresponding employment and wage outcomes. Possibly for these reasons, we have not found consensus on this dimension in the literature, and therefore we will let the data speak.

\footnotetext{
133 The egalitarian attitude of workers' unions has been rationalised by Agell and Lommerud (1992) using the argument that high-productivity risk-adverse workers may prefer pay compression in the absence of a market for private insurance.

134 We do not consider here that institutions may operate in a complementary way, through interactions. In particular employment protection reinforces the impact of union density on unemployment and wage bargaining (Belot and van Ours 2004). Fiori et al. (2012) provide an empirical application of Blanchard and Giavazzi (2003), which shows the substitutability of product and labour market reforms in terms of employment impact.

135 A similar argument can be found in Koeninger et al. (2007), where employment protection has stronger effect for less qualified workers.

136 Flaig and Rottmann $(2011,19)$ conclude from their cross-country analysis covering 19 OECD countries over the 1960 2000 period that "A tighter employment protection legislation, a more generous unemployment insurance system and a bigher tax burden of labour income increase the medium term development of the unemployment rate, whereas a higher centralization of the wage bargaining process lowers unemployment. Union density has no clear effect and seems to be unimportant'.
} 
Table 19.4 - Theoretical expectations of the effects of institutions on earnings inequality

\begin{tabular}{|c|c|c|c|}
\hline $\begin{array}{l}\text { Labour market } \\
\text { institutions }\end{array}$ & Between groups & Within groups & $\begin{array}{l}\text { Overall impact on } \\
\text { earnings inequality }\end{array}$ \\
\hline $\begin{array}{l}\text { Minimum wage } \\
\text { (measured by ratio to } \\
\text { median wage) }\end{array}$ & $\begin{array}{l}* \text { raises the bottom tail of } \\
\text { hourly wage, mostly for the } \\
\text { unskilled }\end{array}$ & $\begin{array}{l}*_{\text {raise the bottom tail }} \\
\text { (typically populated by } \\
\text { marginal workers) }\end{array}$ & $\begin{array}{l}\text { * reducing inequality in } \\
\text { hourly wages - overall } \\
\text { effects depend on hours } \\
\text { dynamics }\end{array}$ \\
\hline $\begin{array}{l}\text { Union presence } \\
\text { (measured by union } \\
\text { density, coverage, } \\
\text { centralization and/or } \\
\text { coordination, strike } \\
\text { activity) }\end{array}$ & $\begin{array}{l}\text { *compresses the skill } \\
\text { premium ("equal pay for equal } \\
\text { work") } \\
\text { * expands the union wage } \\
\text { gap (between union and } \\
\text { non-union sectors/jobs) }\end{array}$ & $\begin{array}{l}* \text { reduce inequality in hours } \\
\text { (control/opposition to } \\
\text { overtime, regulation of part- } \\
\text { time, work sharing as } \\
\text { alternative to layoffs) } \\
* \text { reduces gender wage gap, } \\
\text { thus favouring work-sharing } \\
\text { within the family and female } \\
\text { participation }\end{array}$ & $\begin{array}{l}* \text { reducing (ambiguous when } \\
\text { unemployment effects are } \\
\text { taken into account) }\end{array}$ \\
\hline $\begin{array}{l}\text { Employment protection } \\
\text { (measured by OECD } \\
\text { summary index) }\end{array}$ & $\begin{array}{l}* \text { lowers unskilled wage } \\
\text { when inducing people to } \\
\text { retain unproductive jobs } \\
* \text { increases long term } \\
\text { unemployment }\end{array}$ & $\begin{array}{l}* \text { reduces job flows in/out } \\
\text { of unemployment } \\
* \text { discourages labour market } \\
\text { entry of marginal workers } \\
\text { (young, women) }\end{array}$ & $*$ ambiguous \\
\hline $\begin{array}{l}\text { Unemployment benefit } \\
\text { (measured by } \\
\text { replacement rate and } \\
\text { public expenditure in } \\
\text { passive labour market } \\
\text { policies) }\end{array}$ & $\begin{array}{l}* \text { raises the income of the } \\
\text { unemployed } \\
* \text { raises the outside option, } \\
\text { thus augmenting the } \\
\text { bargaining power of unions } \\
* \text { lowers the incentive to job } \\
\text { search }\end{array}$ & $\begin{array}{l}* \text { potential subsidy traps } \\
\text { (especially on second earner, } \\
\text { since the reservation wage is } \\
\text { positively correlated with } \\
\text { first earner) }\end{array}$ & $*$ ambiguous \\
\hline $\begin{array}{l}\text { Tax wedge (measured by } \\
\text { the ratio between labour } \\
\text { cost and take home pay) }\end{array}$ & $\begin{array}{l}* \text { increases unemployment } \\
\text { (if the employer is unable to } \\
\text { transfer the burden onto the } \\
\text { employee) }\end{array}$ & $\begin{array}{l}\text { * when altering labour cost } \\
\text { (if they cannot be shifted to } \\
\text { workers), taxes and payroll } \\
\text { taxes alter the relative } \\
\text { employment of worker } \\
\text { subgroups } \\
\text { * even within the } \\
\text { household, EITC (earned } \\
\text { income tax credit) measures } \\
\text { may favour joint } \\
\text { participation of spouses to } \\
\text { the labour market, especially } \\
\text { when part-time is easily } \\
\text { available }\end{array}$ & $\begin{array}{l}\text { * increases personal earnings } \\
\text { inequality (because presence } \\
\text { of part-timers) but may } \\
\text { reduce household earnings } \\
\text { inequality (because presence } \\
\text { of an additional income in } \\
\text { the household) }\end{array}$ \\
\hline $\begin{array}{l}\text { Active labour market } \\
\text { policies (measured by } \\
\text { public expenditure on } \\
\text { GDP) }\end{array}$ & $*$ reduces unemployment & $\begin{array}{l}* \text { increasing labour market } \\
\text { participation, possibly with } \\
\text { reduced hours }\end{array}$ & $\begin{array}{l}* \text { ambiguous (due to the } \\
\text { composite effect) }\end{array}$ \\
\hline $\begin{array}{l}\text { Child/old people care } \\
\text { facilities (availability of } \\
\text { ECCE facilities, parental } \\
\text { leave) }\end{array}$ & & $\begin{array}{l}* \text { increasing female } \\
\text { participation, it brings in } \\
\text { additional workers into } \\
\text { employment }\end{array}$ & $\begin{array}{l}* \text { ambiguous (due to a } \\
\text { compositional effect) }\end{array}$ \\
\hline
\end{tabular}

Work redistribution within the household may also be affected by parental leave opportunities and child care provisions (Thévenon and Solaz 2013). As long as these institutional dimensions favour female participation, they should reduce earnings inequality measured at the household level, while they may increase inequality at the individual level, due to a larger fraction of part-timers in the economy. However, these results are conditional on parental leave not exceeding a specific threshold, because otherwise it may produce a reduction in labour supply. ${ }^{137}$ In addition, as long mandated parental leave may raise female supply in the labour market, it may also exert a downward pressure on their relative

${ }^{137}$ Lalive et al. (2011) study the complementarity between job protection associated with parental leave and financial support to new parents, showing that either policy instrument has a detrimental effect on female labour supply in the medium run. 
wage, thus contributing to increased inequality (which, however, is not found in the limited data analysed by Thévenon and Solaz 2013). Also in such a case, we may let the data speak.

A serious problem in assessing the impact of single institutions on labour-market outcomes is that some institutions are likely to interact with each other, in a positive or in a negative way. Consider for example the role of workers' unions, which is typically correlated in a negative way to earnings inequality. The presence of unions is strengthened by employment protection legislation, but is weakened by the presence of minimum-wage provisions. ${ }^{138}$ Similarly, the tax wedge may have a significant impact on employment in a country where the (after tax) minimum wage is relatively high since part of the wedge will be passed on to wages at a higher level. In some countries (like France and Belgium) rebates on payroll taxes for low-wage workers significantly impact on their employability.

Addressing the issue of institutional complementarity opens up another set of literature, which is typically analysed by political economy (Hall and Soskice 2001, Amable 2003). From an empirical point of view it does require a sufficient number of degrees of freedom (either in terms of variety of countries or in terms of repeated observations over the same country). Just as descriptive evidence, the sample bivariate correlations between the inequality measures presented in table 19.4 and the labour market institutions described in Appendix 3 are presented in table 19.5. ${ }^{139}$ Exploiting the decomposability of the Mean Log Deviation, we have considered six dimensions of earnings inequality: its overall measure, the decomposition into between-group and within-group, and the contributions to the within-component attributable to each group of workers (skilled, unskilled and unemployed). ${ }^{140}$

They confirm that union presence (either measured by union density or by coverage) may contribute to reducing earnings inequality, though in a different way. Union density seems statistically correlated with the between-group component, while the coverage of collective agreements (which assures equivalent treatment of all workers) exhibits a negative correlation with the within-component. Similar negative correlations are exhibited by employment protection with respect to the skilled worker group; analogously parental leave facilities are negatively correlated to skilled wage inequality. It is interesting to notice that the generosity of the unemployment benefit seems to contribute positively to the inequality component attributable to the unemployed (even if we are unable to distinguish whether this is due to an increase of the unemployment rate or to a different distribution within the group). Not surprisingly, household or individual taxation does not affect wage inequality, since it may be ineffective in modifying household labour supply (Dingeldey 2001). Active and passive labour market policies seem mostly effective in reducing the within-component of the earnings inequality of unskilled workers.

Overall these results are not satisfying in terms of statistical significance, suggesting that isolating a single institution at a specific point in time (even though here we are considering a decennial average) may not be the best strategy to investigate the association between inequality and institutions. Though it may sometimes be inevitable for empirical reasons, it does seem advisable to consider the degree of embeddedness of individual institutions in a collection of institutions to see whether one can lay more weight on analytical results obtained for one institution compared to another. For example the strong legal nature of an institution may enhance its standalone effect. In addition, bivariate correlations are sensitive to the criticism of spurious correlation and also to omitted-variable bias. For this reason we now consider more robust methods to study the impact of institutions on earnings inequality.

\footnotetext{
138 Checchi and Lucifora (2002) discuss the complementarity/substitutability of labour market institutions with respect to union density.

139 A review of existing datasets on labour market institutions is in Ochel (2005) and Eichhorst et al. (2008).

$140 \mathrm{By}$ considering the contribution to inequality attributable to workers groups we are combining two sources of variation: the group size and its internal inequality. While the fraction of unemployed workers may be directly correlated to labour market institutions (such as unions or unemployment benefit), the skill composition of the labour force may be correlated with the quality and quantity of education available in the country in earlier decades.
} 
Table 19.5 - Correlation between labour market institutions (averages 2001-2010) and different component of earnings inequality (MLD) - SILC 2010 and PSID 2011

\begin{tabular}{|c|c|c|c|c|c|c|}
\hline & $\begin{array}{c}\text { Overall } \\
\text { yearly } \\
\text { gross } \\
\text { earnings } \\
\text { inequality }\end{array}$ & $\begin{array}{l}\text { Between } \\
\text { group } \\
\text { inequality }\end{array}$ & $\begin{array}{c}\text { Within } \\
\text { group } \\
\text { inequality }\end{array}$ & $\begin{array}{l}\text { Inequality } \\
\text { in yearly } \\
\text { gross } \\
\text { earnings } \\
\text { attributable } \\
\text { to skilled } \\
\text { workers } \\
\end{array}$ & $\begin{array}{l}\text { Inequality } \\
\text { in yearly } \\
\text { gross } \\
\text { earnings } \\
\text { attributable } \\
\text { to unskilled } \\
\text { workers } \\
\end{array}$ & $\begin{array}{c}\text { Inequality } \\
\text { in } \\
\text { unemploym } \\
\text { ent benefits } \\
\text { attributable } \\
\text { to } \\
\text { unemployed } \\
\end{array}$ \\
\hline Union density & $-0.415^{*}$ & $-0.420 *$ & $-0.346^{*}$ & -0.112 & $-0.308^{*}$ & $-0.346^{*}$ \\
\hline Agreements coverage & $-0.601 *$ & $-0.3512^{*}$ & $-0.584 *$ & $-0.391 *$ & $-0.378^{*}$ & $-0.436 *$ \\
\hline Centralization & -0.099 & -0.223 & -0.044 & -0.036 & -0.141 & 0.083 \\
\hline Strike activity & -0.280 & -0.190 & -0.268 & -0.115 & -0.343 & -0.144 \\
\hline Minimum wage (Kaitz index) & 0.127 & $0.3219 *$ & 0.043 & 0.026 & -0.161 & 0.216 \\
\hline $\begin{array}{l}\text { Employment protection } \\
\text { legislation }\end{array}$ & -0.330 & 0.074 & $-0.410^{*}$ & $-0.626^{*}$ & 0.018 & 0.011 \\
\hline Unemployment benefit & 0.125 & 0.010 & 0.142 & 0.061 & -0.092 & $0.327 *$ \\
\hline Tax wedge & -0.241 & -0.023 & -0.273 & -0.099 & $-0.316^{*}$ & -0.188 \\
\hline Social expenditure & -0.229 & -0.175 & -0.190 & 0.035 & -0.238 & -0.267 \\
\hline Child care & -0.179 & -0.040 & -0.189 & -0.252 & 0.037 & -0.109 \\
\hline Parental leave & -0.320 & -0.138 & -0.318 & $-0.435^{*}$ & -0.060 & 0.040 \\
\hline $\begin{array}{l}\text { Tax treatment of household } \\
\text { incomes }\end{array}$ & 0.052 & -0.170 & 0.120 & 0.292 & -0.024 & -0.117 \\
\hline Active labour market policies & -0.296 & -0.222 & -0.273 & -0.047 & $-0.322^{*}$ & -0.255 \\
\hline Passive labour market policies & -0.248 & -0.068 & -0.266 & -0.089 & $-0.320^{*}$ & -0.182 \\
\hline
\end{tabular}

30 countries - * significant at $10 \%$

\subsection{Empirical assessment}

\section{Cross-sectional approach}

One crucial issue in the analysis of the role of LMI in shaping earnings inequality is the match of inequality computed from micro-data to the corresponding institutional measures. If we correlate current inequality measured over workers of different ages (who therefore have been staying in the labour market for different durations) to the current union density (which is computed over the workers who are currently working) we are simply considering "industrial relations" regimes, without any claim of causality in one direction or the other. Such an exercise is conducted in table 19.6, where we consider three different dimensions of inequality (yearly earnings from dependent employment, hourly wages and worked hours by dependent employees). In accordance with our previous betweengroup inequality decomposition (see Section

5.2), for each dimension we consider two market phenomena that are correlated with market forces: level of qualification of the labour force ${ }^{141}$ and level of employment (better captured by the female employment rate). In all cases an increasing level of education in the labour force is negatively and significantly associated with inequality. Similarly it occurs for wages, but not for hours: not surprisingly, when more women enter the labour market, the working hours regime as a whole becomes more diversified. ${ }^{142}$

When we introduce institutional measures in order to capture deviations from market equilibrium, we identify a subset of institutions that are significantly correlated with different inequalities (see columns 2-5-8 of Table 19.6). Union density has a negative association with yearly earnings, hourly wages and

\footnotetext{
141 Actually the skill level of the labour force is the joint outcome of the demand for education of the population and the institutional supply of schooling; however replacing it with some measure of the strength of the institutional push towards education (such as the years of compulsory education) did not prove statistically significant.

142 Additional compositional controls related to the age composition do not come out statistically significant, and therefore are left out of the analysis.
} 
hours: this captures different dimensions of union presence (like coverage or wage centralization, which are not statistically significant $\left.{ }^{143}\right)$. Although the unconditional correlation with worked hours appears positive (see Figure 19.31), once we control for compositional effects it turns negative (despite a rather small magnitude). A second institutional dimension with statistical negative correlation with earnings inequality is the presence and the level of minimum wages. However, as discussed in Appendix 3, this institution is present only in a subset of countries, while in other this role is played by legislative or judicial extension of the union bargained wage. In addition, there are often derogations for marginal workers, which are not captured by this measure. Nevertheless, the mere existence of a legal floor to downward flexibility of wages contributes to the containment of inequality.

The third institutional dimension deals with unemployment benefit, whose theoretical expectation is ambiguous due to a potential enhancing effect on the unemployment rate. The replacement rate does not exhibit a statistically significant correlation, whereas the overall public expenditure on passive labour market policies is negatively correlated with earnings and wage inequalities, and positively with hours inequality. ${ }^{144}$ This suggests that transferring money to members of the labour force (which constitutes our sample of investigation) reduces inequality in terms of revenues, but on the other side allows for the continuation of unequally distributed job opportunities. A fourth dimension is connected to the employment protection. ${ }^{145}$ Not surprisingly, its correlation is strongest with the distribution of work: the more regulated are the labour contract, the more equal is the distribution of worked hours. Since employment protection and union activities tend to be complements (Bertola 2004), it does not surprise finding an analogous negative correlation with earnings and wage inequality, as clearly shown in Figure 19.32.

Still restricting to the subsample of OECD countries we find some statistical evidence of negative correlation of earnings inequality with childcare attendance, interpreted as proxy for childcare availability. On a theoretical ground we do expect a larger female participation to the labour market and an evener distribution of external work opportunities in the couple: both should have an impact on the hours inequality, which however do not appear in the data. The negative correlation with earnings inequality could capture some unobservable dimension of welfare provision, which is typically associated to lower inequality (though a direct measure of it, given by social expenditure, does not come out statistically significant). ${ }^{146}$

Despite the limited degrees of freedom, these are the only institutional features that correlate with statistical significance with various dimensions of earnings inequality. Against the potential objection of omitted variables, we have also introduced all measures that we have collected (see columns 3-6-9 of Table 19.6), without finding any other statistical correlation. However despite the richness of the institutional framework, a simple cross-country regression like the actual one does not provide an incontrovertible evidence of labour market institutions contributing to shape earnings inequality. To this goal, we now move to exploit cohort variation in inequalities.

In columns 10-11-12 of Table 19.6 we have considered as dependent variable the correlation computed at country level between hourly wages and worked hours, following the idea that higher correlation (in absolute terms) may reduce earnings inequality (as long as this correlation does not simply capture spurious correlation - see again Figure 19.22 and the discussion there). We find a negative correlation with both union density and employment protection legislation, suggesting that in highly regulated labour market (due to firing restrictions and/or active union presence) the working poor obtain partial compensation of their weak command in the labour market by extended (or just complete) working hours.

\footnotetext{
${ }^{143}$ Also strike activity is not statistically significant, but in addition it reduces the sample to 18 countries, and therefore is not shown.

${ }^{144}$ Data on the expenditure on labour market policies are not available in the case of Iceland.

145 The OECD measure of EPL is not available for non-OECD members (Bulgaria, Cyprus, Latvia, Lithuania, Malta, and Romania). However, in order not to lose these countries in the analysis of other institutions, we have imputed these missing values using the sample mean of non-missing countries.

146 If we reduce the number of countries even further (to 21) by introducing measures of parental leave we find some statistical significance for a negative correlation with inequality in hourly wages (not shown).
} 
Table 19.6 - Gross earnings inequality (SILC 2010-PSID 2011) against market and labour-market institutions (2001-2010) effects - OLS

\begin{tabular}{|c|c|c|c|c|c|c|c|c|c|c|c|c|}
\hline \multirow{3}{*}{\begin{tabular}{|l} 
Dependent variable \\
$\begin{array}{l}\text { Population share with secondary } \\
\text { degree }\end{array}$
\end{tabular}} & \multicolumn{3}{|c|}{$\begin{array}{c}1 \\
\text { Gini of gross annual employee } \\
\text { earnings (working more than } \\
1000 \text { hours per year) }\end{array}$} & \multicolumn{3}{|c|}{$\begin{array}{ccc}4 & 5 & 6 \\
\text { Gini of gross hourly wages }\end{array}$} & \multicolumn{3}{|c|}{$\begin{array}{cc}7 & 8 \\
\text { Gini of employee (all } \\
\text { durations) }\end{array}$} & \multicolumn{3}{|c|}{$\begin{array}{l}10 \quad 11 \quad 12 \\
\text { Correlation of wages and } \\
\text { hours }\end{array}$} \\
\hline & -0.309 & -0.06 & -0.086 & -0.424 & -0.277 & -0.367 & -0.233 & -0.139 & -0.201 & -0.095 & -0.139 & -0.201 \\
\hline & {$[0.073]^{* * *}$} & {$[0.091]$} & {$[0.131]$} & {$[0.151]^{* *}$} & {$[0.190]$} & {$[0.259]$} & {$[0.083]^{* *}$} & {$[0.124]$} & {$[0.148]$} & {$[0.262]$} & {$[0.124]$} & [0.148] \\
\hline Population share with post- & -0.217 & -0.197 & -0.211 & -0.235 & -0.268 & -0.289 & -0.19 & -0.189 & -0.189 & 0.083 & -0.189 & -0.189 \\
\hline secondary degree & {$[0.059]^{* * *}$} & {$[0.067]^{* *}$} & {$[0.095]^{*}$} & {$[0.085]^{* *}$} & {$[0.100]^{* *}$} & {$[0.158]$} & {$[0.078]^{* *}$} & {$[0.058]^{* * *}$} & {$[0.077]^{* *}$} & {$[0.171]$} & {$[0.058]^{* * *}$} & {$[0.077]^{* *}$} \\
\hline Female employment rate & -0.66 & -0.405 & -0.528 & -0.816 & -0.679 & -0.835 & 0.208 & 0.429 & 0.564 & 0.537 & 0.429 & 0.564 \\
\hline & {$[0.211]^{* * *}$} & {$[0.175]^{* *}$} & {$[0.281]^{*}$} & {$[0.426]^{*}$} & {$[0.377]^{*}$} & {$[0.595]$} & {$[0.177]$} & {$[0.115]^{* * *}$} & {$[0.254]^{*}$} & {$[0.417]$} & {$[0.115]^{* * *}$} & {$[0.254]^{*}$} \\
\hline Union density & -0.078 & -0.125 & -0.19 & -0.048 & -0.131 & -0.192 & -0.083 & -0.121 & -0.124 & -0.23 & -0.121 & -0.124 \\
\hline & {$[0.039]^{*}$} & {$[0.038]^{* * *}$} & {$[0.039]^{* * *}$} & {$[0.052]$} & {$[0.075]$} & {$[0.099]^{*}$} & {$[0.037]^{* *}$} & {$[0.036]^{* * *}$} & {$[0.057]^{*}$} & {$[0.147]$} & {$[0.036]^{* * *}$} & {$[0.057]^{*}$} \\
\hline Minimum wage/mean wage & -0.064 & -0.105 & -0.136 & -0.074 & -0.157 & -0.193 & -0.045 & -0.072 & -0.088 & -0.104 & -0.072 & -0.088 \\
\hline & {$[0.043]$} & {$[0.041]^{* *}$} & {$[0.041]^{* *}$} & {$[0.065]$} & {$[0.065]^{* *}$} & {$[0.093]^{*}$} & {$[0.040]$} & {$[0.034]^{*}$} & {$[0.052]$} & {$[0.144]$} & {$[0.034]^{*}$} & {$[0.052]$} \\
\hline Passive labour market & -0.04 & -0.036 & -0.055 & -0.044 & -0.04 & -0.089 & 0.025 & 0.022 & 0.045 & -0.024 & 0.022 & 0.045 \\
\hline policy/gdp $(\times 100)$ & {$[0.010]^{* * *}$} & {$[0.010]^{* * *}$} & {$[0.034]$} & {$[0.015]^{* * *}$} & {$[0.016]^{* *}$} & {$[0.067]$} & {$[0.009]^{* *}$} & {$[0.010]^{* *}$} & {$[0.034]$} & {$[0.027]$} & {$[0.010]^{* *}$} & {$[0.034]$} \\
\hline Employment protection & & -0.022 & -0.023 & & -0.041 & -0.047 & & -0.029 & -0.031 & & -0.029 & -0.031 \\
\hline legislation [1-6] & & {$[0.010]^{* *}$} & {$[0.016]$} & & {$[0.022]^{*}$} & {$[0.031]$} & & {$[0.006]^{* * *}$} & {$[0.007]^{* * *}$} & & {$[0.006]^{* * *}$} & {$[0.007]^{* * *}$} \\
\hline $\begin{array}{l}\text { Enrolment rate in early } \\
\text { childcare and pre-primary }\end{array}$ & & -0.111 & -0.174 & & -0.139 & -0.186 & & -0.019 & -0.002 & & -0.019 & -0.002 \\
\hline education & & {$[0.032]^{* * *}$} & {$[0.042]^{* * *}$} & & {$[0.064]^{* *}$} & {$[0.090]^{*}$} & & {$[0.037]$} & {$[0.057]$} & & {$[0.037]$} & {$[0.057]$} \\
\hline Agreements coverage & & & $\begin{array}{c}0.052 \\
{[0.056]}\end{array}$ & & & $\begin{array}{c}0.064 \\
{[0.100]}\end{array}$ & & & $\begin{array}{c}0.051 \\
{[0.044]}\end{array}$ & & & $\begin{array}{c}0.051 \\
0.044\end{array}$ \\
\hline Bargaining centralization & & & -0.056 & & & -0.052 & & & -0.012 & & & -0.012 \\
\hline & & & {$[0.042]$} & & & {$[0.091]$} & & & {$[0.050]$} & & & {$[0.050]$} \\
\hline Active labour market & & & 0.015 & & & 0.078 & & & -0.042 & & & -0.042 \\
\hline policy/gdp $(\times 100)$ & & & {$[0.047]$} & & & {$[0.103]$} & & & {$[0.051]$} & & & {$[0.051]$} \\
\hline Social expenditure/gdp & & & 0.891 & & & -0.632 & & & 0.22 & & & 0.22 \\
\hline & & & {$[0.937]$} & & & {$[1.855]$} & & & {$[0.711]$} & & & {$[0.711]$} \\
\hline Tax wedge & & & 0.059 & & & -0.031 & & & -0.121 & & & -0.121 \\
\hline & & & {$[0.091]$} & & & {$[0.192]$} & & & {$[0.117]$} & & & {$[0.117]$} \\
\hline Unemployment benefit & & & 0.039 & & & 0.042 & & & -0.022 & & & -0.022 \\
\hline Replacement rate & & & {$[0.074]$} & & & {$[0.105]$} & & & {$[0.052]$} & & & {$[0.052]$} \\
\hline Observations (countries) & 29 & 23 & 23 & 29 & 23 & 23 & 29 & 23 & 23 & 29 & 23 & 23 \\
\hline R-squared & 0.66 & 0.78 & 0.84 & 0.46 & 0.69 & 0.74 & 0.47 & 0.71 & 0.81 & 0.31 & 0.71 & 0.81 \\
\hline
\end{tabular}

Note: unless specified, all variables are in percent points - * significant at 10\%; ** significant at 5\%; *** significant at $1 \%$ - robust standard errors in brackets - constant included 
Figure 19.31 - Earnings inequality (SILC 2010-PSID 2011) and union density (average 2001-2010)

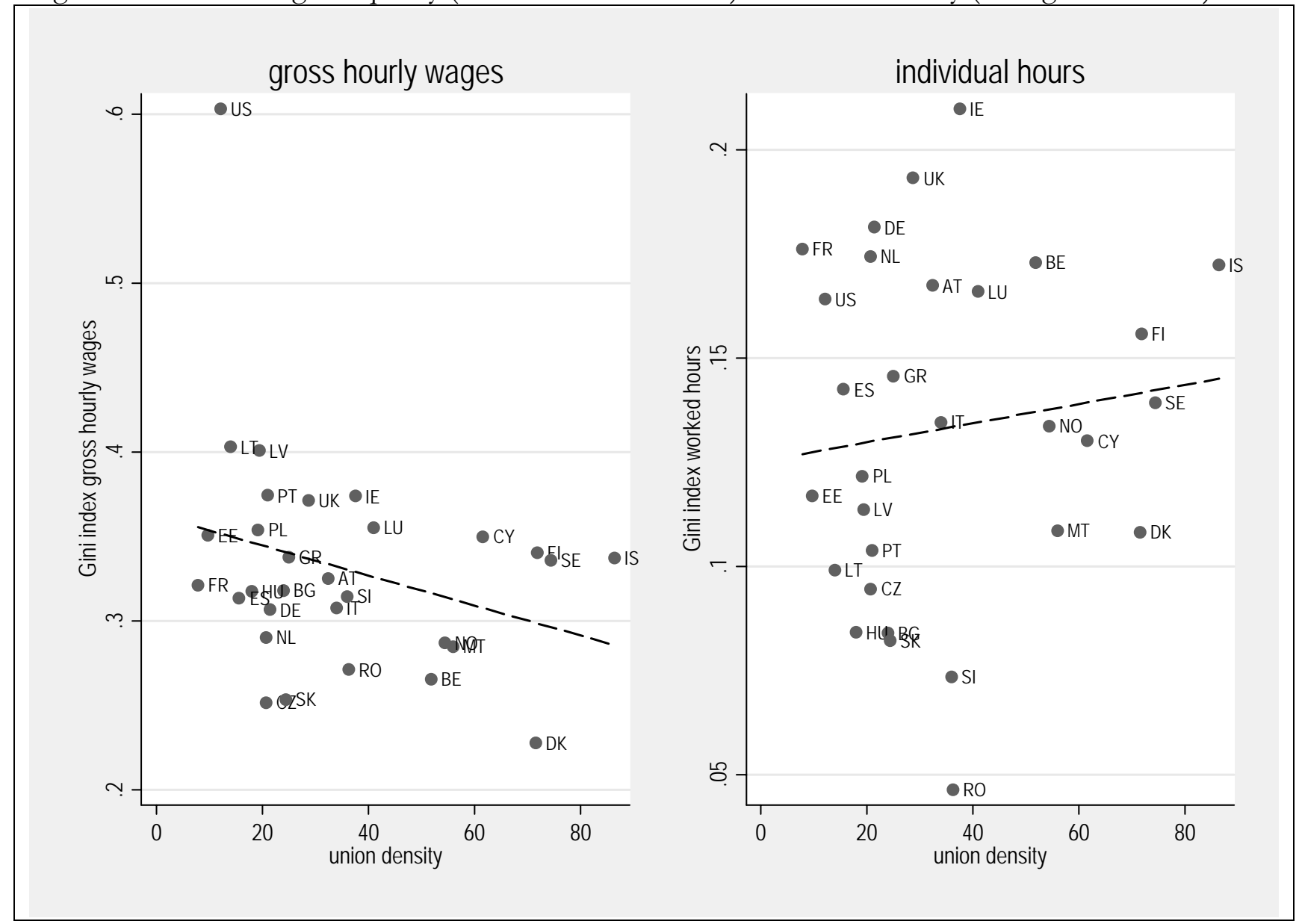

Figure 19.32 - Earnings inequality (SILC 2010-PSID 2011) and employment protection (average 20012010)
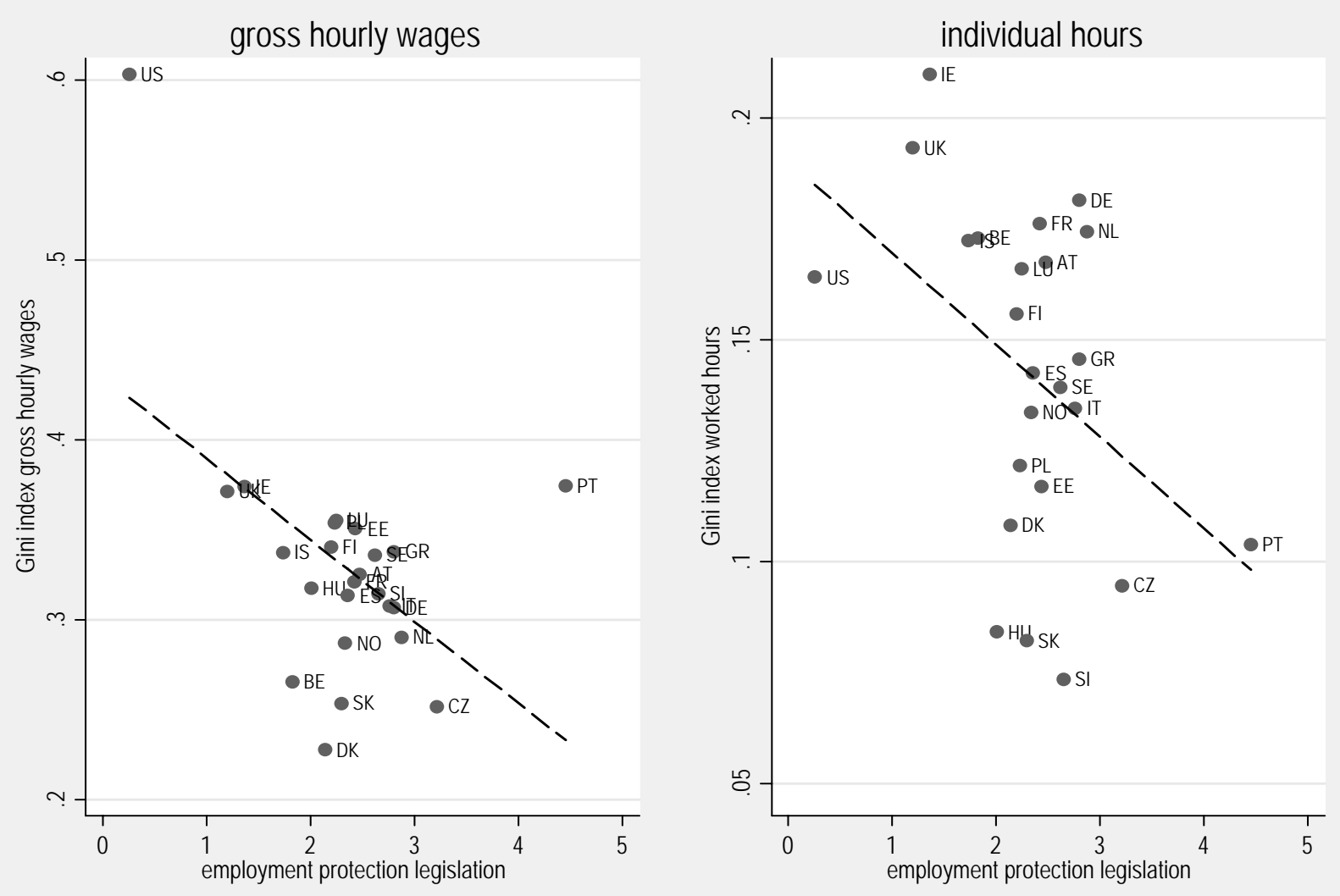


\section{Longitudinal or pseudo-longitudinal approach}

Aiming to obtain more statistical robust results, we need to exploit cross-country and within-country variations of inequality and institutions, in order to be able to dispense with unobservables by means of appropriate country and time fixed effects. If data were available, one could take repeated cross sections for each country, compute inequality measures of the relevant population in each survey and match them with the prevailing institutional measures. Unfortunately, cross-country comparable surveys for the countries under analysis do not go back more than a couple of decades, and this has led us to pursue an alternative strategy. Since we need to match individuals belonging to different age cohorts, who entered the labour market in different years, to institutional profiles that are relevant for their wage determination, we need to discuss the appropriate matching rule.

One possibility would match individuals to the institutions prevailing at the time of their entrance into the labour market (see matching rules $1 \mathrm{a}$ and $1 \mathrm{~b}$ in Table 19.7). This implies that the current difference between a person's wage and the wages of his or her co-workers may be affected by the bargaining activity exerted by the unions thirty years ago. As long as wages are highly persistent (due to seniority rules and/or automatic adjustment clauses) this may be considered a viable assumption. An alternative possibility considers both institutional persistence (institutions are slow-changing variables) and different exposure to an institutional environment (variable treatment). In this second perspective, older individuals are supposed to have been exposed to an institutional framework which has been (on average) available over their entire working life (see matching rule 2 in Table 19.7). In such a case the current difference between someone's wage and the wages of his or her co-workers has been affected by the bargaining activity exerted over the past thirty years. In order to appreciate differences in the institutional measures according to the different matching rules, Figure 19.33 plots the contemporaneous union density (solid line) and the backward (moving) mean according to the third matching rule (dashed line): while the former is more volatile, the latter "keeps" a smoothed memory of past dynamics.

Both strategies are approximations, because they induce measurement errors in the dependent variables (measuring wage inequality by age cohort is used as proxy for overall inequality measured in the past). However they have the advantage of covering a long time span, allowing greater variability in the institutional measures.

Table 19.7 - Matching rules between inequality measures and institutional variables

\begin{tabular}{|c|c|c|c|c|c|}
\hline Cohort & $\begin{array}{c}\text { Individual } \\
\text { birth year }\end{array}$ & Age in 2010 & $\begin{array}{c}\text { Matching rule 1a: } \\
\text { average } \\
\text { institutional } \\
\text { measures } \\
\text { prevailing when } \\
\text { entering the } \\
\text { labour market } \\
\text { aged 20-year-old }\end{array}$ & $\begin{array}{c}\text { Matching rule 1b: } \\
\text { average union } \\
\text { density prevailing } \\
\text { just before the } \\
\text { entrance in the } \\
\text { labour market (5 } \\
\text { year lag) }\end{array}$ & $\begin{array}{c}\text { Matching rule 2: } \\
\text { average union } \\
\text { density prevailing } \\
\text { over the entire } \\
\text { working life } \\
\text { course }\end{array}$ \\
\hline 1 & $1986-90$ & $20-24$ & $2006-10$ & $2001-05$ & $2006-2010$ \\
\hline 2 & $1981-85$ & $25-29$ & $2001-05$ & $1996-00$ & $2001-2010$ \\
\hline 3 & $1976-80$ & $30-34$ & $1996-00$ & $1991-95$ & $1996-2010$ \\
\hline 4 & $1971-75$ & $35-39$ & $1991-95$ & $1986-90$ & $1991-2010$ \\
\hline 5 & $1966-70$ & $40-44$ & $1986-90$ & $1981-85$ & $1986-2010$ \\
\hline 6 & $1961-65$ & $45-49$ & $1981-85$ & $1976-80$ & $1981-2010$ \\
\hline 7 & $1956-60$ & $50-54$ & $1976-80$ & $1971-75$ & $1976-2010$ \\
\hline 8 & $1951-55$ & $55-59$ & $1971-75$ & $1966-70$ & $1971-2010$ \\
\hline 9 & $1946-50$ & $60-64$ & $1966-70$ & $1961-65$ & $1966-2010$ \\
\hline
\end{tabular}

Irrespective of the chosen matching, by treating our cross-section as pseudo-panel we significantly augment the degrees of freedom in the estimation. The different time coverage of institutional measures yields an unbalanced panel, where we control for country and cohort fixed effects. The errors are clustered at the country level. As a consequence, our results are more robust than the previous 
cross-section estimates reported in Table 19.8. As long as the fixed effects clean away all the other sources of confounding variations, we use cross-country and life-cycle variations in inequality for identifying the contribution of institutions to shape the earnings distribution. The contemporaneous insertion of several institutional measures allows for the identification of each specific contribution, other institutions and sample composition kept constant. We have decided to exclude the two oldest cohorts, since information on institutions in the sixties is available only for union density and unemployment benefit. In addition retirement rules vary across countries, introducing large variations in the employment rate for these age cohorts. ${ }^{147}$

Figure 19.33 - Alternative measures of exposition to institutions: union density

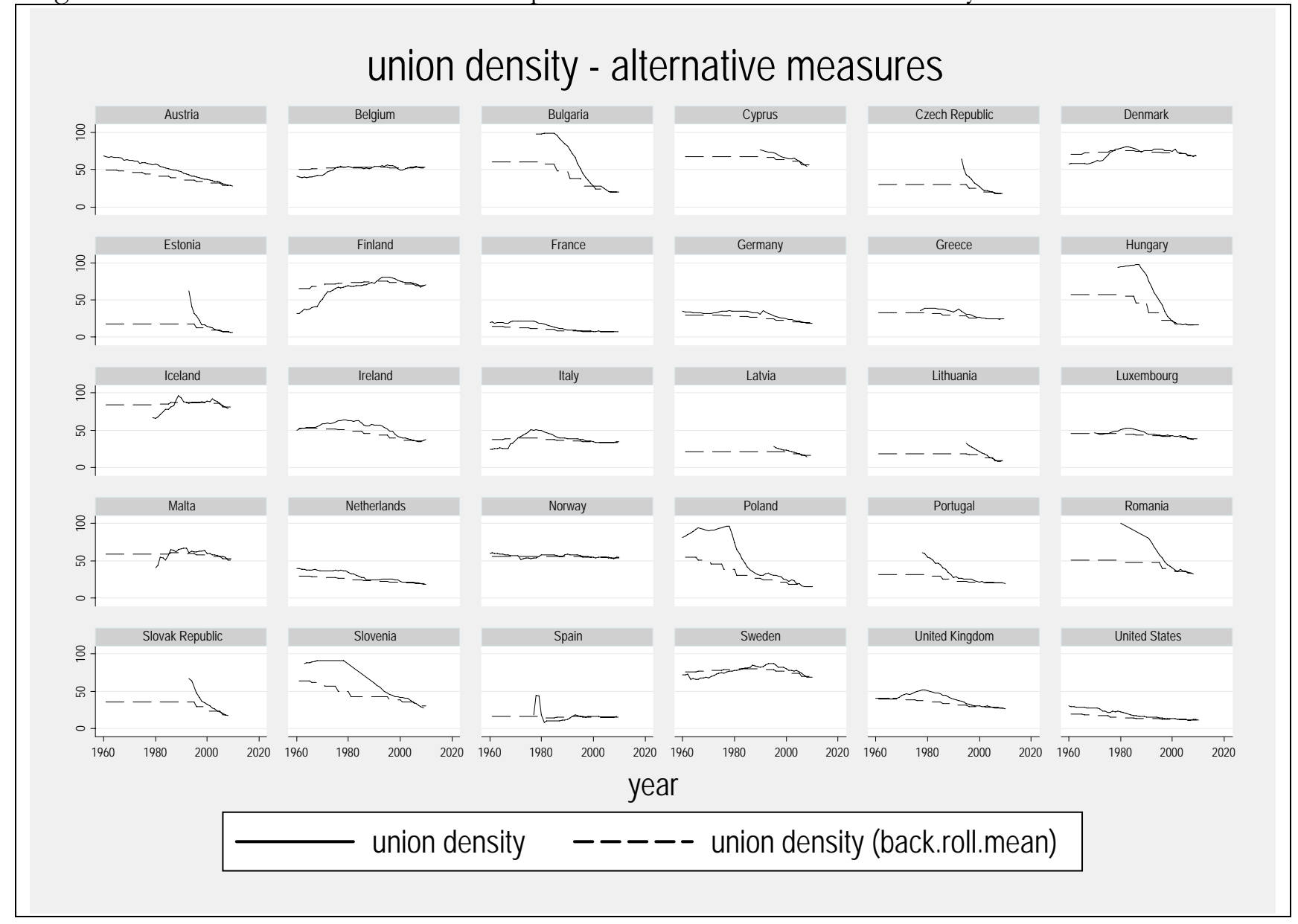

In Table 19.8 we present the estimates corresponding to the Matching rule 1a (individual matched to the institutions prevailing when entering the labour market - the other Matching rule 1b gives similar results on a shorter sample size, and is not reported for brevity). The structure of Table 19.8 resembles the previous Table 19.6 but leaves out the analysis of the correlation between hours and wages. We consider three measures of inequality (yearly earnings for full-time workers, hourly wages and hours worked) and for each of them we control for educational attainment in the labour force and female participation. In both cases they exert a negative impact on inequality, despite the weaker statistical significance of education. For each dependent variable we consider three specifications: country fixed effects (columns 1-4-7), country and cohort fixed effects (columns 2-5-8) and country and cohort fixed effects including OECD indicator for employment protection, which excludes non OECD members (columns 3-6-9). ${ }^{148}$

147 The employment rate for individuals aged 55-64 ranges from 65\% in Sweden (or 62\% in the US) to 30\% for Italy or Romania.

148 The first two columns still exclude Iceland, due to the lack of data on labour-market policies, while the third excludes non-OECD countries. 
Table 19.8 - Gross earnings inequality (SILC 2010-PSID 2011) against market and labour market institutions (1975-2010) effects - OLS - longitudinal cohort data (matching rule 1a)

\begin{tabular}{|c|c|c|c|c|c|c|c|c|c|}
\hline \multirow[t]{2}{*}{ Dependent variable } & \multicolumn{3}{|c|}{$\begin{array}{l}\text { Gini of gross yearly employee earnings } \\
\text { (working more than } 1000 \text { hours per year) }\end{array}$} & \multicolumn{3}{|c|}{ Gini of gross hourly wages } & \multicolumn{3}{|c|}{ Gini of employee hours (all durations) } \\
\hline & -0.022 & 0.041 & 0.028 & -0.074 & -0.075 & -0.093 & 0.082 & 0.089 & 0.093 \\
\hline secondary degree & {$[0.165]$} & {$[0.140]$} & [0.138] & {$[0.154]$} & [0.159] & {$[0.160]$} & [0.104] & [0.109] & {$[0.120]$} \\
\hline Population share with post- & -0.162 & -0.104 & -0.127 & -0.18 & -0.239 & -0.285 & -0.084 & -0.093 & -0.103 \\
\hline secondary degree & {$[0.068]^{* *}$} & {$[0.090]$} & [0.091] & {$[0.069]^{* *}$} & {$[0.100]^{* *}$} & {$[0.097]^{* * *}$} & [0.065] & [0.108] & [0.101] \\
\hline Femole emoloument rote & 0.309 & -0.01 & -0.035 & 0.315 & 0.333 & 0.318 & -0.452 & -0.462 & -0.472 \\
\hline Female employment rate & {$[0.141]^{* *}$} & [0.169] & {$[0.167]$} & {$[0.203]$} & {$[0.211]$} & [0.223] & {$[0.121]^{* * *}$} & {$[0.202]^{* *}$} & {$[0.220]^{* *}$} \\
\hline & 0.138 & 0.053 & 0.051 & 0.09 & 0.073 & 0.058 & -0.058 & -0.063 & -0.076 \\
\hline Union density & {$[0.055]^{* *}$} & {$[0.045]$} & [0.046] & {$[0.041]^{* *}$} & {$[0.060]$} & {$[0.062]$} & {$[0.033]^{*}$} & {$[0.037]$} & {$[0.041]^{*}$} \\
\hline Minimum waoe/mean waoe & -0.127 & -0.136 & -0.149 & 0.064 & 0.066 & 0.059 & -0.053 & -0.049 & -0.04 \\
\hline Minimum wage/mean wage & {$[0.073]^{*}$} & {$[0.055]^{* *}$} & {$[0.063]^{* *}$} & {$[0.055]$} & {$[0.062]$} & {$[0.070]$} & {$[0.028]^{*}$} & {$[0.030]$} & {$[0.031]$} \\
\hline Passive labour market & -0.004 & -0.009 & -0.007 & -0.011 & -0.012 & -0.009 & 0.008 & 0.007 & 0.008 \\
\hline policy/gdp & {$[0.005]$} & {$[0.006]$} & {$[0.006]$} & {$[0.007]$} & {$[0.008]$} & {$[0.008]$} & {$[0.004]^{* *}$} & {$[0.005]$} & {$[0.005]^{*}$} \\
\hline Employment protection & & & 0.026 & & & 0.011 & & & -0.022 \\
\hline legislation & & & {$[0.022]$} & & & {$[0.026]$} & & & {$[0.018]$} \\
\hline Observations & 130 & 130 & 113 & 130 & 130 & 113 & 130 & 130 & 113 \\
\hline Number of countries & 29 & 29 & 23 & 29 & 29 & 23 & 29 & 29 & 23 \\
\hline R-squared & 0.4 & 0.5 & 0.56 & 0.19 & 0.22 & 0.28 & 0.64 & 0.65 & 0.67 \\
\hline Country fixed effects & yes & yes & yes & yes & yes & yes & yes & yes & yes \\
\hline Cohort fixed effects & no & yes & yes & no & yes & yes & no & yes & yes \\
\hline
\end{tabular}

Robust standard errors clustered by countries in brackets - * significant at $10 \%$; ** significant at $5 \%$; *** significant at $1 \%$ 
Table 19.9 - Gross earnings inequality (SILC 2010-PSID 2011) against market and labour market institutions (1975-2010) effects - OLS - longitudinal cohort data (matching rule 2)

\begin{tabular}{|c|c|c|c|c|c|c|c|c|c|}
\hline Dependent variable & \multicolumn{3}{|c|}{$\begin{array}{l}\text { Gini of gross yearly employee earnings } \\
\text { (working more than } 1000 \text { hours per year) }\end{array}$} & \multicolumn{3}{|c|}{ Gini of gross hourly wages } & \multicolumn{3}{|c|}{ Gini of employee hours (all durations) } \\
\hline Population share with & 0.018 & 0.1 & 0.053 & -0.019 & 0.012 & -0.017 & 0.097 & 0.092 & 0.104 \\
\hline secondary degree & [0.102] & [0.089] & [0.118] & [0.089] & [0.099] & {$[0.137]$} & {$[0.070]$} & {$[0.075]$} & [0.088] \\
\hline Population share with post- & -0.12 & -0.052 & 0 & -0.116 & -0.104 & -0.091 & -0.053 & -0.013 & -0.039 \\
\hline secondary degree & {$[0.051]^{* *}$} & {$[0.065]$} & [0.061] & {$[0.047]^{* *}$} & {$[0.060]^{*}$} & {$[0.076]$} & {$[0.043]$} & {$[0.078]$} & [0.095] \\
\hline Female employment rate & $\begin{array}{c}0.283 \\
{[0.115]^{* *}}\end{array}$ & $\begin{array}{l}-0.116 \\
{[0.140]}\end{array}$ & $\begin{array}{c}-0.09 \\
{[0.149]}\end{array}$ & $\begin{array}{c}0.314 \\
{[0.129]^{* *}}\end{array}$ & $\begin{array}{c}0.177 \\
{[0.163]}\end{array}$ & $\begin{array}{c}0.218 \\
{[0.194]}\end{array}$ & $\begin{array}{c}-0.409 \\
{[0.090]^{* * *}}\end{array}$ & $\begin{array}{c}-0.285 \\
{[0.148]^{*}}\end{array}$ & $\begin{array}{c}-0.356 \\
{[0.158]^{* *}}\end{array}$ \\
\hline Union density & $\begin{array}{c}0.094 \\
{[0.064]}\end{array}$ & $\begin{array}{l}-0.053 \\
{[0.035]}\end{array}$ & $\begin{array}{l}-0.042 \\
{[0.053]}\end{array}$ & $\begin{array}{c}0.109 \\
{[0.053]^{*}}\end{array}$ & $\begin{array}{c}0.067 \\
{[0.056]}\end{array}$ & $\begin{array}{c}0.083 \\
{[0.088]}\end{array}$ & $\begin{array}{c}-0.137 \\
{[0.041]^{* * *}}\end{array}$ & $\begin{array}{c}-0.082 \\
{[0.038]^{* *}}\end{array}$ & $\begin{array}{c}-0.123 \\
{[0.037]^{* * *}}\end{array}$ \\
\hline Minimum wage/mean wage & {$[0.127]^{*}$} & {$[0.095]^{* *}$} & {$[0.098]^{* *}$} & {$[0.101]$} & $\begin{array}{c}0.063 \\
{[0.098]}\end{array}$ & $\begin{array}{c}0.051 \\
{[0.105]}\end{array}$ & $\begin{array}{c}-0.102 \\
{[0.058]^{*}}\end{array}$ & $\begin{array}{l}-0.119 \\
{[0.070]^{*}}\end{array}$ & $\begin{array}{l}-0.101 \\
{[0.079]}\end{array}$ \\
\hline Active labour market & -0.094 & -0.101 & -0.102 & -0.113 & -0.119 & -0.119 & -0.043 & -0.049 & -0.051 \\
\hline policy/gdp & {$[0.032]^{* * *}$} & {$[0.024]^{* * *}$} & {$[0.024]^{* * *}$} & {$[0.035]^{* * *}$} & {$[0.037]^{* * *}$} & {$[0.036]^{* * *}$} & {$[0.028]$} & {$[0.026]^{*}$} & {$[0.024]^{* *}$} \\
\hline $\begin{array}{l}\text { Passive labour market } \\
\text { policy/gdp } \\
\text { Employment protection } \\
\text { legislation }\end{array}$ & $\begin{array}{l}-0.009 \\
{[0.020]}\end{array}$ & $\begin{array}{c}-0.037 \\
{[0.014]^{* *}}\end{array}$ & $\begin{array}{c}-0.047 \\
{[0.014]^{* * *}} \\
0.035 \\
{[0.053]}\end{array}$ & $\begin{array}{c}-0.054 \\
{[0.017]^{* * *}}\end{array}$ & $\begin{array}{c}-0.064 \\
{[0.017]^{* * *}}\end{array}$ & $\begin{array}{c}-0.068 \\
{[0.020]^{* * *}} \\
-0.007 \\
{[0.062]}\end{array}$ & $\begin{array}{l}0.007 \\
{[0.013]}\end{array}$ & $\begin{array}{c}0.007 \\
{[0.013]}\end{array}$ & $\begin{array}{c}0.011 \\
{[0.014]} \\
-0.057 \\
{[0.046]}\end{array}$ \\
\hline Observations & 203 & 203 & 161 & 203 & 203 & 161 & 203 & 203 & 161 \\
\hline Number of countries & 29 & 29 & 23 & 29 & 29 & 23 & 29 & 29 & 23 \\
\hline R-squared & 0.33 & 0.48 & 0.56 & 0.33 & 0.37 & 0.4 & 0.61 & 0.65 & 0.67 \\
\hline Country fixed effects & yes & yes & yes & yes & yes & yes & yes & yes & yes \\
\hline Cohort fixed effects & no & yes & yes & no & yes & yes & no & yes & yes \\
\hline
\end{tabular}

Robust standard errors clustered by countries in brackets - * significant at $10 \%$; ** significant at $5 \%$; *** significant at $1 \%$ 
In this framework we find only partial support to our previous findings with cross-sectional analysis. Focussing on a model that includes both country and cohort fixed effects, there is some evidence of a negative impact of unions on the distribution of work (Column 9) and of a stronger impact of the minimum wage on earnings inequality. Contrary to previous results, passive labour-market policies do not reach statistical significance for their negative impact on earnings and wage inequality, but register some positive impact on the Gini index for hours worked. Other institutional variables (such as the tax wedge, unemployment benefit, parental leave, active labour market policies), which are constantly nonsignificant are not reported for brevity. ${ }^{149}$ The same results are reinforced when we adopt the second matching rule, as shown in Table 19.9. The different data organisation significantly extends the sample, and this allows for a more precise identification of the effects (see for example the unconditional correlation with passive labour market policies, depicted in Figure 19.34). Union density is now clearly reducing inequality in hours, while the minimum wage reduces inequality both in earnings and hours. In addition to the negative contribution of passive labour market policies on earnings and wage inequality, we now find that also active labour market policies negatively contribute to inequality reduction, possibly due to the reduction in unemployment (i.e. more workers become employed earning a wage higher than the benefit).

Figure 19.34 - Earnings inequality (SILC 2010-PSID 2011) and passive labour market policies, 5-year averages (1975-2010)

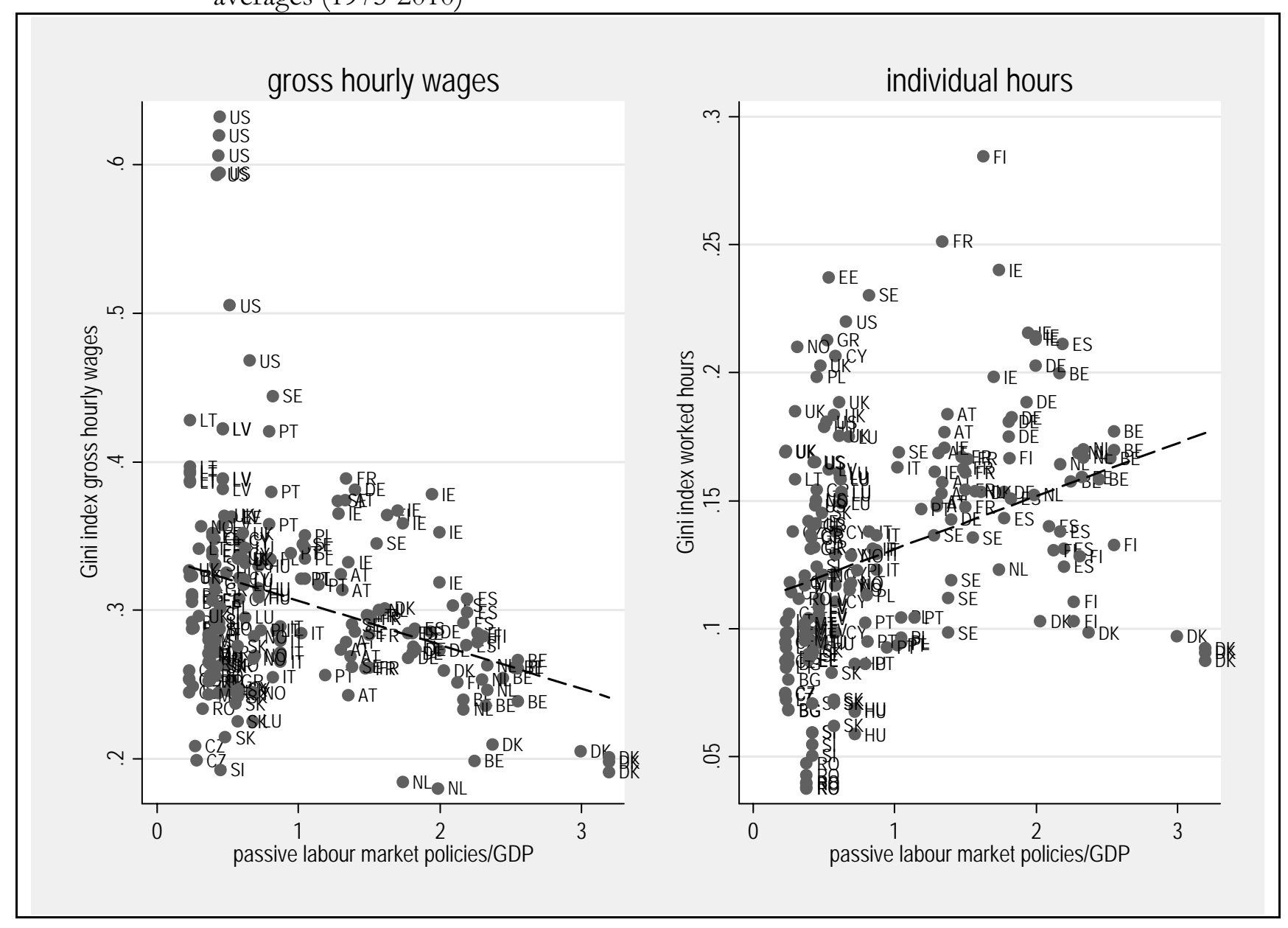

149 The other institutional measures appearing in Table 19.7 and not in Table 19.9 (childcare, social expenditure, tax wedge) are not reported because they are not available over a longer time span going back to the older cohorts. 


\subsection{Discussion}

Our empirical results are consistent with the main findings in the literature reviewed in Section 4.6. ${ }^{150}$ They confirm that the presence and stringency of a minimum wage reduces earnings inequality, also setting an (implicit) control on the distribution of working hours, which seems to be the main channel of inequality reduction of the bargaining activity of unions. Less common in the literature is the finding of a negative impact of both active and passive labour market policies. Here we surmise that most of this effect works through variations in the unemployment rate: when active labour market policies are effective in pushing the unemployed back to work (at least for some hours) they reduce the bottom tail of the earnings distribution; when the unemployment support becomes more generous and/or more universal (as has happened during the current recession) it reduces the income gap between employed and unemployed, but potentially raise the unemployment rate. The combined effect of these channels seems to be overall inequality-reducing.

${ }^{150}$ Issues of data quality and a review of main findings for cross-country analysis can be found in Eichhorst et al. (2008). 


\section{Conclusion and future research}

Putting the literature on the distribution of (individual) wages in the context of the (household) income distribution we are struck by the disconnect between the two. There is an extensive literature with a long tradition on each of them but very little on both, in spite of the fact that wage earnings are by far the most important source of income in modern society. The strong shift from single-earner to dualearner households that has come about with the rapid growth of female and in many cases part-time employment, and the growing attention paid to the phenomenon of household joblessness make this an important lacuna. Significant policy implications may be suspected. The debate on household joblessness has already put into question the workings of labour-market policies. The important debate on job polarization ignores how households may be affected or, alternatively, how they may offer compensation for the process. The interlinking of the two distributions raises doubts about the policies of redistribution. Traditional instruments found on each of the two sides, such as the minimum wage or income taxation, expectedly work out differently in a dual-earner world where household labour supply can involve low-paid jobs or low (part-time) earnings even at high levels of household income. As a result, the effects of these instruments will change and their political support in society may also be altered. Future research will require improved and systematic fact finding, the analysis shall generate a better understanding of earnings as well as hours of work on an annual basis, consistent with incomes, and also broaden to include other, often newly minted institutions that affect joint household labour supply, such as child care provisions. There is no shortage of detailed research on various issues, however the broad picture of the distributions as such is lacking. Connections run in both directions, from earnings to incomes as much as the other way around, and household formation and concomitant household labour supply cannot be taken as a given but is affected by both. Importantly, often the national work force has also doubled over recent decades, as a result of rapidly rising educational attainment and female labour-market participation, and not only the global work force after the demise of communism.

Subsequently turning to the distribution of wages alone we have gone back to the origins of the debate in the early 1980s and sketched developments towards what is now a large and complex literature. We find that the unanticipated rise in earnings inequality in the USA over the 1970s put labour-market institutions, such as (declining) unionization, as one possible explanation among others, such as demography or deindustrialization, on the research agenda. During the 1990 s the debate gave rise to the thesis of skill-biased technological change but also to international comparisons. The former approach has focused on market forces of supply and demand, the latter deemed those insufficient because of the growing international divergence in wage-inequality trends and has put the limelight on the role of national labour-market institutions. After some leapfrogging of the two approaches from one consensus explanation to another during the 1990s, the two seem to be increasingly growing apart during the 2000s when important new contributions are made, to the disadvantage of an integrated approach that could give each its proper place. Both sides may be at risk of creating 'Ptolemaic epicycles' aimed to incorporating new observations. The supply-and-demand approach is challenged by the need for finding better empirical measures of technological change aimed at dispelling doubts that the relative demand of skills may be a tautology. It has added 'tasks', 'offshoring', and even 'consumer preferences', which risk being ad hoc additions, ${ }^{151}$ without realizing their institutional preconditions. The institutional approach, on the other side, faces an abundance of institutions and ever new ones are added. It lacks a sufficiently clear-cut concept of institutions, ranging from laws, regulations, and habits to actual policies, and of their interactions - be they mutually reinforcing or compensating - on the one hand, and a clear criterion for delineating the institutional scope on the other hand.

151 Compare Autor's $(2013,25)$ remark "that there are almost as many distinct task classifications as there are papers in the task literature". 
In the light of this, the double aim of future work on both sides should be to foster itself and to integrate the other side into its own framework at the same time. Pursuing this may seem more a problem of empirical method for the institutional side, while by contrast on the demand and supply side the problem may be more one of theoretical method as long as institutions keep being viewed as bodies alien to the market and to theorizing. For both sides there is a perspective of work to do at the firm level. Matched employer-employee data can help enlighten the role of both institutions as well as labour supply and demand. Such data are increasingly becoming available. This brings us back to the availability and quality of the data in addition to the earnings/incomes fact-finding already mentioned. Data and analysis shall move beyond the commonly used earnings data for full-time workers only, which are less and less representative especially at the margins of earnings and incomes. Thereto, more needs to be done regarding individuals' and households' work efforts and earning outcomes on an annual basis. In addition, though much attention has been paid to data quality, a better grasp of the customary use of inequality measures - currently, each of the two approaches has its own rather exclusive preferences - seems desirable.

Finally, we have set up a simple model accounting for the correlation of the different components of inequality (between and within) with labour market institutions. We find indeed that unionized labour markets are ceteris paribus less unequal in terms of annual earnings, because both hourly wages and worked hours are more evenly distributed. We improve on existing approaches with the help of a pseudo-longitudinal approach linking workers cohort-wise to the change in institutions over their working life in three different ways. Empirical results of three cross-country exercises focusing on different inequality measures and covering the USA and all European countries in 2010-11, suggest inequality-reducing effects of unionization for hours, and of minimum wages for both hours and earnings. 


\section{References}

Abowd, John., Francis Kramarz, Thomas Lemieux et David Margolis. 1999. Minimum Wages and Youth Employment in France and the United States. In: Blanchflower and Freeman (eds), Chapter 11.

Abraham, Katharine, James Spletzer and Michael Harper, editors. 2010. Labor in the New Economy. NBER Books, University of Chicago Press.

Acemoglu, Daron and David Autor. 2011. Skills, Tasks and Technologies: Implications for Employment and Earning. In: Orley Ashenfelter and David Card (eds). Handbook of labor economics, vol.4/B, Elsevier, 10431171.

Acemoglu, Daron and David Autor. 2012. What does human capital do? A review of Goldin and Katz's The race between education and technology. NBER Working Paper 17820.

Acemoglu, Daron. 2003. Cross-Country Inequality Trends. The Economic Journal, 113 (February): F121-F149.

Agell, Jonas, and Kjell Erik Lommerud. 1992. Union Egalitarianism as Income Insurance. Economica, 59 (235), 295-310.

Agell, Jonas and Lommerud, Kjell Erik. 1993. Egalitarianism and Growth. Scandinavian Journal of Economics,. 95:4, 559-79.

Aghion, Philippe, Yann Algan and Pierre Cahuc. 2011. Civil Society And The State: The Interplay Between Cooperation And Minimum Wage Regulation. Journal of the European Economic Association 9:1, 3-42.

Alderson, A. and F. Nielsen. 2002. Globalisation and the great U-turn: income inequality trends in 16 OECD countries. American Journal of Sociology, 107, 1244-1299.

Alesina, Alberto F., Yann Algan, Pierre Cahuc, Paola Giuliano. 2010. Family Values and the Regulation of Labor. NBER Working Paper 15747.

Allegretto, Sylvia, Arindrajit Dube, and Michael Reich. 2011. Do Minimum Wages Really Reduce Teen Employment? Accounting for Heterogeneity and Selectivity in State Panel Data. Industrial Relations, 50:2, 205-240.

Alvaredo, Facundo. 2011. A note on the relationship between top income shares and the Gini coefficient. Economics Letters, 110 3, 274-277.

Alvaredo, Facundo, Anthony B. Atkinson, Thomas Piketty, and Emmanuel Saez. 2013. The Top 1 Percent in International and Historical Perspective. Journal of Economic Perspectives, 27:3, 3-20.

Amable, Bruno. 2003. The Diversity of Modern Capitalism., Oxford University Press

Andersson, Frederik, Matthew Freedman, John Haltiwanger, Julia Lane and Kathryn Shaw. 2006. Reaching for the stars: Who pays for talent in innovative industries? NBER Working Paper 12435.

Antonczyk, Dirk, Thomas DeLeire, and Bernd Fitzenberger. 2010. Polarization and Rising Wage Inequality: Comparing the U.S. and Germany. Discussion Paper 10-015. ZEW, Mannheim.

Atkinson, Anthony B. 1970. On the Measurement of Inequality. Journal of Economic Theory, 2, 244-263.

Atkinson, Anthony B. 1993. What is Happening to the Distribution of Income in the UK? Keynes Lecture in Economics 1992. Proceedings of the British Academy, 82, 317-351. Oxford University Press

Atkinson, Anthony B. 1999. Economic Consequences of Rolling Back the Welfare State. MIT Press and CESifo, Munich.

Atkinson, Anthony. 2007a. The long run earnings distribution in five countries: "remarkable stability," U, V or W?. Review of Income and Wealth. 53:1,1-25.

Atkinson, Anthony. 2007b. The distribution of earnings in OECD countries. International Labour Review, Vol. 146 (2007), No. 1-2, 41-60.

Atkinson, Anthony B. 2008. The Changing Distribution of Earnings in OECD Countries. Oxford University Press.

Atkinson, Anthony B. and François Bourguignon. 2000. Introduction. In: Handbook of Income Distribution, Volume 1, Elsevier North Holland.

Atkinson, Anthony and Andrea Brandolini. 2001. Promise and pitfalls in the use of secondary data-sets: Income inequality in OECD countries as a case study. Journal of Economic Literature, 39, 771-799.

Atkinson, Anthony. B. and S. Morelli (2012). Chartbook of Economic Inequality: 25 Countries 1911-2010. http://ineteconomics.org/sites/inet.civicactions.net/files/Note-15-Atkinson-Morelli.pdf

Atkinson, Anthony. B. and Thomas Piketty (eds). 2007. Top incomes over the twentieth century: A contrast between Continental European and English-Speaking countries. Oxford: Oxford University Press.

Atkinson, Anthony. B. and Thomas Piketty (eds). 2010. Top incomes. A global perspective. Oxford: Oxford University Press. 
Atkinson, Anthony B., Thomas Piketty and Emmanuel Saez. 2011. Top Incomes in the Long Run of History. Journal of Economic Literature, vol. 49:1, 3-71.

Atkinson, Anthony B., Lee Rainwater, and Timothy Smeeding. 1995. Income Distribution in European Countries. Working Paper MU 9506, Department of Applied Economics, University of Cambridge.

Auerbach, Alan, Raj Chetty, Martin Feldstein and Emmanuel Saez (editors). 2013. Handbook of Public Economics, volume 5. Elsevier.

Autor, David. 2013. The "Task Approach" to Labor Markets: An Overview. NBER Working Paper18711.

Autor, David, and David Dorn. 2013. The Growth of Low-Skill Service Jobs and the Polarization of the US Labor Market. American Economic Review, 103:3, 1553-1597.

Autor, David, Lawrence Katz and Melissa Kearney. 2005. Rising Wage Inequality: The Role of Composition and Prices. NBER Working Paper 11628.

Autor, David, Lawrence F. Katz and Melissa S. Kearney. 2006. The Polarization of the U.S. Labor Market. American Economic Review Papers and Proceedings, 96:2, 189-194.

Autor, David, Lawrence Katz, Melissa Kearney. 2008. Trends in U.S. Wage Inequality: Revising the Revisionists. Review of Economics and Statistics, 90:2, 300-323.

Autor, David, Frank Levy and Richard J. Murnane. 2003. The Skill Content of Recent Technological Change: An Empirical Exploration. Quarterly Journal of Economics, 116:4), 1279-1333.

Autor, David, Alan Manning and Christopher Smith. 2010. The contribution of the minimum wage to U.S. wage inequality over three decades: A reassessment, NBER Working Paper 16533.

Baccaro, Lucio. 2008. Labour, Globalisation and Inequality: Are trade Unions Still Redistributive? International Institute for Labour Studies Discussion Paper 192. ILO Geneva.

Bassanini, Andrea and Romain Duval. 2006. The determinants of unemployment across OECD countries: Reassessing the role of policies and institutions. OECD Economic Studies, 2006:1, 7-86.

Bassanini, Andrea, Luca Nunziata and Danielle Venn. 2009. Job Protection Legislation and Productivity Growth in OECD Countries. Economic Policy, April, 349-402.

Bauer, Thomas, Stephan Bender and Holger Bonin. 2007. Dismissal Protection and Worker Flows in Small Establishments, Economica, 74 (296), 804-821.

Becher, Michael and Jonas Pontusson. 2011. Whose interests do unions represent? Unionization by Income in western Europe. In: Brady ed., 181-211.

Bedard, Kelly, and Christopher Ferrall . 2003. Wage and Test Score Dispersion: Some International Evidence. Economics of Education Review, 22:1, 31-43.

Behar, Alberto. 2013. The Endogenous Skill Bias of Technical Change and Inequality in Developing Countries. IMF Working Paper n.13/50.

Bell, Linda A. and Richard B. Freeman. 2001. The incentive for working hard: explaining hours worked differences in the US and Germany. Labour Economics 8: 181-202.

Belot, Michèle and Jan van Ours. 2004. Does the Recent Success of Some OECD Countries in lowering their Unemployment Rates Lie in the Clever Design of their Labour Market Reform?, Oxford Economic Papers, 56:4), 621-642.

Benassi, Chiara. 2011. The Implementation of Minimum Wage: Challenges and Creative Solutions. Global Labour University Working Paper 12, ILO Geneva.

Bertola, Giuseppe and Tito Boeri. 2003. Product Market Integrations, Institutions and the Labour Markets. mimeo.

Bertola, Giuseppe. 2004. A Pure Theory of Job Security and Labour Income Risk. Review of Economic Studies, Oxford University Press, 71:1, 43-61.

Bertola, Giuseppe, Francine Blau, and Lawrence Kahn. 2001. Comparative Analysis Of Labor Market Outcomes: Lessons For The Us From International Long-Run Evidence. NBER Working Paper 8526.

Bertola, Giuseppe, Francine Blau, and Lawrence Kahn. 2007. Labor market institutions and demographic employment patterns. Journal of Population Economics,. 20:4, 833---867.

Bertola, Giuseppe and Tito Boeri. 2003. Product Market Integration, Institutions and the Labour Markets. mimeo. (http://didattica.unibocconi.it/mypage/upload/48791_20090205_034431_48791_20090116_035648_BOERIBERTOLA14-4-03.pdf)

Betcherman, Gordon. 2012. Labour market institutions. A review of the literature. Policy Research Working Paper n.6276, World Bank

Bičáková, Alena. 2006. Market vs. Institutions: The Trade-off between Unemployment and Wage Inequality Revisited. EUI Working Paper ECO No. 2006/31. Florence.

Bingley, Paul, Lorenzo Cappellari and Niels Westergård-Nielsen. 2013. Unemployment Insurance, Wage Dynamics and Inequality over the Life Cycle. Economic Joumal, 123 (568), 341-372.

Blackburn, McKinley, and David E. Bloom. 1987. Earnings and Income Inequality in the United States. Population and Development Review, 13:5, 575-609. 
Blackburn, McKinley and David E. Bloom. 1995. Changes in the Structure of Family Income Inequality in the United States and Other Industrialized Nations during the 1980s. Research in Labor Economics, 14, 141-170.

Blackburn, McKinley, David E. Bloom and Richard Freeman. 1990. An Era of Falling Earnings and Rising Inequality? The Brookings Review, 9:1 38-43.

Blanchard, Olivier and Francesco Giavazzi. 2003. Macroeconomic effects of regulations and deregulation in goods and labor markets. Quarterly Journal of Economics, 118:3, 879-907.

Blanchard, Olivier, and Justin Wolfers. 2000. The role of shocks and institutions in the rise of European unemployment: The aggregate evidence. Economic Journal, 110, C1-C33.

Blanchard, Olivier and Jean Tirole. 2008. The Joint Design of Unemployment Insurance and Employment Protection: A First Pass, Journal of the European Economic Association, 6:1, 45-77.

Blanchflower, David, and Richard Freeman (eds). 1999. Youth Employment and Joblessness in Advanced Countries. NBER and University of Chicago Press.

Blanchflower, David, and Andrew Oswald. 2013. Does High Home-Ownership Impair the Labor Market? Mimeo at andrewoswald.com.

Blau, Francine, and Lawrence Kahn. 1996. International Differences in Male Wage Inequality: Institutions versus Market Forces. Journal of Political Economy. 104:4, 791-837.

Blau, Francine, and Lawrence Kahn. 1999. Institutions and laws in the labor market. In: Orley Ashenfelter and David E. Card (eds), Handbook of Labor Economics. Vol. 3A, Chapter 25, 1399-1461.

Blau, Francine, and Lawrence Kahn. 2002. At Home and Abroad. U.S. Labor Market Performance in International Perspective. Russell Sage, New York.

Blau, Francine, and Lawrence Kahn. 2009. Inequality and Earnings Distribution. In: Salverda, Nolan and Smeeding (eds), Chapter 8, 177-203.

Blinder, Alan. 2007. How Many U.S. Jobs Might Be Offshorable? Working Paper 60, Center for Economic Policy Studies, Princeton.

Blinder, Alan, and Alan Krueger. 2009. Alternative Measures of Offshorability: A Survey Approach. Working Paper 190, Center for Economic Policy Studies, Princeton.

Bluestone, Barry, and Bennett Harrison. 1982. The deindustrialization of America. New York: Basic Books.

Bluestone, Barry, and Bennett Harrison. 1988. The Great U-Turn: Corporate Restructuring and the Polarizing of America. New York: Basic Books.

Blundell, Richard, and Ben Etheridge. 2010. Consumption, Income and Earnings Inequality in Britain. Review of Economic Dynamics, 13;1, 76-102.

Boeri, Tito. 2012. Setting the Minimum Wage. Labour Economics, 19:3, 281-290.

Boeri, Tito, and Juan Jimeno. 2005. The Effects of Employment Protection: Learning from Variable Enforcement, European Economic Review,. 49, 2057-2077.

Boeri, Tito and Jan van Ours. 2008. The Economics of Imperfect Labor Markets. Oxford University Press.

Boeri, Tito. 2011. Institutional Reforms and Dualism in European Labor Markets. In: Orley Ashenfelter and David Card (eds). Handbook of labor economics, Vol.4B, Chapter 13, Elsevier 1173-1236.

Botero, Juan C., Simeon Djankov, Rafael La Porta, Florencio Lopez-de-Silanes, Andrei Shleifer. 2004. The Regulation of Labor. The Quarterly Journal of Economics, 119:4: 1339-1382.

Bound, John, and George Johnson. 1989. Changes in the Structure of Wages During the 1980's: An Evaluation of Alternative Explanations. NBER Working Paper 2983.

Bound, John, and George Johnson. 1992. Changes in the Structure of Wages in the 1980's: An Evaluation of Alternative Explanations. American Economic Review, 82:3, 371-392Bowles, Samuel and Yongjin Park. 2005. Emulation, inequality, and work hours: Was Thorsten Veblen right? The Economic Journal, 115 , F397-F412.

Bourguignon, François, Francisco Ferreira and Nora Lustig, editors. 2004. The Microeconomics of Income Distribution Dynamics in East Asia and Latin America. World Bank and Oxford University Press.

Brady, David (ed.). 2011. Comparing European Workers Part B: Policies and Institutions, Research in the Sociology of Work, 22.

Brandolini, Andrea, and Giovanni D’Alessio. 2001. Household Structure and Income Inequality. Working Paper 6/2001. Center for Household, Income, Labour and demographic Economics CHILD.

Brandolini, Andrea, Alfonso Rosolia, and Roberto Torrini. 2011. The Distribution of Employees' Labour Earnings in the European Union: Data, Concepts and First Results. Working Paper 2011-198, ECINEQ.

Brewer, Mike, Alan Duncan, Andrew Shephard, and María José Suarez. 2006. Did Working Families' Tax Credit Work? The Impact of In-Work Support on Labour Supply in Great Britain. Labour Economics, 13, 699-720.

Brewer, Mike, Alastair Muriel and Liam Wren-Lewis. 2009. Accounting for changes in inequality since 1968: decomposition analyses for Great Britain, mimeo.

Brewer, Mike, and Liam Wren-Lewis. 2012. Why Did Britain's Households Get Richter? Decomposing UK Household Income Growth Between 1968 and 2008-09. Working Paper 2012-08, ISER, University of Essex. 
Brown, Charles. 1999. Minimum Wages, Employment, and the Distribution of Income, In: Orley Ashenfelter and David Card, (eds), Handbook of Labor Economics, Vol. 3, Elsevier, 2101-2163.

Brügemann, Björn. 2012. Does Employment Protection Create Its Own Political Support? Journal of the European Economic Association, 10:2, 369-416.

Bryson, Alex, Richard Freeman, Claudio Lucifora, Michele Pellizzari and Virginie Perotin. 2012. Paying For Performance: Incentive Pay Schemes and Employees' Financial Participation. CEP Discussion Paper 1112, LSE.

Brzozowski, Michael, Martin Gervais, Paul Klein and Michio Suzuki. 2010. Consumption, income, and wealth inequality in Canada. Review of Economic Dynamics, 13:1, 52-75.

Budría, Santiago, and Pedro T. Pereira. 2005. Educational Qualifications and Wage Inequality: Evidence for Europe, IZA Discussion Paper 1763. Bonn.

Burtless, Gary. 1999. Effects of Growing Wage Disparities and Changing Family Composition on the U.S. Income Distribution. European Economic Review, 43, 853-865.

Burtless, Gary. 2009. Demographic Transformation and Economic Inequality. In: Salverda, Nolan and Smeeding (eds), Chapter 18, 435-454.

Butcher, Tim, Richard Dickens and Alan Manning. 2012. Minimum Wages and Wage Inequality: Some Theory and an Application to the UK. CEP Discussion Paper 1177, LSE.

Butcher, Tim. 2011. Still evidence-based? The Role of Policy Evaluation in Recession and Beyond: The Case of the National Minimum Wage. National Institute Economic Review, No. 219, R26-R40.

Cancian, Maria, and Robert Schoeni. 1998. Wives' earnings and the level and distribution of married couples earnings in developed countries. Journal of Income Distribution, 8:1, 45-61.

Card, David, and Alan Krueger. 1995a. Myth and Measurement. The New economics of the Minimum Wage. Princeton University Press.

Card, David, and Krueger, Alan. 1995b. Time-series minimum-wage studies: a meta-analysis. American Economic Review, 85: 238-43.

Card, David, and John DiNardo. 2002. Skill-Biased Technological Change and Rising Wage Inequality: Some Problems and Puzzles. Journal of Labor Economics, 20:4, 733-783.

Card, David, Thomas Lemieux and Craig Riddell. 2004. Unions and Wage Inequality. Journal of Labor Research, 25:4, 519-562.

Cardoso, Ana. 2010. Do Firms Compress the Wage Distribution? In: David Marsden and François Rycx, editors. Wage Structures, Employment Adjustments and Globalization: Evidence from Linked and Firm-level Panel Data, Palgrave Macmillan, 202-218.

Charles, Kerwin Kofi, and Jonathan Guryan (2007). Prejudice and The Economics of Discrimination. NBER Working Paper 13661.

Charles, Kerwin Kofi, and Jonathan Guryan (2008). Prejudice and The Economics of Discrimination. Joumal of Political Economy, 116:5, 773-809.

Checchi, Daniele, and Cecilia Garcia Peñalosa. 2008. Labour market institutions and income inequality. Economic Policy, 56: 600-651.

Checchi, Daniele, and Cecilia Garcia Peñalosa. 2010. Labour shares and the personal distribution of income in the OECD. Economica, 77 (307), 413-450.

Checchi, Daniele, and Claudio Lucifora. 2002. Unions and labour market institutions in Europe. Economic Policy. 17:2, 362-401.

Chetty, Raj. 2008. Moral Hazard vs. Liquidity and Optimal Unemployment Insurance. NBER Working Paper 13967.

Cheon, Byung You, Chang, Jiyeun Hwang, Gyu Seong Shin, Jin Wook Kang, Shin Wook Lee, Byung Hee Kim, Hyun Joo. 2013. Growing Inequality and Its Impacts in Korea. Country Report to the GINI project. http://giniresearch.org/CR-Korea.

Christopoulou, Rebekka, Juan F. Jimeno, and Ana Lamo. 2010. Changes in the Wage Structure in EU Countries. Documentos de Trabajo 1017. Banco de España.

Coelli, Michael, Jerome Fahrer and Holly Lindsay. 1994. Wage Dispersion and Labour Market Institutions: A Cross Country Study. Research Discussion Paper 9404. Reserve Bank of Australia.

Conyon, Martin, Nuno Fernandes, Miguel Ferreira, Pedro Matos and Kevin Murphy. 2011. The Executive Compensation Controversy: A Transatlantic Analysis. Fondazione Rodolfo De Benedetti.

Corluy, Vincent, and Frank Vandenbroucke (2013). Individual Employment, Household Employment and Risk of Poverty in the EU. A Decomposition Analysis. Eurostat.

Corsini, Lorenzo. 2008. Institutions, technological change and the wage differentials between skilled and unskilled workers: theory and evidence from Europe. IRISS Working Paper 2008-02.

Cowell, Frank. 2000. Measurement of inequality, in Atkinson A.B. and Bourguignon F. (Eds), Handbook of Income Distribution, Volume 1, North Holland, Chapter 2, 87-166. 
Cowell, Frank, and Carlo Fiorio. 2011. Inequality Decompositions-A Reconciliation. Journal of Economic Inequality, 9, 509-528.

Dahl, Christian, Daniel le Maire and Jakob Munch. 2011. Wage Dispersion and Decentralization of Wage Bargaining. IZA Discussion Paper 6176.

Daly, Mary, and Robert Valetta. 2006. Inequality and Poverty in United States: The Effects of Rising Dispersion of Men's Earnings and Changing Family Behaviour. Economica, 73 (289.), 75-98.

De Graaf-Zijl, Marloes, and Brian Nolan. 2011. Household Joblessness and Its Impact on Poverty and Deprivation in Europe. Journal of European Social Policy, 21, 413-431.

Deininger, Klaus, and Lyn Squire. 1996. A New Data Set Measuring Income Inequality. World Bank Economic Review, 10(3), 565-591.

De Linde Leonard, Megan, T. D. Stanley and Hristos Doucouliagos. 2013. Does the UK Minimum Wage Reduce Employment? A Meta-Regression Analysis. British Journal of Industrial Relations, early view.

Del Boca, Daniela, and Sylvia Pasqua. 2003. Employment Patterns of Husbands and Wives and Family Income Distribution in Italy (1977-98). Review of Income and Wealth, 49:2, 221-245.

DiNardo, John, Nicole Fortin, and Thomas Lemieux. 1996. Labor Market Institutions and the Distribution of Wages, 1973-1992: A Semiparametric Approach. Econometrica, 64:5, 1001-1044.

DiNardo, John, and Thomas Lemieux. 1997. Diverging Male Wage Inequality in the United States and Canada, 1981-1988: Do Institutions Explain the Difference? Industrial and Labor Relations Review, 50:4, 629-651.

DiNardo, John, and Jorn-Steffen Pischke. 1997. The Returns to Computer Use Revisited: Have Pencils Changed the Wage Structure Too? Quarterly Journal of Economics, 112:1, 291-303.

Dingeldey, Irene. 2001. European Tax Systems and their Impact on Family Employment Patterns. Journal of Social Policy, 30, 653672.

DiPrete, Thomas. 2007. What has Sociology to Contribute to the Study of Inequality Trends? An Historical and Comparative Perspective. American Behavioral Scientist, 50:5, 603-618.

Dolado, Juan, Francis Kramarz, Stephen Machin, Alan Manning, David Margolis and Coen Teulings 1996. The economic impact of minimum wage in Europe, Economic Policy, 23, 317-372

Dolton, Peter, and Chiara Rosazza Bondibene. 2011. An Evaluation of the International Experience of Minimum Wages in an Economic Downturn, Research Report for the Low Pay Commission, Royal Holloway College, University of London.

Domeij, David, and Martin Floden. 2010. Inequality Trends in Sweden 1978-2004. Review of Economic Dynamics. 13:1, 179-208.Dooley, Martin, and Peter Gottschalk. 1984. Earnings Inequality among Males in the United States: Trends and the Effect of Labor Force. Journal of Political Economy, 92:1, 59-89.

Dooley, Martin, and Peter Gottschalk. 1985. The Increasing Proportion of Men with Low Earnings in the United States. Demography, 22:1, 25-34.

Doucouliagos, Hristos, and T. D. Stanley. 2009. Publication Selection Bias in Minimum-Wage Research? A MetaRegression Analysis. British Journal of Industrial Relations, 47:22, 406-428.

Dube, Arindrajit, William Lester and Michael Reich. 2012. Minimum Wage Shocks, Employment Flows and Labor Market Frictions. Berkeley, CA: Institute for Research on Labor and Employment. http://escholarship.org/uc/item/76p927ks.

Dube, Arindrajit, William Lester and Michael Reich. 2010. Minimum Wage Effects across State Borders: Estimates Using Contiguous Counties. Review of Economics and Statistics, 92:4, 945-964.

Dunne, Timothy, Lucia Foster, John Haltiwanger and Kenneth R. Troske. 2004. Wage and Productivity Dispersion in United States Manufacturing: The Role of Computer Investment. Journal of Labor Economics, 22:2, 397-429.

Dupuy, Arnaud, and Daniel Fernández-Kranz. 2011. International Differences in the Family Gap in Pay: The Role of Labour Market Institutions. Applied Economics, 43, 413-438.

Dustmann, Christian, Johannes Ludsteck and Uta Schönberg. 2009. Revisiting the German Wage Structure. Quarterly Journal of Economics, 124:2, 843-881.

Eichhorst, Werner, Michael Feil and Christoph Braun. 2008. What Have We Learned? Assessing Labor Market Institutions and Indicators. IZA Discussion Paper 3470. Bonn.

Eissa, Nada, and Hilary Hoynes. 2004. Taxes and the Labor Market Participation of Married Couples: The Earned Income Tax Credit. Journal of Public Economics, 88, 1931-1958.

Farber, Henry, and Robert Valletta. 2013. Do extended unemployment benefits lengthen unemployment spells? Evidence from recent cycles in the US labour market. Working Paper 573, Princeton University, Industrial Relations section.

Fields, Gary. 2003. Accounting for Income Inequality and Its Change: A New Method, with Application to the Distribution of Earnings in the United States. Research in Labor Economics, 22, 1-38.

Fiori, Giuseppe, Giuseppe Nicoletti, Stefano Scarpetta and Fabio Schiantarelli. 2012. Employment effects of product and labour market reforms: are there synergies? Economic Journal, 122. F79-F104. 
Firpo, Sergio, Nicole Fortin, and Thomas Lemieux 2009. Unconditional Quantile Regressions. Econometrica, 77:3, 953-973.

Firpo, Sergio \& Fortin, Nicole M. \& Lemieux, Thomas. 2011. Occupational Tasks and Changes in the Wage Structure. IZA Discussion Paper 5542. Bonn.

Flaig, Gebhard, and Horst Rottmann. 2011. Labour Market Institutions and Unemployment. An International Comparison. CESifo Working Paper 3558.

Förster, Michael. 1994. Measurement of Low Incomes and Poverty in A Perspective of International Comparisons. OECD Labour Market and Social Policy Occasional Papers 14.

Fortin, Nicole, and Lemieux, Thomas. 1997. Institutional Changes and Rising Wage Inequality: Is There a Linkage? Journal of Economic Perspectives, 1:2, 75-96.

Fortin, Nicole, and Lemieux, Thomas. 2014. Changes in Wage Inequality in Canada: An Interprovincial Perspective. First draft, http://faculty.arts.ubc.ca/nfortin/FortinLemieux Inequality \%20provinces.pdf

Fortin, Nicole, Thomas Lemieux and Sergio Firpo. 2011. Decomposition Methods in Economics. In: Card and Ashenfelter (2011a), Chapter 1, 1-102. (also NBER Working Paper 16045, 2010).

Freeman, Richard. 1980. Unionism and the Dispersion of Wages. Industrial and Labor Relations Review, 34:2, 3-23.

Freeman, Richard. 1988. Labour Market Institutions and Economic Performance. Economic Policy, 3:6, 63-88.

Freeman, Richard. 1991. How Much Has De-Unionisation Contributed to the Rise in Male Earnings Inequality? NBER Working Paper 3826. (In Danziger and Gottschalk, (eds), Uneven Tides, 1992).

Freeman, Richard. 2000. Single Peaked Vs. Diversified Capitalism: The Relation Between Economic Institutions and Outcomes. NBER Working Paper 7556.

Freeman, Richard. 2005. Labour Market Institutions without Blinders: The Debate over Flexibility and Labour Market Performance. NBER Working Paper 11286.

Freeman, Richard. 2006. The Great Doubling: The Challenge of the New Global Labor Market. http://emlab.berkeley.edu/users/webfac/eichengreen/e183_sp07/great_doub.pdf

Freeman, Richard. 2009. Labor Regulations, Unions, and Social Protection in Developing Countries: Market distortions or Efficient Institutions? NBER Working Paper 14789.

Freeman, Richard. 2007. Labor market institutions around the world. NBER Working Paper 13242

Freeman, Richard (ed). 1994. Working under Different Rules. Russell Sage, New York.

Freeman, Richard, and Lawrence Katz (eds). 1995. Differences and Changes in Wage Structures. University of Chicago Press.

Freeman, Richard, and James Medoff. 1984. What do Unions Do? Basic Books

Freeman, Richard, and Ronald Schettkat. 2001. Skill Compression, Wage Differentials and Employment: Germany vs. the US. Oxford Economic Papers, 53 (3): 582-603.

Friedman, Milton. (1968). The Role of Monetary Policy. American Economic Review, 58:1, 1-17.

Fuchs-Schündeln, Nicola, Dirk Krueger and Mathias Sommer. 2010. Inequality Trends for Germany in the Last Two Decades: A tale of Two Countries. Review of Economic Dynamics, 13:1, 103-132.

Garnero, Andrea, Stephan Kampelmann and François Rycx. 2013. Minimum Wage Systems and Earnings Inequalities: Does Institutional Diversity Matter? DULBEA Working Paper 13-06.

Gautié, Jérôme, and John Schmitt (eds). 2010. Low-Wage Work in Wealtby Countries, Russell Sage.

Gindling, Thomas, and Katherine Terrell. 2009. Minimum wages, wages and employment in various sectors in Honduras. Labour Economics, 16(3): 291-303.

Giuliano, Laura. 2013. Minimum Wage Effects on Employment, Substitution, and the Teenage Labor Supply: Evidence from Personnel Data. Journal of Labor Economics, 31:1, 155-194.

Glyn, Andrew, Dean Baker, David Howell, and John Schmitt. 2003. Labor Market Institutions and Unemployment: A Critical Review of the Cross-Country Evidence. University of Oxford. Department of Economics Discussion Paper 168. Oxford.

Golden, Miriam, and Michael Wallerstein. 2011. Domestic and International Causes for the Rise of Pay Inequality in OECD Nations between 1980 and 2000. In: Comparing European Workers Part A: Experiences and Inequalities, Research in the Sociology of Work, 22, 209-249.

Goos, Maarten, and Alan Manning. 2007. Lousy and Lovely Jobs: the Rising Polarization of Work in Britain. Centre for Economic Performance LSE, Discussion Paper 604.

Goos, Maarten, and Alan Manning. 2007. Lousy and Lovely Jobs: the Rising Polarization of Work in Britain. Review of Economics and Statistics, 89:1, 118-133.

Goos, Maarten, Alan Manning and Anna Salomons. 2009. Job Polarization in Europe. American Economic Review, 99:2, 58-63.

Goos, Maarten, Alan Manning and Anna Salomons. 2010. Explaining Job Polarization in Europe: The Roles of Technology, Globalization and Institutions. CEP Discussion Paper 1026, LSE.

Goos, Maarten, Alan Manning and Anna Salomons. 2011. Explaining Job Polarization: The Roles of Technology, Offshoring and Institutions. KU Leuven, Center for Economic Studies, Discussion Paper 11.34. 
Goos, Maarten, Alan Manning, and Anna Salomons. Forthcoming. Explaining Job Polarization: Routine-Biased Technological Change and Offshoring. American Economic Review.

Gottschalk, Peter, and Sheldon Danziger (2005). Inequality of Wage Rates, Earnings and Family Income in the United States 1975-2002. Review of Income and Wealth, 51:2, 231-254.

Gottschalk, Peter, and Mary Joyce, 1998. Cross-National Differences In The Rise In Earnings Inequality: Market and Institutional Factors, Review of Economics and Statistics, 80:4, 489-502.

Gottschalk, Peter, and Timothy Smeeding. 1997. Cross-national Comparisons of Earnings and Income Inequality. Journal of Economic Literature, 35, 633-687.

Gregg, Paul and Jonathan Wadsworth. 2008. Two sides to Every Story: Measuring Polarization and Inequality in the Distribution of Work. Journal of the Royal Statistical Society Series A, 171:4, 857-875.

Gregg, Paul, Rosanna Scutella and Jonathan Wadsworth. 2010. Reconciling workless measures at the individual and household level. Theory and evidence from the United States, Britain, Germany, Spain and Australia. Journal of Population Economics, 23, 139-167.

Gregg Paul, and Jonathan Wadsworth. 1996. More work in fewer households? In: Hills J (ed) New Inequalities. Cambridge University Press, London, 181-207.

Gregg Paul, and Jonathan Wadsworth. 1998. It Takes Two: Employment Polarisation in the OECD. Discussion Paper 304, Centre for Economic Performance, London

Hall, Peter, and David Soskice (eds). 2001. Varieties of Capitalism: The Institutional Foundations of Comparative Advantage. Oxford: Oxford University Press

Hall, Robert, and Alan Krueger. 2010. Evidence on the Determinants of the Choice between Wage Posting and Wage Bargaining. NBER Working Paper 16033.

Harrison, Bennet, Chris Tilly and Barry Bluestone. 1986. Wage Inequality Takes a Great U-Turn. Challenge, 29:1, Symposium of the Joint Economic Committee of Congress on the 40th Anniversary of the Employment Act of 1946 (Part 1), 26-32.

Heathcote, Jonathan, Fabrizio Perri and Giovanni Violante. 2010. Unequal We Stand: An Empirical Analysis of Economic Inequality. Review of Economic Dynamics, 13, 15-51.

Heckman, James, and Guilherme Sedlacek. 1985. Heterogeneity, Aggregation, and Market Wage Functions: An Empirical Model of Self-Selection in the Labor Market. Journal of Political Economy, 93:9, 1077-1125.

Henle, Peter. 1972. Distribution of Earned Income. Monthly Labor Review, 95:12, 16-27.

Henle, Peter, and Paul Ryscavage. 1980. The distribution of earned income among men and women, 1958-77. Monthly Labour Review, 103:4, 3-10.

Heshmati, Almas. 2004. A Review of Decomposition of Income Inequality. Discussion Paper 1221, IZA Bonn.

Hills, John, Mike Brewer, Stephen Jenkins, Ruth Lister, Ruth Lupton, Stephen Machin, Colin Mills, Tariq Modood, Teresa Rees and Sheila Riddell. 2010. An Anatomy of Economic Inequality in the UK: Report of the National Equality Panel. http://sticerd.lse.ac.uk/case/_new/publications/NEP.asp.

Holzmann, Robert, Yann Pouget, Milan Vodopivec and Michael Weber. 2011. Severance Pay Programs around the World: History, Rationale, Status, and Reforms. IZA Discussion Paper 5731.

Hyslop, Dean. 2001, Rising US Earnings Inequality and Family Labor Supply: The Covariance Structure of Intrafamily Earnings, American Economic Review, Vol. 91, pp. 755-777.

ILO 2008. Global Wage Report 2008/09. Minimum wages and collective bargaining: Towards policy coherence. Geneva.

ILO 2010. Global Wage Report 2010/11. Wage policies in times of crisis. Geneva.

Japelli, Tullio, and Luigi Pistaferri. 2010. Does consumption inequality track income inequality in Italy? Review of Economic Dynamics, 13:1, 133-153.

Jenkins, Stephen, 1995. Accounting for inequality trends: decomposition analyses for the UK, 1971-86. Economica 62(245), 29-63.

Jenkins, Stephen, and Philippe van Kerm. 2009. The Measurement of Economic Inequality. In: Salverda, Nolan and Smeeding (eds), Chapter 3, 40-67.

Johnson, David, and Roger Wilkins. 2003. The Effects of Changes in Family Composition and Employment Patterns on the Distribution of Income in Australia: 1982 to 1997-1998. Working Paper 19/03, Melbourne Institute of Applied Economic and Social Research.

Juhn, Chinhui, Kevin Murphy, and Brooks Pierce. 1993. Wage Inequality and the Rise in Returns to Skill. Journal of Political Economy, 101, 410-442.

Kahn, James. 2005. Labor Supply and the Changing Household. Paper presented to Society for Economic Dynamics.

Kampelmann, Stephan, Andrea Garnero and François Rycx. 2013. Minimum wages in Europe: does the diversity of systems lead to a diversity of outcomes? ETUI Report 128, Brussels.

Karabarbounis, Loukas, and Brent Neiman. 2013. The Global Decline of the Labor Share. NBER Working Paper 19136.

Karoly, Lynn. 1992. Changes in the Distribution of Individual Earnings in the United States: 1967-1986. Review of Economics and Statistics, 74:1, 107-115. 
Karoly, Lynn. 1993. The Trend in Inequality among Families, Individuals and Workers in the United States: A Twenty-five Year Perspective. In: Danziger and Gottschalk, Uneven Tides, Rising Inequality in America. Chapter 2, 19-97. Russell Sage, New York.

Karoly, Lynn, and Gary Burtless. 1995. Demographic Change, Rising Earnings Inequality, and the Distribution of Personal Well-Being, 1959-1989. Demography, 32:3, 379-405.

Katz, Lawrence. 2010. Comment on Lemieux, What Do We Really Know about Changes in Wage Inequality? In: Abraham, Spletzer and Harper, (eds), 59-62.

Katz, Lawrence and Kevin Murphy. 1992 .Changes in Relative Wages: Supply and Demand Factors. Quarterly Journal of Economics, CVII, pages 35-78.

Katz, Lawrence, and David Autor. 1999. Changes in the Wage Structure and Earnings Inequality, In: O. Ashenfelter and D. Card, eds., Handbook of Labor Economics Volume IIIA, Amsterdam: Elsevier, pages 1463-1555.

Kenworthy, Lane. 2001. Wage-Setting Measures: A Survey and Assessment. World Politics, 54, 57-98.

Kenworthy, Lane. 2008. Sources of Equality and Inequality: Wages, Jobs, Households, and redistribution. Working Paper 471, Luxembourg Income Study. = Chapter 3 of Kenworthy, Jobs with Equality, Oxford University Press, 2008).

Kenworthy and Pontusson. 2005. Rising Inequality and the Politics of Redistribution in Affluent Countries. Perspectives on Politics, 3:3, 449-471.

Keune, Maarten, and Béla Galgóczi (editors). 2009. Wages and Wage Bargaining in Europe; Developments since the mid1990s. ETUI, Brussels.

Kierzenkowski, Rafal, and Isabel Koske. 2012. Less Income Inequality and More Growth - Are they Compatible? Part 8. The Drivers of Labour Income Inequality - A Literature Review. OECD Economics Department Working Paper 931, OECD Publishing.

Kimhi, Ayal. 2011. On the Interpretation (and Misinterpretation) of Inequality Decompositions by Income Sources. World Development, 39:10, 1888-1890.

Kluve, Jochen. 2010. The effectiveness of European active labor market programs. Labour Economics 17:6, 904918

Koeniger, Winfried, Marco Leonardi, and Luca Nunziata. 2007. Labor Market Institutions and Wage Inequality. Industrial and Labor Relations Review. 60:3, 340-356.

Krueger, Dirk, and Fabrizio Perri. 2006. Does Income Inequality Lead to Consumption Inequality? Evidence and Theory. Review of Economic Studies, 73:1, 163-193.Kugler, Adriana, and Giovanni Pica. 2008. Effects of Employment Protection on Worker and Job Flows: Evidence from the 1990 Italian Reform, Labour Economics, 15:1, 78-95.

Lalive, Rafael, Analía Schlosser, Andreas Steinhauer and Josef Zweimüller. 2011. Parental Leave and Mothers' Careers: The Relative Importance of Job Protection and Cash Benefits. IZA Discussion Paper 5792, Bonn.

Larrimore, Jeff. 2013. Accounting for United States Household Income Inequality Trends: The Changing Importance of Household Structure and Male and female Labour Earnings Inequality. Review of Income and Wealth, 101:3, 173-177.

Lee, David. 1999. Wage Inequality in the United States during the 1980s: Rising Dispersion or Falling Minimum Wage? Quarterly Journal of Economics, 114: 3, 977-1023.

Lehrer, Evelyn. 2000. The impact of women's employment on the distribution of earnings among marriedcouple households: A comparison between 1973 and 1992-1994. Quarterly Review of Economics and Finance, 40, 295-301.

Leigh, Andrew. 2009. Top Incomes. In: Salverda, Nolan and Smeeding (eds), Chapter 7, 150-174.

Lemieux, Thomas. 2006a. Postsecondary Education and Increasing Wage Inequality. American Economic Review, 96: 2, 195-199.

Lemieux, Thomas. 2006b. Postsecondary Education and Increasing Wage Inequality. NBER Working Paper 12077.

Lemieux, Thomas. 2006c. Increasing Residual Wage Inequality: Composition Effects, Noisy Data, or Rising Demand for Skill? American Economic Review, 96:3, 461-498.

Lemieux, Thomas. 2008. The Changing Nature of Wage Inequality. Journal of Population Economics, 21:1, 21-48.

Lemieux, Thomas. 2010. What Do We Really Know about Changes in Wage Inequality? In: Abraham, Spletzer and Harper, (eds), Chapter 1, 17-59.

Lemieux, Thomas. 2011. Wage Inequality: A Comparative Perspective. Australian Bulletin of Labour, 37:1, 2-32.

Lemieux, Thomas, Bentley Macleod and Daniel Parent. 2009. Performance pay and wage inequality. Quarterly Journal of Economics, 124:1, 1-49.

Lemos, Sara. 2009. Minimum wage effects in a developing country. Labour Economics 16, 224-237.

Leonardi, Marco and Giovanni Pica. 2013. Who Pays for It? The Heterogeneous Wage Effects of Employment Protection Legislation. Economic Journal, 123 (573), 1236-1278. 
Lerman, Robert, and Shlomo Yitzhaki. 1984. A Note on the Calculation and Interpretation of the Gini Index. Economic Letters, 15:3-4, 363-68.

Leuven, Edwin, Hessel Oosterbeek and Hans van Ophem. 1997. International comparisons of male wage inequality; Are the findings robust? Tinbergen Institute, Working Paper 97-59, University of Amsterdam.

Leuven, Edwin, Hessel Oosterbeek and Hans van Ophem. 2004. Explaining international differences in male skill wage differentials by differences in demand and supply of skill. Economic Journal, 114 , 466-486.

Levy, Frank, and Richard Murnane. 1992. U.S. earnings levels and earnings inequality: A review of recent trends and proposed explanations. Journal of Economic Literature, 30, 1333-1381.

Levy, Frank, and Richard Murnane. 2005. How Computerized Work and Globalization Shape Human Skill Demands. MIT IPC Working Paper IPC-05-006.

Levy, Frank, and Peter Temin. 2007. Inequality and Institutions in 20th Century America. NBER Working Paper 13106.

Liebman, Jeffrey. 1998. The Impact Of The Earned Income Tax Credit on Incentives and Income Distribution . In: James Poterba, (ed). Tax Policy and the Economy, Volume 12.

Liu, Yujia, and David Grusky. 2013. The Payoff to Skill in the Third Industrial Revolution. American Joumal of Sociology, 118:5, 1330-1374.

Lu, Yuqian, René Morissette and Tammy Schirle. 2011. The Growth of Family Earnings Inequality in Canada 1980-2005. Review of Income and Wealth, 57:1, 23-39.

Lucifora, Claudio, and Wiemer Salverda. 2009. Low Pay. In: Salverda, Nolan and Smeeding (eds), Chapter 11, 256-283.

Lydall, Harold. 1968. The Structure of Earnings. Clarendon Press.

Machin, Stephen. 1997. The decline of labour market institutions rise in wage inequality in Britain. European Economic Review, 41:3-5, 647-657.

Machin, Stephen. 2008. An appraisal of economic research on changes in wage inequality. Labour, 22 (Special issue), 7-26.

Mandel, Hadas, and Moshe Semyonov. 2005. Family policies, Wage structures, and gender gaps: Sources of earnings inequality in 20 countries. American Sociological Review, 70: 949-967.

Mandelbrot, Benoit. 1962. Paretian Distributions and Income Maximization. Quarterly Journal of Economics, 76:1, $57-85$.

Manning, Alan. 2011. Imperfect Competition in the Labour Market. In: Orley Ashenfelter and David Card (eds). Handbook of Labor Economics., Elsevier, Volume 4B, 973-1041.

Manzo IV, Frank, and Robert Bruno. 2014. Which Labor Market Institutions Reduce Income Inequality? Labor Unions, Prevailing Wage Laws, and Right-to-Work Laws in the Construction Industry. Illinois Economic Policy Institute (ILEPI). Research Report.

Martin, John and Stefano Scarpetta. 2011. Setting It Right: Employment Protection, Labour Reallocation and Productivity. IZA Policy Paper 27.

Martins, Pedro. 2009. Dismissals for Cause: The Difference That Just Eight Paragraphs Can Make. Journal of Labor Economics, 27:2, 257-279.

Messina, Julian, and Giovanna Vallanti. 2007. Job Flow Dynamics and Firing Restrictions: Evidence from Europe, Economic Journal, 117, F279-F301.

Metcalf, David. 2004. The Impact of the National Minimum Wage on the Pay Distribution, Employment And Training. The Economic Journal, 114, C84-C86.

Mishel, Lawrence, Heidi Shierholdz and John Schmitt (2013).Don't blame the Robots. Assessing the Job Polarization Explanation of Growing Wage Inequality. Working Paper, EPI, Washington (19 November).

Mookherjee, Dilip, and Anthony Shorrocks. 1982. A Decomposition Analysis of the Trend in UK Income Inequality. Economic Journal, 92(368): 886-902.

Mortensen, Dale 2005. Wage Dispersion: Why Are Similar Workers Paid Differently? MIT Press

Mühlau, Peter, and Justine Horgan. 2001. Labour Market Status and the Wage Position of the Low Skilled: The Role of Institutions and of Demand and Supply - Evidence from the International Adult Literacy Survey. Working Paper 5, European Low-wage employment Research network, http://www.uvaaias.net/uploaded_files/regular/05MuehlauHorgan.pdf.

Neal, Derek, and Sherwin Rosen. 2000. Theories of the distribution of earnings. In: A. Atkinson and F. Bourguignon (eds). Handbook of Income Distribution. North Holland. 379-428.

Neumark, David, Ian Salas and William Wascher. 2013. Revisiting the Minimum Wage-Employment Debate: Throwing Out the Baby with the Bathwater? NBER Working Paper 18681.

Neumark, David, Mark Schweitzer and William Wascher. 2004. Minimum Wage Effects throughout the Wage Distribution. Journal of Human Resources, 39:2, 425-445.

Neumark; David, and William Wascher. 2008. Minimum Wages. MIT Press. 
Nickell, Stephen. 1997. Unemployment and Labor Market Rigidities: Europe versus North America. The Journal of Economic Perspectives, 11: 55-74.

Nickell, Stephen, and Richard Layard 1999. Labour market institutions and economic performance. In: Orley Ashenfelter and David Card (1999), Chapter 46, 3029-3084.

Nickell, Stephen, Luca Nunziata, and Wolfgang Ochel. 2005. Unemployment in the OECD Since the 1960s. What Do We Know? Economic Journal. 115 (500): 1-27.

Ochel, Wolfgang. 2005. Concepts and Measurement of Labour Market Institutions. CESifo DICE Report 4/2005: 40-55.

OECD. 2004. Employment outlook. Paris.

OECD. 2009. What are equivalence scales?' Paris

OECD. 2011. Divided We Stand: Why Inequality Keeps Rising. Paris.

OECD. 2012. Employment outlook. Paris

OECD. 2013. OECD Skills Outlook 2013. First Results from the Survey of Adult Skills. Paris.

Oliver, Rebecca. 2008. Diverging Developments in Wage Inequality Which Institutions Matter? Comparative Political Studies, 41:12, 1551-1582.

Olivetti, Claudia, and Barbara Petrongolo. 2008. Unequal Pay or Unequal Employment? A Cross-Country Analysis of Gender Gaps. Journal of Labor Economics, 26:4,621-654.

Oswald, Andrew. 1996. A conjecture on the explanation for high unemployment in the industrialised nations. Warwick Economic Research Papers 475.

Peichl, Andreas, Nico Pestel and Hilmar Schneider. 2010. Does Size Matter? The Impact of Changes in Household Structure on Income Distribution in Germany. CESifo Working Paper 3219.

Philippon, T. 2001. The Impact of Differential Payroll Tax Subsidies on Minimum Wage Employment. Journal of Public Economics, 82, pp. 115-146.

Pierce, Brooks. 2010. Recent Trends in Compensation Inequality. In: Abraham, Spletzer and Harper, (eds), Chapter 2, 63-98.

Pijoan-Mas, Josep, and Virginia Sánchez-Marcos. 2010. Spain is Different: Falling Trends of Inequality. Review of Economic Dynamics, 13:1, 154-178.

Piketty, Thomas. 2003. Income Inequality in France, 1901-1998. Journal of Political Economy, 111, 1004-1042.

Piketty, Thomas and Emmanuel Saez. 2003. Income Inequality in the United States, 1913-1998. Quarterly Journal of Economics, 118, 1-39.

Piketty, Thomas, and Emmanuel Saez. 2012. Optimal Labor Income Taxation. NBER Working Paper18521.

Piketty, Thomas, and Emmanuel Saez. 2013. Optimal Labor Income Taxation. In: Auerbach et al. (eds), Chapter 7.

Piketty, Thomas, Emmanuel Saez and Stefanie Stantcheva. 2011. Optimal Taxation of Top Labor Incomes: A Tale of Three Elasticities. NBER Working Paper17616.

Plotnick, Robert. 1982. Trends in Male Earnings Inequality. Southern Economic Journal, 48:3, 724-732.

Reed, Deborah, and Maria Cancian. 2001. Sources of Inequality: Measuring the Contributions of Income Sources to Rising Family Income Inequality. Review of Income and Wealth, 47: 3, 321-333.

Rogerson, Richard, Robert Shimer and Randall Wright. 2005. Search-Theoretic Models of the Labor Market: A Survey. Journal of Economic Literature, 43:4, 959-988.

Rogerson, Richard, and Robert Shimer. 2011. Search in macroeconomic models of the labor market. In: Orley Ashenfelter and David Card (eds). Handbook of Labor Economics., Elsevier, Volume 4A, 619-700.

Rosen, Sherwin. 1986. The theory of equalizing differences. In: Orley Ashenfelter and Richard Layard (eds). Handbook of Labor Economics, Volume 1, Elsevier North Holland, 641-692.

Rueda, David, and Jonas Pontusson. 2000. Wage Inequality and Varieties of Capitalism. World Politics, 52:3, 350383.

Saint-Paul, Gilles. 2000. The political economy of labour market institutions. Oxford University Press.

Salverda, Wiemer. 2005. The Bite and Effects of Wage Bargaining in the Netherlands 1995-2005. In: Keune and Galgóczi (eds), 225-254.

Salverda, Wiemer. 2008. Labor Market Institutions, Low-wage Work, and Job Quality. In: Salverda et al., (eds), Chapter 3, 63-131.

Salverda, Wiemer. 2013. The Evolution of Dutch Top-Income Shares until 2012 and the Purzle of Stability. AIAS Working Paper (forthcoming).

Salverda, Wiemer, and Anthony B. Atkinson. 2007. Top Incomes in The Netherlands over the Twentieth Century. In: Atkinson and Piketty (eds), Chapter 10.

Salverda, Wiemer, and Christina Haas. 2014. Earnings, Employment and Income Inequality. In: Salverda et al. (eds), 2014. Chapter 3. 
Salverda, Wiemer, Christina Haas, Marloes de Graaf-Zijl, Bram Lancee, Natascha Notten and Tahnee Ooms. 2013. Growing Inequalities and Their Impacts in The Netherlands. Country Report for The Netherlands. GINI project. http://www.gini-research.org/system/uploads/512/original/Netherlands.pdf?1380138293.

Salverda, Wiemer, Maarten van Klaveren and Marc van der Meer (editors). 2008. Low-wage Work in the Netherlands. Russell Sage, New York.

Salverda, Wiemer, Brian Nolan, Bertrand Maitre and Peter Mühlau. 2001. Benchmarking Low-Wage and High-Wage Employment in Europe and the United States. Report to the European Commission DG Employment and Social Affairs, http://www.uva-aias.net/uploaded_files/regular/draftdef0-1-1.pdf Brussels

Salverda, Wiemer, Brian Nolan and Timothy Smeeding (editors). 2009. The Oxford Handbook of Economic Inequality. Oxford University Press.

Salverda, Wiemer, Brian Nolan, Daniele Checchi, Ive Marx, Abigail McKnight, István György Tóth, and Herman van de Werfhorst (editors). 2014. Changing Inequalities in Rich Countries: Analytical and Comparative Perspectives. Oxford University Press.

Scheve, Kenneth, and David Stasavage. 2009. Institutions, Partisanship, and Inequality in the Long Run. World Politics, 61:2, 215-253.

Schivardi, Fabiano, and Roberto Torrini. 2008. Identifying the effects of firing restrictions through sizecontingent differences in regulation, Labour Economics, 15:3, 482-511.

Schmitt, John. 2013. Why Does the Minimum Wage Have No Discernible Effect on Employment? Center for Economic and Policy Research CEPR, Washington DC.

Schwartz, Christine. 2010. Earnings Inequality and the Changing Association between Spouses' Earnings. American Journal of Sociology, 115: 5, 1524-1557.

Shorrocks, Anthony. 1982. Inequality Decomposition by Factor Components, Econometrica, 50(1): 193-211.

Shorrocks, Anthony. 1983. The Impact of Income Components on the Distribution of Family Incomes. Quarterly Journal of Economics, 98: 2, 311-326.

Slonimczyk, Fabián. 2013. Earnings inequality and skill mismatch. Journal of Economic Inequality, 11:2, 163-194.

Slonimczyk, Fabián, and Peter Skott. 2012. Employment and distribution effects of the minimum wage. Journal of Economic Behavior and Organization, 84:1, 245-264.

Spitz-Oener, Alexandra. 2006. Technical Change, Job Tasks, and Rising Educational Demands: Looking outside the Wage Structure. Journal of Labor Economics, 24:2, 235-270.

Stewart, Mark. 2012. Wage inequality, minimum wage effects, and spillovers. Oxford Economic Papers 64: 616-634.

Sutch, Richard. 2010. The Unexpected Long-Run Impact of the Minimum Wage: An Educational Cascade. NBER Working Paper 16355.

Thévenon, Olivier. 2013. Drivers of Female Labour Force Participation in the OECD, OECD Social, Employment and Migration Working Paper 145, Paris.

Thévenon, Oliver and Anne Solaz. 2013. Labour Market Effects of Parental Leave Policies in OECD Countries, OECD Social, Employment and Migration Working Paper 141, Paris.

Van der Wiel, Karen. 2010. Better protected, better paid: Evidence on how employment protection affects wages. Labour Economics 17, 16-26.

Van Praag, Bernard, Aldi Hagenaars and Hans van Weeren. 1982. Poverty in Europe, Review of Income and Wealth. 28:3, 345-359.

Van Weeren, Hans, and Bernard M.S. Van Praag. 1983. The inequality of actual incomes and earning capacities between households in Europe. European Economic Review, 24, 239-256.

Večerník, Jiř́. 2010. Earnings Disparities and Income Inequality In CEE Countries: An Analysis of Development and Relationships. Working Paper 540, Luxembourg Income Study.

Večerník, Jiři. 2013. The Changing Role of Education in the Distribution of Earnings and Household Income. The Czech Republic, 1988-2009. Economics of Transition, 21: 1, 111-133.

Visser, Jelle. 2009. The ICTWSS Database: Database on Institutional Characteristics of Trade Unions, Wage Setting, State Intervention and Social Pacts in 34 countries between1960 and 2007, http://www.uvaaias.net $/ 208$

Visser, Jelle and Daniele Checchi. 2009. 'Inequality and the labour market: Unions' In: Salverda, Nolan and T. Smeeding (eds), Chapter 10, 230-256.

Vlasblom, Jan Dirk, Peter de Gijsel, and Jacques Siegers. 2001. Taxes, Female Labour Supply and Household Income: Differences between the Netherlands and the Federal republic of Germany. Applies Economics, 33, $735-744$.

Vroman, Wayne. 2007. Replacement Rates and UC Benefit Generosity. mimeo

Wallerstein, Michael. 1999. Wage-setting institutions and pay inequality in advanced industrial societies. American Journal of Political Science, 43:3, 649-680.

Wood, Adrian. 1995. North-South Trade, Employment and Inequality: Changing Fortunes in a Skill-driven World, Oxford University Press. 
World Bank. 2012. World Development Report 2013: Jobs. Washington

Yun, Myeong-Su. 2006. Earnings Inequality in USA, 1969-99: Comparing Inequality Using Earnings Equations. Review of Income and Wealth, 52:1, 127-144. 


\section{Appendix 1-Country codes}

ISO Alpha-3 and Alpha-2 Country codes

$\begin{array}{lll}\text { AUS } & \text { AU } & \text { Australia } \\ \text { AUT } & \text { AT } & \text { Austria } \\ \text { BEL } & \text { BE } & \text { Belgium } \\ \text { BGR } & \text { BG } & \text { Bulgaria } \\ \text { CAN } & \text { CA } & \text { Canada (BC: British Columbia, ON: Ontario) } \\ \text { CHE } & \text { CH } & \text { Switzerland } \\ \text { CYP } & \text { CY } & \text { Cyprus } \\ \text { CZE } & \text { CZ } & \text { Czech Republic } \\ \text { DEU } & \text { DE } & \text { Germany } \\ \text { DEU-W } & \text { DE-W } & \text { West Germany } \\ \text { DNK } & \text { DK } & \text { Denmark } \\ \text { ESP } & \text { ES } & \text { Spain } \\ \text { EST } & \text { EE } & \text { Estonia } \\ \text { EU } & & \text { European Union } \\ \text { FIN } & \text { FI } & \text { Finland } \\ \text { FRA } & \text { FR } & \text { France } \\ \text { GRC } & \text { GR } & \text { Greece } \\ \text { HUN } & \text { HU } & \text { Hungary } \\ \text { IRL } & \text { IE } & \text { Ireland } \\ \text { ISR } & \text { IL } & \text { Israel } \\ \text { ITA } & \text { IT } & \text { Italy } \\ \text { JPN } & \text { JP } & \text { Japan } \\ \text { KOR } & \text { KR } & \text { Korea } \\ \text { LTU } & \text { LT } & \text { Lithuania by Eurostat) } \\ \text { LUX } & \text { LU } & \text { Luxemburg } \\ \text { LVA } & \text { LV } & \text { Latvia } \\ \text { MLT } & \text { MT } & \text { Malta } \\ \text { NLD } & \text { NL } & \text { Netherlands } \\ \text { NOR } & \text { NO } & \text { Norway } \\ \text { NZL } & \text { NZ } & \text { New Zealand } \\ \text { POL } & \text { PL } & \text { Poland } \\ \text { PRT } & \text { PT } & \text { Portugal } \\ \text { ROM } & \text { RO } & \text { Romania } \\ \text { SWE } & \text { SE } & \text { Sweden } \\ \text { SVK } & \text { SK } & \text { Slovak Republic } \\ \text { SVN } & \text { SI } & \text { Slovenia } \\ \text { UK } & \text { UK } & \text { United Kingdom (official code GBR not used) } \\ \text { USA } & \text { US } & \text { United States } \\ & & \\ & & \end{array}$




\section{Appendix 2-Data sources and additional tables on earnings}

We obtain data from EUSILC survey conducted in 2010 (ver.1 dated 01/03/12), to which we added populations from Cyprus and Ireland extracted from the 2009 survey (ver.2 dated 01/08/11). Overall among European countries we consider 476265 observations (of which 9902 Irish and 7557 Cypriots). For these individuals we know relevant demographics (age, gender, education, ${ }^{152}$ marital status, birthplace), occupational characteristics (whether employed or self-employed, full-time or part-time, permanent or temporary contract, ISCO occupational code, workplace size, work experience).

We obtain data on US from participants to PSID survey conducted in 2011. Basic demographics (age, gender, education, ${ }^{153}$ marital status, labour market status) are obtained from individual file (file ind2011er.zip downloaded on 22/07/13), which includes 24661 observations. Information on labour earnings are collected from one respondent for each of 8907 households (typically a male household head), who responds about wage and hours for himself and his spouse (file fam2011er.zip downloaded on $22 / 07 / 13)$.

We adopt two selection rules:

a) population in relevant working age, which we define as being between 20 and 64-year-old. This is justified in order to allow for secondary school completion, and to take into account for different early retirement rules in different countries. This leads to the exclusion of employed youngsters aged 15-19, a fraction of which is employed with an average hourly wage which is on average half of the average wage in the adult population. Since countries differ in the duration of compulsory education as well as in institutional design, we have preferred to leave the youngster component of the labour force out of our analysis. ${ }^{154}$

b) population in the labour market, who self-define as either employed (employee or self-employed) or unemployed. This takes as exogenously given the significant cross-country differences in participation/employment rates (see table A.1). These differences are even enhanced when we consider analogous rates computed at household level. Notice the high share of self-employed in Italy and Greece, which are also the countries where the share of top incomes accruing to them is largest. The final sample is made of 264216 individuals in the labour market, among which 201500 employees, 33384 self-employed and 29332 unemployed.

The labour earnings variable are defined as either "gross yearly earnings from dependent employment cash or near cash"155 or "gross yearly cash benefits or losses from self-employment" (see table A.2 for means and standard deviations). ${ }^{156}$ Unemployed subsidies received by (temporarily) unemployed workers are also considered in the computation of earnings inequality. ${ }^{157}$

\footnotetext{
152 Data on years of education have been computed from maximum educational attainment according to ISCED classification (variable PE040 in SILC) converted into years by using legal duration.

${ }^{153}$ Data on completed years of education are directly reported by the interviewees (variable ER34119 in PSID).

154 There is an additional reason for excluding these cases. As we identify cohabiting couples by taking the two first working members in the household. Retaining these individuals would increase the risk of mixing couples up with single earners and an earning child.

155 Our GW variable (earnings from dependent employment) and GSELFW (earnings from self-employment) correspond to PY010G and PY050G variables respectively in EUSILC. In the case of PSID labour earnings are obtained from the sum of ER47501, ER47552, ER47582 and ER47612 variables (appropriately converted into yearly values) for the household head and from the sum of ER47752, ER47779, ER47809 and ER47839 variables for the working spouse. They are then separated between dependent employment or self-employment earnings according to the nonnegative value of the ER47495 or ER47752 variables ("how much is your salary").

${ }_{156}$ Negative values on earnings from self-employment are recoded into zeros, since most inequality indices (notably the Gini index) are defined over non-negative values.

${ }_{157}$ This corresponds to the variable PY090G in EUSILC and to the variables ER48500/ ER48619 (converted in annual values) in PSID.
} 
In order to distinguish between annual earnings and hourly wages, we need information about the number of hours worked. In both survey hours worked are reconstructed thanks combining answers to two questions (weekly hours usually worked in recent months - thus referred to the period of interview - and number of months worked in the previous year). ${ }^{158}$ The gross hourly wage rate is then computed dividing the yearly earnings by the hours worked. ${ }^{159}$ Descriptive statistics on hours worked and hourly wages are reported in table A.3. Notice that there is a significant loss of information when moving from yearly data (259500 observations with non-negative annual earnings) to hourly wage (228153 observations with non-missing hourly wages), due to missing information about weekly hours worked. A probit estimate indicates that young uneducated women holding a temporary contract are more likely not to report hours.

Table A.1 - Descriptive statistics computed from microdata - SILC 2010 and PSID 2011 labour market attachment (sample weights)

\begin{tabular}{|c|c|c|c|c|c|}
\hline & participation rate & $\begin{array}{c}\text { employment } \\
\text { rate }\end{array}$ & $\begin{array}{c}\text { unemployment } \\
\text { rate }\end{array}$ & $\begin{array}{l}\text { share self- } \\
\text { employed }\end{array}$ & $\begin{array}{c}\text { female participation } \\
\text { rate }\end{array}$ \\
\hline Austria & 0.734 & 0.676 & 0.079 & 0.124 & 0.596 \\
\hline Belgium & 0.732 & 0.650 & 0.112 & 0.106 & 0.597 \\
\hline Bulgaria & 0.800 & 0.670 & 0.163 & 0.096 & 0.620 \\
\hline Cyprus & 0.754 & 0.710 & 0.058 & 0.139 & 0.644 \\
\hline Czech Republic & 0.752 & 0.675 & 0.103 & 0.167 & 0.582 \\
\hline Denmark & 0.782 & 0.715 & 0.085 & 0.094 & 0.702 \\
\hline Estonia & 0.783 & 0.647 & 0.173 & 0.074 & 0.648 \\
\hline \begin{tabular}{|l|} 
Finland \\
\end{tabular} & 0.765 & 0.673 & 0.121 & 0.135 & 0.650 \\
\hline France & 0.754 & 0.672 & 0.109 & 0.099 & 0.637 \\
\hline Germany & 0.792 & 0.711 & 0.102 & 0.055 & 0.659 \\
\hline Greece & 0.736 & 0.644 & 0.125 & 0.304 & 0.553 \\
\hline Hungary & 0.687 & 0.595 & 0.134 & 0.124 & 0.542 \\
\hline Iceland & 0.789 & 0.731 & 0.073 & 0.125 & 0.685 \\
\hline Ireland & 0.707 & 0.592 & 0.162 & 0.149 & 0.532 \\
\hline Italy & 0.682 & 0.607 & 0.109 & 0.219 & 0.485 \\
\hline Latvia & 0.791 & 0.602 & 0.239 & 0.071 & 0.593 \\
\hline Lithuania & 0.804 & 0.649 & 0.193 & 0.100 & 0.662 \\
\hline Luxembourg & 0.739 & 0.692 & 0.063 & 0.078 & 0.609 \\
\hline Malta & 0.632 & 0.593 & 0.063 & 0.136 & 0.423 \\
\hline Netherlands & 0.760 & 0.732 & 0.037 & 0.154 & 0.660 \\
\hline Norway & 0.797 & 0.771 & 0.033 & 0.073 & 0.741 \\
\hline Poland & 0.716 & 0.640 & 0.105 & 0.214 & 0.571 \\
\hline Portugal & 0.788 & 0.672 & 0.148 & 0.144 & 0.617 \\
\hline Romania & 0.689 & 0.653 & 0.053 & 0.265 & 0.547 \\
\hline Slovak Republic & 0.764 & 0.660 & 0.137 & 0.108 & 0.603 \\
\hline \begin{tabular}{|l|} 
Slovenia \\
\end{tabular} & 0.737 & 0.633 & 0.141 & 0.096 & 0.587 \\
\hline Spain & 0.787 & 0.624 & 0.207 & 0.161 & 0.546 \\
\hline Sweden & 0.823 & 0.776 & 0.057 & 0.043 & 0.751 \\
\hline United Kingdom & 0.768 & 0.728 & 0.052 & 0.122 & 0.677 \\
\hline United States & 0.791 & 0.709 & 0.104 & 0.109 & 0.683 \\
\hline Average & 0.752 & 0.671 & 0.108 & 0.138 & 0.605 \\
\hline
\end{tabular}

158 In EUSILC this corresponds to the variable PL060 (Number of hours usually worked per week in main job) and the variables PL073-74-75-76-80 (Number of months spent at full-time/part-time work as employee/self-employed (including family worker)/unemployed). In PSID this corresponds to the variables ER47456/ER47713 (On average, how many hours a week did (you/he/she) work on (all of) (your/his/her) (job/jobs) during 2010?) multiplied by variables ER47454/ER47711 (weeks employed last year - reconstructed variable from work histories) net of variables ER47633/ER47890 (weeks of vacation)).

${ }^{159}$ In EUSILC data on hourly wages are not fully temporally consistent, since the gross yearly wage and the months of work are referred to 2009, while the information about the weekly hours is referred to 2010. In PSID the interviewees directly provide a measure of hourly wage (variables ER47501/ER47758: What is your hourly wage rate for your regular work time?). In the case of US, where both measures are available, computed and elicited wages with positive values exhibit a correlation of 0.53 . 
Table A.2 - Descriptive statistics computed from microdata - SILC 2010 and PSID 2011labour earnings (sample weights)

\begin{tabular}{|c|c|c|c|c|c|}
\hline country name & \begin{tabular}{|} 
Gross earnings \\
from \\
dependent \\
employment \\
(mean) \\
\end{tabular} & $\begin{array}{c}\text { Gross earnings } \\
\text { from } \\
\text { dependent } \\
\text { employment } \\
\text { (st.dev.) } \\
\end{array}$ & $\begin{array}{l}\text { Gross earnings } \\
\text { from self- } \\
\text { employment } \\
\text { (mean) }\end{array}$ & $\begin{array}{l}\text { Gross earnings } \\
\text { from self- } \\
\text { employment } \\
\text { (st.dev.) }\end{array}$ & $\begin{array}{l}\text { no of observations } \\
\text { with non-missing } \\
\text { values on yearly } \\
\text { earnings }\end{array}$ \\
\hline Austria & 26461.08 & 25858.63 & 4096.55 & 17355.84 & 6116 \\
\hline Belgium & 26723.36 & 20772.17 & 2717.21 & 11508.15 & 6387 \\
\hline Bulgaria & 3024.31 & 2925.93 & 446.67 & 2378.81 & 7731 \\
\hline Cyprus & 18748.41 & 16532.35 & 3139.14 & 13762.04 & 3970 \\
\hline Czech Republic & 7499.50 & 6937.02 & 1752.81 & 6380.98 & 9489 \\
\hline Denmark & 38504.27 & 26550.36 & 2017.71 & 18497.89 & 7005 \\
\hline Estonia & 7507.27 & 6367.43 & 122.38 & 959.08 & 5891 \\
\hline Finland & 27382.17 & 21351.46 & 2076.83 & 10272.64 & 12705 \\
\hline France & 22219.13 & 19263.07 & 2110.23 & 15184.50 & 11518 \\
\hline Germany & 24586.15 & 22526.16 & 1968.18 & 14598.60 & 12693 \\
\hline Greece & 12219.81 & 14306.38 & 5645.76 & 18567.37 & 7163 \\
\hline Hungary & 5038.98 & 5062.23 & 777.84 & 3393.05 & 10240 \\
\hline Iceland & 23832.86 & 17620.38 & 818.24 & 3899.32 & 4075 \\
\hline Ireland & 26624.65 & 28929.35 & 4520.33 & 19799.64 & 4766 \\
\hline Italy & 17593.58 & 17522.40 & 7017.56 & 24495.35 & 19637 \\
\hline Latvia & 5942.19 & 6430.71 & 207.53 & 1370.13 & 6742 \\
\hline Lithuania & 4979.52 & 5607.18 & 447.30 & 2589.25 & 6097 \\
\hline Luxembourg & 42588.71 & 38248.88 & 2896.52 & 22171.74 & 5717 \\
\hline Malta & 13787.59 & 11406.58 & 2393.88 & 8493.19 & 3678 \\
\hline Netherlands & 31138.58 & 26156.98 & 3186.18 & 16507.76 & 11621 \\
\hline Norway & 42686.63 & 32290.34 & 3409.42 & 23335.28 & 6269 \\
\hline Poland & 5567.64 & 6017.03 & 1020.09 & 3613.49 & 14693 \\
\hline Portugal & 10768.63 & 12283.16 & 1432.51 & 6260.98 & 5655 \\
\hline Romania & 2664.20 & 2452.14 & 333.46 & 1338.79 & 7342 \\
\hline Slovak Republic & 6322.45 & 8057.32 & 683.42 & 2971.25 & 8071 \\
\hline Slovenia & 14493.82 & 12900.63 & 1125.57 & 4699.40 & 14085 \\
\hline Spain & 14620.40 & 14235.10 & 1305.97 & 7504.83 & 16812 \\
\hline Sweden & 25384.12 & 18901.72 & 753.78 & 5208.48 & 8355 \\
\hline United Kingdom & 24787.20 & 28023.56 & 3654.77 & 26042.01 & 7818 \\
\hline United States & 51786.79 & 840084.88 & 7103.13 & 35807.86 & 7159 \\
\hline Average & 18819.88 & 32903.78 & 2627.03 & 16288.20 & 259500 \\
\hline
\end{tabular}

Note: data in 2010 Euros except US where data are in 2011 US dollars 
Table A.3 - Descriptive statistics computed from microdata - SILC 2010 and PSID 2011- hours and wages (sample weights)

\begin{tabular}{|c|c|c|c|c|c|}
\hline & $\begin{array}{l}\text { Hours worked } \\
\text { (mean) }\end{array}$ & $\begin{array}{l}\text { Hours worked } \\
\text { (st.dev.) }\end{array}$ & $\begin{array}{c}\text { Hourly wage } \\
\text { (mean) }\end{array}$ & $\begin{array}{l}\text { Hourly wage } \\
\text { (st.dev.) }\end{array}$ & $\begin{array}{c}\text { No of } \\
\text { observations } \\
\text { with non- } \\
\text { missing values } \\
\text { of hourly wages }\end{array}$ \\
\hline Austria & 1801.05 & 648.58 & 17.14 & 25.54 & 5689 \\
\hline Belgium & 1742.40 & 630.42 & 18.74 & 16.46 & 5662 \\
\hline Bulgaria & 1924.69 & 413.00 & 1.83 & 1.67 & 6381 \\
\hline Cyprus & 1844.24 & 527.32 & 10.67 & 8.73 & 3743 \\
\hline Czech Republic & 1979.71 & 489.53 & 4.23 & 3.29 & 8685 \\
\hline Denmark & 1752.24 & 449.20 & 24.02 & 15.45 & 6615 \\
\hline Estonia & 1761.99 & 498.25 & 5.22 & 5.93 & 4795 \\
\hline Finland & 1718.94 & 558.07 & 19.46 & 21.05 & 11479 \\
\hline France & 1746.34 & 617.55 & 15.20 & 18.75 & 10223 \\
\hline Germany & 1746.93 & 619.15 & 15.24 & 11.98 & 11569 \\
\hline Greece & 1829.68 & 553.70 & 7.96 & 8.64 & 6212 \\
\hline \begin{tabular}{|l|} 
Hungary \\
\end{tabular} & 1844.58 & 403.42 & 3.05 & 2.71 & 8876 \\
\hline Iceland & 1914.37 & 642.18 & 14.38 & 19.49 & 3783 \\
\hline Ireland & 1637.80 & 693.63 & 22.17 & 29.44 & 3917 \\
\hline Italy & 1829.60 & 474.38 & 11.17 & 10.77 & 17248 \\
\hline Latvia & 1816.58 & 487.95 & 4.07 & 4.06 & 5092 \\
\hline \begin{tabular}{|l} 
Lithuania \\
\end{tabular} & 1784.31 & 415.07 & 3.38 & 3.41 & 4995 \\
\hline \begin{tabular}{|l|} 
Luxembourg \\
\end{tabular} & 1833.12 & 576.49 & 25.13 & 20.55 & 5311 \\
\hline Malta & 1863.97 & 517.44 & 8.22 & 7.08 & 3353 \\
\hline Netherlands & 1582.64 & 553.61 & 21.33 & 19.91 & 11212 \\
\hline Norway & 1765.72 & 504.90 & 25.81 & 21.14 & 6043 \\
\hline Poland & 1894.65 & 517.62 & 3.40 & 4.36 & 13077 \\
\hline Portugal & 1866.69 & 470.88 & 7.02 & 7.65 & 4281 \\
\hline Romania & 1950.27 & 352.44 & 1.46 & 1.24 & 6589 \\
\hline Slovak Republic & 1913.54 & 395.13 & 3.81 & 4.11 & 7180 \\
\hline Slovenia & 1897.84 & 415.46 & 8.76 & 7.16 & 12131 \\
\hline Spain & 1821.19 & 536.07 & 10.32 & 10.42 & 12783 \\
\hline Sweden & 1516.64 & 496.22 & 19.80 & 24.18 & 7755 \\
\hline United Kingdom & 1785.60 & 637.22 & 15.39 & 19.19 & 7328 \\
\hline Unites States & 1937.14 & 848.38 & 8.65 & 26.66 & 6146 \\
\hline Average & 1793.65 & 564.99 & 12.37 & 15.44 & 228153 \\
\hline
\end{tabular}

Note: data in 2010 Euros except US where data are in 2011 US dollars 
Table A.4 - Estimates of model relevant parameters - employed or unemployed individuals - SILC 2010 and PSID 2011

\begin{tabular}{|c|c|c|c|c|c|c|c|c|c|c|c|c|c|}
\hline & (1) & (2) & (3) & (4) & (5) & (6) & (7) & (8) & (9) & $(10)$ & (11) & (12) & (13) \\
\hline & $\begin{array}{c}\text { Skilled } \\
\text { workers }\end{array}$ & $\begin{array}{c}\text { Unskilled } \\
\text { workers }\end{array}$ & $\begin{array}{l}\text { Unem- } \\
\text { ployed }\end{array}$ & $\begin{array}{l}\text { Average } \\
\text { wage }\end{array}$ & $\begin{array}{c}\text { Unemploy- } \\
\text { ment } \\
\text { benefit }\end{array}$ & $\begin{array}{l}\text { Replace- } \\
\text { ment rate }\end{array}$ & $\begin{array}{l}\text { Skilled } \\
\text { wage }\end{array}$ & $\begin{array}{l}\text { Unskilled } \\
\text { wage }\end{array}$ & $\begin{array}{c}\text { Wage } \\
\text { premium }\end{array}$ & $\begin{array}{l}\text { Between- } \\
\text { group } \\
\text { inequality }\end{array}$ & $\begin{array}{c}\text { Overall } \\
\text { inequality }\end{array}$ & & \\
\hline & $\begin{array}{c}\alpha(1-u) \\
\text { pct. points }\end{array}$ & $\begin{array}{c}(1-\alpha) \cdot \\
(1-u) \\
\text { pct. points }\end{array}$ & $\begin{array}{c}u \\
\text { pct. points }\end{array}$ & $\begin{array}{c}\bar{w} \\
\text { euros/ } \\
\text { dollars }\end{array}$ & $\begin{array}{c}b \\
\text { euros/ } \\
\text { dollars }\end{array}$ & $\begin{array}{c}\gamma \\
\text { pct. points }\end{array}$ & $\begin{array}{c}w^{s} \\
\text { euros/ } \\
\text { dollars }\end{array}$ & $\begin{array}{c}w^{u} \\
\text { euros/ } \\
\text { dollars }\end{array}$ & $\begin{array}{c}\sigma \\
\text { pct. points }\end{array}$ & Gini $_{\text {est }}$ & Gini $_{o b s}$ & $\Delta G i n i$ & $\frac{\text { Gini }_{\text {est }}}{\text { Gini }_{\text {obs }}}$ \\
\hline AUT & 0.321 & 0.616 & 0.063 & 32205.34 & 3948.59 & 0.12 & 41021.68 & 27604.24 & 0.49 & 0.073 & 0.348 & 0.28 & 0.21 \\
\hline BEL & 0.439 & 0.461 & 0.100 & 33006.56 & 5958.73 & 0.18 & 39378.79 & 26940.58 & 0.46 & 0.086 & 0.299 & 0.21 & 0.29 \\
\hline BGR & 0.225 & 0.654 & 0.121 & 3789.24 & 449.98 & 0.12 & 5186.9 & 3309.31 & 0.57 & 0.100 & 0.346 & 0.25 & 0.29 \\
\hline CYP & 0.391 & 0.567 & 0.042 & 21922.22 & 2928.37 & 0.13 & 28080.84 & 17672.54 & 0.59 & 0.074 & 0.364 & 0.29 & 0.20 \\
\hline $\mathrm{CZE}$ & 0.176 & 0.764 & 0.060 & 9785.79 & 926.04 & 0.09 & 14118.73 & 8786.53 & 0.61 & 0.067 & 0.3 & 0.23 & 0.22 \\
\hline$\overline{\mathrm{DEU}}$ & 0.454 & 0.470 & 0.076 & 47286.8 & 6110.35 & 0.13 & 55418.81 & 41882.96 & 0.32 & 0.067 & 0.387 & 0.32 & 0.17 \\
\hline $\mathrm{DNK}$ & 0.377 & 0.566 & 0.057 & 8493.88 & 1626.26 & 0.19 & 10215.24 & 7451.71 & 0.37 & 0.060 & 0.24 & 0.18 & 0.25 \\
\hline EST & 0.322 & 0.532 & 0.145 & 34994.66 & 4483.46 & 0.13 & 42707.44 & 27756.81 & 0.54 & 0.116 & 0.361 & 0.24 & 0.32 \\
\hline ESP & 0.345 & 0.483 & 0.171 & 25870.6 & 5178.83 & 0.20 & 32662.33 & 21905.82 & 0.49 & 0.119 & 0.352 & 0.23 & 0.34 \\
\hline FIN & 0.434 & 0.463 & 0.103 & 30659.61 & 3949.61 & 0.13 & 38298.93 & 23276.59 & 0.65 & 0.104 & 0.317 & 0.21 & 0.33 \\
\hline FRA & 0.336 & 0.576 & 0.087 & 19628.96 & 3255.67 & 0.17 & 23998.9 & 16440.65 & 0.46 & 0.080 & 0.321 & 0.24 & 0.25 \\
\hline GRC & 0.381 & 0.522 & 0.097 & 6403.25 & 955.58 & 0.15 & 9143.06 & 5173.97 & 0.77 & 0.108 & 0.344 & 0.24 & 0.31 \\
\hline HUN & 0.273 & 0.608 & 0.119 & 27111.2 & 3831.86 & 0.14 & 32224.25 & 23284.92 & 0.38 & 0.089 & 0.366 & 0.28 & 0.24 \\
\hline IRE & 0.484 & 0.361 & 0.155 & 38583.85 & 8978.04 & 0.23 & 45739.25 & 28977.96 & 0.58 & 0.111 & 0.404 & 0.29 & 0.27 \\
\hline ISL & 0.394 & 0.527 & 0.079 & 23958.99 & 3936.05 & 0.16 & 29992.45 & 22250.91 & 0.35 & 0.069 & 0.326 & 0.26 & 0.21 \\
\hline ITA & 0.203 & 0.718 & 0.079 & 7518.82 & 1252.23 & 0.17 & 10476.27 & 5644.96 & 0.86 & 0.091 & 0.32 & 0.23 & 0.29 \\
\hline LTU & 0.574 & 0.296 & 0.131 & 6335.65 & 961.26 & 0.15 & 7365.67 & 4337.72 & 0.70 & 0.108 & 0.424 & 0.32 & 0.26 \\
\hline LUX & 0.296 & 0.649 & 0.055 & 44751.21 & 11201.46 & 0.25 & 67207.76 & 34529.19 & 0.95 & 0.095 & 0.372 & 0.28 & 0.25 \\
\hline LVA & 0.314 & 0.495 & 0.192 & 16856.53 & 3797.42 & 0.23 & 22378.49 & 14985.31 & 0.49 & 0.125 & 0.44 & 0.31 & 0.28 \\
\hline MLT & 0.242 & 0.713 & 0.045 & 37965.09 & 7090.32 & 0.19 & 47164.16 & 30699.66 & 0.54 & 0.061 & 0.305 & 0.24 & 0.20 \\
\hline NLD & 0.432 & 0.547 & 0.021 & 48789.02 & 6094.77 & 0.12 & 56535.29 & 41581.87 & 0.36 & 0.047 & 0.317 & 0.27 & 0.15 \\
\hline NOR & 0.470 & 0.505 & 0.024 & 7390.9 & 996.99 & 0.13 & 9625.72 & 6253.77 & 0.54 & 0.062 & 0.316 & 0.25 & 0.20 \\
\hline POL & 0.312 & 0.614 & 0.074 & 14248.9 & 3843.58 & 0.27 & 26901.73 & 11502.8 & 1.34 & 0.122 & 0.362 & 0.24 & 0.34 \\
\hline PRT & 0.159 & 0.734 & 0.106 & 3684.08 & 966.96 & 0.26 & 5262.04 & 3126.16 & 0.68 & 0.081 & 0.385 & 0.30 & 0.21 \\
\hline ROM & 0.254 & 0.720 & 0.026 & 7954.01 & 1245.76 & 0.16 & 10154.17 & 7159.13 & 0.42 & 0.046 & 0.27 & 0.22 & 0.17 \\
\hline SWE & 0.426 & 0.530 & 0.045 & 18068.09 & 2233.65 & 0.12 & 27336.91 & 14716.41 & 0.86 & 0.093 & 0.295 & 0.20 & 0.32 \\
\hline SVNI & 0.242 & 0.669 & 0.089 & 20305.54 & 4503.04 & 0.22 & 26071.97 & 16187.4 & 0.61 & 0.083 & 0.329 & 0.25 & 0.25 \\
\hline SVK & 0.248 & 0.687 & 0.065 & 28105.98 & 5413.02 & 0.19 & 31987.71 & 24987.56 & 0.28 & 0.051 & 0.29 & 0.24 & 0.18 \\
\hline UK & 0.427 & 0.541 & 0.033 & 30438.71 & 4831.86 & 0.16 & 39293.29 & 23445.94 & 0.68 & 0.076 & 0.404 & 0.33 & 0.19 \\
\hline USA & 0.531 & 0.378 & 0.091 & 39150.52 & 9903.6 & 0.25 & 47253.16 & 27769.21 & 0.70 & 0.090 & 0.408 & 0.32 & 0.22 \\
\hline Mean & 0.342 & 0.571 & 0.087 & 23162.53 & 4147.73 & 0.18 & 31462.71 & 18192.87 & 0.73 & 0.099 & 0.342 & 0.24 & 0.29 \\
\hline
\end{tabular}




\section{Appendix 3-Data sources and descriptive statistics on labour market institutions}

Data on institutional measures were collected over a time interval spanning half century, from 1960 to 2010.

\section{Union density}

It measures the fraction of wage and salary earners who are members of trade unions. It excludes unemployed and retired workers (net version). Source: ICTWSS database version 2 (Database on Institutional Characteristics of Trade Unions, Wage Setting, State Intervention and Social Pacts in 34 countries between 1960 and 2007 - see Visser 2009 - variable UD - downloaded on 04/04/13). ${ }^{160}$

\section{Coverage}

It measures the fraction of employees covered by wage bargaining agreements over all wage and salary earners in employment with the right to bargaining. Source: ICTWSS database version 2 (variable AdjCOV)

\section{Wage centralization}

It represents a summary measure (ranging between 0 and 1) of centralization and coordination of union wage bargaining, taking into account both union authority and union concentration at multiple levels source: ICTWSS database version 2 (variable CENT).

\section{Strike activity}

It measures the days not worked for strikes and lockouts divided by participant worker - total economy. Source is ILO (downloaded on 04/04/13).

\section{Minimum wage}

It takes the ratio of the statutory minimum wage relative to mean wage of full-time workers (sometimes known as "Kaitz index" - see Dolado et al. 1994). However this measure does not consider the possibility of differentiation across workers types. For this reason, Aghion et al. (2011) have combined the ratio of the minimum wage to the GDP per capita with an index of stringency derived from ILO. ${ }^{161}$ For this reason, the variable is set to zero when minimum wage provision is absent. Data are downloaded from the OECD Stats website (except than in the case of Iceland, whose values are taken from table 5.5 of Danish Technological Institute. Assessment of the Labour Market in Iceland. Contract no. VC/2010/038 Final report - Policy and Business Analysis - April 2011.

\section{Employment protection legislation}

The measure we use is provided by OECD, which recently have partially revised their country assessment (OECD 2012). ${ }^{162}$ It measures the stringency of firing regulation and is based on eighteen dimensions of the firing procedure. ${ }^{163}$ There is a second series is provided by World Bank and have been used among others by Botero et al. (2004). ${ }^{164}$

\footnotetext{
160 This measures highly correlates with the OECD corresponding measure (0.95) and with the ILO one (0.99), which is not surprising given the background studies conducted by the same author (Jelle Visser).

${ }^{161}$ This index takes value of 1 if there is a legal statutory minimum wage and if the minimum wage is set at the national level without any derogation, value of 0.5 if there is a legal statutory minimum wage but with derogations by age, qualification, region, sector or occupation; or if the wage floor is set by collective bargaining but extended to all workers, and a value of 0 if the wage is set by collective bargaining and only applies to the unionized workers. This solution introduce a value of the index even if a country does not have the provision of a minimum wage, because otherwise these countries should be left out of picture. See the ILO TRAVAIL legal databases (http://www.ilo.org/dyn/travail), which however provides only the contemporaneous information (thus preventing us to use the measure for past periods).

162 Data used in the analysis of the main text have been downloaded on $02 / 08 / 13$. A preliminary download conducted on 4/4/2013 yields a different series for overall EPL, which however exhibit a correlation with the new one of 0.97.

1638 dimensions concern "regular contracts": Notification procedures, Delay involved before notice can start, Length of the notice period at various tenure durations, Severance pay at various tenure duration, Definition of justified or unfair dismissal, Length of trial period, Compensation following unfair dismissal, Possibility of reinstatement following unfair dismissal; 6 dimensions concern "temporary employment": Valid cases for use of fixed-term contracts (FTC), Maximum
} 


\section{Unemployment benefit}

Unemployment insurance and unemployment assistance benefits - gross replacement rate (ratio to the average wage) for a full-time adult worker. The source is OECD historical series, which is available in odd years and imputed using intermediate means in even years. It is the average between single worker and one-earner married couple with two children. ${ }^{165}$

\section{Tax wedge}

Average tax wedge (sum of social contributions and income taxes as ratio to the average wage). It considers the average between single worker with no child and one-earner married couple with two children. The source are the estimates from the OECD micro-simulation model.

\section{Social expenditure}

It measures the expenditure for cash benefits and benefit in kind for social assistance, as percentage of GDP. The source is OECD historical series, which are available on five-year base, and then interpolated.

\section{Child care}

It measures the enrolment rate in early childcare and pre-primary education (average between age 3, 4 and 5 - full and part-time students ) and proxies the availability of childcare facilities. Available values for years 2005 and 2010, while intermediate values are interpolated. The source is OECD, Education at a glance 2012, table C2.1.

\section{Parental leave}

It captures the possibility of reconciling work and fertility, by measuring weeks of paid leave for child birth. The series is available since 1970. The source is Thévenon and Solaz (2013). Further documentation can be found at http://www.oecd.org/social/soc/oecdfamilydatabase.htm

\section{Tax treatment of household incomes}

This variable aims to capture the potential favourable tax treatment of working couples vis-à-vis individual taxation. It is constructed as the ratio between the average tax rate of single earner family (earning $170 \%$ of average wage) and the average tax rate of a two earners family (main earner at average wage and second earner making $67 \%$ of average wage). The reported variable consists of a further averaging between two household situation with respect to children (zero children and two children families). A higher value would indicate a favourable treatment of labour market participation of a second earner. Data available since 2001. The underlying data is obtained from the OECD microsimulation model, available at http://stats.oecd.org/Index.aspx?DataSetCode=FIXINCLSA.

\section{Active and passive labour market policies}

It considers the public expenditure on active or passive labour market policies as percentage of GDP. It combines two data sources: when available we have been using OECD statistics for homogeneity with other series; otherwise we have resorted to Eurostat, which classifies as actives expenditure categories from 2 to 7 (2.Training - 3.Job rotation and job sharing - 4.Employment incentives - 5.Supported

number of successive FTC, Maximum cumulated duration of successive FTC, Types of work for which temporary work agency (TWA) employment is legal, Restrictions on number of renewals, Maximum cumulated duration of TWA contracts; 4 dimensions concern "collective dismissal: Definition of collective dismissal, Additional notification requirements, Additional delays involved before notice can start, Other special costs to employers - methodology is accurately described in chpt.2 of OECD 2004)

164 The World Bank index measures firing costs in terms of weeks of salary and it is based on three components: the notice period for redundancy dismissal, the severance pay for redundancy dismissal and the legally mandated penalty for redundancy dismissal.

165 It combines GRR(APW) until 2001 and GRR(AW) afterward. Eurostat provides a measure of the unemployment benefit net replacement rate for a single worker, which has a correlation index with OECD gross ratio equal to 0.55 and a limited time coverage, since it starts with 2001 and does not cover US. 
employment and rehabilitation - 6.Direct job creation - 7.Start-up incentives) and passive expenditure categories 8 and 9 (8.Out-of-work income maintenance and support - 9.Early retirement).

Overall means and standard deviations for these variables are reported in table A.5. Country means are reported in table with reference to the most recent decade.

Table A.5 - Descriptive statistics for institutional measures, sample period 1960-2010, 30 countries

\begin{tabular}{|c|c|c|c|c|c|}
\hline Variable & $\begin{array}{c}\text { No of } \\
\text { observations }\end{array}$ & Mean & $\begin{array}{l}\text { Standard. } \\
\text { Deviation }\end{array}$ & Minimum & Maximum \\
\hline union density & 1123 & 45.99 & 22.97 & 6.67 & 100.00 \\
\hline coverage & 931 & 70.70 & 21.74 & 7.50 & 100.00 \\
\hline centralization & 1016 & 0.42 & 0.19 & 0.08 & 0.98 \\
\hline strike activity & 730 & 5.09 & 7.29 & 0.00 & 61.14 \\
\hline minimum wage & 1179 & 0.19 & 0.21 & 0.00 & 0.71 \\
\hline employment protection legislation & 506 & 2.37 & 0.88 & 0.26 & 5.00 \\
\hline unemployment benefit & 918 & 27.02 & 15.48 & 0.00 & 70.00 \\
\hline tax wedge & 294 & 25.32 & 7.75 & 8.17 & 41.88 \\
\hline social expenditure & 615 & 2.07 & 1.00 & 0.20 & 4.40 \\
\hline child care & 144 & 81.73 & 16.46 & 24.70 & 101.13 \\
\hline parental leave & 887 & 40.82 & 43.57 & 0.00 & 214.00 \\
\hline $\begin{array}{l}\text { tax treatment of household } \\
\text { incomes }\end{array}$ & 228 & 1.93 & 1.47 & 0.26 & 8.21 \\
\hline active labour market policies & 560 & 0.70 & 0.52 & 0.03 & 3.04 \\
\hline passive labour market policies & 572 & 1.25 & 0.99 & 0.08 & 5.45 \\
\hline
\end{tabular}


Table A.6 - Sample means of institutional measures - recent years (average 2000-2010)

\begin{tabular}{|c|c|c|c|c|c|c|c|c|c|c|c|c|c|c|}
\hline & $\begin{array}{l}\text { union } \\
\text { density }\end{array}$ & coverage & centralization & strike & $\begin{array}{l}\text { minimum } \\
\text { wage }\end{array}$ & $\begin{array}{l}\text { employment } \\
\text { protection } \\
\text { legislation }\end{array}$ & $\begin{array}{c}\text { unemployment } \\
\text { benefit }\end{array}$ & $\begin{array}{c}\text { tax } \\
\text { wedge }\end{array}$ & $\begin{array}{c}\text { social } \\
\text { expenditure }\end{array}$ & $\begin{array}{l}\text { child } \\
\text { care }\end{array}$ & $\begin{array}{l}\text { parental } \\
\text { leave }\end{array}$ & $\begin{array}{c}\text { tax } \\
\text { treatment } \\
\text { of } \\
\text { household } \\
\text { incomes }\end{array}$ & $\begin{array}{l}\text { active } \\
\text { labour } \\
\text { market } \\
\text { policies }\end{array}$ & $\begin{array}{l}\text { passive } \\
\text { labour } \\
\text { market } \\
\text { policies }\end{array}$ \\
\hline Austria & 32.37 & 98.91 & 0.90 & 1.03 & 0.00 & 2.47 & 31.67 & 31.90 & 2.72 & 78.00 & 117.09 & 0.85 & 0.66 & 1.32 \\
\hline Belgium & 51.88 & 96.00 & 0.46 & 23.07 & 0.44 & 1.82 & 40.91 & 36.97 & 2.63 & 99.54 & 28 & 1.93 & 1.17 & 2.23 \\
\hline Bulgaria & 24.01 & 32.50 & 0.31 & na & 0.00 & na & 46.40 & 21.43 & na & na & na & na & 0.30 & 0.25 \\
\hline Cyprus & 61.63 & 57.35 & 0.25 & 2.33 & 0.00 & na & 60.40 & 8.50 & na & na & na & 0.56 & 0.13 & 0.58 \\
\hline $\begin{array}{l}\text { Czech } \\
\text { Republic }\end{array}$ & 20.74 & 43.77 & 0.25 & na & 0.31 & 3.21 & 6.14 & 17.74 & 1.87 & 82.01 & 185.64 & 0.33 & 0.23 & 0.27 \\
\hline Denmark & 71.62 & 81.87 & 0.47 & 3.49 & 0.00 & 2.13 & 52.72 & 39.19 & 3.55 & 91.91 & 48.91 & 2.26 & 1.72 & 2.06 \\
\hline Estonia & 9.69 & 25.06 & 0.36 & 0.21 & 0.30 & 2.43 & 50.00 & 17.60 & 1.79 & 87.08 & na & 0.67 & 0.11 & 0.39 \\
\hline Finland & 71.84 & 87.13 & 0.40 & 2.16 & 0.00 & 2.19 & 34.56 & 32.57 & 2.98 & 51.29 & 42.35 & 2.69 & 0.90 & 1.84 \\
\hline France & 7.84 & 90.00 & 0.21 & 22.47 & 0.47 & 2.42 & 39.88 & 24.90 & 3.02 & 100.99 & 32.55 & 0.69 & 1.02 & 1.46 \\
\hline Germany & 21.44 & 64.40 & 0.48 & 1.60 & 0.00 & 2.80 & 25.85 & 36.73 & 1.96 & 91.57 & 60.1 & 4.11 & 1.03 & 1.78 \\
\hline Greece & 25.03 & 65.00 & 0.34 & na & 0.33 & 2.80 & 14.42 & 22.77 & 1.14 & 72.30 & 24.09 & 1.06 & 0.17 & 0.44 \\
\hline Hungary & 18.01 & 37.85 & 0.23 & 1.36 & 0.36 & 2.00 & 13.31 & 34.13 & 3.26 & 86.86 & 110 & 1.11 & 0.42 & 0.44 \\
\hline Iceland & 86.47 & 88.02 & na & 16.74 & 0.51 & 1.73 & 40.76 & 26.00 & 3.00 & 95.44 & 25.97 & 3.16 & na & na \\
\hline Italy & 34.01 & 80.00 & 0.34 & 1.01 & 0.00 & 2.76 & 34.64 & 24.59 & 1.31 & 97.71 & 48 & 4.05 & 0.50 & 0.83 \\
\hline Latvia & 19.41 & 19.41 & 0.48 & 4.01 & 0.33 & na & 60.00 & 25.11 & na & na & na & 1.08 & 0.19 & 0.46 \\
\hline Lithuania & 13.93 & 12.16 & 0.30 & 2.41 & 0.36 & na & 47.62 & 23.61 & na & na & na & 2.74 & 0.18 & 0.23 \\
\hline Luxembourg & 41.00 & 58.22 & 0.31 & na & 0.34 & 2.25 & 26.67 & 19.89 & 3.36 & 85.95 & 42 & 1.19 & 0.42 & 0.60 \\
\hline Malta & 56.02 & 58.26 & 0.37 & 1.35 & 0.00 & na & 30.63 & 14.94 & na & na & na & 1.13 & 0.04 & 0.36 \\
\hline Netherlands & 20.69 & 82.63 & 0.57 & 2.58 & 0.43 & 2.87 & 41.74 & 32.36 & 1.67 & 68.02 & 20.73 & 1.40 & 1.31 & 1.74 \\
\hline Norway & 54.44 & 72.94 & 0.51 & 11.38 & 0.00 & 2.33 & 51.80 & 28.46 & 2.93 & 91.93 & 37.91 & 5.97 & 0.65 & 0.44 \\
\hline Poland & 19.18 & 39.00 & 0.23 & 3.48 & 0.34 & 2.23 & 10.89 & 28.74 & 1.13 & 49.00 & 122.55 & 0.70 & 0.43 & 0.74 \\
\hline Portugal & 20.92 & 60.07 & 0.34 & 1.35 & 0.36 & 4.45 & 42.23 & 18.55 & 1.15 & 81.19 & 18.65 & 1.75 & 0.64 & 1.11 \\
\hline Romania & 36.28 & 70.00 & 0.25 & 13.27 & 0.29 & na & 32.20 & 27.34 & na & na & na & na & 0.08 & 0.38 \\
\hline $\begin{array}{l}\text { Slovak } \\
\text { Republic }\end{array}$ & 24.34 & 44.70 & 0.50 & 0.01 & 0.35 & 2.30 & 9.50 & 18.22 & 1.89 & 72.53 & 164 & 0.99 & 0.30 & 0.46 \\
\hline Slovenia & 35.96 & 97.40 & 0.40 & na & 0.43 & 2.65 & 61.64 & 29.09 & 1.07 & 80.67 & na & 1.00 & 0.29 & 0.41 \\
\hline Spain & 15.60 & 87.84 & 0.36 & 2.55 & 0.34 & 2.36 & 34.98 & 16.41 & 1.16 & 98.68 & 16 & 0.65 & 0.79 & 1.78 \\
\hline Sweden & 74.40 & 93.17 & 0.51 & 3.58 & 0.00 & 2.62 & 37.62 & 31.25 & 3.29 & 90.39 & 59.95 & 3.50 & 1.20 & 1.06 \\
\hline $\begin{array}{l}\text { United } \\
\text { Kingdom }\end{array}$ & 28.74 & 34.64 & 0.11 & 2.20 & 0.36 & 1.20 & 15.99 & 25.87 & 3.14 & 91.88 & 28.55 & 1.84 & 0.36 & 0.23 \\
\hline
\end{tabular}


Table A.7 Household incomes and earnings (see Section 2)

\begin{tabular}{|c|c|c|c|c|}
\hline Authors & $\begin{array}{l}\text { Years and } \\
\text { countries }\end{array}$ & $\begin{array}{l}\text { Datasets* and } \\
\text { sample selection }\end{array}$ & Method and important variables & Main findings \\
\hline \multicolumn{5}{|c|}{ Comparison of aggregate inequality measures } \\
\hline $\begin{array}{l}\text { Atkinson } \\
\text { and } \\
\text { Brandolini } \\
2006\end{array}$ & $\begin{array}{l}\text { CAN, DEU, } \\
\text { FIN, NLD, } \\
\text { NOR, SWE, } \\
\text { UK, USA; } \\
\text { around } 2000\end{array}$ & $\begin{array}{l}\text { LIS; sample } \\
\text { consecutively } \\
\text { extending from } \\
\text { employees aged 15-65 } \\
\text { to all individuals in } \\
\text { households. }\end{array}$ & $\begin{array}{l}\text { International comparisons of earnings dispersion: cross-section and } \\
\text { trends. Comparison Gini's of wages, earnings of employed 15-64, } \\
\text { earnings of all 15-64, income all 15-64, income all, equivalized income } \\
\text { all. }\end{array}$ & $\begin{array}{l}\text { They aim to take stock of existing research and conclude to, inter alia: } \\
\text { - need to model supply and demand and institutional variables in a common framework, } \\
\text { linked to an underlying economic model; } \\
\text { - differences in definitions and coverage may affect cross-country comparisons and } \\
\text { cannot be assumed to be fixed over time. } \\
\text { - need for care with different income concepts and different populations. } \\
\text { - important interdependences between different explanatory variables. }\end{array}$ \\
\hline Brown 1999 & & $\begin{array}{l}\text { Mainly US studies, } \\
\text { from Gramlich } 1976 \\
\text { to Neumark and } \\
\text { Wascher } 1997 .\end{array}$ & $\begin{array}{l}\text { Several simple statistics: poor fraction among low-wage workers: } \\
\text { around } 20 \% \text {. Card and Krueger (1995a) argue that other forces have } \\
\text { increased the fraction. Probability of low pay among workers in low- } \\
\text { income families. But many poor families have no workers. Gains of } \\
\text { minimum wage increase comparable across deciles. Small impacts, } \\
\text { difficult to find. }\end{array}$ & $\begin{array}{l}\text { Effects of the minimum wage on the wage distribution became clearer with the declining } \\
\text { real minimum wage in the 1980s; nevertheless the ability of minimum wages to equalize } \\
\text { the distribution of family incomes remains quite limited. }\end{array}$ \\
\hline $\begin{array}{l}\text { Burtless } \\
1999\end{array}$ & $\begin{array}{l}\text { USA; } 1979 \text { vs } \\
1996 .\end{array}$ & CPS; ages 25-59. & $\begin{array}{l}\text { Counterfactuals for Gini coefficient of household-equivalent personal } \\
\text { income: holding constant male, female earnings distributions, or } \\
\text { partners' earnings correlation. }\end{array}$ & $\begin{array}{l}\text { Much of the rise in overall US inequality is due to family composition shifts and other } \\
\text { causes rather than the change in pay patterns. Household income inequality change } \\
\text { attributed to 33-44\% earnings, shift to single and single-parent households } 21-25 \% \text {, } \\
\text { partners' increased earnings correlation } 13 \% \text {. }\end{array}$ \\
\hline $\begin{array}{l}\text { Gottschalk } \\
\text { and } \\
\text { Smeeding } \\
1997\end{array}$ & $\begin{array}{l}\text { AUS, ISR, } \\
\text { JPN, NOR, } \\
\text { NZL, USA, } \\
\text { and most of } \\
\text { EU15; 1980s } \\
\text { into early } \\
1990 \text { s. }\end{array}$ & National datasets. & $\begin{array}{l}\text { Comparison of studies of income inequality with discussion of roles } \\
\text { of earnings, demography and social protection. The inclusion of } \\
\text { multiple income sources received by multiple individuals thwarts } \\
\text { attempts to identify the causal links that led to variations across time } \\
\text { and across countries in the distribution of total post-tax and transfer } \\
\text { family income. Researchers have, therefore, limited themselves largely } \\
\text { to purely accounting exercises which decompose changes in overall } \\
\text { inequality into a set of component parts that may reflect endogenous } \\
\text { as well as exogenous changes. }\end{array}$ & $\begin{array}{l}\text { Better structural models of income distribution and redistribution that can be applied } \\
\text { across nations are badly needed. Ideally, an overall framework would simultaneously } \\
\text { model the generation of all sources of income (labour income, capital income, private } \\
\text { transfers, public transfers, and all forms of taxation) as well as the formation of income } \\
\text { sharing units. While most of the components of such a model were identified as early as } \\
\text { the mid-1960s, our progress toward building such a model has been slow. If we are to } \\
\text { understand why we observe the extent and pattern of inequality levels and trends that are } \\
\text { extant in this review, an overall conceptual framework with empirically testable } \\
\text { components is the next big step that must be taken. }\end{array}$ \\
\hline $\begin{array}{l}\text { Gottschalk } \\
\text { and } \\
\text { Danziger } \\
2005\end{array}$ & $\begin{array}{l}\text { USA; 1975- } \\
2002 .\end{array}$ & $\begin{array}{l}\text { CPS; ages } 22-62 \text { with } \\
\text { positive earnings, } \\
\text { males/females } \\
\text { separately. }\end{array}$ & $\begin{array}{l}\text { Comparison of wage rates: between/within inequality, and annual } \\
\text { hours, family earnings, family incomes and equivalized incomes. } \\
\text { No attempt to decompose the change in family income into its } \\
\text { component parts because there are many ways to do so and there is } \\
\text { no consensus on the most appropriate decomposition. }\end{array}$ & $\begin{array}{l}\text { The similarity in the timing of changes in male wage rate inequality and family income } \\
\text { inequality has been used as evidence that increased family income inequality primarily } \\
\text { reflects increased inequality of wage rates. Authors show that other important factors } \\
\text { were also at work. Female wage inequality actually declined steadily from } 1975 \text { through } \\
\text { 2002. While earnings inequality of males grew even more rapidly than wage inequality } \\
\text { during the early } 1980 \text { s, this largely reflects cyclical changes in hours. For females, changes } \\
\text { in hours more than offset the rise in wage inequality. The acceleration in male wage and } \\
\text { earnings inequality during the early } 1980 \text { s disappears when earnings of other family } \\
\text { members are included. Thus, changes in work hours by other family members seems to } \\
\text { have largely offset increased male labour market inequality. }\end{array}$ \\
\hline
\end{tabular}

${ }^{166}$ Tables A.7 and A.8 make generous use of summaries, abstracts, introduction and conclusions of the underlying papers. 
Table A.7 Household incomes and earnings (see Section 2)

\begin{tabular}{|c|c|c|c|c|}
\hline Authors & $\begin{array}{l}\text { Years and } \\
\text { countries }\end{array}$ & $\begin{array}{l}\text { Datasets* and } \\
\text { sample selection }\end{array}$ & Method and important variables & Main findings \\
\hline $\begin{array}{l}\text { Kenworthy } \\
2008\end{array}$ & $\begin{array}{l}\text { 12: } 9 \text { old EU, } \\
\text { USA, CAN, } \\
\text { AUS; } \\
1980-2005\end{array}$ & $\begin{array}{l}\text { LIS for households, } \\
\text { OECD for } \\
\text { employment. }\end{array}$ & $\begin{array}{l}\text { Cross-country comparison circa } 2000 \text { of pre-tax pre-transfer } \\
\text { equivalized household income inequality (P75:P25 ratios) to } \\
\text { individual earnings inequality, (part-time) employment rate, zero- } \\
\text { earner household rate, singles and marital homogamy, and to post-tax } \\
\text { post-transfer inequality (Gini's). }\end{array}$ & $\begin{array}{l}\text { Thus, while much of the cross-country variation in levels of post-tax-post-transfer income } \\
\text { inequality is a product of differences in levels of market inequality, redistribution is also } \\
\text { important. For understanding developments over time, redistribution is essential. Thus } \\
\text { the focus ought to be chiefly on employment and redistribution, rather than on wage } \\
\text { inequality and/or household composition. }\end{array}$ \\
\hline $\begin{array}{l}\text { Reed and } \\
\text { Cancian } \\
2001\end{array}$ & $\begin{array}{l}\text { USA; } 1969 \text { to } \\
1999 .\end{array}$ & $\begin{array}{l}\text { March CPS; families } \\
\text { with adults aged 25- } \\
59 .\end{array}$ & $\begin{array}{l}\text { A new approach to measuring source contributions that has three } \\
\text { advantages over inequality decompositions. First, a clear } \\
\text { counterfactual, "What would have been the change in family income } \\
\text { inequality were it not for the change in the distribution of the income } \\
\text { source?" Second, simulation of counterfactual distribution of family } \\
\text { income, allowing use of multiple summary measures of inequality and } \\
\text { evaluation of impact at various points in the distribution (e.g. the 10th } \\
\text { and 90th percentiles). Third, incorporate married-couple and single- } \\
\text { person families and account for changes in marriage rate. }\end{array}$ & $\begin{array}{l}\text { Changes in distribution of male earnings account for more of the growth in family income } \\
\text { inequality than do changes in any other source of income. Changes in the distribution of } \\
\text { female earnings have reduced family income inequality. }\end{array}$ \\
\hline $\begin{array}{l}\text { Salverda and } \\
\text { Haas } 2014\end{array}$ & $\begin{array}{l}\text { EU (ex. CYP, } \\
\text { MLT); 2010. }\end{array}$ & \begin{tabular}{|l|} 
SILC 2011; employees \\
in households with \\
main income from \\
earnings and working- \\
age non-student head.
\end{tabular} & $\begin{array}{l}\text { Decile comparisons with fixed household rankings of individuals; } \\
\text { annual earnings with breakdown by hourly rates and annual hours } \\
\text { worked; number of earners in household over deciles of household } \\
\text { earnings. }\end{array}$ & $\begin{array}{l}\text { Households do in fact magnify labour-market inequality substantially, but cross-country to } \\
\text { a comparable extent cross-country while between countries the initial individual labour- } \\
\text { market earnings inequality is decisive. }\end{array}$ \\
\hline \begin{tabular}{|l} 
Večerník \\
2010
\end{tabular} & $\begin{array}{l}\text { CZE, HUN, } \\
\text { POL, SVK, } \\
\text { and AUT, } \\
\text { DEU; from } \\
\text { late } 1980 \text { s on } \\
\text { for CZE, } \\
\text { HUN, POL, } \\
\text { SVK, } 2007 \text { for } \\
\text { all six. }\end{array}$ & $\begin{array}{l}\text { LIS, and SILC for } \\
\text { 2007; employees only. }\end{array}$ & $\begin{array}{l}\text { Quintile shares and Gini's. Pearson coefficient correlations of } \\
\text { household incomes with personal earnings for males/females; } \\
\text { decomposition of Gini's. }\end{array}$ & $\begin{array}{l}\text { Even with the best possible data on personal and household incomes available for } \\
\text { analysis, there is still much we do not know about income sources, development and } \\
\text { inequality. In fact, we cannot expect that income statistics will ever be capable of } \\
\text { describing real incomes and income inequality in full. However, not having any other } \\
\text { source of general information about income distribution, we cannot do anything else but } \\
\text { examine the surveys from various angles and try, from time to time, to look beyond just } \\
\text { data. }\end{array}$ \\
\hline \begin{tabular}{|l|} 
Večerník \\
2013
\end{tabular} & $\begin{array}{l}\text { CZE; } 1988 \\
\text { 1992, } 1996 \\
\text { 2002, } 2009\end{array}$ & $\begin{array}{l}\text { National } \\
\text { microcensuses and } \\
\text { Czech part of SILC. }\end{array}$ & $\begin{array}{l}\text { OLS regressions of contributions by sex, age and education to } \\
\text { couples' earnings. }\end{array}$ & $\begin{array}{l}\text { Increasing influence of education is the personal earnings of employees; in couples, } \\
\text { education has an important impact on both women's employment and their earnings; the } \\
\text { importance of marital partners' education levels on household income grew even more } \\
\text { than its effect on earnings. }\end{array}$ \\
\hline \multicolumn{5}{|c|}{ ii. Decompositions of incomes } \\
\hline \begin{tabular}{|l|} 
Brewer, \\
Muriel and \\
Wren-Lewis \\
2009
\end{tabular} & $\begin{array}{l}\text { UK; } 1968- \\
2006 .\end{array}$ & HBAI; all individuals. & $\begin{array}{l}\text { Decomposition: Shorrocks } 1982 \text { (Paul 2004). Incomes: regression- } \\
\text { based methodology developed by Fields (2003) and Yun (2006). } \\
\text { Incomes: after all direct taxes and all state benefits and tax credits; } \\
\text { Individual earnings: gross. }\end{array}$ & $\begin{array}{l}\text { Changes in within-group inequality are always the dominant explanatory factor in changes } \\
\text { in overall inequality, although between-group effects also contribute significantly in some } \\
\text { periods. Changes in relative incomes between groups are the major source of this } \\
\text { between-group variation, though population changes also have a particularly significant } \\
\text { impact in the early } 1980 \text { s - presumably due to the rising number of workless households. } \\
\text { The relative incomes of multi-earner households climbed steadily throughout almost the } \\
\text { entire period we study. Income inequality: large unexplained residual term, even more so } \\
\text { for change; employment status and occupation is by far the most significant explanatory } \\
\text { variable, explaining almost a third of total income inequality in 1972. The residual is also } \\
\text { important for earnings though less. }\end{array}$ \\
\hline
\end{tabular}


Table A.7 Household incomes and earnings (see Section 2)

\begin{tabular}{|c|c|c|c|c|}
\hline Authors & $\begin{array}{l}\text { Years and } \\
\text { countries }\end{array}$ & \begin{tabular}{|l|} 
Datasets* and \\
sample selection
\end{tabular} & Method and important variables & Main findings \\
\hline $\begin{array}{l}\text { Brewer and } \\
\text { Wren-Lewis } \\
2012\end{array}$ & $\begin{array}{l}\text { UK; } 1968- \\
2009 .\end{array}$ & HBAI; all individuals. & $\begin{array}{l}\text { Three complementary decomposition methods: } \\
\text { 1. decomposition by income source, following Shorrocks (1982); } 2 . \\
\text { decomposition by population subgroup, following Mookherjee and } \\
\text { Shorrocks (1982) and Jenkins (1995); 3. decomposition by factor, } \\
\text { following Fields (2003). } \\
\text { Because inequality in earnings (among individuals in employment) is } \\
\text { an important source of changes in overall income inequality, the } \\
\text { second and third decompositions are performed on individual } \\
\text { earnings inequality, as well as on household income inequality. }\end{array}$ & $\begin{array}{l}\text { Inequality in gross employment and self-employment income grew but since } 1991 \text { effect } \\
\text { on inequality in total income almost entirely offset by: } 1 \text {. declining inequality between } \\
\text { those with different employment statuses, primarily due to a fall in unemployed people, } 2 \text {. } \\
\text { mitigation by employment taxes, } 3 \text {. investment income became less unequal largely due to } \\
\text { the decline in its importance, } 4 \text {. rise in relative incomes of pensioners and households } \\
\text { with children under five. }\end{array}$ \\
\hline $\begin{array}{l}\text { Cancian and } \\
\text { Reed } 1999\end{array}$ & $\begin{array}{l}\text { USA; } 1968- \\
1995 .\end{array}$ & \begin{tabular}{|l|} 
March CPS; all \\
persons related and \\
residing are part of the \\
same family, only \\
families with prime- \\
age heads (22-55). \\
Exclude military, \\
farmers, self- \\
employed, students, \\
and those living in \\
group quarters.
\end{tabular} & $\begin{array}{l}\text { Decomposing coefficient of variation. } \\
\text { Estimate impact of wives' earnings using four alternative } \\
\text { counterfactual reference distributions. If observed distribution of } \\
\text { income is more equal than counterfactual distribution, then wives' } \\
\text { earnings can be said to be equalizing. }\end{array}$ & $\begin{array}{l}\text { Changes in husbands' earnings are substantially more important in explaining recent } \\
\text { trends. }\end{array}$ \\
\hline $\begin{array}{l}\text { Cancian and } \\
\text { Schoeni } \\
1998\end{array}$ & $\begin{array}{l}\text { AUS, CAN, } \\
\text { FRA, DEU- } \\
\text { W, NOR, ISR, } \\
\text { SWE, CHE, } \\
\text { UK, USA; } \\
\text { 1980s. }\end{array}$ & $\begin{array}{l}\text { LIS; husbands and } \\
\text { wives. }\end{array}$ & $\begin{array}{l}\text { Splitting CV2 when there are only two components of income: } \\
\text { earnings of husband and of wife, into parts. Interest in change in } \\
\text { inequality when wives' earnings are included as a source of income, } \\
\text { i.e. (CVfamily - CVhead ) / CVhead. The key components of this } \\
\text { change are the share of total earnings attributable to wives' earnings } \\
\text { relative to husbands', the correlation of spouses' earnings, and the } \\
\text { dispersion of wives' and husbands' earnings. }\end{array}$ & $\begin{array}{l}\text { Mitigating effect of wives' earnings actually increased slightly in all countries; the } \\
\text { correlation of spouses' earnings would have to experience an unprecedented increase in } \\
\text { order for wives' earnings to become disequalizing. }\end{array}$ \\
\hline $\begin{array}{l}\text { Corluy and } \\
\text { Vanden- } \\
\text { broucke } \\
2013\end{array}$ & $\begin{array}{l}\text { EU, } 1995- \\
2008 .\end{array}$ & $\begin{array}{l}\text { ELFS and SILC; aged } \\
20 \text { to } 59 .\end{array}$ & $\begin{array}{l}\text { Decomposes household employment rate by individual employment } \\
\text { rate, household structure, and jobs distribution over households. } \\
\text { Decompose changes in at-risk-of-poverty rates on the basis of } \\
\text { changes in the poverty risks of jobless household, and of other (non- } \\
\text { jobless) households, and of changes in household joblessness due to } \\
\text { individual employment rates, household structures and distribution of } \\
\text { employment. }\end{array}$ & $\begin{array}{l}\text { Incorrect to attribute disappointing poverty trends during the EU employment boom } \\
\text { years solely to the modest conversion of individual employment successes in household } \\
\text { employment successes, or more specifically to on-going polarization of jobs over } \\
\text { households. Complementarity of employment creation and poverty reduction through } \\
\text { social transfers and inclusive labour market policies. }\end{array}$ \\
\hline
\end{tabular}


Table A.7 Household incomes and earnings (see Section 2)

\begin{tabular}{|c|c|c|c|c|}
\hline Authors & $\begin{array}{l}\text { Years and } \\
\text { countries }\end{array}$ & $\begin{array}{l}\text { Datasets* and } \\
\text { sample selection }\end{array}$ & Method and important variables & Main findings \\
\hline \begin{tabular}{|l|} 
Daly and \\
Valetta 2006
\end{tabular} & $\begin{array}{l}\text { USA; 1967- } \\
1989 / 1989- \\
1998 .\end{array}$ & \begin{tabular}{|l|} 
March CPS \\
Demographic \\
Supplement; including \\
men with earnings \\
equal to zero to \\
account for the \\
possibility that \\
declining labour force \\
participation by low- \\
wage men contributed \\
to rising inequality in \\
family income; \\
Equivalent family \\
income
\end{tabular} & $\begin{array}{l}\text { Semiparametric density estimation. For complete decomposition, } \\
\text { four factors are considered: (i) distribution of men's earnings;( ii) } \\
\text { women's labour force participation;(iii) family structure and (iv) } \\
\text { underlying family characteristics, in this and by way of sensitivity test } \\
\text { also in reversed order. The latter led to a somewhat larger role for } \\
\text { residuals. }\end{array}$ & $\begin{array}{l}\text { For the period 1969-1989, the growing dispersion of men's earnings and changing family } \\
\text { structure can account for most of the rise in family income inequality. By contrast, the } \\
\text { increase in labour force participation by women tended to offset this trend. Inequality } \\
\text { grew at a slower rate in the 1990s largely because of stabilization in the relative earnings of } \\
\text { men from low-income families. Larger effect found than by Burtless (1999) because of } \\
\text { accounting for increasing inactivity. Consistent with 'episodic' inequality change } \\
\text { (Atkinson, 1997). }\end{array}$ \\
\hline $\begin{array}{l}\text { Del Boca } \\
\text { and Pasqua } \\
2003\end{array}$ & $\begin{array}{l}\text { ITA; } 1977- \\
1998 .\end{array}$ & SHIW (and ECHP). & $\begin{array}{l}\text { Decomposition of the CV2 of total household income. Three sources } \\
\text { of income are considered: husband's earnings, wife's earnings and } \\
\text { other sources of income (both from other components and non- } \\
\text { labour income). Simulations of household income distribution that } \\
\text { would occur if wives had no earnings. }\end{array}$ & $\begin{array}{l}\text { Total income distribution would have been more unequal without women's labour } \\
\text { income. }\end{array}$ \\
\hline \begin{tabular}{|l|} 
Johnson and \\
Wilkins 2003
\end{tabular} & $\begin{array}{l}\text { AUS; } 1982- \\
1997 / 98 .\end{array}$ & $\begin{array}{l}\text { Seven waves of the } \\
\text { IDS. }\end{array}$ & $\begin{array}{l}\text { Semiparametric procedure developed by DiNardo, Fortin and } \\
\text { Lemieux (1996). }\end{array}$ & $\begin{array}{l}\text { Changes in the distribution of work across families - for example, an increase in both } \\
\text { two-earner families and no-earner families - were the single most important source of the } \\
\text { increase in private income inequality, with such changes on their own accounting for half } \\
\text { the increase in inequality. }\end{array}$ \\
\hline \begin{tabular}{|l|} 
Karoly and \\
Burtless \\
1995
\end{tabular} & $\begin{array}{l}\text { USA; 1959, } \\
1969,1979, \\
1989 .\end{array}$ & $\begin{array}{l}\text { Census and March } \\
\text { CPS; Personal } \\
\text { equivalent income } \\
\text { distribution. }\end{array}$ & $\begin{array}{l}\text { Decompose changes in Gini coefficient following Lerman and } \\
\text { Yitzhaki (1985). }\end{array}$ & $\begin{array}{l}\text { Increase in proportion of single-head families boosted inequality over entire period. Forty } \\
\text { percent reduction in income inequality in the } 1960 \text { s because of the decline in earnings } \\
\text { inequality among male heads of families; more than one-third of increase in inequality } \\
\text { after } 1969 \text { because inequality in male earnings soared. Since } 1979 \text { females' gains in } \\
\text { earnings have increased inequality because these gains have been concentrated } \\
\text { increasingly in families with high incomes. }\end{array}$ \\
\hline \begin{tabular}{|l} 
Larrimore \\
2013
\end{tabular} & $\begin{array}{l}\text { USA; 1979- } \\
2007\end{array}$ & \begin{tabular}{l|} 
March CPS, $<1992$ \\
adjusted upward \\
Square root equivalent \\
income.
\end{tabular} & $\begin{array}{l}\text { Shift share decomposition given Cowell-Fiorio's (2011) critique of } \\
\text { Dinardo et al. (1996) and Daly-Valetta (2006) decomposition; the data } \\
\text { intensity prevents this method from being suitable for all } \\
\text { decompositions of interest. In particular, it is limited in its ability to } \\
\text { observe how a range of income sources interact to account for } \\
\text { changing inequality. }\end{array}$ & $\begin{array}{l}\text { Factors contributing to rapid rise in income inequality in 1980s differ substantially from } \\
\text { those contributing to slower increase since that time. In 1980s changes in the correlation } \\
\text { of spouses' earnings accounted for income inequality growth, but not thereafter. } \\
\text { Additionally, the 2000s business cycle is the first full business cycle in at least } 30 \text { years } \\
\text { where changes in earnings of male household heads accounted for declines in income } \\
\text { inequality. Instead, continued growth in income inequality was accounted for primarily by } \\
\text { increases in female earnings inequality and declines in both male and female employment. }\end{array}$ \\
\hline Lehrer 2000 & $\begin{array}{l}\text { USA; } 1973 \text {, } \\
1992 / 93 .\end{array}$ & $\begin{array}{l}\text { NSFH; married } \\
\text { couples. }\end{array}$ & Decompose CV2 of husband's plus wife's earnings. & $\begin{array}{l}1973 \text { and 1992-1994 important similarity: spouse's contribution is equalizing in all life-cycle } \\
\text { stages (no children, young < } 6 \text { yrs, and older children). However, equalizing influence of } \\
\text { wife's contribution grew substantially stronger - partly due to a decrease in the } \\
\text { dispersion of female earnings relative to that of male earnings. Actual gap between "rich" } \\
\text { and "poor" married-couple households, as measured by their income from labour, is } \\
\text { narrower than if all wives were out of the labour force. }\end{array}$ \\
\hline
\end{tabular}


Table A.7 Household incomes and earnings (see Section 2)

\begin{tabular}{|c|c|c|c|c|}
\hline Authors & $\begin{array}{l}\text { Years and } \\
\text { countries }\end{array}$ & $\begin{array}{l}\text { Datasets* and } \\
\text { sample selection }\end{array}$ & Method and important variables & Main findings \\
\hline $\begin{array}{l}\text { Lu et al. } \\
2011\end{array}$ & $\begin{array}{l}\text { CAN; 1980, } \\
\text { 1995, } 2005 .\end{array}$ & $\begin{array}{l}\text { Census; heads 16-64; } \\
\text { Census family as } \\
<2000 \text { (opposite sex); } \\
\text { excl. no earnings; } \\
\text { square root equivalent } \\
\text { income; head } \\
\text { wages }>0 \text {; full-time } \\
\geq 30 \text { hours. } \\
\end{array}$ & $\begin{array}{l}\text { Semi-parametric decomposition methods Dinardo et al. (1996), } \\
\text { closely following the work of Fortin and Schirle (2006). by male and } \\
\text { female earnings structure, female EPOP, assortative mating, family } \\
\text { compos. and characteristics. }\end{array}$ & $\begin{array}{l}\text { 1980-95 substantial increases in family earnings inequality, some decrease 1995-2005 } \\
\text { although earnings of Top- } 1 \% \text { of families increase substantially. Employment rates of men } \\
\text { and women, increases in their educational attainment, and decreases in assortative mating } \\
\text { had equalizing effects (women coupling below their level); increases in the returns to } \\
\text { higher education and in proportion of single individuals and lone-parent families drove } \\
\text { increases in family earnings inequality. }\end{array}$ \\
\hline $\begin{array}{l}\text { Review of } \\
\text { Economic } \\
\text { Dynamics } \\
\text { Special issue } \\
2010 \text { : } \\
\text { 'Cross- } \\
\text { sectional } \\
\text { economic } \\
\text { facts for } \\
\text { macro- } \\
\text { economists' }\end{array}$ & $\begin{array}{l}\text { Relevant } \\
\text { countries: } \\
\text { CAN, DEU, } \\
\text { ESP, ITA, } \\
\text { SWE, UK, } \\
\text { USA; } \\
\text { 1960s/70s/80 } \\
\text { s/90s up to } \\
\text { mid-2000s. }\end{array}$ & $\begin{array}{l}\text { National datasets on } \\
\text { earnings, incomes and } \\
\text { expenditures. }\end{array}$ & $\begin{array}{l}\text { Country contributions by Brzozowski et al., Fuchs-Schündeln et al., } \\
\text { Pijoan-Mas and Sanchéz-Marcos, Japelli and Pistaferri, Domeij and } \\
\text { Floden., Blundell and Etheridge, and Heathcote et al. These } \\
\text { document level and evolution, over time and over life cycle, of } \\
\text { inequality of wages, labour earnings, income, consumption, and } \\
\text { wealth, adopting as much as possible a uniform approach. }\end{array}$ & $\begin{array}{l}\text { Substantial increases in wages and earnings inequality, over the last three decades; } \\
\text { experience premium rose and gender premium fell virtually everywhere. Earnings } \\
\text { inequality appears to be strongly counter-cyclical. In all countries, government } \\
\text { redistribution through taxes and transfers reduced level, trend and cyclical fluctuations in } \\
\text { income inequality. The rise in income inequality was stronger at the bottom of the } \\
\text { distribution. Consumption inequality increased less than disposable income inequality, and } \\
\text { tracked the latter much more closely at the top than at the bottom of the distribution. } \\
\text { Measuring the age-profile of inequality is challenging because of the interplay of time and } \\
\text { cohort effects. }\end{array}$ \\
\hline $\begin{array}{l}\text { Shorrocks } \\
1983\end{array}$ & $\begin{array}{l}\text { USA; } 1968- \\
1977 .\end{array}$ & $\begin{array}{l}\text { PSID, households } \\
\text { excl. those with } \\
\text { change of head. }\end{array}$ & $\begin{array}{l}\text { Empirical approach to decomposition rules proposed by Shorrocks } \\
\text { (1982). }\end{array}$ & $\begin{array}{l}\text { Dollar for dollar capital income and taxes have more distributional impact than earnings, } \\
\text { which in turn exceeds the impact of transfer income (defined to include retirement } \\
\text { pensions and annuities). }\end{array}$ \\
\hline $\begin{array}{l}\text { Van Weeren } \\
\text { and Van } \\
\text { Praag } 1983\end{array}$ & $\begin{array}{l}\text { BEL, DEU- } \\
\text { W, DNK, } \\
\text { FRA, ITA, } \\
\text { NLD, UK; } \\
\text { 1979. }\end{array}$ & $\begin{array}{l}\text { Special survey (van } \\
\text { Praag et al., 1982); net } \\
\text { household income. }\end{array}$ & $\begin{array}{l}\text { Between-group decomposition of variance of log incomes and Theil } \\
\text { index by several socioeconomic characteristics. }\end{array}$ & $\begin{array}{l}\text { In most countries the greatest inequality exists between employment subgroups } \\
\text { (employees, self-employed and not-working). Other important characteristics are age and } \\
\text { education of the main breadwinner. The place of living household appeared to be of } \\
\text { minor importance, and number of breadwinners is only of secondary importance. }\end{array}$ \\
\hline
\end{tabular}

Table A.8 Wage dispersion and the recent polarization and offshorability approaches to supply and demand (see Section 4.5)

\begin{tabular}{|c|c|c|c|c|}
\hline Authors & $\begin{array}{l}\text { Years and } \\
\text { countries }\end{array}$ & $\begin{array}{l}\text { Datasets* and } \\
\text { sample selection }\end{array}$ & Method and important variables & Main findings \\
\hline $\begin{array}{l}\text { Acemoglu \& } \\
\text { Autor } 2011\end{array}$ & $\begin{array}{l}\text { Mainly USA, } \\
\text { going back to } \\
\text { around } 1960, \\
\text { and } 10 \text { EU15 } \\
\text { countries, } \\
\text { going back to } \\
1992 .\end{array}$ & $\begin{array}{l}\text { Appendix provides } \\
\text { detail of US data } \\
\text { sources used for } \\
\text { depicting trends; } \\
\text { truncate at bottom and } \\
\text { top 5\% of earnings } \\
\text { distribution. Census is } \\
\text { used for empirical } \\
\text { example. }\end{array}$ & $\begin{array}{l}\text { Takes stock of US trends in wage inequality in detail and adds some } \\
\text { detail of polarization in EU countries. Evaluates shortcomings of } \\
\text { canonical model explaining those and develops a model with } \\
\text { endogenous assignment of three levels of skills to a continuum of } \\
\text { tasks and possible substitution of machines for certain tasks } \\
\text { previously performed by labour. }\end{array}$ & $\begin{array}{l}\text { Provides a stylized empirical application of the new framework to US data, and suggests } \\
\text { further directions for empirical exploration. }\end{array}$ \\
\hline
\end{tabular}


Table A.8 Wage dispersion and the recent polarization and offshorability approaches to supply and demand (see Section 4.5)

\begin{tabular}{|c|c|c|c|c|}
\hline Authors & $\begin{array}{l}\text { Years and } \\
\text { countries }\end{array}$ & $\begin{array}{l}\text { Datasets* and } \\
\text { sample selection }\end{array}$ & Method and important variables & Main findings \\
\hline $\begin{array}{l}\text { Antonczyk } \\
\text { et al. } 2010\end{array}$ & $\begin{array}{l}\text { DEU-W, } \\
\text { USA; 1979- } \\
2004 .\end{array}$ & $\begin{array}{l}\text { IABS and ORG CPS, } \\
\text { full-time working men. }\end{array}$ & $\begin{array}{l}\text { This paper compares trends in wage inequality in the USA and } \\
\text { Germany separating age, cohort, and time macro-economic effects. It } \\
\text { accounts for potential cohort effects, an issue which is mostly ignored } \\
\text { by the recent literature on wage inequality, even though SBTC may } \\
\text { have a bias in the age/cohort dimension. }\end{array}$ & $\begin{array}{l}\text { Between } 1979 \text { and 2004, wage inequality increased strongly in both the U.S. and Germany } \\
\text { but there were various country specific aspects of this increase. There is a large role played } \\
\text { by cohort effects in Germany, while it only small in the US. Although there is evidence in } \\
\text { both the US and Germany which is consistent with a technology-driven polarization of } \\
\text { the labour market, the patterns of trends in wage inequality differ strongly enough that } \\
\text { technology effects alone cannot explain the empirical findings. Episodic changes resulting } \\
\text { from changes in institutional factors such as unionization or the minimum wage may } \\
\text { explain the differences. }\end{array}$ \\
\hline Autor 2013 & USA & Recent literature. & $\begin{array}{l}\text { An emerging literature argues that changes in the allocation of } \\
\text { workplace "tasks" between capital and labour, and between domestic } \\
\text { and foreign workers, has altered the structure of labour demand in } \\
\text { industrialized countries and fostered employment polarization - that } \\
\text { is, rising employment in the highest and lowest paid occupations. } \\
\text { Analyzing this phenomenon within the canonical production function } \\
\text { framework is challenging, however, because the assignment of tasks is } \\
\text { essentially static. This essay sketches an alternative model of the } \\
\text { assignment of skills to tasks based upon comparative advantage, } \\
\text { reviews key conceptual and practical challenges that researchers face } \\
\text { in bringing the "task approach" to the data, and cautions against two } \\
\text { common pitfalls that pervade the growing task literature. }\end{array}$ & $\begin{array}{l}\text { The paper concludes with a cautiously optimistic forecast for the potential of the task } \\
\text { approach to illuminate the interactions among skill supplies, technological capabilities, and } \\
\text { trade and offshoring opportunities, in shaping the aggregate demand for skills, the } \\
\text { assignment of skills to tasks, and the evolution of wages. For further research the } \\
\text { classification of tasks is a challenge as the four task attributes - routine, abstract, manual, } \\
\text { offshorable - though broadly distinct show important overlaps which hinder the } \\
\text { classification of tasks. It is advisable to use, re-use, recycle, replicate, repeatedly apply } \\
\text { existing task classifications and thus attempt to converge upon a shared and standardized } \\
\text { set of task measures. It is mistaken to give up on "middle skill" education because there is } \\
\text { no future for middle skill jobs, as education is cumulative and middle skill jobs are not } \\
\text { slated to disappear though many middle skill tasks may. }\end{array}$ \\
\hline $\begin{array}{l}\text { Autor \& } \\
\text { Dorn } 2013\end{array}$ & $\begin{array}{l}\text { USA; } 1980- \\
2005 .\end{array}$ & $\begin{array}{l}\text { Census IPUMS and } \\
\text { ACS. }\end{array}$ & $\begin{array}{l}\text { The paper offers a unified analysis of the growth of low-skill service } \\
\text { occupations and the concurrent polarization of employment and } \\
\text { wages. It hypothesizes that polarization stems from the interaction } \\
\text { between consumer preferences, which favour variety over } \\
\text { specialization, and the falling cost of automating routine, codifiable } \\
\text { job tasks. Applying a spatial equilibrium model where local labour } \\
\text { markets have differential degrees of specialization in routine-intensive } \\
\text { industries, it corroborates four implications of this hypothesis. Local } \\
\text { labour markets that specialized in routine tasks differentially adopted } \\
\text { information technology, reallocated low-skill labour into service } \\
\text { occupations (employment polarization), experienced earnings growth } \\
\text { at the tails of the distribution (wage polarization), and received } \\
\text { inflows of skilled labour. }\end{array}$ & $\begin{array}{l}\text { The twisting of the lower tail of the employment and earnings distributions is substantially } \\
\text { accounted for by rising employment and wages in a single broad category. The paper } \\
\text { considers a panoply of alternative explanations including offshoring of jobs tasks, income } \\
\text { and substitution effects in high-skill consumption and labour supply, and demographic } \\
\text { and economic shifts including immigration, population aging, female labour force entry, } \\
\text { and declining manufacturing employment. Many of these alternative explanations receive } \\
\text { some empirical support but none appears to play a leading role. }\end{array}$ \\
\hline $\begin{array}{l}\text { Autor, Levy } \\
\& \text { Murnane } \\
2003\end{array}$ & $\begin{array}{l}\text { USA; } 1960 \text { to } \\
1998 .\end{array}$ & $\begin{array}{l}\text { DOT occupational } \\
\text { characteristics } \\
\text { appended to Census } \\
\text { IPUMS } 1960-1990 \text { and } \\
\text { ORG CPS 1980-1998; } \\
\text { employees aged 18-64, } \\
\text { FTE weights. }\end{array}$ & $\begin{array}{l}\text { The paper argues that computer capital (1) substitutes for workers in } \\
\text { performing cognitive and manual tasks that can be accomplished by } \\
\text { following explicit rules; and (2) complements workers in performing } \\
\text { non-routine problem-solving and complex communications tasks. } \\
\text { Provided that these tasks are imperfect substitutes, the model implies } \\
\text { measurable changes in the composition of job tasks. }\end{array}$ & $\begin{array}{l}\text { Within industries, occupations, and education groups, computerization is found to be } \\
\text { associated with reduced labour input of routine manual and routine cognitive tasks and } \\
\text { increased labour input of non-routine cognitive tasks. Translating task shifts into } \\
\text { education demand, the model can explain } 60 \text { percent of the estimated relative demand } \\
\text { shift favouring college labour during } 1970 \text { to } 1998 \text {. Task changes within nominally } \\
\text { identical occupations account for almost half of this impact. }\end{array}$ \\
\hline
\end{tabular}


Table A.8 Wage dispersion and the recent polarization and offshorability approaches to supply and demand (see Section 4.5)

\begin{tabular}{|c|c|c|c|c|}
\hline Authors & $\begin{array}{l}\text { Years and } \\
\text { countries }\end{array}$ & $\begin{array}{l}\text { Datasets* and } \\
\text { sample selection }\end{array}$ & Method and important variables & Main findings \\
\hline Blinder 2007 & USA; 2004. & O*NET. & $\begin{array}{l}\text { Using detailed information on the nature of work done in over } 800 \\
\text { BLS occupational codes, this paper ranks those occupations } \\
\text { according to how easy/hard it is to offshore the work - either } \\
\text { physically or electronically. }\end{array}$ & $\begin{array}{l}\text { Using that ranking, it estimates that somewhere between } 22 \% \text { and } 29 \% \text { of all US jobs are } \\
\text { or will be potentially offshorable within a decade or two. Since the rankings are subjective, } \\
\text { two alternatives are presented - one objective, the other is an independent subjective } \\
\text { ranking. It is found that there is little or no correlation between an occupation's } \\
\text { "offshorability" and the skill level of its workers (as measured either by educational } \\
\text { attainment or wages). However, it appears that, controlling for education, the most highly } \\
\text { offshorable occupations were already paving significantly lower wages in } 2004 \text {. }\end{array}$ \\
\hline \begin{tabular}{|l} 
Blinder and \\
Krueger \\
2009
\end{tabular} & USA; 2008. & $\begin{array}{l}\text { Special survey for } \\
\text { Princeton Data } \\
\text { Improvement } \\
\text { Initiative (PDII). }\end{array}$ & $\begin{array}{l}\text { This paper reports on a pilot study of the use of conventional } \\
\text { household survey methods to measure something unconventional: } \\
\text { what we call "offshorability," defined as the ability to perform one's } \\
\text { work duties (for the same employer and customers) from abroad. } \\
\text { Notice that offshorability is a characteristic of a person's job, not of } \\
\text { the person. }\end{array}$ & $\begin{array}{l}\text { Offshorability appears to be particularly prevalent in production work and in office and } \\
\text { administrative jobs. By industry group, it is most common in manufacturing, finance and } \\
\text { insurance, information services, and professional and technical services. More educated } \\
\text { workers appear to hold somewhat more offshorable jobs. But differences in offshorability } \\
\text { by race, sex, age, and geographic region are all minor. In estimated multivariate } \\
\text { econometric models, offshorability does not appear to have consistent systematic effects } \\
\text { on either wages or the probability of layoff. union members and people in licensed } \\
\text { positions are always less likely to hold offshorable jobs; and, perhaps surprisingly, routine } \\
\text { work is no more likely to be offshorable than other work. }\end{array}$ \\
\hline \begin{tabular}{|l|} 
Dunne et al. \\
2004
\end{tabular} & $\begin{array}{l}\text { USA; } 1977 \\
\text { and } 1992 .\end{array}$ & $\begin{array}{l}\text { March CPS and LRD; } \\
\text { only plants that } \\
\text { reported investments. }\end{array}$ & $\begin{array}{l}\text { Using establishment-level data, we shed light on the sources of the } \\
\text { changes in the structure of production, wages, and employment that } \\
\text { have occurred over recent decades. }\end{array}$ & $\begin{array}{l}\text { The findings are: (1) the between-plant component of wage dispersion is an important } \\
\text { and growing part of total wage dispersion; (2) much of the between-plant increase in wage } \\
\text { dispersion is within industries; (3) the between-plant measures of wage and productivity } \\
\text { dispersion have increased substantially over recent decades; and (4) a significant fraction } \\
\text { of the rising dispersion in wages and productivity is accounted for by changes in the } \\
\text { distribution of computer investment across plants. }\end{array}$ \\
\hline $\begin{array}{l}\text { Goos \& } \\
\text { Manning } \\
2007 \text { (See } \\
\text { also 2003) } \\
\end{array}$ & $\begin{array}{l}\text { UK; } 1976- \\
1999 .\end{array}$ & $\begin{array}{l}\text { NES complemented } \\
\text { by for part-time } \\
\text { workers. }\end{array}$ & $\begin{array}{l}\text { The more nuanced version of SBTC recently proposed by Autor, } \\
\text { Levy and Murnane (2003) makes a different prediction about what is } \\
\text { happening to employment in low-wage jobs. }\end{array}$ & $\begin{array}{l}\text { This paper presents evidence that employment in the UK is polarizing into lovely and } \\
\text { lousy jobs in consistence with the nuanced view. Job polarization can explain one-third of } \\
\text { the rise in the } \log (50 / 10) \text { wage differential and one-half of the rise in the } \log (90 / 50) \text {. }\end{array}$ \\
\hline $\begin{array}{l}\text { Goos, } \\
\text { Manning \& } \\
\text { Salomons } \\
2011 \text { (see } \\
\text { also 2009 } \\
\text { and 2010) } \\
\end{array}$ & $\begin{array}{l}15 \text { EU } \\
\text { countries; } \\
1996-2006 .\end{array}$ & $\begin{array}{l}\text { LFS-EU, excl. } \\
\text { agriculture and fishing, } \\
\text { and OECD STAN }\end{array}$ & $\begin{array}{l}\text { This paper develops a simple and empirically tractable model of } \\
\text { labour demand to explain recent changes in the occupational } \\
\text { structure of employment as a result of technology, offshoring and } \\
\text { institutions. This framework takes account not just of direct effects } \\
\text { but indirect effects through induced shifts in demand for different } \\
\text { products. }\end{array}$ & $\begin{array}{l}\text { The routinization hypothesis of Autor, Levy and Murnane (2003) is found to be the most } \\
\text { important factor behind the observed shifts in employment but offshoring does also play } \\
\text { a role. Shifts in product demand are acting to attenuate the impacts of recent } \\
\text { technological progress and offshoring. By implication, wage-setting institutions play little } \\
\text { role in explaining job polarization in Europe. }\end{array}$ \\
\hline \begin{tabular}{|l|} 
Liu \& \\
Grusky 2013
\end{tabular} & $\begin{array}{l}\text { USA; 1979- } \\
2010 .\end{array}$ & $\begin{array}{l}\text { ORG CPS, O*NET; } \\
\text { non-military wage and } \\
\text { salary workers } \\
\text { including part-time, } \\
\text { aged 16-65. }\end{array}$ & $\begin{array}{l}\text { Is the third industrial revolution indeed driven by rising payoffs to } \\
\text { skill? This simple but important question has gone unanswered } \\
\text { because conventional models of earnings inequality are based on } \\
\text { exceedingly weak measurements of skill. By attaching occupational } \\
\text { skill measurements to the CPS, it becomes possible to adjudicate } \\
\text { competing accounts of the changing returns to cognitive, creative, } \\
\text { technical, and social skill. }\end{array}$ & $\begin{array}{l}\text { The well-known increase in between-occupation inequality is fully explained when such } \\
\text { skills are taken into account, while returns to schooling prove to be quite stable once } \\
\text { correlated changes in workplace skills are parsed out. The most important trend, however, } \\
\text { is a precipitous increase in the wage payoff to synthesis, critical thinking, and related } \\
\text { "analytic skills." The payoff to technical and creative skills, often touted in discussions of } \\
\text { the third industrial revolution, is shown to be less substantial. }\end{array}$ \\
\hline
\end{tabular}


Table A.8 Wage dispersion and the recent polarization and offshorability approaches to supply and demand (see Section 4.5)

\begin{tabular}{|l|l|l|l|}
\hline Authors & $\begin{array}{l}\text { Years and } \\
\text { countries }\end{array}$ & $\begin{array}{l}\text { Datasets* and } \\
\text { sample selection }\end{array}$ & Method and important variables \\
\hline $\begin{array}{l}\text { Mishel, } \\
\text { Shierholz \& } \\
\text { Schmitt } \\
2013\end{array}$ & $\begin{array}{l}\text { USA; 1973- } \\
2007 .\end{array}$ & $\begin{array}{l}\text { ORG and May CPS } \\
\text { (provide an } \\
\text { independent test of } \\
\text { earlier results based } \\
\text { primarily on the } \\
\text { decennial census and } \\
\text { the American } \\
\text { Community } \\
\text { Survey); wage and } \\
\text { salary workers aged } \\
\text { 18-64. }\end{array}$ & $\begin{array}{l}\text { The influential "skill-biased technological change" (SBTC) } \\
\text { explanation claims that technology raises demand for educated } \\
\text { workers, thus allowing them to command higher wages - which in } \\
\text { turn increases wage inequality. A more recent SBTC explanation } \\
\text { focuses on computerization's role in increasing employment in both } \\
\text { higher-wage and lower-wage occupations, resulting in "job } \\
\text { polarization." This paper contends that current SBTC models - such } \\
\text { as the education-focused "canonical model" and the more recent } \\
\text { "tasks framework" or “job polarization" approach mentioned above } \\
\text { - do not adequately account for key wage patterns (namely, rising } \\
\text { wage inequality) over the last three decades. }\end{array}$ \\
\hline $\begin{array}{l}\text { Spitz-Oener } \\
2006\end{array}$ & $\begin{array}{l}\text { DEU-W 1979, } \\
1985 / 86, \\
1991 / 92, \\
1998 / 99 .\end{array}$ & $\begin{array}{l}\text { Qualification and } \\
\text { Career Survey BBIB; } \\
\text { employees living in } \\
\text { West Germany, } \\
\text { German nationals, } \\
\text { aged 18-65. }\end{array}$ & $\begin{array}{l}\text { A unique data set from West Germany enables looking at how skill } \\
\text { requirements have changed within occupations. Two hypotheses are } \\
\text { tested: (1) IT is a substitute for routine manual and routine cognitive } \\
\text { activities, and (2) IT is complementary to analytic and interactive } \\
\text { activities. }\end{array}$ \\
\hline
\end{tabular}

\section{Main findings}

Principal findings include: 1 . Technological and skill deficiency explanations of wage inequality have failed to explain key wage patterns over the last three decades, including the 2000s. 2. History shows that middle-wage occupations have shrunk and higher-wage occupations have expanded since the 1950s. This has not driven any changed pattern of wage trends. 3. Evidence for job polarization is weak. 4 . There was no occupational job polarization in the 2000s. 5. Occupational employment trends do not drive wage patterns or wage inequality. 6. Occupations have become less, not more, important determinants of wage patterns. 7. An expanded demand for low-wage service occupations is not a key driver of wage trends. 8. Occupational employment trends provide only limited insights into the main dynamics of the labour market, particularly wage trends.

Occupations are found to require more complex skills today than in 1979 and the changes in skill requirements have been most pronounced in rapidly computerizing occupations. I occurred within occupations, within occupation-education groups, and within occupationage groups . changes in skill requirements similar to those in the United States. the question that now arises is why similar changes in skill requirements in all of these countries have not led to similar changes in the structure of wages.

Table A.9 Wage dispersion and institutions (see Section 4.6)

\begin{tabular}{|c|c|c|c|c|c|}
\hline Authors & $\begin{array}{l}\text { Countries } \\
\text { and years }\end{array}$ & \begin{tabular}{|l|} 
Datasets* and \\
sample selection
\end{tabular} & Methods and important variables & \begin{tabular}{|l|} 
Types of \\
institutions **
\end{tabular} & Main findings \\
\hline \multicolumn{6}{|c|}{ Overviews of the literature } \\
\hline \begin{tabular}{|l|} 
Blau \& \\
Kahn 1999
\end{tabular} & $\begin{array}{l}13 \text { EU } \\
\text { countries and } \\
\text { CHE, AUS, } \\
\text { CAN, JPN, } \\
\text { NZL, USA; } \\
1970 \text { s to } \\
1990 \text { s. }\end{array}$ & $\begin{array}{l}\text { Draws on existing } \\
\text { literature and data } \\
\text { sources used there. }\end{array}$ & $\begin{array}{l}\text { This chapter examines the impact of wage-setting } \\
\text { institutions and government policies on wages and } \\
\text { employment, focusing on the OECD countries. }\end{array}$ & $\begin{array}{l}\text { AP, CP, DI, MW, } \\
\text { UB, UD }\end{array}$ & $\begin{array}{l}\text { There is considerable evidence that centralized collective bargaining, minimum } \\
\text { wages and anti-discrimination policies raise the relative wages of the low paid. } \\
\text { Evidence of the impact of these institutions and other policies such as mandated } \\
\text { severance pay, advance notice or unemployment insurance is more mixed with } \\
\text { some studies finding active employment effects while others do not. This may } \\
\text { reflect the adoption by many OECD countries of off-setting policies, such as public } \\
\text { employment, temporary employment contracts and active labour market programs, } \\
\text { which, while they may have reduced the adverse relative employment effects of } \\
\text { their less flexible labour market institutions on the low skilled, appear not to have } \\
\text { prevented high overall unemployment. }\end{array}$ \\
\hline \begin{tabular}{|l|} 
Blau \& \\
Kahn 2009
\end{tabular} & $\begin{array}{l}\text { IALS: } 8 \\
\text { countries; } \\
\text { OECD: } 12 \\
\text { countries. }\end{array}$ & $\begin{array}{l}\text { IALS, } 1994,200+ \\
\text { annual hours and } 10+ \\
\text { annual weeks; OECD } \\
\text { Earnings database, } \\
\text { 1980, 1990, 2000. }\end{array}$ & $\begin{array}{l}\text { Documents and provides explanations for levels of and } \\
\text { trends in earnings inequality focusing on international } \\
\text { (OECD) differences. Distinguishes between wage rates, } \\
\text { hours worked and earnings. }\end{array}$ & ED, HR, MW, UB & $\begin{array}{l}\text { International differences reflect diversity of working population and prices, which in } \\
\text { turn are affected by supply and demand as well as institutions. Collective bargaining } \\
\text { and the minimum wage bring up the bottom, leading to employment losses. } \\
\text { Offshoring deserves further attention (and may actually narrow wage differentials); } \\
\text { so do employment protection, product market regulation and norms. }\end{array}$ \\
\hline
\end{tabular}


Table A.9 Wage dispersion and institutions (see Section 4.6)

\begin{tabular}{|c|c|c|c|c|c|}
\hline Authors & $\begin{array}{l}\text { Countries } \\
\text { and years }\end{array}$ & $\begin{array}{l}\text { Datasets* and } \\
\text { sample selection }\end{array}$ & Methods and important variables & \begin{tabular}{|l|} 
Types of \\
institutions $* *$
\end{tabular} & Main findings \\
\hline $\begin{array}{l}\text { Doucouliago } \\
\text { s \& Stanley } \\
2009\end{array}$ & USA & $\begin{array}{l}\text { Extensive literature } \\
\text { search. }\end{array}$ & $\begin{array}{l}\text { Multivariate meta-regression analysis accommodate a } \\
\text { potentially complex employment effect, } \\
\text { misspecification biases and differential propensities to } \\
\text { report adverse employment effects. It uses employment } \\
\text { elasticity with respect to the minimum wage as the } \\
\text { metric. }\end{array}$ & MW & $\begin{array}{l}\text { Recently developed meta-analysis methods applied to } 64 \text { US minimum-wage studies } \\
\text { (almost } 1500 \text { estimates) show that the minimum-wage effects literature is } \\
\text { contaminated by publication selection bias, which is estimated to be slightly larger } \\
\text { than the average reported minimum wage effect. Once this is corrected, little or no } \\
\text { evidence of a negative association between minimum wages and employment } \\
\text { remains. The results confirm those of the meta-analysis of Card and Krueger } \\
\text { (1995b). }\end{array}$ \\
\hline \begin{tabular}{|l|} 
De Linde \\
Leonard, \\
Stanley \& \\
Doucouliago \\
s, 2013 \\
\end{tabular} & $\mathrm{UK}$ & $\begin{array}{l}\text { Extensive literature } \\
\text { search. }\end{array}$ & $\begin{array}{l}\text { Multivariate meta-regression analysis of } 236 \text { estimated } \\
\text { minimum-wage elasticities and } 710 \text { partial correlation } \\
\text { coefficients from } 16 \text { UK studies. }\end{array}$ & MW & $\begin{array}{l}\text { The study finds no overall practically significant adverse employment effect. Unlike } \\
\text { US studies (see Doucouliagos \& Stanley, 2009), there seems to be little, if any, } \\
\text { overall reporting bias. It identifies several research dimensions that are associated } \\
\text { with differential employment effects. In particular, the residential home care } \\
\text { industry may exhibit a genuinely adverse employment effect. }\end{array}$ \\
\hline \begin{tabular}{|l|} 
Freeman \\
2005
\end{tabular} & OECD & No new empirics. & $\begin{array}{l}\text { This paper argues that there are two reasons for } \\
\text { inconclusive debate over the claim that labour } \\
\text { institutions impair aggregate performance. The first } \\
\text { reason is that many adherents to the claim hold strong } \\
\text { priors that labour markets operate nearly perfectly in } \\
\text { the absence of institutions and let their priors dictate } \\
\text { their modelling choices and interpretation of empirical } \\
\text { results. The second reason is that the cross-country } \\
\text { aggregate data at issue is weak - too weak to decisively } \\
\text { reject strong prior views or to convince those with } \\
\text { weaker priors. }\end{array}$ & Various & $\begin{array}{l}\text { The debate over the influence of labour market flexibility on performance is } \\
\text { unlikely to be settled by additional studies using aggregate data and making cross- } \\
\text { country comparisons. While this approach holds little promise, micro-analysis of } \\
\text { workers and firms and increased use of experimental methods represent a path } \\
\text { forward. Steps along this path could help end the current 'lawyer's case' empiricism } \\
\text { in which priors dominate evidence. }\end{array}$ \\
\hline \begin{tabular}{|l|} 
Freeman \\
2007
\end{tabular} & OECD & No new empirics. & $\begin{array}{l}\text { The paper documents the large cross-country } \\
\text { differences in labour institutions that make them a } \\
\text { candidate explanatory factor for the divergent } \\
\text { economic performance of countries and reviews what } \\
\text { economists have learned about the effects of these } \\
\text { institutions on economic outcomes. It identifies three } \\
\text { ways in which institutions affect economic } \\
\text { performance: by altering incentives, by facilitating } \\
\text { efficient bargaining, and by increasing information, } \\
\text { communication, and trust. }\end{array}$ & $\mathrm{CP}, \mathrm{UB}$ & $\begin{array}{l}\text { The evidence shows that labour institutions reduce the dispersion of earnings and } \\
\text { income inequality, which alters incentives, but finds equivocal effects on other } \\
\text { aggregate outcomes, such as employment and unemployment. Given weaknesses in } \\
\text { the cross-country data on which most studies focus, the paper argues for increased } \\
\text { use of micro-data, simulations, and experiments to illuminate how labour } \\
\text { institutions operate and affect outcomes. }\end{array}$ \\
\hline
\end{tabular}


Table A.9 Wage dispersion and institutions (see Section 4.6)

\begin{tabular}{|c|c|c|c|c|c|}
\hline Authors & $\begin{array}{l}\text { Countries } \\
\text { and years }\end{array}$ & $\begin{array}{l}\text { Datasets* and } \\
\text { sample selection }\end{array}$ & Methods and important variables & $\begin{array}{l}\text { Types of } \\
\text { institutions** }\end{array}$ & Main findings \\
\hline $\begin{array}{l}\text { Katz \& } \\
\text { Autor } 1999\end{array}$ & USA & No new empirics. & $\begin{array}{l}\text { The chapter presents a framework for understanding } \\
\text { changes in the wage structure and overall earnings } \\
\text { inequality. It emphasizes the role of supply and demand } \\
\text { factors and the interaction of market forces and labour } \\
\text { market institutions. Recent changes in the US wage } \\
\text { structure are analyzed in detail to highlight crucial } \\
\text { measurement issues that arise in studying wage } \\
\text { structure changes and to illustrate the operation of the } \\
\text { framework. The roles of skill-biased technological } \\
\text { change, globalization forces, changes in demographics } \\
\text { and relative skill supplies, industry labour rents, unions, } \\
\text { and the minimum wage in the evolution of the US } \\
\text { wage structure arc examined, as are differences and } \\
\text { similarities in wage structure changes among OECD } \\
\text { nations. }\end{array}$ & IR, MW, UB, UD & $\begin{array}{l}\text { Several directions for future research are suggested: the roles of changes in labour } \\
\text { market institutions (the incidence of labour market rents) and changes in } \\
\text { competitive supply and demand factors. A key issue model is how to model the } \\
\text { effects of institutions on employment rates and composition as well as on wages. } \\
\text { The extent to which institutional changes reflect exogenous political events as } \\
\text { opposed to responses to market forces can help sorting out the effects of } \\
\text { institutions from supply and demand factors. Taking a longer-term historical } \\
\text { perspective will also be helpful as the US experience for the 1970s, 1980s and 1990s } \\
\text { illustrates. Cross-country comparative work and differences across regions within a } \\
\text { country may also provide useful variation in demand and supply shocks and } \\
\text { institutional factors. }\end{array}$ \\
\hline $\begin{array}{l}\text { Kierzenkow } \\
\text { ski \& Koske } \\
2012\end{array}$ & OECD & Recent literature. & $\begin{array}{l}\text { Despite a general trend of increasing labour income } \\
\text { inequality, there have been differences in the timing, } \\
\text { intensity and even direction of these changes across } \\
\text { OECD countries. These stylized facts have led to } \\
\text { numerous studies about the main determinants of } \\
\text { labour income inequality and, as a result, a significant } \\
\text { revision of the previous consensus about the key } \\
\text { drivers. The most researched channels include skill- } \\
\text { biased technological change, international trade, } \\
\text { immigration, education as well as the role of labour } \\
\text { market policies and institutions. }\end{array}$ & MW, UB & $\begin{array}{l}\text { SBTC (canonical view) fails to explain why inequality has diminished at the bottom } \\
\text { relative to the median since the late } 1980 \text { s as well as why within-group wage } \\
\text { dispersion has grown substantially and mainly for college-educated workers. SBTC } \\
\text { (nuanced view) explains why OECD labour markets have become polarised. } \\
\text { International trade seems to have important implications for at least some groups of } \\
\text { workers. Immigration has a rather small impact on native workers and sizeable } \\
\text { adverse wage or employment effects on the cohorts of previous immigrants. } \\
\text { Education: Wage inequality is negatively correlated with the average level of } \\
\text { educational attainment. Labour market policies and institutions: The impact of } \\
\text { declining unionisation and of the lower relative minimum wage is most pronounced } \\
\text { at the lower end of the wage distribution while } \\
\text { cross-country evidence suggests that government employment reduces wage } \\
\text { inequality. }\end{array}$ \\
\hline \begin{tabular}{|l|} 
Lemieux \\
2011
\end{tabular} & $\begin{array}{l}\text { AUS, CAN, } \\
\text { USA; since } \\
\text { 1980s. }\end{array}$ & No new empirics. & \begin{tabular}{|l|} 
Wage inequality has been increasing is most \\
industrialized countries over the last three decades. \\
There are, nonetheless, major differences across \\
countries in terms of the timing and magnitude of the \\
growth in inequality. A large number of explanations \\
have been suggested for these observed changes, \\
including technological progress and the computer \\
revolution, labour market institutions and social norms, \\
and changes in the relative supply of highly educated \\
workers. This paper assesses the validity of these \\
explanations in light of the large differences in \\
inequality growth across countries, and the stunning \\
growth in the concentration of income at the top end \\
of the distribution.
\end{tabular} & MW, UD, UW & $\begin{array}{l}\text { While demand factors linked to technological change may be a leading factor } \\
\text { behind the secular growth in wage inequality (or the more recent polarization of } \\
\text { wages), they cannot account for the large differences in inequality growth observed } \\
\text { across countries. Supply factors and institutions are more successful than demand at } \\
\text { explaining differences across countries. None provides a compelling answer to the } \\
\text { question of why inequality at the very top end of the distribution has increased so } \\
\text { much in some countries but not in others. Two main conclusions are, first, that the } \\
\text { SDI explanation is still alive and well, in the sense that no single explanation } \\
\text { (supply, demand, or institution) can account for all of the changes in wage inequality } \\
\text { observed across countries. Second, we still do not understand very well why } \\
\text { inequality at the very top end of the distribution has increased so much in countries } \\
\text { like the United States, Canada, or Australia. }\end{array}$ \\
\hline
\end{tabular}


Table A.9 Wage dispersion and institutions (see Section 4.6)

\begin{tabular}{|c|c|c|c|c|c|}
\hline Authors & $\begin{array}{l}\text { Countries } \\
\text { and years }\end{array}$ & $\begin{array}{l}\text { Datasets* and } \\
\text { sample selection }\end{array}$ & Methods and important variables & $\begin{array}{l}\text { Types of } \\
\text { institutions** }\end{array}$ & Main findings \\
\hline Machin 1997 & $\begin{array}{l}\text { UK; } 1979 \text { and } \\
1993 .\end{array}$ & & $\begin{array}{l}\text { At the same time as the role of labour market } \\
\text { institutions declined very dramatically in Britain there } \\
\text { was a very sharp rise in wage inequality. It therefore } \\
\text { provides a very good testing ground for evaluating the } \\
\text { importance of labour market institutions in explaining } \\
\text { the evolution of the wage structure. Regression of wage } \\
\text { inequality measures distinguished by Wage Council } \\
\text { applicability. }\end{array}$ & MW, UD & $\begin{array}{l}\text { The weakening of unions and minimum wages that have traditionally propped up } \\
\text { wage levels at the bottom end of the wage distribution, is found to play an } \\
\text { important part in the rise in wage inequality in Britain. }\end{array}$ \\
\hline Machin 2008 & Various. & No new empirics. & $\begin{array}{l}\text { The paper describes the origins of the recent work } \\
\text { documenting trends in wage inequality, the sizable } \\
\text { body of research trying to understand national and } \\
\text { international differences, and discuss the directions in } \\
\text { which more recent work has moved and where it may } \\
\text { go in future. }\end{array}$ & Various & $\begin{array}{l}\text { It is concluded that the evidence shows that the wage distribution has been } \\
\text { characterized by long-run growth in the relative demand for skills driven by } \\
\text { technological change (rather than trade) and that changes in skill supply and } \\
\text { institutional changes have affected the timing of how SBTC impacts on the wage } \\
\text { structure in different contexts. Slower inequality growth in the lower tail in the USA } \\
\text { and UK and rising inequality in previously stable (European) distributions together } \\
\text { with a polarization of job growth have refined explanations and added } \\
\text { sophistication to the SBTC story. }\end{array}$ \\
\hline \begin{tabular}{|l} 
Manning, \\
2011
\end{tabular} & International. & No new empirics. & $\begin{array}{l}\text { The paper defends the claim that is simply not true to } \\
\text { claim that the perspective of perfect competition tells } \\
\text { us all we need to know. There are rents in the typical } \\
\text { jobs, though the size and distribution are not well } \\
\text { known. }\end{array}$ & $\begin{array}{l}\mathrm{DI}, \mathrm{IR}, \mathrm{MW}, \mathrm{UB}, \\
\text { and employer } \\
\text { collusion }\end{array}$ & $\begin{array}{l}\text { Many empirical observations (e.g. equilibrium wage dispersion, the gender pay gap, } \\
\text { geographical agglomeration, the effect of minimum wages on employment, } \\
\text { employers paying for general training, costs of job loss for workers with no specific } \\
\text { skills to list only a few) that are puzzles in the perspective of a perfectly competitive } \\
\text { labour market are simply what one might expect if one thinks the labour market is } \\
\text { characterized by pervasive imperfect competition. Views of the likely effects of } \\
\text { labour market regulation should be substantially altered once one recognizes the } \\
\text { existence of imperfect competition. However, although imperfect competition can } \\
\text { be used as a justification for some regulation on efficiency grounds, it always } \\
\text { predicts some limits to regulation with quite what those limits are left to empirical } \\
\text { research to decide. }\end{array}$ \\
\hline \begin{tabular}{|l|} 
Nickell \& \\
Layard 1999
\end{tabular} & $\begin{array}{l}\text { Various } \\
\text { subsets of } \\
\text { OECD } \\
\text { countries. }\end{array}$ & Various. & $\begin{array}{l}\text { Aims to survey the literature to see propositions such } \\
\text { as these depends on which labour-market institutions } \\
\text { really are bad for unemployment and growth, and } \\
\text { which are not. }\end{array}$ & $\begin{array}{l}\text { AP, CP, ED, MW, } \\
\text { PM, TA, UB, UD, } \\
\text { WE }\end{array}$ & $\begin{array}{l}\text { There is quite strong evidence that the compressed earnings distributions in some } \\
\text { OECD countries relative to the United States are a consequence of equally } \\
\text { compressed skill distributions. Most of the gross features of unemployment and } \\
\text { wage distributions across the OECD in recent years seem explicable by supply and } \\
\text { demand shifts and the role required of special institutional features such as unions } \\
\text { and minimum wages is correspondingly minimal. Labour-market institutions on } \\
\text { which policy should be focussed are unions and social security systems. } \\
\text { Encouraging product-market competition is a key policy to eliminate the negative } \\
\text { effects of unions. For social security the key policies are benefit reform linked to } \\
\text { active labour market policies to move people from welfare to work. By comparison, } \\
\text { time spent worrying about strict labour-market regulations, employment protection } \\
\text { and minimum wages is probably time largely wasted. }\end{array}$ \\
\hline
\end{tabular}


Table A.9 Wage dispersion and institutions (see Section 4.6)

\begin{tabular}{|c|c|c|c|c|c|}
\hline Authors & $\begin{array}{l}\text { Countries } \\
\text { and years }\end{array}$ & $\begin{array}{l}\text { Datasets* and } \\
\text { sample selection }\end{array}$ & Methods and important variables & \begin{tabular}{|l|} 
Types of \\
institutions**
\end{tabular} & Main findings \\
\hline $\begin{array}{l}\text { Rogerson } \\
\text { and Shimer } \\
\text { (2011) }\end{array}$ & $\begin{array}{l}17 \text { OECD } \\
\text { countries; } \\
1965 \text { to late- } \\
2000 \text { s. }\end{array}$ & $\begin{array}{l}\text { LFS-OECD and } \\
\text { GGDC. }\end{array}$ & $\begin{array}{l}\text { This chapter assesses how models with search frictions } \\
\text { have shaped understanding of aggregate labour market } \\
\text { outcomes in two contexts: business cycle fluctuations } \\
\text { and long-run (trend) changes (and the shock-and- } \\
\text { institutions explanation of international differences). It } \\
\text { consolidates data on aggregate labour market outcomes } \\
\text { for a large set of OECD countries, and asks how } \\
\text { models with search improve our understanding of } \\
\text { these data. }\end{array}$ & Various & $\begin{array}{l}\text { Results are mixed. Search models are useful for interpreting the behaviour of some } \\
\text { additional data series, but search frictions per se do not seem to improve our } \\
\text { understanding of movements in total hours at either business cycle frequencies or in } \\
\text { the long-run. Still, models with search seem promising as a framework for } \\
\text { understanding how different wage setting processes affect aggregate labour market } \\
\text { outcomes. }\end{array}$ \\
\hline \begin{tabular}{|l} 
Schmitt \\
2013
\end{tabular} & USA & $\begin{array}{l}\text { Recent literature since } \\
\text { about } 2000 .\end{array}$ & $\begin{array}{l}\text { Labour markets have imperfections in the } \\
\text { form of inadequate information, uneven } \\
\text { bargaining power, limited ability to enforce } \\
\text { long-term commitments, and insufficient } \\
\text { insurance mechanisms against employment-related } \\
\text { risks. Labor policies and institutions can in principle be } \\
\text { used to address these imperfections. The report } \\
\text { examines recent research on the employment effect of } \\
\text { the minimum wage to determine the best current } \\
\text { estimates of the impact of increases in the minimum } \\
\text { wage on the employment prospects of low-wage } \\
\text { workers. In particular, it discusses channels of } \\
\text { adjustment to an increase in the minimum wage. }\end{array}$ & MW & $\begin{array}{l}\text { The evidence points to little or no employment response to modest increases in the } \\
\text { minimum wage. Evidence on eleven possible adjustments to minimum-wage } \\
\text { increases may help to explain why the measured employment effects are so } \\
\text { consistently small. The strongest evidence suggests that the most important } \\
\text { channels of adjustment are: reductions in labour turnover; improvements in } \\
\text { organizational efficiency; reductions in wages of higher earners ("wage } \\
\text { compression"); and small price increases. These adjustment mechanisms appear to } \\
\text { be more than sufficient to avoid employment losses, even for employers with a } \\
\text { large share of low-wage workers. }\end{array}$ \\
\hline \begin{tabular}{|l|} 
World Bank \\
2012
\end{tabular} & Worldwide & $\begin{array}{l}\text { Recent literature since } \\
\text { about } 2000 .\end{array}$ & $\begin{array}{l}\text { Labour markets have imperfections in the form of } \\
\text { inadequate information, uneven bargaining power, } \\
\text { limited ability to enforce long-term commitments, and } \\
\text { insufficient insurance mechanisms against } \\
\text { employment-related risks. Labour policies and } \\
\text { institutions can in principle be used to address these } \\
\text { imperfections. It is important, then, to understand the } \\
\text { role and the impacts of policies and institutions like } \\
\text { labour market regulation, collective bargaining, active } \\
\text { labour market programs, and social insurance. But the } \\
\text { main constraints to the job creation often lie outside } \\
\text { the labour market, and a clear approach is needed to } \\
\text { support appropriate policy responses. }\end{array}$ & $\begin{array}{l}\text { AP, CP, MW, TA, } \\
\text { UB, WE }\end{array}$ & $\begin{array}{l}\text { Policies should seek to avoid the distortive interventions that stifle labor } \\
\text { reallocation and undermine the creation of jobs in functional cities and global value } \\
\text { chains. But policies should also ensure voice and social protection, especially for the } \\
\text { most vulnerable. Ideally, policies should aim at removing the market imperfections } \\
\text { and institutional failures preventing the private sector from creating more of those } \\
\text { jobs. If the constraints cannot be easily singled out or are difficult to remove, } \\
\text { offsetting policies may be considered. }\end{array}$ \\
\hline
\end{tabular}


Table A.9 Wage dispersion and institutions (see Section 4.6)

\begin{tabular}{|c|c|c|c|c|c|}
\hline Authors & $\begin{array}{l}\text { Countries } \\
\text { and years }\end{array}$ & $\begin{array}{l}\text { Datasets* and } \\
\text { sample selection }\end{array}$ & Methods and important variables & \begin{tabular}{|l|} 
Types of \\
institutions**
\end{tabular} & Main findings \\
\hline $\begin{array}{l}\text { Acemoglu } \\
2003\end{array}$ & $\begin{array}{l}\text { AUS, BEL, } \\
\text { CAN, DEU, } \\
\text { DNK, FIN, } \\
\text { ISR, NLD, } \\
\text { NOR, SWE, } \\
\text { UK, USA; } \\
\text { mid-80s to } \\
\text { mid-90s. }\end{array}$ & $\begin{array}{l}\text { CPS and LIS; annual } \\
\text { earnings of full-time- } \\
\text { full-year male } \\
\text { household heads aged } \\
\text { of } 18-64 \text {. }\end{array}$ & \begin{tabular}{|l|} 
Relative-supply-demand model to determine \\
differential effects, followed by a model of Differential \\
Technology Responses across countries (not tested).
\end{tabular} & $\begin{array}{l}\text { MW, UW, some } \\
\text { Demographics }\end{array}$ & $\begin{array}{l}\text { Relative demand for skills increased differentially across countries. Labour market } \\
\text { institutions creating wage compression in Europe also encourage more investment } \\
\text { in technologies increasing the productivity of less-skilled workers, implying less } \\
\text { skill-biased technical change in Europe than the USA. }\end{array}$ \\
\hline $\begin{array}{l}\text { Alderson \& } \\
\text { Nielsen } \\
2002\end{array}$ & $\begin{array}{l}16 \text { OECD; } \\
1967-1992 .\end{array}$ & $\begin{array}{l}\text { Deininger \& Squire } \\
1996 \text { for income } \\
\text { inequality. }\end{array}$ & $\begin{array}{l}\text { Gini of incomes regressed on economic aggregate } \\
\text { measures. }\end{array}$ & OP, UD, WE & $\begin{array}{l}\text { Direct investment and North-South trade have played a role in the determination of } \\
\text { income inequality in the contemporary period; likewise for immigration. }\end{array}$ \\
\hline $\begin{array}{l}\text { Autor, Katz } \\
\& \text { Kearney } \\
2005\end{array}$ & $\begin{array}{l}\text { USA; } 1973- \\
2003 .\end{array}$ & $\begin{array}{l}\text { March CPS and } \\
\text { May/ORG CPS; } \\
\text { real log hourly wages } \\
\text { of wage and salary } \\
\text { workers. }\end{array}$ & $\begin{array}{l}\text { Extends quantile decomposition that nests DiNardo, } \\
\text { Fortin, and Lemieux (1996) in view of more } \\
\text { differentiated developments over the earnings } \\
\text { distribution after 1990s (as } 90 / 50 \text { and } 50 / 10 \text { trends } \\
\text { diverge). }\end{array}$ & MW & $\begin{array}{l}\text { Compositional shifts in labour force have contributed to earnings inequality during } \\
\text { the 1990s. }\end{array}$ \\
\hline \begin{tabular}{l|} 
Autor, Katz \\
$\&$ Kearney \\
2008
\end{tabular} & $\begin{array}{l}\text { USA; } 1963- \\
2005 .\end{array}$ & $\begin{array}{l}\text { March CPS, matched } \\
\text { with DOT;: } \\
\text { FTFY workers log } \\
\text { earnings. Abstract, } \\
\text { routine and manual } \\
\text { tasks within } \\
\text { occupations. }\end{array}$ & $\begin{array}{l}\text { Kernel reweighting approach of Lemieux used to } \\
\text { facilitate a direct comparison. } \\
\text { Overall } 90 / 10,90 / 50 \text { and } 50 / 10 \text {; between-group } \\
\text { educational differentials; within-group } 90 / 10,90 / 50, \\
\text { and } 50 / 10 \text { residual wage gaps conditioned on measures } \\
\text { of education, age/experience, and gender. }\end{array}$ & $\begin{array}{l}\text { ED, occupations } \\
\text { by mean years of } \\
\text { schooling, MW }\end{array}$ & $\begin{array}{l}\text { Upper-tail }(90 / 50) \text { inequality has increased steadily since } 1980 \text { and fluctuations in } \\
\text { the real minimum wage are not a plausible explanation; a puzzling deceleration in } \\
\text { relative demand growth for college workers in the early 1990s potentially reconciled } \\
\text { by a modified version of the skill-biased technical change hypothesis that } \\
\text { emphasizes the role of information technology in complementing abstract (high- } \\
\text { education) tasks and substituting for routine (middle-education) tasks. Employment } \\
\text { and wage growth by skill percentile are found to be positively correlated in each of } \\
\text { the last two decades. }\end{array}$ \\
\hline $\begin{array}{l}\text { Blanchard \& } \\
\text { Wolfers } \\
2000\end{array}$ & $\begin{array}{l}20 \text { OECD; } \\
1960-1995 .\end{array}$ & $\begin{array}{l}\text { Nickell's \& OECD } \\
\text { institutions data. }\end{array}$ & & $\begin{array}{l}\text { AP, CP, ED, MW, } \\
\text { PM, TA, UB, UD, } \\
\text { WE }\end{array}$ & $\begin{array}{l}\text { Interactions shock and institutions are essential for understanding international } \\
\text { differences. }\end{array}$ \\
\hline \begin{tabular}{l|} 
Bedard \& \\
Ferrall 2003
\end{tabular} & \begin{tabular}{|l|} 
AUS, BEL, \\
CAN- \\
BC/ON, \\
DEU-W, FIN, \\
FRA, JPN, \\
NLD, SWE, \\
UK, USA; \\
$1964 / 1982$ vs \\
$1969 . . .1992$ \\
\end{tabular} & $\begin{array}{l}\text { Wage data from } \\
\text { national sources; test } \\
\text { data from IME } \\
\text { conducted in } \\
1964 \text { and } 1982 .\end{array}$ & Compares test scores at age 13 to wages later in life. & ED & $\begin{array}{l}\text { Wage dispersion, as summarized by Gini coefficients, is significantly related to test- } \\
\text { score dispersion. For U.S., the U.K., and Japan), with more data, evidence of skill- } \\
\text { biased changes in wage dispersion between the early 1970s and the late 1980s is } \\
\text { found. }\end{array}$ \\
\hline $\begin{array}{l}\text { Bertola \& } \\
\text { Boeri } 2003\end{array}$ & $\begin{array}{l}\text { EU15; 1982- } \\
1995 .\end{array}$ & $\begin{array}{l}\text { OECD, Eurostat, } \\
\text { ILO. }\end{array}$ & $\begin{array}{l}\text { Institutions protective of labour serve some intended } \\
\text { purpose. More intense competition may increase } \\
\text { demand for protection, and certainly calls for reforms. } \\
\text { A stylized model of the effects of structural change and } \\
\text { resulting reform tensions is used to examine recent } \\
\text { evidence. }\end{array}$ & CP, TA, UD, WE & $\begin{array}{l}\text { Labour market reforms are becoming relatively more frequent in EMU countries, } \\
\text { and many of them reduce welfare system generosity and deregulate labour markets. } \\
\text { Most reforms are marginal, however, and in many cases deregulation-oriented } \\
\text { reforms are accompanied by measures which appear to try and offset the } \\
\text { implications of stronger competition instead. In order to exploit fully the } \\
\text { advantages of economic and monetary integration, the institutional structure of } \\
\text { labour and other markets needs to be revised extensively. }\end{array}$ \\
\hline
\end{tabular}


Table A.9 Wage dispersion and institutions (see Section 4.6)

\begin{tabular}{|c|c|c|c|c|c|}
\hline Authors & $\begin{array}{l}\text { Countries } \\
\text { and years }\end{array}$ & $\begin{array}{l}\text { Datasets* and } \\
\text { sample selection }\end{array}$ & Methods and important variables & $\begin{array}{l}\text { Types of } \\
\text { institutions } * *\end{array}$ & Main findings \\
\hline $\begin{array}{l}\text { Budría \& } \\
\text { Pereira } 2005\end{array}$ & $\begin{array}{l}\text { DEU, FIN, } \\
\text { FRA, GRC, } \\
\text { ITA, NOR, } \\
\text { PRT, SWE, } \\
\text { UK; } 1980 \text { s, } \\
\text { 1990s. }\end{array}$ & $\begin{array}{l}\text { EDWIN microdata, } \\
\text { private-sector males } \\
\text { ages } 18-60,35+\text { hours, } \\
\text { non-agricultural } \\
\text { employees. }\end{array}$ & Quantile regression and OLS of returns to education. & ED & $\begin{array}{l}\text { Inequality increasing effect of tertiary education, through the 'within' dimension, } \\
\text { became more acute over last years. }\end{array}$ \\
\hline $\begin{array}{l}\text { Christo- } \\
\text { poulou et al. } \\
2010\end{array}$ & $\begin{array}{l}\text { AUT, BEL, } \\
\text { DEU, ESP, } \\
\text { GRC, HUN, } \\
\text { IRL, ITA, } \\
\text { NLD, } 1995 \\
\text { and } 2002 \text {. } \\
\end{array}$ & $\begin{array}{l}\text { EU-SES } 1995,2002 ; \\
\text { hourly wage including } \\
\text { regular bonuses and } \\
\text { payment for overtime. }\end{array}$ & $\begin{array}{l}\text { Split between composition effect and returns effect, } \\
\text { and residual. }\end{array}$ & MW, OP, UB, UD & $\begin{array}{l}\text { Wage inequality growth diverges across countries. Only minor contribution of } \\
\text { compositional change, but association with technology and globalization, while with } \\
\text { immigration wages decline. Mixed effect of labour-market institutions. }\end{array}$ \\
\hline \multicolumn{6}{|c|}{ iii. Specific institutions in more depth (See iv for jobs polarization) } \\
\hline $\begin{array}{l}\text { Baccaro } \\
2008\end{array}$ & \begin{tabular}{|l|}
51 Advanced, \\
Central and \\
Eastern \\
European, \\
Latin \\
American and \\
Asian \\
countries late \\
1980 s to early \\
2000s; and \\
analysis of 16 \\
Advanced \\
countries from \\
the late 1970s.
\end{tabular} & \begin{tabular}{|l|} 
New ILO dataset on \\
industrial relations and \\
labour law, various \\
dimensions of \\
globalization, and \\
controls for demand \\
and supply of skilled \\
labour.
\end{tabular} & Between- and within-country regressions. & $\begin{array}{l}\text { UB, UD, labour- } \\
\text { law compliance }\end{array}$ & $\begin{array}{l}\text { What changes from the 1990s on in advanced countries is the capacity of industrial } \\
\text { relations institutions to reduce inequality directly by compressing market earnings. } \\
\text { In particular, centralized collective bargaining seems to have become less } \\
\text { redistributive than in the past. To the extent that industrial relations institutions } \\
\text { continue to support and reproduce the welfare state, they reduce inequality } \\
\text { indirectly though this channel. }\end{array}$ \\
\hline $\begin{array}{l}\text { Barth \& } \\
\text { Lucifora } \\
2006\end{array}$ & $\begin{array}{l}\text { AUT, BEL, } \\
\text { DEU, DNK, } \\
\text { ESP, FIN, } \\
\text { FRA, GRC, } \\
\text { ITA, NOR, } \\
\text { SWE, UK; } \\
1973 \ldots . .2003 .\end{array}$ & $\begin{array}{l}\text { EDWIN, ECHP; non- } \\
\text { agricultural employees } \\
18-6415+\text { hours, } \\
\text { gross hourly earnings. }\end{array}$ & $\begin{array}{l}\text { Model with supply and demand for different types of } \\
\text { labour, as well as institutions affecting the bargained } \\
\text { relative wage. }\end{array}$ & $\mathrm{CP}, \mathrm{ED}, \mathrm{UB}, \mathrm{UD}$ & $\begin{array}{l}\text { No evidence of increasing "over-education" in Europe. Bargaining co-ordination } \\
\text { and employment protection have compressing effect on wages, but at different } \\
\text { points of the wage distribution. }\end{array}$ \\
\hline $\begin{array}{l}\text { Bassanini \& } \\
\text { Duval } 2006\end{array}$ & $\begin{array}{l}21 \text { OECD; } \\
1982-2003 .\end{array}$ & & $\begin{array}{l}\text { Aggregate employment and group-specific } \\
\text { participation, institutional/policies interactions. }\end{array}$ & $\begin{array}{l}\text { AP, MW, PM, TA, } \\
\text { WE }\end{array}$ & $\begin{array}{l}\text { Changes in policies and institutions appear to explain almost two thirds of } \\
\text { noncyclical unemployment changes over the past two decades. }\end{array}$ \\
\hline
\end{tabular}


Table A.9 Wage dispersion and institutions (see Section 4.6)

\begin{tabular}{|c|c|c|c|c|c|}
\hline Authors & $\begin{array}{l}\text { Countries } \\
\text { and years }\end{array}$ & $\begin{array}{l}\text { Datasets* and } \\
\text { sample selection }\end{array}$ & Methods and important variables & \begin{tabular}{|l|} 
Types of \\
institutions**
\end{tabular} & Main findings \\
\hline $\begin{array}{l}\text { Bassanini et } \\
\text { al. } 2009\end{array}$ & $\begin{array}{l}\text { OECD; } 1982- \\
2003 .\end{array}$ & $\begin{array}{l}\text { OECD annual cross- } \\
\text { country aggregate data } \\
\text { on the stringency of } \\
\text { employment } \\
\text { protection legislation } \\
\text { and industry-level data } \\
\text { on productivity. }\end{array}$ & $\begin{array}{l}\text { Examines effect of dismissal regulation on } \\
\text { productivity. }\end{array}$ & $\mathrm{CP}$ & $\begin{array}{l}\text { Empirical results suggest that mandatory dismissal regulations have a depressing } \\
\text { impact on productivity growth in industries where layoff restrictions are more likely } \\
\text { to be binding. By contrast, no evidence is found of a productivity effect of } \\
\text { regulations concerning temporary contracts, which suggests that partial reforms, } \\
\text { facilitating the use of fixed-term and atypical contracts, are unlikely to have an } \\
\text { important impact on efficiency and technological change and cannot therefore be a } \\
\text { substitute for comprehensive reforms whereby dismissal restrictions for open- } \\
\text { ended contracts are also weakened. }\end{array}$ \\
\hline $\begin{array}{l}\text { Bertola, Blau } \\
\text { \& Kahn } \\
2001\end{array}$ & $\begin{array}{l}28 \text { OECD } \\
\text { countries; } \\
1960-1999 .\end{array}$ & $\begin{array}{l}\text { Database of Blanchard } \\
\text { and Wolfers together } \\
\text { with wage } \\
\text { distributions from } \\
\text { OECD Earnings } \\
\text { database and labour } \\
\text { force and population } \\
\text { data from ILO. }\end{array}$ & $\begin{array}{l}\text { Analysis why the US moved from relatively high to } \\
\text { relatively low unemployment over the last three } \\
\text { decades. Institutions are largely assumed to be } \\
\text { invariant. }\end{array}$ & $\begin{array}{l}\text { AP, CP, TA, UB, } \\
\text { UD, WE }\end{array}$ & $\begin{array}{l}\text { While macroeconomic and demographic shocks and changing labour market } \\
\text { institutions explain a modest portion of this change, the interaction of these shocks } \\
\text { and labour market institutions is the most important factor explaining the shift in } \\
\text { US relative unemployment. This is consistent with Blanchard and Wolfers (2000). } \\
\text { Controlling for country- and time-specific effects, high employment is associated } \\
\text { with low wage levels and high levels of wage inequality. Disaggregating, the } \\
\text { employment of both younger and older people fell sharply in other countries } \\
\text { relative to the United States since the 1970s, with much smaller differences in } \\
\text { outcomes among the prime-aged. }\end{array}$ \\
\hline $\begin{array}{l}\text { Bičáková } \\
2006\end{array}$ & $\begin{array}{l}\text { FRA, UK, } \\
\text { USA; 1990- } \\
2002 .\end{array}$ & $\begin{array}{l}\text { National LFS; } 25-54 ; \\
\text { incl. self-employed; } \\
\text { hourly wages (net in } \\
\text { FR); skill groups: sex x } \\
\text { age x education. }\end{array}$ & $\begin{array}{l}\text { Focus is changes in the between-group variation in } \\
\text { earnings, employment, unemployment, and inactivity; } \\
\text { labour supply and demand model with heterogeneous } \\
\text { types of labour, using a pseudo-panel of different skill- } \\
\text { groups; three equations for wage, employment, and } \\
\text { labour force participation as a function of exogenous } \\
\text { supply and demand shifters, as implied by the structural } \\
\text { model, is estimated by two-way fixed effects on group- } \\
\text { level panel data. }\end{array}$ & $\begin{array}{l}\text { Wage rigidity (MW } \\
\text { in sideshow) }\end{array}$ & $\begin{array}{l}\text { Trade-off inequality to unemployment for declining demand for low-skilled is found } \\
\text { for FRA vs UK and USA. }\end{array}$ \\
\hline $\begin{array}{l}\text { Bingley et al. } \\
2013\end{array}$ & $\begin{array}{l}\text { DNK; } 1980- \\
2003 .\end{array}$ & $\begin{array}{l}\text { LFS; males aged } 21-55 \\
\text { working full-time in } \\
\text { private sector. }\end{array}$ & $\begin{array}{l}\text { Investigates the relationship between life cycle wages } \\
\text { and individual membership of unemployment } \\
\text { insurance schemes, separating permanent from } \\
\text { transitory wages and characterise them using } \\
\text { membership of unemployment insurance funds. }\end{array}$ & WE & $\begin{array}{l}\text { Unemployment insurance is associated with lower wage growth heterogeneity over } \\
\text { the life cycle and greater wage instability, changing the nature of wage inequality } \\
\text { from permanent to transitory. Robustness checks suggest that moral hazard is } \\
\text { relevant. }\end{array}$ \\
\hline $\begin{array}{l}\text { Blau \& } \\
\text { Kahn } 2002 \\
(\text { See also } \\
1996)\end{array}$ & \begin{tabular}{|l|} 
OECD; 1979- \\
1999
\end{tabular} & $\begin{array}{l}\text { Various, both macro } \\
\text { and micro. }\end{array}$ & $\begin{array}{l}\text { Discusses the literature and builds on own earlier } \\
\text { contributions to compare US labour-market } \\
\text { performance to other countries. }\end{array}$ & $\begin{array}{l}\text { AP, CP, ED, TA, } \\
\text { UB, WE }\end{array}$ & $\begin{array}{l}\text { Interventionist labour market institutions in Europe compress wages and lower } \\
\text { wage inequality; however, jobs most be lost for some groups. Institutional and } \\
\text { demographic change and macroeconomic policy also differs to the advantage of the } \\
\text { USA. }\end{array}$ \\
\hline Boeri 2011 & $\begin{array}{l}\text { Europe; since } \\
1980 .\end{array}$ & $\begin{array}{l}\text { fRDB-IZA social } \\
\text { policy reforms } \\
\text { database. }\end{array}$ & $\begin{array}{l}\text { Reviews literature building on institutional reforms as } \\
\text { quasi-natural experiments. }\end{array}$ & $\begin{array}{l}\text { AP, CF, CP, TA, } \\
\text { UB, WE }\end{array}$ & $\begin{array}{l}\text { Literature is very informative but insufficiently accounts for long-lasting } \\
\text { asymmetries between reformed and unreformed segments of the labour market. } \\
\text { Extends Mortensen-Pissarides model with this segmentation for a theoretical } \\
\text { approach that can help improving the identification of causal effects using reforms. } \\
\text { Also gives empirical evidence on reforms. }\end{array}$ \\
\hline
\end{tabular}


Table A.9 Wage dispersion and institutions (see Section 4.6)

\begin{tabular}{|c|c|c|c|c|c|}
\hline Authors & $\begin{array}{l}\text { Countries } \\
\text { and years }\end{array}$ & \begin{tabular}{|l|} 
Datasets* and \\
sample selection
\end{tabular} & Methods and important variables & $\begin{array}{l}\text { Types of } \\
\text { institutions** }\end{array}$ & Main findings \\
\hline \begin{tabular}{l|} 
Boeri and \\
Jimeno 2005
\end{tabular} & $\begin{array}{l}\text { ITA; } 1986- \\
1995 .\end{array}$ & $\begin{array}{l}\text { LFS rotation panel, } \\
\text { Italian social } \\
\text { security records (INPS } \\
\text { archives). }\end{array}$ & $\begin{array}{l}\text { Within-country exemptions to coverage of employment } \\
\text { protection provisions allow making inferences on the } \\
\text { impact of EPL when assessing the effects on dismissal } \\
\text { probabilities and, using a change in EPL in 1990, on } \\
\text { the equilibrium size distribution of firms. }\end{array}$ & $\mathrm{CP}$ & $\begin{array}{l}\text { Results are in line with predictions of the theoretical model. Workers under } \\
\text { permanent contracts in firms with less restrictive EPL are more likely to be } \\
\text { dismissed. However, there is no effect on the growth of firms. }\end{array}$ \\
\hline $\begin{array}{l}\text { Bryson et al. } \\
2012\end{array}$ & $\begin{array}{l}\text { Europe and } \\
\text { USA; early } \\
\text { 2000s. }\end{array}$ & \begin{tabular}{l|} 
GSS 2002 and 2006, \\
EWCS 2000 and 2005; \\
employees with a \\
permanent contract in \\
private sector and in \\
profit oriented firms \\
only excluding \\
managers and CEOs.
\end{tabular} & $\begin{array}{l}\text { Presents new comparable data on the incidence of } \\
\text { performance pay schemes. The percentage of } \\
\text { employees exposed to incentive pay schemes ranges } \\
\text { from around } 10-15 \text { percent in some European } \\
\text { countries to over } 40 \text { percent in Scandinavian countries } \\
\text { and the US. Individual pay and profit/gain sharing } \\
\text { schemes are widely diffused, whereas share ownership } \\
\text { schemes are much less common, particularly in } \\
\text { Europe. }\end{array}$ & UW & $\begin{array}{l}\text { A number of empirical regularities are found. Incentive pay is less common in } \\
\text { countries with a higher share of small firms. Higher product and labour market } \\
\text { regulation are associated with lower use of incentive pay. Capital market } \\
\text { development is a necessary requirement for a wider diffusion of incentive pay, } \\
\text { particularly sharing and ownership schemes. Controlling for a large set of individual } \\
\text { characteristics and company attributes, the probability that a worker is covered by } \\
\text { an incentive scheme is higher in large firms and in high-skilled occupations, while it } \\
\text { is much lower for females. }\end{array}$ \\
\hline $\begin{array}{l}\text { Card and } \\
\text { DiNardo } \\
2002\end{array}$ & $\begin{array}{l}\text { USA; around } \\
1970 \text { to } 2000 .\end{array}$ & \begin{tabular}{l|} 
CPS: March, May and \\
ORG; diverging \\
samples are compared.
\end{tabular} & $\begin{array}{l}\text { Extended discussion of the measurement of } \\
\text { technological change and of changes in the structure of } \\
\text { wages in the U.S. labour market over the past twenty to } \\
\text { thirty years, concluding to myriad shifts. }\end{array}$ & MW & $\begin{array}{l}\text { Viewed from 2002, it now appears that the rise in wage inequality was an episodic } \\
\text { event. A key problem for the SBTC hypothesis is that wage inequality stabilized in } \\
\text { the } 1990 \text { s despite continuing advances in computer technology; SBTC also fails to } \\
\text { explain the evolution of other dimensions of wage inequality. }\end{array}$ \\
\hline $\begin{array}{l}\text { Card et al. } \\
2004\end{array}$ & $\begin{array}{l}\text { CAN, UK, } \\
\text { USA; } \\
1973 / 1984 \\
2001 .\end{array}$ & \begin{tabular}{l|} 
CAN-LFS + \\
supplements, UK-LFS \\
and GHS, May and \\
ORG CPS; hourly \\
wages of employees \\
aged 16-65.
\end{tabular} & $\begin{array}{l}\text { Comprehensive analysis of the evolution of } \\
\text { unionization and wage inequality for both men and } \\
\text { women in all three countries over the past two to three } \\
\text { decades, as a sequel to Freeman (1980) and Freeman } \\
\text { and Medoff (1984). The countries collect comparable } \\
\text { data and share similar collective bargaining institutions. }\end{array}$ & UB, UD, MW & $\begin{array}{l}\text { Unions reduce male inequality also after controlling for skill; but they increase } \\
\text { female inequality; over time the declining unionization has eroded equalization. }\end{array}$ \\
\hline $\begin{array}{l}\text { Checchi \& } \\
\text { Garcia- } \\
\text { Peñalosa } \\
2008\end{array}$ & $\begin{array}{l}11 \text { EU } \\
\text { countries, } \\
\text { AUS, CAN, } \\
\text { NOR, CHE } \\
\text { and USA; } \\
\text { 1969-2004. }\end{array}$ & LIS; n.a. & $\begin{array}{l}\text { Labour market institutions are a crucial determinant of } \\
\text { wage inequality, the wage share in aggregate income, } \\
\text { and the unemployment rate. Since these variables } \\
\text { affect, in turn, the distribution of income across } \\
\text { households, the question arises of whether stronger } \\
\text { labour market institutions have an impact on income } \\
\text { inequality. Institutions can in principle have conflicting } \\
\text { effects. This paper examines what is the overall impact } \\
\text { of labour market institutions on household income } \\
\text { inequality. And counterfactually simulates adoption in } \\
\text { other countries of labour standards of USA, UK or EU } \\
\text { average. }\end{array}$ & $\begin{array}{l}\text { CP, MW, TA, UB, } \\
\text { UD }\end{array}$ & $\begin{array}{l}\text { The evidence indicates that stronger institutions are associated with lower income } \\
\text { inequality, but in some cases also with higher rates of unemployment. The } \\
\text { magnitude of this trade-off is explored, and the changes in inequality and } \\
\text { unemployment are quantified that would be observed if a common labour standard } \\
\text { were imposed on members states of the European Union - results are not } \\
\text { encouraging as a consequence of a lowering of employment protection; this could } \\
\text { be accompanied though by a reinforcement of wage coordination and union density } \\
\text { but these are no obvious policy targets. }\end{array}$ \\
\hline $\begin{array}{l}\text { Checchi \& } \\
\text { Garcia- } \\
\text { Peñalosa } \\
2010\end{array}$ & $\begin{array}{l}\text { OECD; } 1960- \\
2000 .\end{array}$ & $\begin{array}{l}\text { Aggregate data from } \\
\text { various sources (see } \\
\text { paper's Appendix). }\end{array}$ & $\begin{array}{l}\text { This paper argues that personal income inequality } \\
\text { depends on the wage differential, the labour share and } \\
\text { the unemployment rate. Labour market institutions } \\
\text { affect income inequality through these three channels, } \\
\text { and their overall effect is theoretically ambiguous. }\end{array}$ & MW, TA, UB, UD & $\begin{array}{l}\text { It is found that greater unionization and greater wage bargaining coordination have } \\
\text { opposite effects on inequality, implying conflicting effects of greater union presence } \\
\text { on income inequality. }\end{array}$ \\
\hline
\end{tabular}


Table A.9 Wage dispersion and institutions (see Section 4.6)

\begin{tabular}{|c|c|c|c|c|c|}
\hline Authors & $\begin{array}{l}\text { Countries } \\
\text { and years }\end{array}$ & \begin{tabular}{|l|} 
Datasets* and \\
sample selection
\end{tabular} & Methods and important variables & \begin{tabular}{|l|} 
Types of \\
institutions**
\end{tabular} & Main findings \\
\hline $\begin{array}{l}\text { Coelli et al. } \\
1994\end{array}$ & $\begin{array}{l}14 \text { OECD } \\
\text { countries; } \\
\text { around } 1970 \\
\text { to } 1990 .\end{array}$ & $\begin{array}{l}\text { OECD National } \\
\text { accounts sectoral data. }\end{array}$ & $\begin{array}{l}\text { This paper examines the issue of wage flexibility in an } \\
\text { international context using sectoral wage dispersion } \\
\text { data from fourteen OECD countries. It draws } \\
\text { comparisons between a measure of wage dispersion } \\
\text { and the degree of centralization of a country's wage } \\
\text { setting institution to determine whether decentralised } \\
\text { wage setting institutions are necessarily associated with } \\
\text { more flexible wages. Inter-country comparisons are } \\
\text { drawn among the levels of wage dispersion over time, } \\
\text { and the relationship between wages and demand } \\
\text { conditions for labour, including productivity and } \\
\text { relative prices, are examined. }\end{array}$ & UB & $\begin{array}{l}\text { No strong systematic relationship exists between wage dispersion and the degree of } \\
\text { centralization of labour market institutions. }\end{array}$ \\
\hline Corsini 2008 & $\begin{array}{l}11 \text { EU } \\
\text { countries; } \\
\text { early } 1990 \text { s to } \\
\text { early } 2000 \text { s }\end{array}$ & $\begin{array}{l}\text { BHPS, GSOEP and } \\
\text { ECHP; employees. }\end{array}$ & $\begin{array}{l}\text { The paper studies the evolution of wage differentials } \\
\text { between graduate (skilled) and non-graduate (unskilled) } \\
\text { workers. All countries show an increasing relative } \\
\text { supply of skilled workers but different behaviours of } \\
\text { the wage differentials. The standard explanation for } \\
\text { non-decreasing differentials in the face of rising relative } \\
\text { supply is that technological progress is skill biased. This } \\
\text { in turn would imply that technological progress differs } \\
\text { in its magnitude and effects across Europe. Turning } \\
\text { then to institutions a model is built of imperfect } \\
\text { competition and wage bargaining which relates the } \\
\text { differentials to the technological progress but also to } \\
\text { several labour market institutions. }\end{array}$ & $\begin{array}{l}\text { R\&D and CP, } \\
\text { UD, WE }\end{array}$ & $\begin{array}{l}\text { The findings show that what is relevant in the determination of the differentials it is } \\
\text { the pace and intensity at which technological progress takes place. Adding } \\
\text { institutions to the role of R\&D employment rates of different groups as well as } \\
\text { union density and generosity of unemployment benefits are found to be important } \\
\text { for explaining the evolution of the wage differentials between skilled and unskilled } \\
\text { workers. They do not produce wage compression between skilled and unskilled } \\
\text { workers. }\end{array}$ \\
\hline $\begin{array}{l}\text { Dahl et al. } \\
2011\end{array}$ & $\begin{array}{l}\text { DNK; 1992- } \\
2001 .\end{array}$ & $\begin{array}{l}\text { IDA, Income Register; } \\
\text { full-time workers aged } \\
25-65 \text { years employed } \\
\text { in bargaining } \\
\text { segments. }\end{array}$ & \begin{tabular}{|l|} 
This paper studies how decentralization of wage \\
bargaining from sector to firm-level influences wage \\
levels and wage dispersion. We use detailed panel data \\
covering a period of decentralization in the Danish \\
labour market. The decentralization process provides \\
variation in the individual worker's wage-setting system \\
that facilitates identification of the effects of \\
decentralization.
\end{tabular} & $\mathrm{UB}$ & $\begin{array}{l}\text { We find a wage premium associated with firm-level bargaining relative to sector- } \\
\text { level bargaining, and that the return to skills is higher under the more decentralized } \\
\text { wage-setting systems. Using quantile regression, we also find that wages are more } \\
\text { dispersed under firm-level bargaining compared to more centralized wage-setting } \\
\text { systems. }\end{array}$ \\
\hline $\begin{array}{l}\text { Dinardo, } \\
\text { Fortin \& } \\
\text { Lemieux } \\
1996\end{array}$ & $\begin{array}{l}\text { USA; } 1979- \\
1988 .\end{array}$ & CPS; hourly wages. & $\begin{array}{l}\text { This paper presents a semiparametric procedure to } \\
\text { analyze the effects of institutional and labor market } \\
\text { factors on recent changes in the U.S. distribution of } \\
\text { wages. The effects of these factors are estimated by } \\
\text { applying kernel density methods to appropriately } \\
\text { weighted samples. The procedure provides a visually } \\
\text { clear representation of where in the density of wages } \\
\text { these various factors exert the greatest impact. }\end{array}$ & MW, UD & $\begin{array}{l}\text { De-unionization and supply and demand shocks were important factors in } \\
\text { explaining the rise in wage inequality from } 1979 \text { to } 1988 \text {. The decline in the real } \\
\text { value of the minimum wage explains a substantial proportion of this increase in } \\
\text { wage inequality, particularly for women. Labour market institutions are as important } \\
\text { as supply and demand considerations in explaining changes in the U.S. distribution } \\
\text { of wages from } 1979 \text { to } 1988 \text {. }\end{array}$ \\
\hline
\end{tabular}


Table A.9 Wage dispersion and institutions (see Section 4.6)

\begin{tabular}{|c|c|c|c|c|c|}
\hline Authors & $\begin{array}{l}\text { Countries } \\
\text { and years }\end{array}$ & $\begin{array}{l}\text { Datasets* and } \\
\text { sample selection }\end{array}$ & Methods and important variables & $\begin{array}{l}\text { Types of } \\
\text { institutions** }\end{array}$ & Main findings \\
\hline $\begin{array}{l}\text { DiNardo \& } \\
\text { Lemieux } \\
1997\end{array}$ & $\begin{array}{l}\text { CAN, USA; } \\
1981-1988 .\end{array}$ & $\begin{array}{l}\text { CAN-LFS and CPS; } \\
\text { men aged } 17-64 \text { excl. } \\
\text { university graduates } \\
17-19 .\end{array}$ & \begin{tabular}{|l|} 
During the period 1981-88 the decline in the \\
percentage of workers belonging to unions and an \\
increase in hourly wage inequality were much more \\
pronounced in the United States than in Canada. Study \\
the effect of labour market institutions on changes in \\
wage inequality by computing simple counterfactuals \\
such as the distribution of wages that would prevail if \\
all workers were paid according to the observed non- \\
union wage schedule.
\end{tabular} & MW, UD & $\begin{array}{l}\text { Results suggest that much more severe declines in the unionization rate in the } \\
\text { United States than in Canada account for two-thirds of the differential growth in } \\
\text { wage inequality between the two countries. }\end{array}$ \\
\hline $\begin{array}{l}\text { Dustmann } \\
\text { et al. } 2009\end{array}$ & $\begin{array}{l}\text { DEU-W; mid- } \\
\text { 1970s to mid- } \\
\text { 2000s. }\end{array}$ & $\begin{array}{l}\text { IABS 1975-2004, and } \\
\text { LIAB 1995-2004; ages } \\
\text { 21-60. }\end{array}$ & $\begin{array}{l}\text { Using the kernel reweighting procedure } \\
\text { (DiNardo, Fortin, and Lemieux, 1996) it is } \\
\text { shown that it is important to account for changes in } \\
\text { workforce composition, in particular at the upper end } \\
\text { of the wage distribution. Fluctuations in relative supply } \\
\text { explain the evolution of the wage differential between } \\
\text { the low- and medium skilled very well, but do a poor } \\
\text { job in predicting the evolution of the wage differential } \\
\text { between the medium- and high-skilled. }\end{array}$ & UD & $\begin{array}{l}\text { Wage inequality in West Germany has increased over the past three decades, } \\
\text { contrary to common perceptions. During the } 1980 \text { s, the increase was concentrated } \\
\text { at the top of the distribution; in the } 1990 \text { s, it occurred at the bottom end as well. } \\
\text { Technological change is responsible for the widening of the wage distribution at the } \\
\text { top. At the bottom of the wage distribution, the increase in inequality is better } \\
\text { explained by episodic events, such as supply shocks and changes in labour market } \\
\text { institutions. Occupations with high median wages in } 1980 \text { experienced the highest } \\
\text { growth rate, whereas occupations in the middle of the } 1980 \text { wage distribution lost } \\
\text { ground relative to occupations at the bottom. }\end{array}$ \\
\hline $\begin{array}{l}\text { Eissa \& } \\
\text { Hoynes } \\
2004\end{array}$ & $\begin{array}{l}\text { USA; } 1984- \\
1996 .\end{array}$ & $\begin{array}{l}\text { March CPS; married } \\
\text { couples residing in the } \\
\text { same household, ages } \\
25-54 \text {, and less than } \\
\text { high school in main } \\
\text { estimates }\end{array}$ & $\begin{array}{l}\text { Simulation of } 1984 \text { and } 1996 \text { EITC rules on married } \\
\text { couples labour participation. Effects estimated using } \\
\text { both quasi-experimental and traditional reduced-form } \\
\text { labour supply models, with same conclusion. }\end{array}$ & TA & $\begin{array}{l}\text { EITC family targeting can disincentivize secondary earners: } 1 \% \text { fall married women, } \\
\text { strong increase for single-parent women, slight increase married men. }\end{array}$ \\
\hline $\begin{array}{l}\text { Firpo, } \\
\text { Fortin \& } \\
\text { Lemieux } \\
2011\end{array}$ & $\begin{array}{l}\text { USA; } \\
1976 / 77 \\
1988 / 90 \\
2000 / 02 \\
2004 / 04 \\
2009 / 10\end{array}$ & $\begin{array}{l}\text { CPS and O*Net; male } \\
\text { employees }\end{array}$ & $\begin{array}{l}\text { Changes in returns to occupational tasks have } \\
\text { contributed to changes in the wage distribution over } \\
\text { the last three decades. Using a decomposition based on } \\
\text { Firpo, Fortin, and Lemieux (2009). }\end{array}$ & OP, UD & $\begin{array}{l}\text { Technological change and deunionization played a central role in the 1980s and } \\
1990 \text { s, while offshorability became an important factor from the 1990s onwards. }\end{array}$ \\
\hline $\begin{array}{l}\text { Fortin \& } \\
\text { Lemieux } \\
1997\end{array}$ & $\begin{array}{l}\text { USA; } 1979 \\
\text { and } 1988 .\end{array}$ & $\begin{array}{l}\text { CPS; workers aged 16- } \\
65 .\end{array}$ & $\begin{array}{l}\text { Show what the variance of the }(\log ) \text { wage distribution } \\
\text { would have been, if each of the three institutional } \\
\text { changes had not happened. Decompose distribution of } \\
\text { wages using three elements: the fraction of workers } \\
\text { "affected" by the institutional factor of interest; the } \\
\text { mean level of log wages among affected and non- } \\
\text { affected workers; and the dispersion of log wages } \\
\text { among affected and non-affected workers. By reverting } \\
\text { some of these measures to their previous level, simulate } \\
\text { what would have happened if the institutional changes } \\
\text { had not taken place. }\end{array}$ & MW, PM, UB, UD & $\begin{array}{l}\text { Historical evidence from the United States, international comparisons among } \\
\text { industrialized countries and analyses of U.S. data for the } 1980 \text { s all yield the same } \\
\text { conclusion: institutional forces simply cannot be overlooked in any serious attempt } \\
\text { to understand the recent rise in wage inequality in the U.S. labour market. }\end{array}$ \\
\hline
\end{tabular}


Table A.9 Wage dispersion and institutions (see Section 4.6)

\begin{tabular}{|c|c|c|c|c|c|}
\hline Authors & $\begin{array}{l}\text { Countries } \\
\text { and years }\end{array}$ & $\begin{array}{l}\text { Datasets* and } \\
\text { sample selection }\end{array}$ & Methods and important variables & $\begin{array}{l}\text { Types of } \\
\text { institutions** }\end{array}$ & Main findings \\
\hline $\begin{array}{l}\text { Golden \& } \\
\text { Wallerstein } \\
2006\end{array}$ & $\begin{array}{l}16 \text { OECD } \\
\text { countries; } \\
1980-2000\end{array}$ & & $\begin{array}{l}\text { Examine three main hypotheses for the rise of pay } \\
\text { inequality: post-industrial, globalization, and } \\
\text { institutional. Main idea is determinants of wage } \\
\text { inequality underwent considerable substantive change } \\
\text { over the period. A statistical model uses first } \\
\text { differences over five-year periods, because effects of } \\
\text { the explanatory variables are not instantaneous. }\end{array}$ & $\mathrm{OP}, \mathrm{UB}, \mathrm{UD}, \mathrm{WE}$ & $\begin{array}{l}\text { Causes for pay inequality are quite different in the 1980s than in the } 1990 \mathrm{~s} \text {. In the } \\
1980 \text { s, growing wage dispersion is due to changes in the institutions of the labour } \\
\text { market. Declining unionization and declines in the level at which wages are } \\
\text { bargained collectively both contribute to widening pay dispersion in the } 1980 \text { s. In } \\
\text { the } 1990 \text { s, by contrast, increases in pay inequality are due to increasing trade with } \\
\text { less developed nations. To the extent that low-pay workers have been protected } \\
\text { from rising wage differentials in the 1990s, it has been because of government } \\
\text { policy, in the form of social insurance, and not thanks to labour organizations. }\end{array}$ \\
\hline $\begin{array}{l}\text { Hall \& } \\
\text { Krueger } \\
2010\end{array}$ & USA; 2008. & \begin{tabular}{|l|} 
Special survey of a \\
representative sample \\
of US workers to \\
inquire about the wage \\
determination process \\
at the time they were \\
hired into their current \\
or most recent jobs.
\end{tabular} & $\begin{array}{l}\text { Some workers bargain with prospective employers } \\
\text { before accepting a job. Others face a posted wage as a } \\
\text { take-it-or-leave-it opportunity. Theories of wage } \\
\text { formation point to substantial differences in labour- } \\
\text { market equilibrium between bargained and posted } \\
\text { wages. A third of the respondents reported bargaining } \\
\text { over pay before accepting their current jobs. About a } \\
\text { third of workers had precise information about pay } \\
\text { when they first met with their employers, a sign of } \\
\text { wage posting. About } 40 \text { percent of workers could have } \\
\text { remained on their earlier jobs at the time they accepted } \\
\text { their current jobs, indicating a more favourable } \\
\text { bargaining position than is held by unemployed job- } \\
\text { seekers. }\end{array}$ & UW & $\begin{array}{l}\text { Our analysis of the distribution of wages shows that wage dispersion is higher } \\
\text { among workers who bargained for their wages. Wages are higher among bargainers } \\
\text { than non-bargainers, after adjusting for the differing compositions of the groups. } \\
\text { Our results on wages give substantial support to the job-ladder model--workers } \\
\text { who had the option to remain at their earlier jobs when they took their current jobs } \\
\text { can earn higher wages than those without that option. }\end{array}$ \\
\hline $\begin{array}{l}\text { Kenworthy } \\
2001\end{array}$ & $\begin{array}{l}\text { AUS, AUT, } \\
\text { BEL, CAN, } \\
\text { CHE, DEU, } \\
\text { DNK, FIN, } \\
\text { FRA, ITA, } \\
\text { JPN, NLD, } \\
\text { NOR, SWE, } \\
\text { UK, USA }\end{array}$ & $\begin{array}{l}15 \text { Bargaining } \\
\text { Indicators found in the } \\
\text { literature. }\end{array}$ & $\begin{array}{l}\text { This article offers a survey and assessment of the } \\
\text { principal existing measures in the literature: eight } \\
\text { measures of wage centralization and seven measures of } \\
\text { wage coordination. There are three aims: provide an } \\
\text { inventory of existing indicators, examine their features } \\
\text { and merits, and assess sensitivity of findings generated } \\
\text { by these measures. }\end{array}$ & UB & $\begin{array}{l}\text { The two best available measures of centralization of wage bargaining are the Iversen } \\
\text { and Traxler-Blaschke-Kittel indicators. The former is based on structural features, } \\
\text { while the latter aims to measure behaviour. There is currently only one available } \\
\text { measure of wage-setting centralization. The conceptual differences between wage- } \\
\text { setting measures lead to some noteworthy differences in scoring of certain countries } \\
\text { and years. A potentially problematic gap is the lack of any measure of wage setting } \\
\text { at the subnational level. }\end{array}$ \\
\hline $\begin{array}{l}\text { Koeninger } \\
\text { et al. } 2007\end{array}$ & $\begin{array}{l}\text { AUS, CAN, } \\
\text { FIN, FRA, } \\
\text { DEU, ITA, } \\
\text { JPN, NLD, } \\
\text { SWE, UK, } \\
\text { USA; 1970s, } \\
\text { 1980s, 1990s. }\end{array}$ & Various. & Variance decomposition of aggregates. & C, MW, U, WE & Institutions explain at least as much as trade and technology. \\
\hline $\begin{array}{l}\text { Kugler and } \\
\text { Pica } 2008\end{array}$ & $\begin{array}{l}\text { ITA; 1986- } \\
1995 .\end{array}$ & \begin{tabular}{|l|} 
Social Security \\
employer-employee \\
panel.
\end{tabular} & $\begin{array}{l}\text { Study effects of the Italian reform of } 1990 \text { on worker } \\
\text { and job flows, exploiting the fact that this reform } \\
\text { increased unjust dismissal costs for businesses below } \\
15 \text { employees, while leaving dismissal costs unchanged } \\
\text { for bigger businesses, to set up a natural experiment } \\
\text { research design. }\end{array}$ & $\mathrm{CP}$ & $\begin{array}{l}\text { The increase in dismissal costs decreased accessions and separations for workers in } \\
\text { small relative to large firms, especially in sectors with higher employment volatility, } \\
\text { with a negligible impact on net employment. Also some evidence is found } \\
\text { suggesting that the reform reduced firms' entry rates and employment adjustments, } \\
\text { but had no effect on exit rates. }\end{array}$ \\
\hline
\end{tabular}


Table A.9 Wage dispersion and institutions (see Section 4.6)

\begin{tabular}{|c|c|c|c|c|c|}
\hline Authors & $\begin{array}{l}\text { Countries } \\
\text { and years }\end{array}$ & $\begin{array}{l}\text { Datasets* and } \\
\text { sample selection }\end{array}$ & Methods and important variables & $\begin{array}{l}\text { Types of } \\
\text { institutions** }\end{array}$ & Main findings \\
\hline \begin{tabular}{|l|} 
Lemieux \\
2008
\end{tabular} & $\begin{array}{l}\text { USA; 1973- } \\
2005 .\end{array}$ & $\begin{array}{l}\text { May and ORG CPS, } \\
\text { PSID; mainly males } \\
\text { but females partly } \\
\text { considered separately. }\end{array}$ & $\begin{array}{l}\text { The paper reviews recent developments in the literature } \\
\text { on wage inequality with a particular focus on why } \\
\text { inequality growth has been particularly concentrated in } \\
\text { the top end of the wage distribution over the last } 15 \\
\text { years. Several possible institutional and demand-side } \\
\text { explanations are discussed for the secular growth in } \\
\text { wage inequality in the United States and other } \\
\text { advanced industrialized countries. }\end{array}$ & $\begin{array}{l}\text { MW, NO, UB, } \\
\text { UD, UW }\end{array}$ & $\begin{array}{l}\text { The nature of the changes in inequality has been dramatically altered over the last } 15 \\
\text { years. While the growth in inequality in the } 1980 \text { s was pervasive, it has been } \\
\text { concentrated at the top end of the distribution since then unlike SBTC, the } \\
\text { institutional change explanation can help explain why inequality changes became } \\
\text { concentrated in the top end after } 1990 \text { and why inequality grew more in the United } \\
\text { States and the United Kingdom than in other advanced countries. This being said, } \\
\text { just like in the 1980s, available estimates indicate that institutional change can only } \\
\text { account for about a third of the observed recent changes in wage inequality. } \\
\text { However, broadening the traditional institutional explanation to include pay setting } \\
\text { mechanisms such as performance-pay can help explain more of the growth in } \\
\text { inequality at the top end. For the time being, however, most of the growth in top- } \\
\text { end inequality over the last } 15 \text { years remains unaccounted for. }\end{array}$ \\
\hline $\begin{array}{l}\text { Lemieux et } \\
\text { al. } 2009\end{array}$ & $\begin{array}{l}\text { USA; 1976- } \\
1998 .\end{array}$ & \begin{tabular}{|l|} 
PSID (some \\
robustness test using \\
NLSY); male \\
household heads, aged \\
18 to 65, employees in \\
private sector.
\end{tabular} & $\begin{array}{l}\text { An increasing fraction of jobs explicitly pay workers for } \\
\text { their performance using bonus pay, commissions, or } \\
\text { piece-rate contracts. Variance components analysis. }\end{array}$ & UD, UW & $\begin{array}{l}\text { Compensation in performance-pay jobs is more closely tied to both observed and } \\
\text { unobserved productive characteristics of workers than compensation in non- } \\
\text { performance-pay jobs. The return to these productive characteristics increased } \\
\text { faster over time in performance-pay jobs. Performance pay provides a channel } \\
\text { through which underlying changes in returns to skill get translated into higher wage } \\
\text { inequality, accounting for } 21 \% \text { of the growth in the variance of male wages between } \\
\text { the late } 1970 \text { s and the early } 1990 \text { s and for most of the increase in wage inequality } \\
\text { above the eightieth percentile over the same period. }\end{array}$ \\
\hline \begin{tabular}{|l|} 
Leonardi \& \\
Pica 2013
\end{tabular} & $\begin{array}{l}\text { ITA; 1985- } \\
1997 .\end{array}$ & $\begin{array}{l}\text { Italian Social Security } \\
\text { Institute (INPS) } \\
\text { matched employer-- } \\
\text { employee panel: } \\
\text { Veneto Workers } \\
\text { History dataset; } \\
\text { private-sector } \\
\text { excluding agriculture, } \\
\text { male employees aged } \\
\text { 20-55. }\end{array}$ & \begin{tabular}{|l|} 
This study estimates the effect of employment \\
protection legislation on wages, exploiting the 1990 \\
Italian reform that introduced unjust dismissal costs for \\
firms below 15 employees. It combines a regression \\
discontinuity design (RDD) with a difference-in- \\
difference (DID) approach for identifying the effect.
\end{tabular} & $\mathrm{CP}$ & $\begin{array}{l}\text { The slight average wage reduction induced by the reform hides highly } \\
\text { heterogeneous effects. Workers who change firm during the reform period suffer a } \\
\text { drop in the entry wage, while incumbent workers are left unaffected. Also, the } \\
\text { negative effect of the reform is stronger for young blue collars, low-wage workers } \\
\text { and workers in low-employment regions. This pattern suggests that the ability of } \\
\text { employers to shift firing costs onto wages depends on workers' relative bargaining } \\
\text { power. }\end{array}$ \\
\hline $\begin{array}{l}\text { Levy \& } \\
\text { Temin } 2007\end{array}$ & $\begin{array}{l}\text { USA; 1930s to } \\
\text { mid-2000s. }\end{array}$ & Various. & $\begin{array}{l}\text { We provide a comprehensive view of widening income } \\
\text { inequality in the United States contrasting conditions } \\
\text { since } 1980 \text { with those in earlier post-war years. We } \\
\text { argue that the income distribution in each period was } \\
\text { strongly shaped by a set of economic institutions. A } \\
\text { Bargaining Power Index is used (\% of output captured } \\
\text { by full-time worker's compensation), split by categories } \\
\text { of workers. }\end{array}$ & MW, OP, TA, UB & $\begin{array}{l}\text { The early post-war years were dominated by unions, a negotiating framework set in } \\
\text { the Treaty of Detroit, progressive taxes, and a high minimum wage -- all parts of a } \\
\text { general government effort to broadly distribute the gains from growth. More recent } \\
\text { years have been characterized by reversals in all these dimensions in an institutional } \\
\text { pattern known as the Washington Consensus. Other explanations for income } \\
\text { disparities including skill-biased technical change and international trade are seen as } \\
\text { factors operating within this broader institutional story. }\end{array}$ \\
\hline \begin{tabular}{|l|} 
Manzo \& \\
Bruno 2014
\end{tabular} & \begin{tabular}{|l|} 
USA \\
construction \\
industry; 2007 \\
to 2011.
\end{tabular} & $\begin{array}{l}\text { IPUMS data from the } \\
\text { ACS, } 5.0 \text { percent } \\
\text { sample. }\end{array}$ & \begin{tabular}{|l|} 
An ordinary least squares (OLS) regression model is \\
run evaluating the effects on decile ratios of income \\
inequality of unionization, distinguishing between \\
prevailing-wage-law states and right-to-work law states, \\
and controlling for demographic, educational, and \\
work factors, including 24 distinct occupations. \\
\end{tabular} & UD, UB & $\begin{array}{l}\text { The largest contributor to rising income inequality has been the gradual, long-term } \\
\text { decline in labour union membership. The union wage premium is between } 10 \text { and } \\
17 \text { percent, helping lower- and middle-income workers most. Right-to-work laws } \\
\text { decrease unionization by between } 5 \text { and } 8 \text { percentage points and reduce the average } \\
\text { construction worker's earnings by } 6 \text { percent in the national economy. }\end{array}$ \\
\hline
\end{tabular}


Table A.9 Wage dispersion and institutions (see Section 4.6)

\begin{tabular}{|c|c|c|c|c|c|}
\hline Authors & $\begin{array}{l}\text { Countries } \\
\text { and years }\end{array}$ & $\begin{array}{l}\text { Datasets* and } \\
\text { sample selection }\end{array}$ & Methods and important variables & $\begin{array}{l}\text { Types of } \\
\text { institutions } * *\end{array}$ & Main findings \\
\hline $\begin{array}{l}\text { Nunziata } \\
2005\end{array}$ & $\begin{array}{l}\text { OECD; } 1960- \\
1994 .\end{array}$ & Various. & \begin{tabular}{|l|} 
An empirical analysis of the determinants of labour \\
cost, with particular reference to the impact of labour \\
market institutions from 1960 to 1994 . The paper also \\
discusses the econometric issues related to the \\
estimation of a macro pooled model like ours: among \\
other things, the hypothesis of poolability and the \\
cointegration properties of the model. The explanatory \\
power of the model is finally tested by means of a \\
series of country by country dynamic simulations.
\end{tabular} & $\begin{array}{l}\text { CP, MW, TA, UB, } \\
\text { UD, UW, WE }\end{array}$ & $\begin{array}{l}\text { Labour market regulations can explain a large part of the labour cost rise in the last } \\
\text { few decades once we control for productivity. }\end{array}$ \\
\hline Oliver 2008 & \begin{tabular}{|l}
14 OECD \\
countries; \\
1980 to 2002.
\end{tabular} & $\begin{array}{l}\text { Unpublished data set } \\
\text { from the OECD }\end{array}$ & $\begin{array}{l}\text { With a series of cross-sectional time-series analyses, } \\
\text { this article investigates how a particular wage- } \\
\text { bargaining institution: the extent to which industry- } \\
\text { wide wage minima (wage scales) cover both higher and } \\
\text { lower skilled workers, mitigates pressures from growing } \\
\text { international competition and new production } \\
\text { techniques and affects the degree of wage inequality } \\
\text { growth. }\end{array}$ & UW & $\begin{array}{l}\text { The results strongly indicate that the presence of industry-wide wage scales is a key } \\
\text { factor in the evolution of wage inequality across OECD countries. }\end{array}$ \\
\hline $\begin{array}{l}\text { Plotnick } \\
1982\end{array}$ & $\begin{array}{l}\text { USA; } 1957- \\
1977 .\end{array}$ & \begin{tabular}{l|} 
Unpublished earnings \\
data Henle \& \\
Ryscavage (1980), CPS \\
(unpublished and \\
several specific data \\
sources; males.
\end{tabular} & $\begin{array}{l}\text { This study uses newly available time series data to } \\
\text { analyze trends in earnings inequality. It shows that } \\
\text { while a human capital approach fits the data well and } \\
\text { most of its predictions on signs are correct, the model's } \\
\text { more exacting implications are not satisfied. A } \\
\text { complementary more ad hoc approach retains variables } \\
\text { found to be significant and looks beyond aggregate } \\
\text { inequality measures into parts of the distribution which } \\
\text { gain or lose. }\end{array}$ & UD & $\begin{array}{l}\text { The major finding is that the observed slow upward trend in earnings inequality is } \\
\text { well explained by a small number of plausible economic factors. Earnings inequality } \\
\text { is significantly related to the level of unionization, dispersion in weeks worked, the } \\
\text { age distribution of workers, and inequality of education. Once such factors are } \\
\text { considered, there was no secular trend in earnings inequality over the 1958-77 } \\
\text { period. }\end{array}$ \\
\hline $\begin{array}{l}\text { Scheve \& } \\
\text { Stasavage } \\
2009\end{array}$ & $\begin{array}{l}\text { AUS, CAN, } \\
\text { CHE, DEU, } \\
\text { DNK, FRA, } \\
\text { IRL, JPN, } \\
\text { NLD, NZL, } \\
\text { SWE, UK, } \\
\text { USA; 1916- } \\
2000 .\end{array}$ & \begin{tabular}{l|} 
Top-incomes data, \\
OECD earnings \\
database, Lydall \\
(1968), existing data \\
on political institutions \\
and new political data \\
coded by the authors.
\end{tabular} & $\begin{array}{l}\text { While explaining post-1970 differences in income } \\
\text { inequality between OECD countries is an important } \\
\text { task, it is also the case that convincing comparative } \\
\text { political economy hypotheses should be able to } \\
\text { account as well for inequality trends in earlier time } \\
\text { periods. The article considers the correlation of } \\
\text { centralized wage bargaining and government } \\
\text { partisanship with three separate top incomes fractions. } \\
\text { With a longer time span there has been significantly } \\
\text { more variation within countries over time than there } \\
\text { has been between countries. A longer time span also } \\
\text { enables examining whether within-country changes in } \\
\text { institutions like wage bargaining centralization have } \\
\text { been associated with changes in inequality. }\end{array}$ & UB & $\begin{array}{l}\text { Regression analysis over the } 13 \text { countries and the whole period gives little evidence } \\
\text { that government partisanship and wage bargaining centralization can account for } \\
\text { variation in inequality over the long run. A test of } 4 \text { individual countries that } \\
\text { established a centralized system of wage bargaining in the middle of the twentieth } \\
\text { century (DNK, IRL, NLD, SWE) also shows little evidence of an effect on } \\
\text { inequality. } \\
\text { This raises questions about the extent to which centralized wage bargaining is an } \\
\text { institution that has a causal effect on inequality or alternatively whether centralized } \\
\text { bargaining is simply an outcome that has, along with income equality, evolved over } \\
\text { time in response to an underlying political or economic process. }\end{array}$ \\
\hline
\end{tabular}


Table A.9 Wage dispersion and institutions (see Section 4.6)

\begin{tabular}{|c|c|c|c|c|c|}
\hline Authors & $\begin{array}{l}\text { Countries } \\
\text { and years }\end{array}$ & $\begin{array}{l}\text { Datasets* and } \\
\text { sample selection }\end{array}$ & Methods and important variables & \begin{tabular}{|l|} 
Types of \\
institutions**
\end{tabular} & Main findings \\
\hline $\begin{array}{l}\text { Schivardi \& } \\
\text { Torrini } 2008\end{array}$ & $\begin{array}{l}\text { ITA; 1986- } \\
1998 .\end{array}$ & $\begin{array}{l}\text { INPS comprehensive } \\
\text { longitudinal matched } \\
\text { employer-employees } \\
\text { dataset. }\end{array}$ & $\begin{array}{l}\text { The paper studies the effects of the more stringent } \\
\text { employment protection legislation that applies to firms } \\
\text { with over } 15 \text { employees. It considers firms' propensity } \\
\text { to grow when close to that threshold and changes in } \\
\text { employment policies when they pass it. Using a the } \\
\text { stochastic transition matrix for firm size. }\end{array}$ & $\mathrm{CP}$ & $\begin{array}{l}\text { The probability of firms' growth is reduced by around } 2 \text { percentage points near the } \\
\text { threshold. The long-run effects of EPL on the size distribution of firms are } \\
\text { quantitatively modest. Contrary to the implications of more stringent firing } \\
\text { restrictions, workers in firms just above the threshold have on average less stable } \\
\text { employment relations than those just below it; this might be because firms above } \\
\text { the threshold make greater use of flexible employment contracts, arguably to } \\
\text { circumvent the stricter regulation on open-end contracts. }\end{array}$ \\
\hline $\begin{array}{l}\text { Van der } \\
\text { Wiel } 2010\end{array}$ & $\begin{array}{l}\text { NLD; 1997- } \\
2001 .\end{array}$ & $\begin{array}{l}\text { Dutch Socio- } \\
\text { Economic Panel } \\
\text { SEP1984-2002: five } \\
\text { waves containing } \\
\text { contractual } \\
\text { information. }\end{array}$ & $\begin{array}{l}\text { This paper empirically establishes the effect of the } \\
\text { employer's term of notice on the wage level of } \\
\text { employees through a fixed effects regression model. The } \\
\text { term of notice is defined as the period an employer has } \\
\text { to notify workers in advance of their upcoming } \\
\text { dismissal. The wages paid during this period are an } \\
\text { important element of firing costs and hence } \\
\text { employment protection. To find a causal effect, the } \\
\text { paper exploits the exogenous change in the term of } \\
\text { notice that resulted from the introduction of a new } \\
\text { Dutch law in } 1999 \text {. }\end{array}$ & CP & $\begin{array}{l}\text { Strong evidence is found that a longer 'dormant' term of notice leads to higher } \\
\text { wages. In the sample used, an additional month of notice increases wages by three } \\
\text { percent, ceteris paribus. }\end{array}$ \\
\hline
\end{tabular}




\section{*) Dataset abbreviations}

ACS: American Community Survey (USA)

BHPS: British Household Panel Survey (UK)

CPS: Current Population Survey - ORG: Outgoing Rotation Groups (USA)

Deininger \& Squire: Income Inequality Dataset (World Bank)

DOT: Dictionary of Occupational Titles (USA)

ECHP: European Community Household Panel (EU, Eurostat)

EDWIN: Education and Wage Inequality in Europe (EU Research Project)

EU-SES: European Structure of Earnings Survey (EU, Eurostat)

EWCS: European Working Conditions Surveys (EU, European Foundation)

fRDB-IZA: Labor market institutions and labor market reforms database (International, at Fondazione

Rodolfo Debenedetti and IZA)

GGDC: Groningen Growth and Development Centre (International, at University of Groningen)

GSS: General Social Survey (USA)

GHS: General Household Survey (UK)

GSOEP: German Socioeconomic Panel (DEU)

HBAI: Households Below Average Income UK)

HES: Household Expenditure Survey (AUS)

IABS: IAB Employment Samples (DEU)

IALS: International Adult Literacy Survey (OECD / Statistics Canada)

IDA: Longitudinal data of Integrated Database of Labor Market Research (DNK)

IDS: Income Distribution Survey (AUS)

IME: International Mathematics Examinations (International)

IPUMS: Integrated Public Use Microdata Series: IPUMS-CPS and IPUMS-USA for Census/ACS (USA)

LFS: Labour Force Survey (CAN, EU, OECD, and UK)

LIAB: Linked Employer-Employee Data from the IAB (DEU)

LIS: Luxembourg Income Study (International)

LRD: Longitudinal Research Database (USA)

NES: New Earnings Survey (UK)

NLSY: National Longitudinal Survey of Youth (USA)

NSFH: National Survey of Families and Households (USA)

OECD STAN: Structural Analysis Database (International, at OECD)

O*NET: Occupational Information Network (USA)

PSID: Panel Study of Income Dynamics (USA)

SHIW: Survey of Household Income and Wealth (ITA)

SILC: Statistics on Income and Living Conditions (EU, Eurostat)

Top-incomes data: World Top Incomes Database (International, at Paris School of Economics)
**) Codes for categories of institutions

- AP active labour market policies (concerning unemployed)

- $\mathrm{CF}$ contract - flexibility

- CP contract-employment protections

- DI discrimination (gender)

- ED educational system

- HR working hours (part0-time)

- IR industry (rents)

- MW minimum wage

- NO Norms

- PM product market (deregulation, competition)

- OP openness (globalization, migration, offshorability)

- TA taxation

- UD union - density

- UB union - bargaining coverage, bargaining coordination, collective labour agreements

- UW union - wage outcomes, pay systems (performance pay)

- WE welfare (UI, benefits, EITC, in-work benefits) 